\title{
OUTSIDE IN: WELLINGTON JAZZ AMONG THE DISCOURSES
}

BY

NICHOLAS PETER TIPPING

\author{
A thesis \\ submitted to Victoria University of Wellington \\ in fulfilment of the requirements for the degree of \\ Doctor of Philosophy
}

Victoria University of Wellington 


\section{Contents}

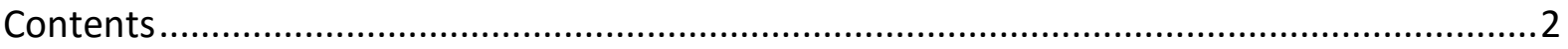

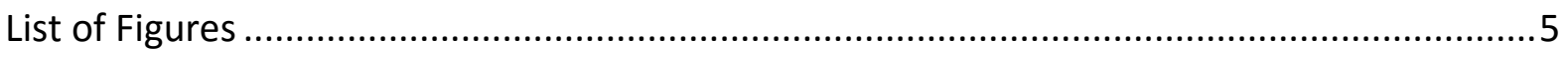

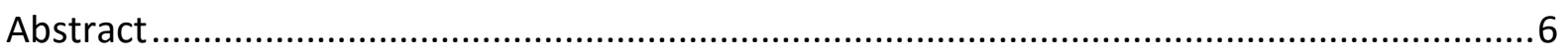

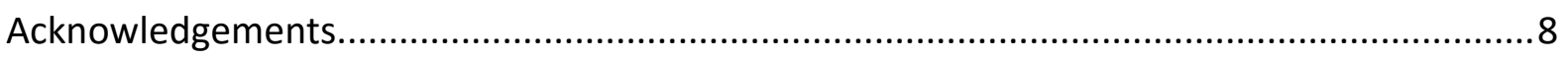

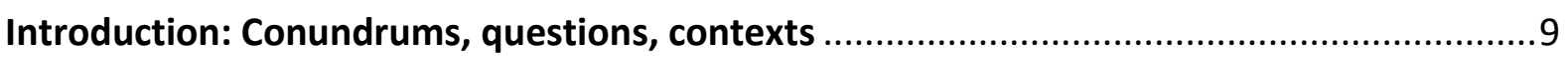

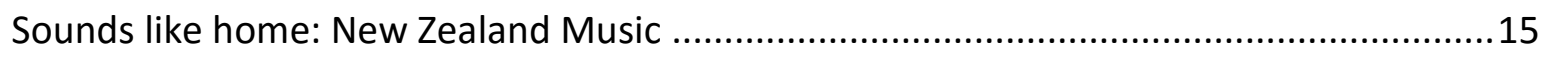

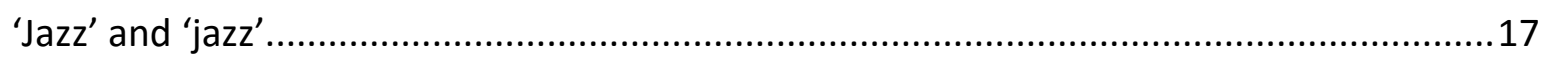

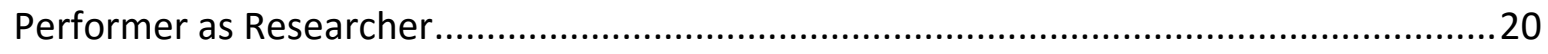

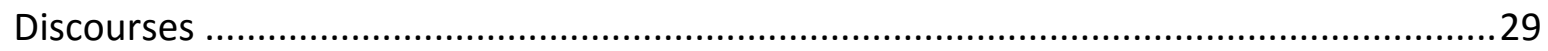

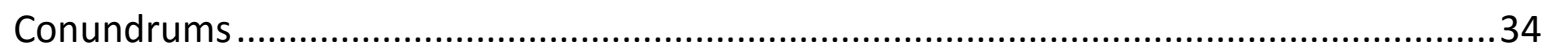

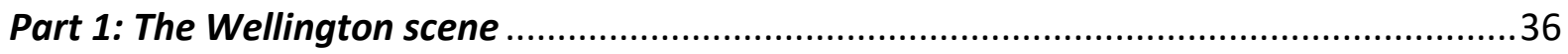

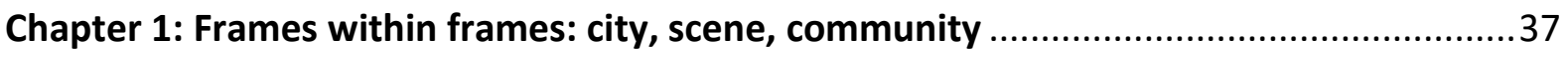

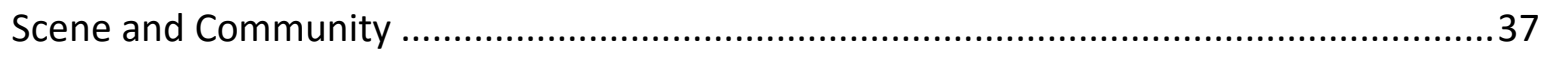

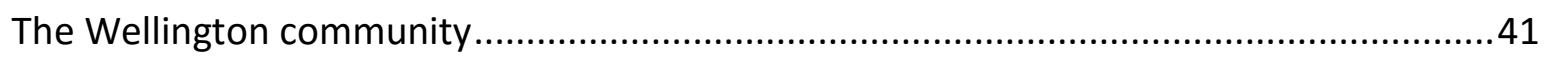

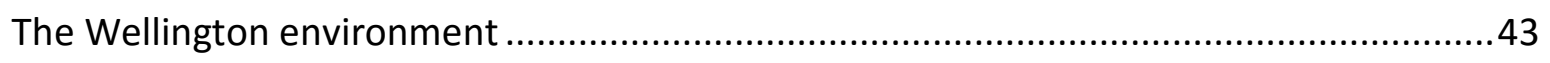

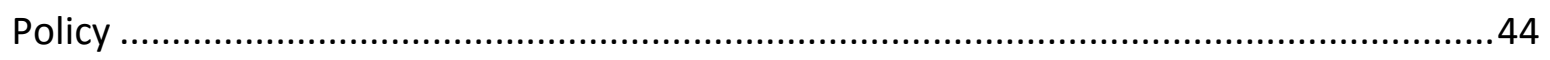

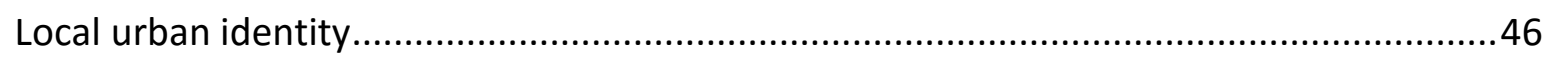

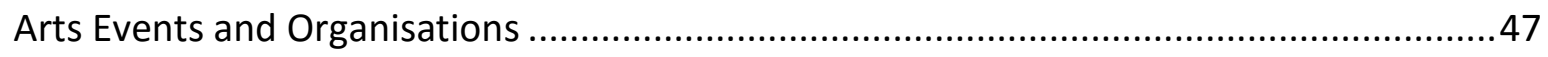

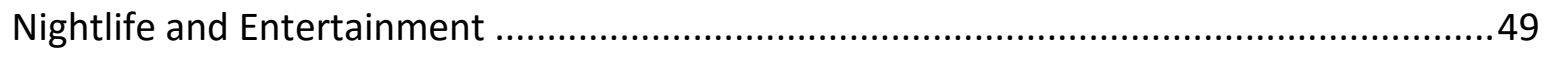

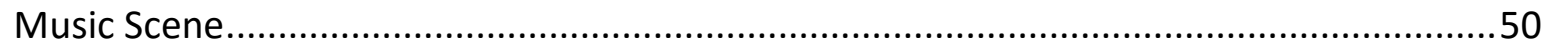

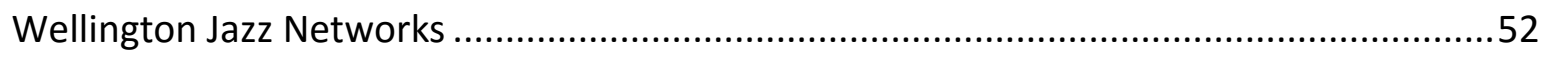

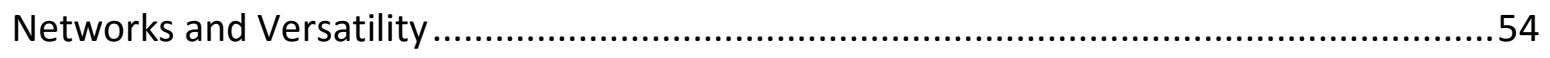

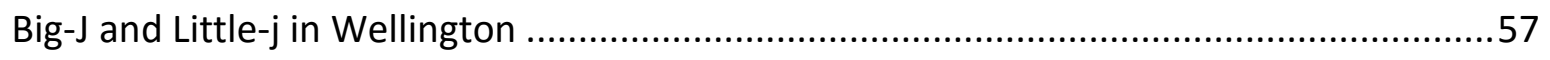


Chapter 2: Baby, it's cold outside: music funding and national identity ...........................62

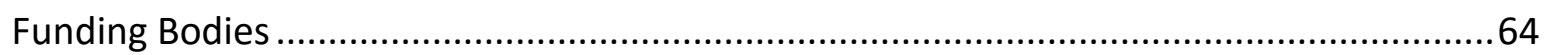

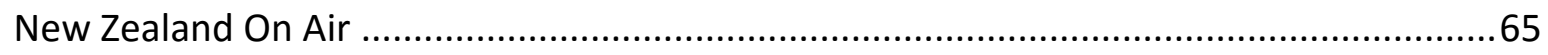

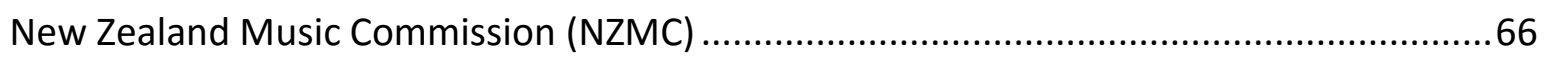

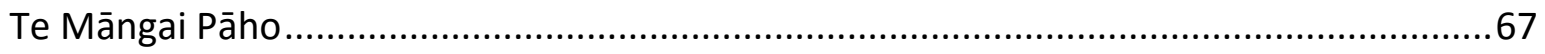

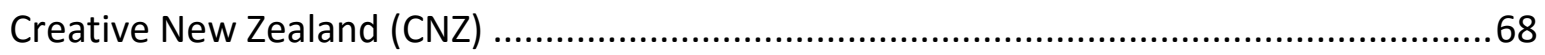

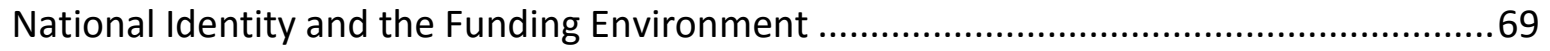

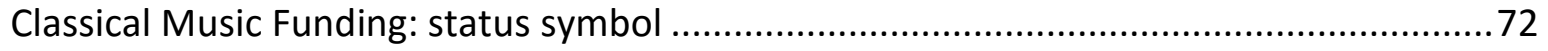

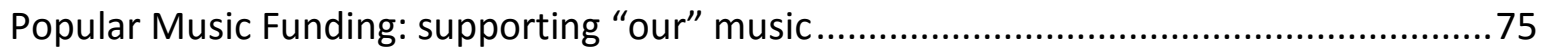

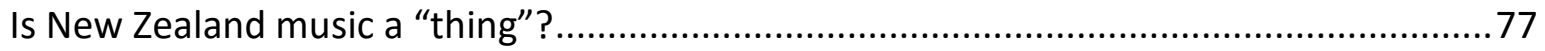

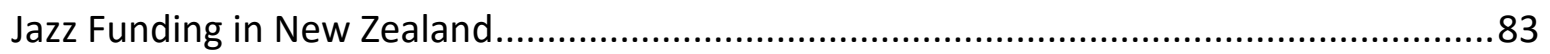

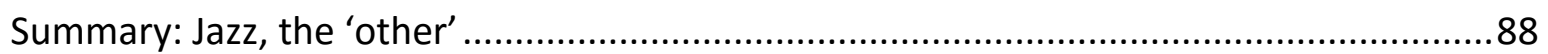

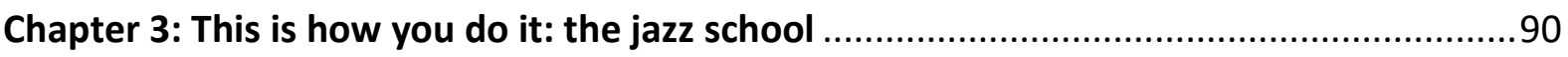

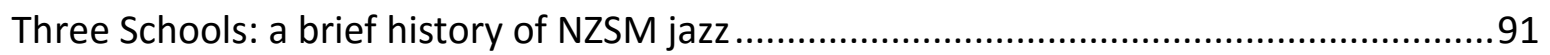

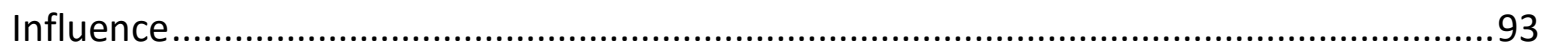

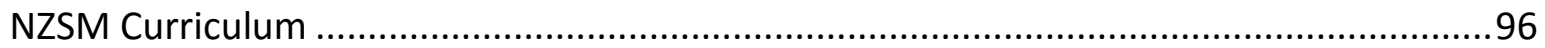

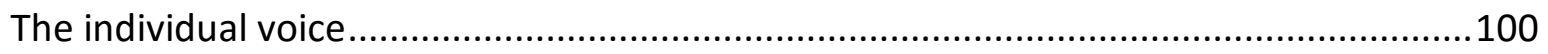

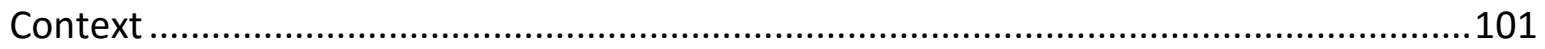

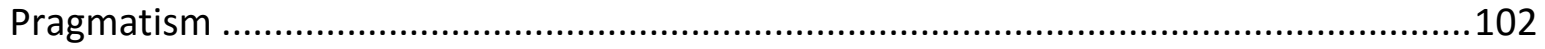

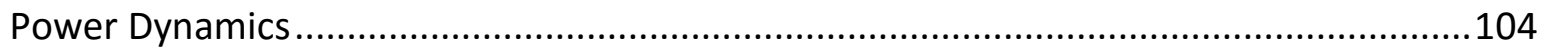

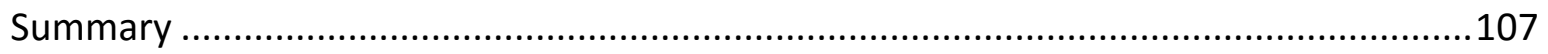

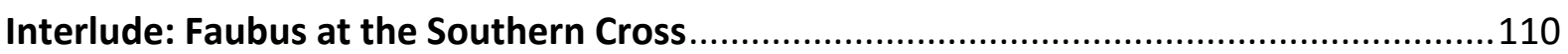

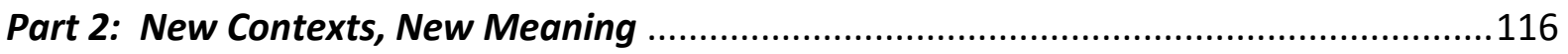

Chapter 4: You got to know to understand: the problem of authentic jazz performance.117

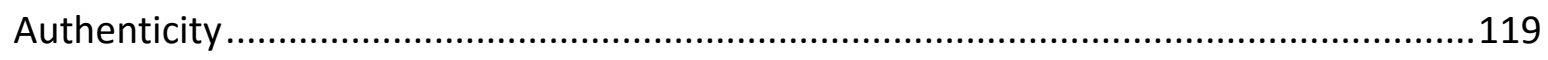

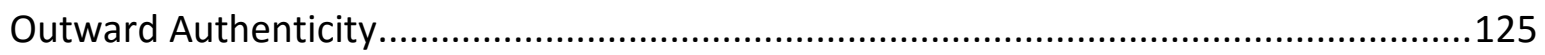




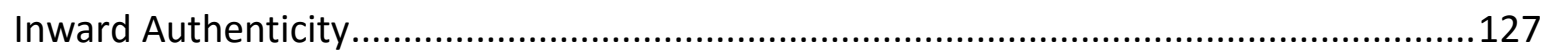

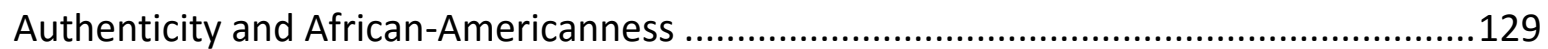

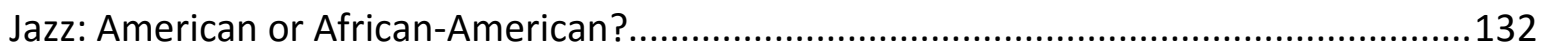

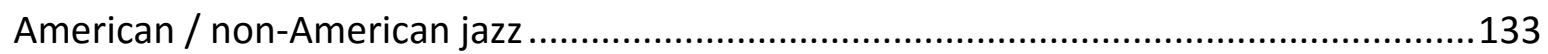

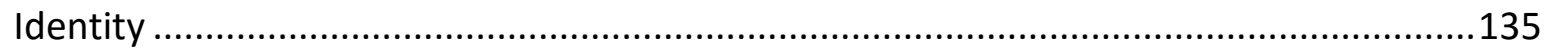

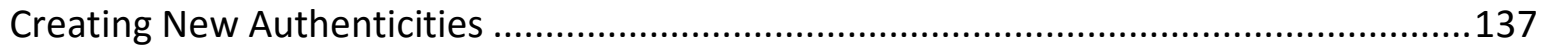

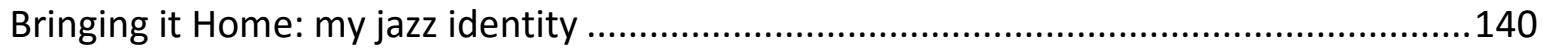

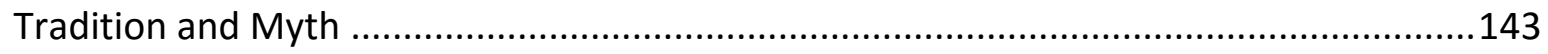

Summary: Authenticity, Identity and Tradition in Wellington Jazz ...............................146

Chapter 5: The song is you: the unique meaning of Wellington jazz .............................149

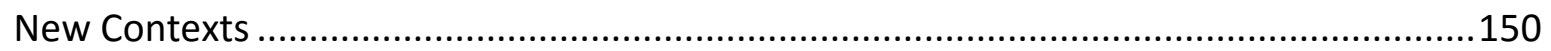

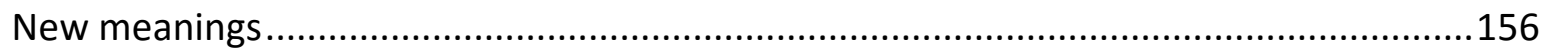

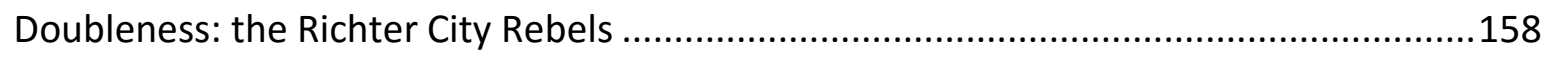

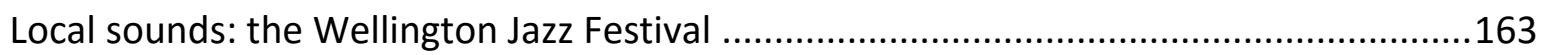

A Distinctive Approach? New Directions in Melbourne ...........................................172

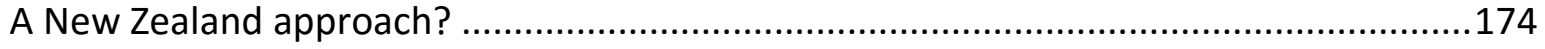

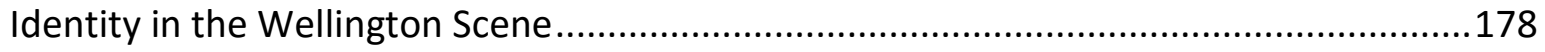

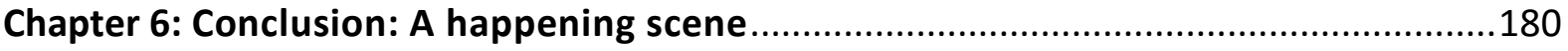

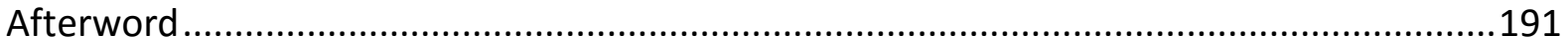

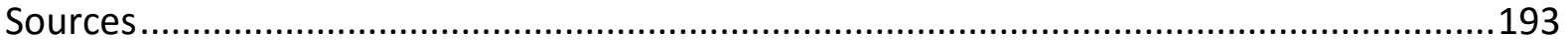




\section{List of Figures}

Figure 1 (p.36): James Illingworth (keyboard) and Rick Cranson (drums), with the author (obscured, bass) at Sandwiches bar, April 29, 2009

Figure 2 (p.60) Wellington Jazz Venues, as at April 2015

Figure 3 (p.61): Soldiers of the Pharaoh, February 2014

Figure 4 (p.75): New Zealand popular music funding structure

Figure 5 (p.116): The Roseneath Centennial Ragtime Band of Wellington, pictured in c.2014

Figure 6 (p.183): Wellington jazz gigs in the last week of September 2014 


\section{Abstract}

The jazz community in Wellington, New Zealand, is vibrant and energetic: this small, geographically isolated city hosts between 90 and 100 jazz performances each month. Yet in terms of both New Zealand music and the international profile of jazz, Wellington (and New Zealand) jazz occupies a curious blind spot, absent from the scholarly and mainstream discourses of both. This absence is reflected in Wellingtonians' own practice, in which perspectives from overseas (usually the U.S.) are privileged. Combining ethnography, practice-led research, and a variety of theoretical lenses, I examine the Wellington scene and its dynamics.

Initially describing the local scene in geographical, economic, and social terms, I examine notions of "scene" and "community", illustrating the ways in which they privilege dominant perspectives at the expense of a broader, collective identity. Through detailed case studies of central government music funding and the New Zealand School of Music jazz programme, I illustrate the dual hegemonies with which Wellington jazz musicians must contend: underlying discursive assumptions about the nature of both New Zealand music and the jazz tradition combine to leave local jazz in a liminal space, in which it arguably fits both categories, but is present within the discourse of neither.

In the second part of the thesis, engaging with the discourses on authenticity in jazz, the tradition, and identity, I consider the nature of jazz expression. On one hand, 'true' jazz expression requires the performer to perform their identity; on the other, it is bound by a set of practices and/or aesthetics, deriving from a Black (or Blues) aesthetic. The combination of imperatives is problematic for musicians of other cultures, as E. Taylor Atkins (2001) has pointed out, and it is for this reason that jazz discourse remains largely rooted in the U.S. By turning the concept of authenticity in jazz back on itself, I propose that the creativity mandated by jazz aesthetics allows for new, culturally specific forms of jazz that draw on the individual identity of the performer, and which therefore sit firmly within the jazz tradition, at least in relation to particular definitions.

Presenting a number of case studies, I illustrate the concepts of authenticity and identity in relation to performance in the Wellington scene: local musicians imbue the jazz 
they perform with new, locally specific meanings that derive from their own identity and context, despite overtly drawing on overseas influences. As a result, the jazz performed in local scenes like Wellington may fruitfully add to the discourses of both New Zealand music and jazz, by presenting additional perspectives that challenge preconceptions of both. 


\section{Acknowledgements}

A project like this one would have been impossible without the support of Wellington's talented, vibrant, and enthusiastic jazz community. Thanks to all the musicians who generously shared their perspectives in interviews: from Wellington: Blair Clarke, Bruce Brown, Nick Granville, Norman Meehan, Paul Dyne, Rick Cranson, Rodger Fox, Dave Lisik, Simon Bowden, Lucien Johnson, Lauren Ellis, Lex French, Mike Isaacs, Reece McNaughten, and Reuben Bradley; from Melbourne: Paul Van Ross, James Sherlock, Michelle Nicolle, Tony Gould, Andrea Keller, and Tim Willis; and from the US: Brenda Boykin, Joey DeFrancesco, and Mike Stern. Thanks also to the many more musicians and friends who have taken an interest in my research and findings, who have indulged my self-indulgent and occasionally confronting questions in gigs, on long car journeys, and on Facebook, and who have continued to allow me to play with them over the last few years, despite wondering if I might be analysing their every move.

Thank you to those who have lent an ear and provided perspectives from outside jazz, including Victoria Spackman, Sue Paterson ONZM, Bevin Linkhorn, Michelle Williams, and Dr. Jeremy Mayall.

Also thanks to those who have provided other essential support: Kerry Prendergast CNZM, Angela Humphrey, Massey University, Victoria University, and the New Zealand School of Music.

I am especially grateful to my supervisors, Professor Elizabeth Hudson, Dr. Brian Diettrich, and Dr. David Cosper, for their encouragement and wisdom.

Lastly, special thanks to my family, especially Molly, without whose support I would not have had the courage nor the opportunity to attempt something this crazy. 


\section{Introduction: Conundrums, questions, contexts}

A June night in Wellington is a long way from the steamy heat of the American Deep South. And so while it's a relatively warm night in Wellington on June 15th, 2013, the festive sight and sound of a New Orleans-style marching band blasting their way down Cuba St, past the Amcal Pharmacy, the adult store, and the bucket fountain is somewhat striking. Dressed in a mixture of African-Americana and New Orleans fancy dress, the Richter City Rebels parade through late-night Cuba Mall on their way to their gig at the English-style pub, the Rogue and Vagabond. Trading brass and vocal breaks, backed by the unceasing groove of percussion and sousaphone, and calling out the figures to each other as they play, the Rebels arrive at the Rogue to find their significant following packed in to the bar, all grooving to the sound of the second line.

Classic New Orleans songs are given an airing one after another: 'When My Dreamboat Comes In' follows 'St Louis Blues', and 'Bourbon Street Parade'. Fans call out encouragement, and sing and dance along. At the climax of the evening the band once again sets out on a march around the room. Amid a festive frenzy of singing, dancing, feathers, beads, and cries of encouragement, the Rebels have transported themselves and the bar to a kind of imagined New Orleans - a place few, if any of them have ever visited in real life, but with which, tonight, many of them identify.

These are not the sounds of New Zealand. The band's appeal lies in its exoticism: costumes, musical style and aesthetic, and repertoire all evoke a foreign culture and an idealised environment, accessible to most only through media imagery and recorded sound, and reconstructed on the edge of Glover Park in central Wellington. Yet the process is not unique. Across Wellington, local spaces are being filled with imagined environments, by virtue of sound and spectacle. While the Richter City Rebels are perhaps the most exotic, their evocation of American sounds, spaces and values in the heart of New Zealand's "creative capital" is by no means unique. 
It's a Monday night in late 2013, and a crowd gathers as the members of the Meow All-Star Big Band prepare for their regular show. Tucked away on Edward Street in the heart of Wellington, Meow hosts an eclectic range of music and performers on a weekly basis; it is known as a mildly experimental venue. The All-Stars are a collection of familiar faces, members of different bands with more or less regular residencies at Meow and a number of other venues around town. The jazz-club setup of the venue creates a timeless feel: tables are set up in front of the stage; the lighting is dim. The musicians are crammed in to a space which may be better suited to a small combo than a big band. They're dressed in an eclectic mixture of 1920s-1950s hipster period costume and suits. Audience members stand by the bar or settle down with a beer or wine in anticipation of the show. Squint and it could be a classic Kansas City, Philadelphia or Chicago setting Bandleader John Rae stands up from behind the drums and announces the evening's repertoire: a faithful recreation, track by track, of the classic Count Basie album The Atomic Mr. Basie. We're transported back to a particular moment in jazz history: we're in New York in 1958, as some of Wellington's finest carry us across 9,000 miles and 55 years of history.

Duck down Wigan Street--a tiny side street running between industrial Abel Smith St and the four-lane arterial Taranaki Street--and after nine o'clock you will find it deserted. The mixture of warehouses and offices are dark, and Havana Bar and the Lighthouse art house cinema, on opposite corners of the 90-degree dogleg, are the only two buildings with lights on. Wednesday night at Havana Bar is jazz night, and on this Wednesday in May 2013, the sound of live music echoes down the darkened lane. Inside, at one end of the bar, the Big City Boys are playing a mixture of leader Jeff Henderson's original jazz compositions, and tunes by luminaries such as Ornette Coleman. It's a loud, enclosed room, and the musicians compete with audience conversation. The lights are low, and the atmosphere is casual; the jazz band, while the focus of attention for some, is by no means the only reason people have chosen to be here. Henderson's alto sax, Patrick Bleakley's double bass and Rick Cranson's drums act and interact in a manner familiar to jazz musicians and fans around the world. The music is an Ornette-ish blend of changing tempi and solid grooves, free improvisation and traditional instrumental roles. As leader, Henderson is the focus of proceedings; he takes long solos, moving away from mainstream, diatonic playing to 
passionate improvisation using extended techniques. He is known for his uncompromising approach to his art, and before the end of the first set any members of the public who had been seated near the performance space before the band began have moved away so they can continue their conversations; a phenomenon familiar to Wellington jazz musicians. Tonight their places are taken by other musicians who have come along to listen; Jeff, Patrick and Rick are well-known and highly regarded in the jazz community. The musicians in the audience respond enthusiastically to the band, applauding loudly and sometimes calling out encouragement. One member jumps up and dances wildly in front of the band; he's a friend of the musicians, and they seem unaffected. The first set takes just under an hour; after a fifteen-minute break the band is back, and, following the format common to Wellington jazz gigs, they play until two hours are up.

As is the usual manner in jazz performance, the music is newly created, and creative freedom is essential; yet the structures, the instrumentation, the interaction, and the format of performance all follow the mainstream conventions of jazz. While the musical material is of contemporary Wellington, the methods of organisation and execution of that material are common to jazz scenes worldwide, and are grounded in the jazz tradition of the 1940 s to 1970 s.

The Richter City Rebels, the Meow All-Star Big Band and Jeff Henderson: all are familiar names to anyone with an interest in jazz in Wellington. Yet in the above examples, all three look very clearly towards the U.S. On the surface, at least, there is little to link each group with New Zealand; any of the three gigs could be transported wholesale to another jazz scene somewhere in the world without any sense of incongruity. Success in New Zealand jazz is often measured against the global scene, and the U.S. in particular; musicians who have achieved any kind of success in New York, Los Angeles or elsewhere are feted. ${ }^{1}$ In the same way, jazz gigs in Wellington often seek (consciously or subconsciously) to evoke

\footnotetext{
${ }^{1}$ Recent examples of Wellington jazz musicians succeeding in the U.S. include Richard Thai, Mark Lockett, Jasmine Lovell-Smith, Ben Shepherd, and Umar Zakaria. I noted on my own return from two years in the U.S. in 2003 that I was ascribed more authority in comparison to musicians who had followed similar paths in New Zealand, as a result. The privileging of overseas success could easily be seen as part of a wider "cultural cringe" phenomenon in New Zealand culture, which, while arguably beginning to wear off due to the international success of exports including the film industry (Calder 2012), still endures, albeit in a complex relationship with national pride (see p.165).
} 
American images: the New Orleans street band; the New York jazz club; the Chicago speakeasy. Where is the New Zealand-ness in all this? If legitimacy is still conferred by virtue of one's relationship to a mythical ideal, or imagined place, is there room for true selfexpression? In other words, if jazz must always refer to its American roots, can a New Zealand jazz musician, who may never have even visited the U.S., ever truly express themselves?

It was consideration of such questions in my own practice and teaching which led to the investigation, the outcomes of which I present in this thesis. While I am a frequent performer in the Wellington scene, and have been for 18 years, it was five years spent in a position of responsibility in the jazz programme at the New Zealand School of Music that led me to begin examining, questioning, and finally reconsidering much of what I had assumed about the place of jazz in the local Wellington scene, and of Wellington jazz in the wider world. Initially coming from a conservative perspective, and re-teaching what I myself had been taught in terms of jazz language and history, I found myself, as leader of the jazz programme, having to present jazz as a relevant pursuit in a contemporary New Zealand context, worthy of a considerable investment in terms of time and money. From a very practical perspective, I had to go out and market the programme to prospective students (and protective parents); and I had to advocate for the significance of jazz history in the lives of young New Zealand jazz musicians, for whom Miles Davis was less relevant than the Black Seeds ${ }^{2}$, and many of whom had never heard of Horace Silver, Art Blakey, or Sarah Vaughan.

As a result, I began to examine critically my own practice as a jazz bass player, and to attempt to reconcile the music I listened to and played with the cultural context in which I listened and played. Why do I, in contemporary Wellington, identify with a music created a long time ago in other places, all of which are far away? And what does that tell me about myself as a musician? When I attempt to channel the vibe of Ray Brown, or Dave Holland, or Oscar Pettiford in my playing, whose identity am I performing? And, as a teacher and university administrator whose job it was to impart the knowledge and techniques required to play this music, did I have a moral obligation to take into account the contexts in which it is going to be played? How does jazz fit into New Zealand life? Is there a New Zealand jazz,

\footnotetext{
${ }^{2}$ The Black Seeds are a popular Wellington reggae/pop band.
} 
and if so, does it sound or feel different? Does it even feel any more right than other jazz? This investigation is an attempt to answer those questions - or at least to begin the process of finding an answer. In this dissertation I examine jazz in Wellington, New Zealand: my home town, and the place I have spent all but two years of my life and my career in jazz. ${ }^{3}$

Jazz is a contextual music. ${ }^{4}$ The choices made by soloists, accompanists, rhythm sections, horn players, singers, and ensembles in general are affected deeply by the surroundings in which those choices are made. Jazz is a conversation, not only between musicians on a stage (Monson 1996), but also between musicians and their environment. A jazz performance results from the assimilation of sounds and other sensory input, as well as attitudes, approaches, and other cultural information, all of which are drawn from both history (of the performer(s), and of jazz expression itself) and the real-time surroundings in which the music is made (which include both musical and non-musical contextual factors); and which affect musical parameters as varied and fundamental as instrumentation, tempo, meter, feel, and note choice. Change in one's context results in change in one's music. ${ }^{5}$

Jazz in Wellington, New Zealand, exists within a context (or set of contexts) which, when taken together, present a series of conundrums. For local jazz musicians, performing jazz as New Zealanders in New Zealand involves negotiating (consciously or otherwise) a number of conflicts, which pertain to the portrayal and value of jazz in the local context, and to their place in the international jazz community. Jazz musicians in Wellington both experience and produce the mixed messages regarding each conflict: the tensions generated by these conundrums affect the sonic aspects of the jazz played in Wellington, as well as the discourse, the value systems, and the self-image of Wellington jazz musicians.

\footnotetext{
${ }^{3}$ It is fitting at this point to acknowledge the influence of Richard Hardie and Allan Thomas. Their edited collection Jazz Aotearoa (2009) explicitly called for scholarly investigation into New Zealand jazz, and became the foundational text of seminars I taught at the New Zealand School of Music and the University of Auckland. ${ }^{4}$ The connection between (improvising) musicians and their environment is well documented; see Merriam (1964) and Béhague (1984), Monson (1996), Berliner (1994), and Jackson (2012), for example.

${ }^{5}$ The development of the 'new jazz studies' has entailed the examination of jazz in relation to diverse contextual factors and discourses; publications such as Representing Jazz and Jazz Among the Discourses (both ed. Krin Gabbard, 1995) represented a broadening in critical perspectives in jazz scholarship, in which scholars began to view jazz through multiple lenses, including gender studies (Tucker 2001/2002) and cultural studies (B. Johnson 2000), for example. The idea of context has also broadened significantly in jazz studies, as evidenced by the number of studies of jazz in diverse geocultural locations which have been published in the last 20 years; see discussion below.
} 
Each element of context carries meaning not only for local jazz musicians, but other groups as well: the broad Wellington and/or New Zealand musical community, whose discourse often privileges concepts of New Zealand-ness in music, but whose materials, inspiration, and practices are frequently borrowed from overseas; and educators, who must negotiate the promotion of imported musical traditions in a contemporary New Zealand environment. As a result, the following investigation into the local scene not only sheds light on the various questions faced by musicians, but also presents issues with a broader relevance to both jazz and New Zealand music.

In the discourse and attitudes of jazz musicians and scholars in a global context, the history and tradition of jazz, in its most common form, remains the history of American jazz. The jazz mainstream is still considered to reside in the U.S., and discourse (both scholarly and non-scholarly) reflects that. Wellington musicians therefore create music in a discursive context in which they are marginalised by default, and in which the image of jazz in the popular imagination (and, often, the scholarly context) is rendered in terms that exclude them. At the same time, much (although not all) of the jazz created in Wellington privileges U.S. influences, whether through emulation or invocation, or via the familiar appeals to tradition which characterise much of the discourse on jazz. As a result, is Wellington jazz New Zealand music, American music, both, or neither? If New Zealand jazz is neither truly jazz, nor truly New Zealand music, then either it constitutes a new art form, or the definitions of both must be revised. This is a potentially fraught ambition; both traditions carry significant cultural weight, and the cultural space carved out by each is hard-won.

In investigating the conundrums surrounding Wellington jazz, then, I hope to challenge preconceptions in two areas. Firstly, I contest notions surrounding the nature of New Zealand music: a powerful trope in the local New Zealand context, yet one which, as we shall see, contains embedded assumptions about what constitutes New Zealand-ness. Secondly, I question the general construction of authenticity in jazz, which, despite the effects of globalisation and diaspora, remains predicated on its U.S. origins. 


\section{Sounds like home ${ }^{6}$ : New Zealand Music}

Considering the place of New Zealand jazz in the world leads inevitably to an examination of its place in a local context, and its relationship to "New Zealand music". Since the late 1990s, and the government-assisted revival of New Zealand popular music, the phrase "New Zealand music" has become a potent marketing tool as well as a discursive trope with overtones which include both authenticity, and the particular notions and ideas that make up a New Zealand sense of nationality and place, including a do-it-yourself ethic, a vaguely colonial / frontier mentality, a closeness to the landscape, nostalgia, and bi- and multiculturalism. The phrase is deployed in a multitude of contexts, and used to describe a variety of styles of and approaches to music. It is variously used in reference to music made within New Zealand; music composed by New Zealanders; music played by but not composed by New Zealanders; and music which overtly conveys aspects of New Zealandness (whatever they might be). As a result, the label is not consistently applied, but it is employed in order to add value and legitimacy to music (or to add a quality which may not be immediately apparent to the listener). Organisations like the SOUNZ Centre for New Zealand Music, or the New Zealand Music Commission (which provides the New Zealand music trope with its highest-profile manifestation, New Zealand Music Month) use the phrase in their name; others (Creative NZ, the Ministry for Culture and Heritage) allude to it in their organisational documents, without defining what actually counts as New Zealand Music (the Ministry refers to "New Zealand music and composition" [italics mine] (Manatū Taonga - Ministry for Culture and Heritage 2013), suggesting that, at least in its view, "New Zealand music" encompasses the performance in New Zealand of music composed elsewhere).

"New Zealand music" is difficult to define, therefore, but as a phrase it is powerful in its implication. New Zealand music is a valuable commodity; locally produced music is a central part of the cultural life of the country, with potential in terms of export, and in generating and supporting national pride. New Zealand musical icons such as Fat Freddy's Drop, the New Zealand Symphony Orchestra, Lorde and Kiri Te Kanawa achieve both ends; as successful ambassadors for the country, they allow New Zealanders (at least those who

\footnotetext{
${ }^{6}$ The phrase is borrowed from a nationalistic marketing campaign run by Radio New Zealand.
} 
follow them) to feel a vicarious sense of achievement, as do the All Blacks (the national rugby union team), and Team New Zealand (New Zealand's entry in the America's Cup yachting regatta). "New Zealand music" is music made by us, which conveys national pride and identity.

Yet "New Zealand music", rather than being a positively inclusive concept, can sometimes exclude as well as include. Jazz seems to occupy a curious blind spot in the New Zealand music trope, and is largely absent from conversations involving New Zealand music. New Zealand jazz gets little traction in the media, and receives a miniscule amount of government support. The implication with which New Zealand jazz musicians must contend is that their musical activity is not New Zealand music. In fact, the issue is more complex: many jazz musicians (at least in Wellington) pursue multiple musical careers concurrently, in jazz, popular, and other styles of music; their activities in dub, rock or reggae genres may fit the New Zealand music rubric, but the same is not true when they play jazz.

And yet the exclusion of jazz from the "New Zealand music" category does not bear scrutiny. Much of the music played by New Zealand jazz musicians was, originally, composed elsewhere (usually in the U.S., in the case of jazz standards); yet the same applies to the majority of music played by the major orchestras, which all play central roles in the discourse surrounding New Zealand music. The repertoire and culture of New Zealand's orchestras is still heavily influenced by European norms, and any attachment to this approach could be ascribed to New Zealand's European colonial heritage; yet local popular music, perhaps the central pillar of the "New Zealand music" discursive trope, is heavily based on styles which arose out of the U.S., as did jazz. Perhaps most importantly, an increasing amount of jazz recorded and released in New Zealand was written in this country, and is played by New Zealanders; there is no more compelling argument for its classification as New Zealand music. Nevertheless, whichever way one looks at it, jazz remains distinct from "New Zealand music", and New Zealand jazz musicians (at least, when they play jazz) are faced with an uphill battle for funding, media attention, and official support. 


\section{'Jazz' and 'jazz'}

In an effort to address the conflicts and conundrums I outline above, I have kept my field of investigation deliberately broad. Studies of jazz tend to take as their focus the masters: musicians who innovate, or who have some unique aspect to their music-making. Those musicians who perform jazz which follows in the footsteps of the masters, which builds tradition without necessarily pushing the boundaries of the art-form (and without which, therefore, the tradition would not exist), tend not to feature in studies of a music which privileges uniqueness. We do not tend to hear about working musicians who never cut a record deal; we ignore hobbyists, who do not reach the arbitrary standards required to catch our attention. We do not consider musicians who play not to express some artistic or political imperative, but simply for enjoyment, or to make a living. Yet those musicians are the jazz community; a picture of the jazz created in a scene which did not take such musicians into account would not be truly representative.

In his PhD thesis on creativity in jazz, New Zealand pianist, composer and researcher Norman Meehan (2014, 45-6), drawing on Kaufman (2009) and Boden (2009), distinguishes between levels of creativity, by making a distinction between "big-c creativity" and "little-c creativity". He characterises "big-c creativity" as "genius-level" creativity, which challenges and changes historical domains. It is the sort of creativity expressed by the great men (I use the term advisedly) of history, whose work precipitated new modes of thought or practice. "Little-c creativity" is still creativity; but it is the sort of creativity that operates in a smaller sphere, affecting everyday actions, or evident in the solutions to everyday problems. "Little$c^{\prime \prime}$ creativity may not change the world, but it still involves the exercising of creative ability. ${ }^{7}$

Applying the distinction between "big-c" and "little-c" creativity in a broadly analogous way to jazz discourse, I theorise "big-j" and "little-j" jazz. "Big-j” jazz is Jazz ${ }^{8}$. It is an idealised, canonised collective of musicians, albums, locations, schools, record labels, and genres. "Big-j" Jazz is Miles Davis, Jelly Roll Morton and Art Blakey; it is Mingus Ah Um,

\footnotetext{
${ }^{7}$ It should be noted in reference to Meehan's work that for my purposes I have consciously elided two analytical dialectics: Kaufman's "big-c" and "little-c" creativity, and Boden's "H-creative" and "P-creative". Meehan draws a more careful distinction.

${ }^{8}$ The implied reference to the monolithic, definitive title of DeVeaux and Giddins' recent textbook Jazz (2009), and to Ken Burns' similarly-presented documentary (2000) is intentional.
} 
Headhunters, and Time Out; the Juilliard School and the Manhattan School of Music; it is New York, Philadelphia and New Orleans. It represents the focus of much investigation, conversation, and aspiration. It is the basis of myth and tradition (see Chapter 4), and the foundation on which jazz historiography is built (notwithstanding DeVeaux's admonitions to the contrary (1991))."Big-j" Jazz is the face of jazz; it represents the music and culture in the popular imagination. As such, "big-j" Jazz inhabits a self-perpetuating cycle, in which is it both the source of inspiration, and the object of aspiration.

"Little-j” jazz is, essentially, everything else. "Little-j” covers that jazz, whether manifested as musicians, albums, or any other category above, whose activity or existence is absent from the scholarly and/or popular discourse, and thence from generalised conceptions of the "jazz community". Whether by dint of approach, geography, identity, level of education, ability, or purely historical circumstance, "little-j" jazz falls in the shadow of "big-j". In a sense, the "big" and "little" are misleading terms, and I use them with a dash of irony. "Little" implies "lesser"; but its practitioners are by no means necessarily less gifted, passionate, or active ${ }^{9}$. Rather, their activity is of less consequence to the hegemonically constructed narratives and representations of jazz which exist in the scholarly and popular discourse. Peter Hollerbach (2004), in an effort to counteract the "congeries of unexamined assumptions, impressionistic accounts, romance paradigms, subjective processes of canon formation, and geographic chauvinism" (155-6) which informs "big-j"-based jazz scholarship, takes as his example one who we might therefore refer to as a "little-j" jazz musician. His "LC" is a "work-a-day musician", one of "the many musicians who labour in relative obscurity on jazz scenes worldwide and thus maintain the music's viability through a multidimensional act of commitment no less intense than that of those documented, 'real' jazz musicians of jazz historiography." (156) This investigation takes a similar perspective, in that almost all jazz that takes place in Wellington (and New Zealand more broadly) might be categorised as "little-j"; mostly invisible in global terms, and absent from scholarship, but yet of deep and significant consequence to the musicians who make it, and therefore situated to complement and/or challenge canonised perspectives.

\footnotetext{
${ }^{9}$ And of course, the sheer amount of activity represented by "little-j" jazz far outweighs that of "big-j".
} 
Unlike other cities like New York, Los Angeles or London, or Brisbane or Melbourne in Australia, there are no dedicated jazz clubs in Wellington. Some venues (including the Lido, the Rogue and Vagabond, and occasionally Meow) are more associated with jazz than others, however; but with the exception of the Rogue and Vagabond (which has regular jazz gigs up to four or five times per week) those venues host jazz bands no more than twice per week. The "typical" jazz club such as Birdland, the Village Vanguard, Ronnie Scott's, Bennett's Lane or the Uptown Jazz Cafe, ${ }^{10}$ with six or seven nights of jazz every week, and to which audiences go specifically to experience the music, does not find an equivalent in Wellington. ${ }^{11}$ The vast majority of Wellington gigs take place at commercial bars and restaurants. Door charges are rare, and bands tend to be paid a set fee by the venue. As a result the venue is open to the public, and the performers and audience at a gig are most often sharing the space with patrons who are not present to hear the music.

As a result of these circumstances, jazz in Wellington takes place in a different context to that represented in most commentary and scholarship, which tends towards investigation and discussion of agents and moments of "big-c" creativity. ${ }^{12}$ Rather than acting as featured performance, much live jazz in Wellington is in effect background music. As a result, the majority of the performance activities in the Wellington scene involve a negotiation between the demands of musician and audience. Live jazz in most Wellington venues therefore, rather than consisting of unmediated self-expression, is a negotiation between creative freedom and commercial necessity. And while a survey of jazz globally is impractical, my own experience in the U.S., Italy, Seoul, and Australia, would suggest that the dynamics are similar across the world, in that jazz performance is far more often unfeatured than featured.

Thus the "big-j" and "little-j" jazz phenomenon occurs at all levels; it is manifested both in the formulation of the jazz canon, but also in the characterisation of jazz in localised

\footnotetext{
${ }^{10}$ Birdland and the Village Vanguard are in New York City; Ronnie Scott's is in London; Bennett's Lane (since closed in June 2015) and the Uptown Jazz Café are in Melbourne.

${ }^{11}$ Nor anywhere in New Zealand: Auckland, for example, hosts just one dedicated jazz club-style evening in one venue on a monthly basis (the Creative Jazz Club Aotearoa, held at 1885 Bar), where audiences pay a cover charge and are expected to listen attentively.

12 For example Berliner (1994), Benevento et al. (2010), Burns (2000), Collier (1993), Heffley (2005), Travis Jackson (2012), Mandel (2007), O'Meally et al. (2004), and Shand (2009), all of which contribute in important ways to the discourse, by focusing on the innovation and idealised practice of great artists.
} 
scenes. Following the chain of logic, my survey of jazz activity in Wellington takes into account the whole picture, from (relatively speaking) "big-j" to "little-j"; from concerts and jazz club performances to the myriad other contexts in which jazz occurs in public; from the creative and original jazz played at Wellington's experimental venues to the standards played in the window at the Lido Café. Irish composer Charles Villiers Stanford remarked "We cannot all be Palestrinas and Bachs, but there is no cream without plenty of milk" (2013, 100-1); without presupposing the qualities which define each, I am concerned with both the cream and the milk, in that in a jazz community one cannot exist without the other, and to understand the complete picture one must take both into account.

\section{Performer as Researcher}

The process of engaging with the questions I pose at the beginning of this thesis has taken place on multiple levels and in a multifaceted way. Overall, my approach has involved a combination of ethnographic fieldwork, critical reflection, and practice-led research. Consideration of the impact on the local community of the tensions generated by the discourse around New Zealand music and jazz has meant ongoing involvement in that community as both performer and researcher (as, indeed, has consideration of such impacts on my own playing). At the same time, tackling the questions involved has necessitated engagement with a variety of scholarly frameworks. Inevitably, each informs the other, creating an interesting dynamic in which, many times over the course of this investigation, I have performed with a group of musicians while simultaneously viewing our individual and collective performances through a critical lens.

Significantly, however, my position within the scene has been key in allowing me to undertake such analysis in an ongoing way. The trust I have earned through having participated in the local jazz community in various capacities over 17 years has proved invaluable, in that I have had the luxury of approaching this project as a true insider. Various roles I have occupied in the Wellington community over that time have allowed me access to virtually every aspect of the scene. I have been centrally involved as a performer; I have booked bands, and been booked by others; I have taught at the New Zealand School of Music, the jazz institution which looms large over the scene; and I have managed the jazz 
programme at the school. I have written and presented programmes on jazz for the national broadcaster Radio New Zealand, performed with both professional classical orchestras located in Wellington, and worked variously in an advisory capacity, as a hired performer, in managing social media, and as a media spokesperson, for the Wellington Jazz Festival, an organisation which plays an important role in the scene.

As a result, when I began work on this project in 2011 I was already personally acquainted with the vast majority of jazz musicians working in Wellington, and given the length and breadth of my career I have performed with most of the members of the community. I have been fortunate to earn respect as a performer (an attribute of real value to a researcher working with performers; see below), and given the nature of the Wellington jazz community and its complex networks, my years playing jazz in Wellington have meant that I have established collegial professional relationships with musicians from a wide range of ages, styles, and backgrounds. During my years as a teacher and tertiary education manager I developed professional relationships with a large number of students, many of whom are now among the most active and central members of the Wellington jazz community, and with many of the major institutions in the Wellington scene. The existence of such relationships meant that from the very beginning of this project, and during the period leading up to its commencement, most doors in the community and scene have been wide open to me. Gaining access to musicians has been entirely straightforward, and has often been a matter of sending a request for an interview via email, text message, or Facebook.

Nevertheless, while my interest in the Wellington community stems in part from the respect I have developed for it over 17 years of involvement, the depth and nature of my own levels of involvement with the music and musicians I am studying has necessitated careful consideration of my positionality. In 2011 I undertook a project that sought to explore my own position within the Wellington jazz scene, and the various possible responses I might elicit as a result of the "constellation of roles" (to paraphrase Turino (2008)) which I have played over that period of time. The results were generally positive: the musicians I spoke to (and who I chose deliberately, in order to represent a wide range of perspectives) were supportive of my intention to investigate the community, although reservations were expressed about the academic nature of the project. This speaks to a long-time distrust of 
academia by performers, an attitude with which I'm sure many scholars will be familiar, and which certainly finds a place in Wellington:

If you've never done it, you don't really deserve a right to talk about it. You can talk about what you've done, and if you've done a whole lot of study in something, then you have every right to talk about what you've studied. You don't have any right to talk about playing, if you haven't played. (Granville 2011)

However, my experience as a performer was fortunately judged to outweigh such concerns:

...the fact that you (NT)... come from being a performer at a ground level, you have a fairly good look at both sides of it. (Cranson 2011)

In this way I have been able to take advantage of my reputation as a practising musician, and the trust that has accrued to me as a result, to access musicians and perspectives which otherwise might have been closed to me, had I come to the project as an academic, or as an outsider to the community. On the other hand, I have felt the responsibility keenly; as well as holding my respect as musicians, the members of the scene are my colleagues and friends, and I have felt a measure of trepidation at the prospect of reporting analyses or results which may not have met with their approval. And so, rather than facing the ethnographer's classic problem of building trust and gaining access to a community, I have faced the opposite: achieving and maintaining an externalised, impartial perspective, has proven a challenge. My positionality in this respect has thus on occasion been a doubleedged sword. Interestingly, the idea of an insider studying the scene led to various assumptions about the purpose of the project. It became clear that some members of the community regarded an ethnographic study of Wellington jazz as a vehicle for the advancement of the aims of the members of the community, particularly in terms of marketing or lobbying. There seemed to be two related elements behind the assumptions. Firstly, members of the community felt that the interests of all performers should naturally align; performers like to perform (and many in Wellington derive a significant proportion of their income through performance). And so, secondly, it would follow that any project undertaken by a recognised performer such as myself, which focuses on describing the scene and community, would arise out of the desire to improve the lot of that community. 
Purely academic aims, such as critical reflection and consideration of identity are, as we shall see in Chapter 3, quite foreign in this context. ${ }^{13}$

This negotiation has been challenging, and has led on very rare occasions to tension. I have been asked to focus on particular people; to mention specific musicians so that they might quote me in funding applications; even to cite some musicians' activity as more influential than that of others. From time to time, musicians I interviewed expressed surprise that I was not necessarily focusing on biographical details or historiography, but on perceptions and values. On several occasions I have been praised for using my project to advocate for Wellington and New Zealand jazz, when that has not necessarily been my purpose. I have at times received criticism for not focusing on the most interesting, creative musicians in Wellington, when my purpose has been to take a broad, representative approach.

My situation illustrates the fine line ethnographers tread when working in their home communities. Indeed, I am a passionate advocate for local jazz, and believe strongly that jazz in my native country is underrepresented on the world stage (and the local stage; this is a recurring theme throughout this dissertation). I deliberately play local music whenever possible in my occasional employment at Radio New Zealand. I promote local acts (and the localness of those acts) through my social media role with the Wellington Jazz Festival. I am indeed a local performer in the Wellington community, with the same concerns as other local performers. It is natural, therefore, to read as advocacy an investigation into Wellington jazz, which has, in part, been motivated by a desire to introduce the values and perspectives of the Wellington community into discursive frames from which they are largely absent. But inasmuch as there is advocacy involved, it takes place at a scholarly level, rather than a practical one.

Thus an interesting new level has been added to my relationships with the musicians around me: while the topic has only infrequently come up, I have become known as the guy who is doing the PhD on Wellington jazz. In conversation, if topics of contention arise (whether or not the topic is raised by me), I have been frequently advised (only slightly

\footnotetext{
${ }^{13}$ Aaron Fox (2004), in his ethnography of working-class country musicians in Lockhart, Texas, notes the advantages and the complications that result from the blurring of the researcher/participant boundary.
} 
tongue-in-cheek) that perhaps I could "do a PhD on that". But there are other relationships to consider, which are complex at a practical level. Within the performing community itself, there are elements of insider-ness and outsider-ness to be negotiated. Musicians in Wellington are defined by a number of criteria, including the styles they play (and the styles they don't play), the other musicians and ensembles they play with, and the standard of their playing. Some musicians I interviewed in the early stages of this project in 2011 suggested that such emic distinctions might present barriers, making accessing some information more problematic. Indeed, while in the Wellington scene there are few social barriers between musicians, I was conscious that musico-social dynamics might subtly affect my investigation. There are certainly forms of jazz I tend (and tend not) to play. I tend to play with some musicians and not with others, and those alliances contribute to my overall identity: for instance, I have very rarely played in any free jazz context in Wellington. There are strengths and weaknesses in my playing which make me more or less likely to be invited to play in certain environments, and with certain other musicians.

My involvement with the New Zealand School of Music added an additional layer of complexity. Acting as I did as a teacher, assessor and administrator entails the development of certain power relationships. When I commenced this project, to various musicians in the scene I was a university department head; or the person who gave them a certain grade for their final recital, or who taught them in their first-year history of jazz course, who "encouraged" them to keep studios clean, or reminded them to show up for class. I was the manager who hired certain members of the community to teach, and not others: I was aware that my hiring decisions inevitably illustrated and telegraphed my own particular proclivities in terms of jazz pedagogy. Furthermore, to some I represented the school itself, in that the "Head of Jazz"14 is the conduit by which broader school policy intersects with the community, through the experiences of the staff and students. I was aware, then, that the dynamics which had been inherent in my school-based interactions with some members of the community might affect their responses in an interview, or even in conversation. To take two examples, in one case I was declined when I approached a former staff member for an interview, as the project was connected with the NZSM; and in another I received

\footnotetext{
${ }^{14}$ This is not the official job title, but it is the commonly used referent for the Programme Leader of Jazz at the New Zealand School of Music
} 
interview responses from a former student that I was certain were affected by the power dynamic which had been a hallmark of our recent relationship.

My positionality is made yet more complex by the fact that I am an alumnus of the Victoria University and Massey University music programmes. Some members of the community are my former teachers; and some of those teachers then reported to me during my time at the NZSM. The web of power relationships (and social relationships) in which I found myself at the commencement of this project was therefore tremendously complicated; but this complexity was not necessarily new to me: as we shall see, in the Wellington community teacher / student dynamics are commonly blurred.

With those various factors in mind, at the start of this project in 2012 I put effort into reinventing myself somewhat in the community. My position as Acting Programme Leader of Jazz ("Head of Jazz") at the NZSM ended at the commencement of my enrolment in the PhD programme, but the after-effects lingered; I felt it necessary in some cases to distance myself actively from the running of the programme, in order to generate a degree of independence so that interviewees might give their opinions freely. Additionally, I myself found the adjustment of role from teacher and manager to ethnographer a significant one. The process of consciously adjusting my perspective on the scene (from one in which the interests of the NZSM were a major consideration, to as independent a perspective as I could manage) took several months. Although the role officially ended at the end of 2011 , it was some months before I could feel that I had divested myself of any responsibility to the school, and could approach my research from an impartial standpoint.

The method by which I have undertaken this investigation, then, has varied as a result of the different positions I have occupied in the community, and according to the relationships I have with individual musicians. Before the project commenced, I let the word spread that I was planning an investigation into Wellington jazz, and that I was planning to interview local musicians. As a result, when I came to request interviews, interest was high, and consent was almost always enthusiastically forthcoming (only one request was turned down, as I noted above). As I mentioned previously, I selected participants in order to achieve a representative sample of musicians from across the spectrum of the local community: they included teachers, alumni of the NZSM, administrators, musicians whose practice tended towards fusion, Dixie, free jazz, post-bop, or big band; those who tend to 
play original music and those whose preference is for classic sounds and repertoire (and the many points between those two poles). A side project for an article in Jazz Research Journal (Tipping 2014) took me to Melbourne, Australia, where I interviewed several other jazz performers; and a week-long tour with the Wellington Jazz Orchestra provided me with the opportunity to interview Brenda Boykin, Mike Stern, and Joey DeFrancesco, jazz musicians of major international significance. ${ }^{15}$

Interviews, which generally took between 45 minutes and two hours took place in a venue of the interviewee's choosing, often over a coffee, beer, or wine (and in one case, lunch); while I had certain topics in mind, conversation frequently deviated into other areas of mutual interest. Often, reflecting the complex dynamics I describe above, the interviews began in a somewhat formal fashion, given the purpose for which we were meeting; however, in most cases (with local Wellington musicians at least) our familiarity with one another soon allowed us to relax and explore issues together. ${ }^{16}$

Thus my positionality in relationship to my field of study and my subjects is different to that of many jazz ethnographers. Jackson (2012), Monson (1996), Atkins (2001), Berliner (1994), and Feld (2012), for example, all began as relative outsiders in relation to the communities they studied, in that they were not personally acquainted with many of their subjects before commencing their projects (although Jackson and Monson's networks each developed out of a handful of pre-existing relationships), and were not able to relate to musicians in their studies as co-performers. In contrast, while I adopted the new role of ethnographer for this project, I come from a position entirely within the community in

\footnotetext{
${ }^{15}$ It should be noted that all the Wellington-based musicians with whom I conducted formal interviews are either alumni or current / former teachers of the New Zealand School of Music jazz programme (or its antecedents). While this may suggest a bias in my sample, it should be noted that this, to a significant extent, reflects the influence of the NZSM on the Wellington community. As I note in Chapter 3, only a significantly small minority of jazz musicians in Wellington have had no involvement with the school. Additionally, alumni (and staff) have adopted a broad variety of approaches to jazz, whether consonant with or dissonant in relation to the direction of the NZSM. While in Chapter 3 I focus on the particular effects of the NZSM curriculum on the shape and direction of the community, as I note above I selected musicians to interview in order to achieve an overall representation of the perspectives present in Wellington. Therefore, although it may appear as though NZSM staff and alumni are overrepresented in my sample, it is in fact representative of the community as it currently exists.

${ }^{16}$ Alvarez (2013) notes the blurring of the line between 'researcher'/'researched' and a more intimate, collegial relationship, which can occur when ethnographer and interviewee share a social space. As I related to my Wellington-based interviewees as both a researcher and a colleague (and often a friend), I found this to be the case in most of the formal interviews which took place during this project.
} 
question, and while such a position is complicated (as I have explained above), I have continued to perform with the musicians I am studying throughout. Crucially, then, in view of the concerns expressed above, I am a member of the community first, and a researcher second. This puts me in a notably small category; ethnomusicological studies (especially of jazz) from a truly insider perspective (Pietraszewski (2014), Johnson (2000), for example) are rare.

When it came to interviewing musicians in Melbourne ${ }^{17}$, as well as Boykin, Stern, and DeFrancesco, however, I had no previous relationship to fall back on. Like Jackson, Monson and Feld above, in Melbourne I relied on a local musician, with whom I had performed in Wellington, to provide an introduction; in one case I sat in with the band in advance of the interview. In the case of DeFrancesco, Stern and Boykin I became known to them as a member of the band with whom they were touring. In each case, then, I intentionally relied on some musical connection in order to establish my credentials as a bona fide jazz musician (and a fellow insider), before the interview took place. Nevertheless, my relationships with the international musicians I interviewed were more formalised; in general, they were focused on the research task at hand. While the interactions were entirely collegial, they were, in general, less relaxed in nature. ${ }^{18}$

Taking advantage of my positionality, then, over the course of the project I engaged with the community via a number of other means. Alongside interviews, I engaged in frequent informal discussion with members of the community, at gigs and rehearsals, on tour (long car journeys are particularly conducive to profundity in conversation), at social occasions, and on Facebook. In one sense, the informality led to a freer exchange of ideas than was generally the case in formal interviews, where the interviewee (and I) was aware that the conversation was being recorded for subsequent analysis; but on the other, the range of musicians with whom I generally had such informal conversations was perhaps more limited than the broad cross-section of musicians I interviewed formally. I have generally tended to be in a position to chat informally only with musicians with whom I

\footnotetext{
${ }^{17}$ Although the significance of the Melbourne side project is minor in the context of this study, it is worth noting in terms of the contrast in positionality.

${ }^{18}$ The session with Joey DeFrancesco assumed, more than any other interview, a question-and-answer format; this reflects, I suspect, both our relative unfamiliarity with each other, and the frequency with which he gives media interviews.
} 
already had something in common (although this has not exclusively been the case), given such conversations take place in a social setting; indeed, the diversity in the group of my formal interviewees was a response to this very issue. Yet informality also allows a frank exchange of views; at times this has been most enlightening, and informal communication has allowed me the opportunity to test ideas in a way that would otherwise have been difficult. My position within the scene has afforded me particular access to musicians' conversations on Facebook, in which context I have been able both to generate and to observe conversations, on issues such as jazz education, gender in jazz, and boundaries of style and genre. Occasionally such conversations (on social media or in person) have raised important points; and in a number of such instances I have followed up via email, in order that I might cite (or be granted permission to cite) salient points; this thesis contains a number of quotes obtained via this method.

Of course, my central mode of engagement with the community has been as a bass player. Throughout the course of this project I have been a regular professional performer in the Wellington jazz scene (and, on occasion, around the country ${ }^{19}$ ). Ongoing involvement in this way has allowed me to develop and maintain professional and social relationships, to observe and reflect on a wide variety of jazz performance from the inside (including the rehearsal process), and to consider the implications of my observations and conclusions in the real-life, everyday context of jazz performance in Wellington. I have had the good fortune to perform and fraternise with many of the musicians cited and mentioned in this thesis, and some of the observations and conclusions which are documented herein are drawn directly from those experiences. The nature of my career has meant that I have had relatively unrestricted access to all levels of the local and national jazz and classical (and, to a lesser extent, pop, electronica, musical theatre, and barbershop) communities, and to musicians whose experience covers a very wide range of approaches. It has been enlightening to compare (and to find similarities between) my experiences of performing in duo and trio configurations with a wide range of musicians, in medium-sized ensembles including the Jac and Pleasure Point, and in big bands including the Wellington Jazz

\footnotetext{
${ }^{19}$ Over the duration of this project I have performed jazz (with Wellingtonians) in Auckland, Hamilton, Tauranga, Napier, Palmerston North, New Plymouth, Whanganui, Kapiti, Nelson, Blenheim, Christchurch, and Dunedin, as well as Sydney, Canberra, Brisbane, Melbourne, and Adelaide in Australia.
} 
Orchestra, the Wellington Mingus Ensemble, the Roseneath Centennial Ragtime Band, and the Meow All-Star Big Band, as well as occasional performances as a guest jazz musician in non-jazz contexts. ${ }^{20}$

In an effort to enhance my visibility and approachability, from 2012 onwards I increased my attendance at jazz gigs, and deliberately broadened the range of playing engagements I accepted. This raised some interesting issues: firstly, as a result of taking a scholarly track, I actually ended up playing a broader range of music than I had in the previous few years. Secondly, the breadth of the music I began to play, alongside the reading, discussion, and reflection in which I continued to engage, impacted on my approach to performance. As a performer, I began to think much more actively about my identity, and how it is represented and communicated through the music I choose to play. Thus the process turned back on itself: the reflections on identity, music-making in Wellington, and jazz, which underpinned the genesis of this project, led me to change my identity, in the process generating further reflection.

Such deep and ongoing engagement has allowed me the luxury of far more and wider experiences than I could chronicle or cite. Yet in their entirety they have fed into this thesis in a constructive way, allowing me to draw conclusions and make observations based on either a collective or specific impression of the activity in the scene. Although I cannot pretend that every perspective present within the local community is represented within this thesis, the combination of participant observation and practice-led research, alongside the fact that I am a member of the community (and was before I began this project), has provided a level of insight which would have been difficult to achieve in any other way.

\section{Discourses}

Given my subject matter, then, I have approached this thesis in a multifaceted way. I combine factual data, perspectives drawn from interviews, and first-hand experiential

\footnotetext{
${ }^{20}$ Performances with non-jazz ensembles and performers have been helpful in providing external perspectives on jazz within the New Zealand context; during this project such groups have included the New Zealand Symphony Orchestra, the New Zealand Pops Orchestra, and members of the Auckland Philharmonic Orchestra, and various nationally-recognised popular music identities, including iconic singers Suzanne Prentice (country) and Don McGlashan (pop/rock), and indie pop singer Julia Deans.
} 
knowledge, with a parallel focus on jazz discourse, both informal and formal. In so doing I have played each against the other: comparing values drawn from scholarly discourse with the attitudes of performers and the activity in the Wellington scene, and vice versa. In so doing I employ a composite ethnomusicological model, in which I draw on autoethnography (often in a processual sense (Kisliuk (1998), Berliner (1994)) as I consider my own practice in relation to the discourse); practice-led research (Fox 2004), and engagement with the complex theoretical discourse on jazz.

Consideration of the nature of the Wellington jazz community, and its engagement with multiple discourses, necessitates the construction of a complex theoretical framework. In a sense, that necessity illustrates the point at the very heart of this thesis: that, in a number of ways, no single framework exists in which the issues pertaining to Wellington jazz may adequately be described: it exists outside the discourses which ought most closely to apply to it. It is notable that very little writing exists on New Zealand jazz; this thesis is only the second full-length investigation into the area, and it is the first which deals with the contemporary scene (the other, Aleisha Ward's PhD thesis Any Rags, Any Jazz, Any Boppers Today (2012) examined New Zealand jazz up to 1955). Hardie and Thomas' short 2009 anthology Jazz Aotearoa, a handful of other articles and chapters (Meehan (2010), (2011); Tipping (2014), Ward (2014)), an article on Wellington's erstwhile performance venue, The Space (Edwards 2009), and Norman Meehan's biography of Mike Nock (2011), represent the entirety of the scholarly investigation into New Zealand jazz so far. Thus in order to place New Zealand jazz in its cultural context I draw on a number of parallel discourses. As an examination of a local jazz scene outside the U.S., this thesis adds to a relatively small but growing literature, which deals with jazz in other diasporic locations, ${ }^{21}$ each of which may add depth and complexity to our understanding of what is truly a global art form. (B. Johnson 2014)

\footnotetext{
${ }^{21}$ Harris (2003), Bakriges (2003), Heffley (2005), Hellhund (2012), Johnson (2002), Nicholson (2005), (2014), and Porter (2012) all examine jazz outside the U.S. in a broad, transnational sense. Examples of studies focused on individual local or national scenes include Atkins (2001) in Japan; Ballantine (2012) in South Africa; Feld (2012) in Accra, Ghana; Johnson (1987) and (2000), Rechniewski (2008), and Shand (2009) in Australia; McKay (2005) and Moore (2007) in Britain; and Tsioulakis (2013) in Athens.
} 
The dissertation itself is divided into two parts. Part 1 (Chapters 1-3) examines jazz within the local Wellington scene, and Part 2 (Chapters 4-6) take a broader, trans-national perspective. Chapter 1 frames the discussion: I tease out the notions of scene and community, ${ }^{22}$ by characterising the scene as the backdrop against which the community operates. Introducing Wellington city as the scene, which provides the cultural, geographical and economic context in which Wellington jazz takes place, I illustrate the way Wellington jazz is affected by both sets of frames.

Chapters 2 and 3 provide thick descriptions of two important aspects of the local scene, each of which profoundly affects the context within which Wellington jazz musicians make music. Chapter 2 presents the first broad survey of central government music funding and policy in New Zealand, ${ }^{23}$ in view of its mandate to support and encourage the development of New Zealand's unique musical culture (funding is a topic of increasing discussion in the Wellington and New Zealand jazz community, and abroad; ${ }^{24}$ interestingly, it is this chapter which has generated the most interest from the local community). By examining both the flows of capital and the justifications for its distribution, I draw conclusions about the intersections between New Zealand music and New Zealand identity, and the particular aspects of each which are considered appropriate from a funding perspective. In order to do so, given the lack of discourse on local jazz, I draw on the discourses pertaining to New Zealand popular music and identity, ${ }^{25}$ and its intersection with policy. ${ }^{26}$ I contrast these findings with observations about the cultural space occupied by jazz in New Zealand, and the cultural climate in which Wellington jazz musicians operate, and I suggest reasons for the absence of jazz from funding statistics and policy. Chapter 3 presents an account of the influence of the New Zealand School of Music (NZSM) on Wellington jazz: the vast majority

\footnotetext{
22 Drawing on various perspectives espoused by Travis Jackson (2012), Shelemay (2011), Prouty (2012), Anderson (1983), and Martin (2005), for example.

${ }^{23}$ Given no such survey exists, I necessarily spend some time in this chapter laying out the funding structure and flows, drawing on a wide variety of official sources and publicly available data.

${ }^{24}$ Mahika (2013), Hewett (2014). As I write, a nascent New Zealand Jazz Federation is in its early stages of development; a lack of funding and representation for jazz musicians was one of the primary reasons for its inception.

25 Mitchell (1994), (1996), (2009), (2010); Mitchell and Waipara (2011); Shuker and Pickering (1994); ZemkeWhite (2007); Bodkin-Allen (2011); Bourke (2011); Cattermole (2011); Gibson (2010). Keam (2006a) and (2006b), Lilburn (2011) and Brunt (2011) also examine New Zealand identity in relation to classical music (Keam and Lilburn) and the Cuba Street Carnival in Wellington (Brunt).

${ }^{26}$ Shuker (2007), (2008); Zuberi (2007); Scott (2008), (2012), (2013); Scott and David (2012); Stahl (2011)
} 
of the members of the local jazz community spent their formative years at the city's only jazz school, and it provides employment and performance opportunities for local professional musicians. Locating the NZSM's curricular and pedagogical approach within various critiques of jazz education, ${ }^{27}$ I suggest ways in which the school's approach is reflected in the values and activity of the community.

Having examined significant aspects of the local scene, in Part 2 (Chapters 4-6) of this thesis I consider the relationship of Wellington jazz to the broader, global (particularly American ${ }^{28}$ ) jazz scene. As the vignettes at the beginning of the thesis show, the existence of jazz in Wellington involves a negotiation between Wellington and New Zealand identity ${ }^{29}$ on one hand, and the identity attached to participation in the sphere of jazz on the other: much has been written on the connection between African-American identity and authenticity in $\mathrm{jazz}^{30}$, and the status of jazz as a quintessentially American art form ${ }^{31}$. In order to parse out the implications of these perspectives for non-American jazz musicians, and to suggest points of intersection between these diverse identities, I draw on various theories and discourses of authenticity (including from the field of historical performance practice) ${ }^{32}$ and the 'jazz tradition'33; in doing so I suggest that the key to authenticity may lie in the motivations of the musicians themselves, rather than any specifically American or AfricanAmerican cultural practice or knowledge. I suggest a new model for authenticity in jazz, which may encompass the participation and perspectives of musicians from a range of diverse cultures, who are already active in jazz, yet whose identities (or practices) conflict with accepted notions of jazz authenticity.

\footnotetext{
${ }^{27}$ Ake (2002), (2012); Baker (1979); Kennedy (2002); Nicholson (2005), (2014); Prouty (2005), (2008); Roberts (2009), for example

${ }^{28}$ The focus on American perspectives in jazz (rather than those based on the rich European jazz tradition, for example), and their contrast to New Zealand identity, is based on the discourse and proclivities of Wellington musicians. Interestingly, traditions of jazz deriving from elsewhere in the world find far less of a foothold in Wellington; indeed, the discussions in Part 2 (and on jazz education in Chapter 4) may be seen in this very light. ${ }^{29}$ New Zealand identity is the subject of much investigation and discussion: Bannister (2005); Belich (2001); Bell (1996); Benson (1998); Brunt (2011); Fairburn (2008); Hanson (1989); Keith (2008); Lawn (2006); Liu et al (2005); Volkerling (2006); Ward and Lin (2005)

${ }^{30}$ For instance: Baraka (1998), Crouch (2002), DeVeaux (1996), Ho (1995), Travis Jackson (2012), Lewis (2004), Murray (1976), and Tomlinson (1991)

${ }^{31}$ Collier (1993), Davenport (2009), Gioia (2011), O’Meally (1998), and Taylor (1986)

32 Atkins (2001), Hall (1999), Roland Jackson (1997), Radano and Bohlman (2000), Jolly (1992), Kivy (1995), Lindholm (2002) (2013), Taruskin (1988), and Yacobi (2015)

33 Travis Jackson (2004), Malm (1993), DeVeaux (1991), Small (1998), Taruskin (1992), Tucker (2012), and Whyton (2010)
} 
In Chapter 5, I draw on a number of case studies in order to illustrate the way that Wellington jazz musicians, in the context of the Wellington scene (as illustrated in Part 1), negotiate the tensions and conflicts described in Chapter 4. Analyses of a Richter City Rebels performance, and the history and politics of the Wellington Jazz Festival, and consideration of differing approaches to tradition in Melbourne and Wellington, demonstrate ways in which the questions of authenticity and identity which underpin this thesis may be outworked in the activity of the local community. Chapter 6 concludes the thesis: I draw together the threads of discussion, using an account of the intense jazz activity in Wellington over a single weekend to demonstrate both the dynamics and values of the Wellington jazz community, within the Wellington scene, and the additional perspectives that Wellington jazz, an intensely creative and energetic community, can bring to the various discourses (of New Zealand music, of global jazz) from which it is still missing.

This project has been conducted against the backdrop of a hugely complex set of social and musical dynamics; and those dynamics have themselves affected and informed the investigation as it has progressed. My desire to reflect, in a scholarly manner, on concepts such as national identity, the intersection of the jazz tradition and New Zealand-ness, and the local musical environment, derives from my experience not only as a performer and teacher in this particular context, but as a colleague and bandmate. The contesting and formation of my own performing identity forms a major element in both my motivation and my analysis.

My positionality, while complex, is not atypical in terms of the kinds of interaction and dynamic flux which is characteristic of the activity and relationships within the scene in Wellington. That complexity is fed by the nature of the scene itself: a tightly cohesive and interactive space, bounded by geography, informed by policy, and fed by a particularly localised momentum. It is a highly active community, which operates in a local environment which is conducive to both the performance of jazz and the sharing of energy, inspiration and motivation. The scene not only allows musicians to develop in a variety of directions simultaneously, but encourages them to do so. 


\section{Conundrums}

Much of the time, the tensions and negotiations outlined above bear no direct influence on Wellington musicians' discourse. Discussions of the discrepancy between the image of jazz in an international scholarly context and the reality on the ground in Wellington, or Wellington's place in the jazz world, or the relationship of jazz to "New Zealand music", tend not to come up in conversation, and indeed when I approached the topics in interviews some participants appeared surprised at my questions. Yet Wellington jazz musicians, by virtue of playing jazz in Wellington, create these conundrums: and although the tensions may have little bearing on one's musical choices as a Wellington jazz musician, under the surface they carry deeper implications, for jazz both locally and globally. The pervasive characterisation of Wellington jazz as American (whether openly or implicitly) allows local musicians to identify with a dominant and rich tradition, but also limits the identity of the Wellington jazz community as a creative community in its own right, and as creators of New Zealand music (which in turn has serious implications in terms of funding, publicity and other institutional support).

The effect of these conundrums and tensions is that jazz in Wellington occupies a liminal space. It sits at the nexus of competing discourses: it is both New Zealand music and American music, and at the same time it is neither. It is both traditional and novel; both homegrown and exotic. The scene in Wellington is hospitable to jazz, and yet the New Zealand music funding apparatus treats New Zealand jazz almost as if it does not exist. The liminality is such that, as we shall see, it is even possible in Wellington to be a jazz musician, and not a jazz musician, from one day to the next.

And yet Wellington jazz thrives. Between 90 and 100 gigs take place a month, consistently, in an area of less than one square kilometre; the musicians are (almost always) paid; and there exists a diversity of styles and approaches which allows musicians to constantly seek and find new performing opportunities and combinations. The following chapters explore the scene, examining the activity present within it, its dynamics, and its people; while considering the negotiations above, in terms of Wellington jazz performance and discourse. In parsing out the various issues, this thesis provides a starting point. It represents the first full-scale scholarly investigation into contemporary New Zealand jazz of 
any kind, and as such it provides a foundation on which, to echo the call of Hardie and Thomas, others may build a more comprehensive literature. 


\section{Part 1: The Wellington scene}

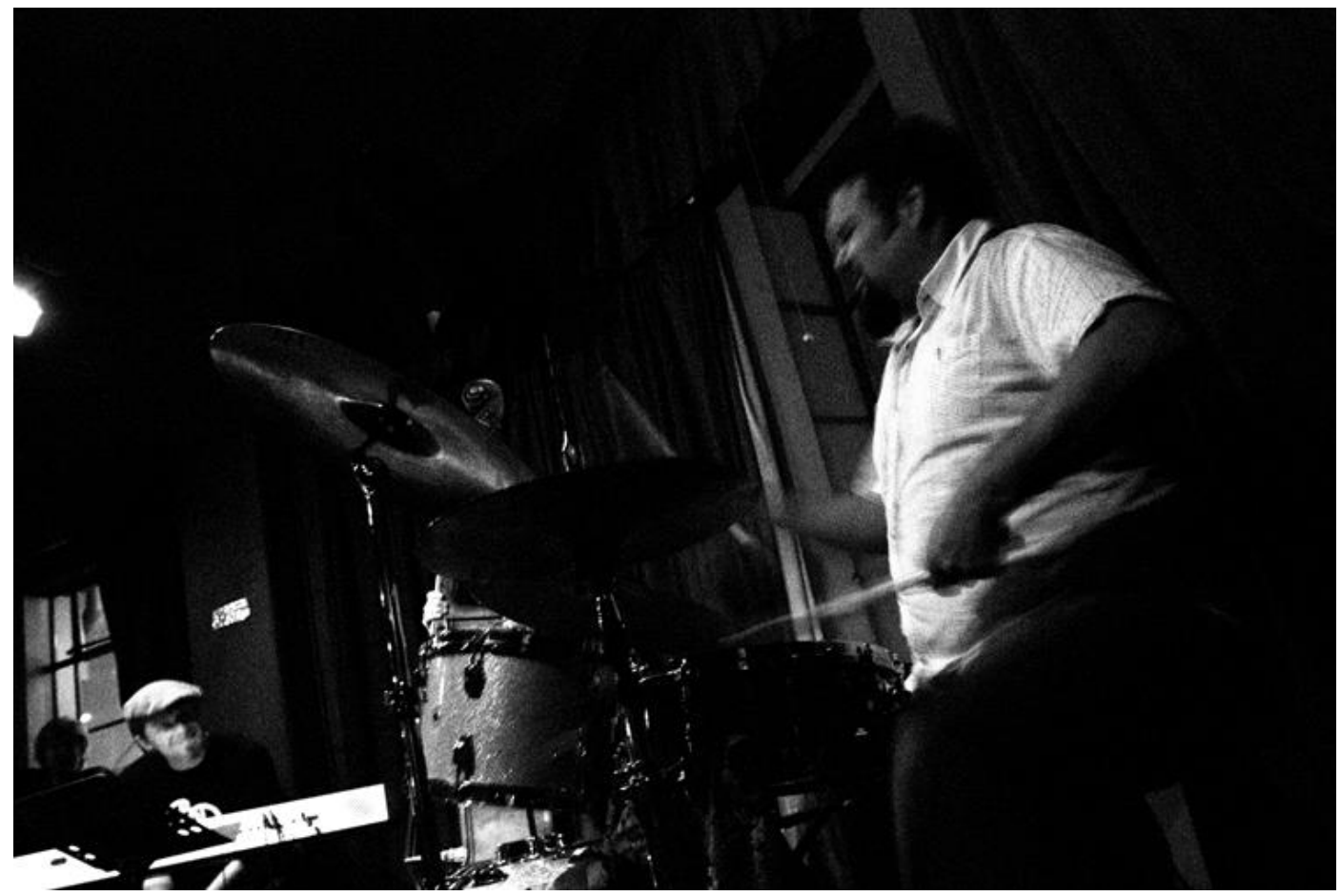

Fig. 1: James Illingworth (keyboard) and Rick Cranson (drums), with the author (obscured, bass) at Sandwiches bar, April 29, 2009 


\section{Chapter 1: Frames within frames: city, scene, community}

Jazz activity in Wellington can be viewed within a set of concentric frames. At the centre is the individual musician, surrounded by their community. The actions of the community take place against the backdrop of the scene; and that scene in turn exists within the frame of the city. Thus my own positionality determines, to a certain extent, my interaction with scene and community; having described my interactions with the community in the introduction, I now broaden my focus to provide contextual reference, in the light of which the activity and values of Wellington jazz musicians may be examined. The unique circumstances and environment which obtain in Wellington shape the activity of the community in various ways.

In examining Wellington as the scene in which the local jazz community operates, I first deconstruct notions of "scene" and "community", providing a theoretical basis for each; as we shall see, the concepts must be treated carefully, as each has the potential to reinforce dominant perspectives. I continue by taking a broad perspective to first describe Wellington as a city, then narrowing my focus progressively in order to illustrate the factors which create the unique dynamics present in the Wellington jazz community.

\section{Scene and Community}

In dealing with the scene as a concept, we must remember that it is complex, rather than monolithic: it consists of a variety of actors, influences, and environmental factors, and as such it requires unpacking. Travis Jackson (2012), in his study of jazz in New York in the mid1990s, conceives of a scene as providing spatial and temporal context to action. Jackson (548) alludes to the dramaturgical notion of a scene, which consists of the geographical, economic, social and musical circumstances within which activity takes place. The action in a scene is performed against a backdrop which at once circumscribes and informs it. Thus, as Jackson points out, the scene is "more than an inert setting for musical activity", and he 
goes on to describe the history of the New York scene, paying particular attention to the way regulatory, legislative and economic issues contributed to the scene's development. Indeed, it would be difficult to find musical activity anywhere in the world which is not in some way affected by the set of circumstances in which it is located.

However, Jackson extends this concept. In Jackson's reading, the cultural backdrop, the set of circumstances within which jazz is made in New York, acts upon that musicmaking and is therefore both context and agent in the formulation of New York jazz. As a result, and citing the "emic valence and specificity" of the term "scene" 34 , Jackson does not distinguish between the contextual backdrop and the actors. Jackson's definition of a scene allows the researcher to focus on the relationships between subjects, rather than the differences between the negotiations made by musicians among themselves and those made by musicians and institutions, for example.

While Jackson's definition emphasises the agency of such factors as economy and geography, the net result is not a gain in specificity, but a loss. To classify together the actions of the above factors and those of agents such as musicians, managers, teachers and fans glosses over the crucial difference between those types of actions. In this ethnographic study I have found it necessary to be more specific, and to distinguish between actors and background (to continue Jackson's metaphor). In order to do so, I utilise another term: community.

"Community" suggests a defined group of people, as opposed to a set of circumstances. It is a flexible concept, ${ }^{35}$ and as such it allows us to be rather more particular: there may be multiple communities within a single scene, and a musician may be a part of several different communities simultaneously. The term is also commonly found in scholarship (as Jackson points out), suggesting that its emic valence is appropriate in an ethnographic description.

However, Ken Prouty (2012) takes issue with the uncritical way that scholars utilise the phrase "jazz community". While acknowledging that communities can be bounded by geography and/or time, Prouty notes that "jazz community" means anything the author

\footnotetext{
${ }^{34}$ While eschewing the term "community" for its "connotations...among scholars"

${ }^{35}$ Shelemay (2011) provides a helpful deconstruction of the term as it applies to musicians.
} 
wants it to mean; from a small localised group of musicians, to the global jazz community, which may entail anyone from performers to recording engineers, executives, fans, and so forth; anyone, in fact, who engages in jazz musicking (to paraphrase Small). To enhance the usefulness of the term, Prouty builds on one model based on Anderson's “imagined community" (1983), and another drawn from Martin's (2005) and Becker's (1982) "art world", to propose a "community of practice"; 36 a "recording-listening continuum" in which the common practice referred to is listening to recordings. The community of practice includes performers, listeners, and anyone in between. The defining attribute of a member of Prouty's jazz community is that they actively listen to jazz ${ }^{37}$; the act of performing or recording, and its consumption, being the central focus. That the focus should be so is hard to contest; direct involvement with the act at the centre of a community would seem to be a sensible qualification for membership of that community.

Rather than cite live performance, and the attendance of live performance, as a unifying activity, he points out that many in the jazz community "have never heard, and will likely never hear, live performances by many iconic artists (especially those who are deceased)." (Prouty, 41) A jazz fan born after 1991, for instance, will never share the experience of live performance with Miles Davis, but is able to construct a relationship with him by way of the recording process. Prouty argues that recordings do not solely exist as documents, but that "recordings are made with the intent of being listened to, and thus the listening is part of the social process of its production". This implies a two-way relationship between artist and listener: between the deceased Davis, for example, and the listener in 2014; a relationship which defines Prouty's model of community.

However, in aiming for specificity, Prouty falls into the trap he was trying to avoid, in that it is unclear where the boundaries of Prouty's community lie. How often must one listen to jazz to be included? Could one be a member if one listens to jazz once a month, and never goes to a live performance? If one hears jazz in the elevator, or by accident when going out to a bar, is one then a member of that community? While the act of listening to jazz is indeed common to all those whom one would ordinarily consider members of the jazz

\footnotetext{
${ }^{36}$ Grounded in similar theory to Turino's "cultural formations" (Turino 2008, 95)

37 "After performance, the act of listening to recorded jazz might be the most readily identifiable activity among all those individuals who align themselves with jazz." (Prouty 2012, 44)
} 
community, establishing exact borders around a community such as this is of course difficult, if not futile. Additionally, Prouty's definition is so broad as to include many factors which, under Jackson's model, would be classed as elements of scene rather than community.

It is clear that boundaries may be set wherever we like; as Prouty originally pointed out, scene and community are such fluid notions that they may be deployed to advance any argument. What is important, though, is that they include; and by including, they exclude. A "community of practice", or a "jazz scene", is defined strategically; as Jackson points out in reference to the issues of race and culture, "what is arguably at stake is legitimation" (T. Jackson 2012, 24). In other words, the inclusiveness and exclusiveness of scene and community are easily manipulated (whether consciously or not) to serve ideological ends. Jackson's New York scene, for example, does not include practitioners of smooth jazz, jazz rock fusion, or free jazz, as they would not serve his concept of a blues aesthetic.

Community, on the other hand, is often used in a catch-all sense (as Prouty lamented). The "global jazz community" (ironically, the title of one of Prouty's chapters), for instance, is a common trope. As Prouty argues, it is used uncritically; but there is nevertheless an ideology at play. Reducing effectively all of jazz to one phrase is an inclusive act, but the danger is that it essentialises what is a huge variety of jazz played in a vast number of contexts. While the term "community" might focus on the commonalities among a group for ideological reasons ${ }^{38}$, it elides a range of different identities, thereby deemphasising them. Thus, depending on the point the writer wishes to make, the "jazz community" might be progressive, conservative, or a site of racial tolerance; it might be male-dominated, or it might use certain jargon.

Yet such categorisation glosses over the differences inherent within such a vast group, and the effect of this essentialisation is to privilege dominant perspectives within the "community". Essentialising sacrifices alternative voices in the service of a unifying definition, and in the process it focuses the discourse on well-known figures and/or groups. As a result, the ideology behind jazz discourse has resulted in the canonisation of jazz

\footnotetext{
38 Prouty $(2012,15-17)$ cites a range of sources, each of whom essentialise by citing the "jazz community" in support of a different philosophical or sociological point.
} 
scholarship; and we are left with a detailed literature on a relatively small number of artists, from a particularly circumscribed background. Of course this in itself is a generalisation; I would be remiss to acknowledge the broadening of the discourse (particularly in the New Jazz Studies) to include a wider range of competing and conflicting jazz perspectives. However, I would argue further that the canon itself, while updated, nevertheless remains the frame upon which New Jazz Studies is built. The introduction to Uptown Conversation: The New Jazz Studies (O'Meally, Edwards and Griffin, Uptown Conversation: the New Jazz Studies 2004), for example, announces that its authors "insist that we look around or behind the Giants of Jazz [authors' capitalisation] to consider less well known figures as well as the communities that surround, support and imbibe the music." A glance at the contents, however, reveals that while non-canonical musicians and topics do appear (Senegalese jazz, the AACM, Nathaniel Mackey, the "new underground" and the problems of Ken Burns' "Jazz" (2000)), and although fresh interdisciplinary perspectives are explored, much of the writing nevertheless privileges artists from the conventional canon, the "Giants of Jazz": four separate chapters focus on Louis Armstrong, three on Duke Ellington, and one each on Charles Mingus, Dave Brubeck, and Miles Davis.

What is usually excluded from the canonised version of jazz history and scholarship is the vast majority of musicians who play jazz: the unnamed masses who invest considerable amounts of energy in the music. Building on the concepts of "big-j" and "little-j" jazz which I developed in the introduction, I address this issue by viewing jazz activity in Wellington through those lenses.

\section{The Wellington community}

Given the predisposition in scholarship towards "big-j" Jazz, the term "community" does not serve well the broader jazz world. Yet "scene" and "community" are, as Jackson notes, emic notions; they yet have use in describing a model with which we are familiar, despite the issues laid out above. Bearing in mind this "emic valence", in this investigation I adapt Jackson's model, while extending and inverting it. I conceptualise "scene" quasidramaturgically, to include the background personnel, institutions, activity and circumstances which affect and inform, but do not actively participate in, the jazz music- 
making in Wellington. To describe the collectivity of musicians who do perform jazz (regardless of circumstance) in Wellington, I apply the term "community", invoking (advisedly) its catch-all implications, but also its notions (also acknowledged by Prouty) of interconnectedness. Thus, the community operates against the backdrop of the scene; and the scene may include the economic, artistic and cultural background of Wellington, or that of New Zealand; or it may instead include the global field of jazz, which provides the backdrop to the action on which this investigation focuses.

The community I examine in this investigation is constructed with the above ideological issues in mind. Like Prouty, I focus on a community of practice, but one based both on musical performance and, given the inclusive approach inherent in my invocation of "little-j" jazz, geographical location. ${ }^{39}$ While this de-emphasises the "listening" end of Prouty's continuum, this is for reasons of practicality: focusing on the discourse and practice of performers is the first step in discerning the values inherent in that performance. The Wellington jazz community includes musicians who are both well-known (locally or more broadly) and those who are not. It is a small, vibrant community which includes a wide range of approaches to music making. I do not discriminate by style, except to the extent that different stylistic approaches are extant (or not) within the community itself. The approaches, practice and discourse evident within the community interact with the manner in which the Wellington jazz community relates to the various scenic frames which inform it, to both reinforce and challenge various themes within the wider jazz discourse.

To invoke Jackson's dramaturgical metaphor once more, then, I will begin this investigation by broadly "setting the scene", before continuing with a more detailed description of the community. Through the descriptions, I will illustrate the ways that the ideologies which underpin the scholarly and non-scholarly discourse on jazz (and which influence and are influenced by jazz practice) are visible, challenged or otherwise, in the Wellington context.

\footnotetext{
${ }^{39}$ As "little-j" jazz, in contrast to "big-J" jazz, necessarily includes as wide a range as possible of approaches to jazz, the Wellington jazz community, existing in an isolated city, is extraordinarily interconnected, to the extent that most members of the community are at least acquainted with one another, and the borders of the community are therefore defined as much by geography as by style.
} 


\section{The Wellington environment}

The capital city of New Zealand, Wellington is a compact, diverse city located at the southern tip of New Zealand's North Island. The city is set beside one end of a small harbour, which opens on to Cook Strait, the stretch of water separating the North and South Islands of New Zealand. Its position close to Cook Strait and location within the "roaring forties" mean that Wellington's climate is temperate and often windy. Wellington is the southernmost, and most isolated, capital city in the world. The nearest major cities are Auckland and Christchurch: each are 8 hours' travel away by road (and ferry, in the case of

Christchurch). New Zealand itself is isolated; Australia, its nearest neighbour, with the major cities of Brisbane, Sydney and Melbourne, is approximately $2500 \mathrm{~km}$ away, and in a practical sense accessible only by air. To reach the west coast of the U.S., or any of the major Asian cities (including Tokyo, Singapore, Seoul, Shanghai, or Bangkok) requires an 11 to 12-hour flight (from Auckland); Europe is twice as far, literally on the opposite side of the world.

Four main population centres make up the Greater Wellington region: Wellington City, the Hutt Valley to the northeast, and Porirua and the Kapiti Coast to the north. The combined population of the city's main centres in in 2013 was 430,194, and of that Wellington City represented 190,956, or 44\% (Statistics New Zealand 2013). With the highest household income of any New Zealand region (ibid.), Wellington brands itself as "vibrant and cosmopolitan, compact and safe". Key employment sectors include government (employing $12 \%$ of the Wellington City workforce), health (7.8\%), science \& research, and education (Grow Wellington 2010). Wellington is a significant centre for tertiary education, with three universities occupying six city campuses; and for the arts, with most national arts organisations (Including the New Zealand Symphony Orchestra (NZSO), Royal New Zealand Ballet, Creative New Zealand, and Toi Whakaari: New Zealand Drama School,) housing their headquarters in the city.

Wellington City (hereafter referred to metonymically as "Wellington") is centred around the south-western reaches of the harbour. Most residents live in suburbs to the north, northwest, south and southeast, and the city centre largely consists of commercial and retail real estate. However, since 2000 , central city land has been opened up for residential development, resulting in a significant increase in the number of small, city 
apartments. The layout of Wellington's urban area is significantly affected by geography; the city centre itself is squeezed into a narrow area of land bordered by hills on one side and the harbour to the other, resulting in a somewhat triangular shape, $3 \mathrm{~km}$ long by $1.5 \mathrm{~km}$ wide. The Town Belt, an extensive series of public recreation reserves which encircles the downtown area, was set aside in 1873; this has had the effect of reinforcing the geographic restrictions on urban development. As a result, the land area of the central city is a tiny $1.44 \mathrm{~km}^{2}$.

For marketing purposes, the city is divided into four quarters (residents do not tend to use these distinctions): the Courtenay, Cuba, and Lambton Quarters (named for the main thoroughfare in each) and the Waterfront Quarter. The combined Cuba and Courtenay Quarters, the site of most arts and entertainment activity in the city, total just $0.71 \mathrm{~km}^{2}(0.27$ mile ${ }^{2}$ ) in area: $80 \%$ of the size of Greenwich Village in Manhattan, or 1/4 the size of London's Soho. The city centre and its arts district is therefore compact and walkable.

\section{Policy}

Following the privatisation and deregulation of the New Zealand economy in the late 1980s, many companies and organisations relocated to Auckland; Wellington remained the seat of government, but saw rising unemployment as a result (McLean 2013). Beginning in the 1990s, Wellington's local government took a proactive role in terms of urban development and renewal (Volkerling 2006). Successive mayors undertook to help Wellington discard its sleepy, bureaucratic reputation by encouraging tourism, enhancing infrastructure, beautifying public areas, and hosting major events.

In 2003, American urban studies theorist Richard Florida undertook research in Wellington. Florida's theories on the "creative city" and "creative class" examine the links between creative individuals and industries and the economy; he suggested that attracting the "creative class" would enhance the economic development of cities. Florida cited Wellington as an example of a city where his theories could be demonstrated to work (Volkerling 2006); Wellington film-maker Peter Jackson, he wrote, "was an example of the sort of visionary who realized what many American cities discovered during the '90s: 
Paradigm-busting creative industries could single-handedly change the ways cities flourish and drive dynamic, widespread economic change" (Florida, Creative Class War: how the GOP's anti-elitism could ruin America's economy 2004). Florida's work has proven both influential and controversial; Michael Volkerling argues that "Florida's theories have done little other than to re-describe characteristics of the city that were already apparent and are grounded in historical circumstances" (Volkerling 2006, 299).

Nevertheless, after Florida's 2003 visit, then mayor of Wellington Kerry Prendergast took Florida's recommendations seriously, implementing policies aimed at creating an environment conducive to the "creative class". These policies were intended to create an environment, as articulated by Florida, which would encourage the attraction and retention of members of that class: as summarised by Volkerling, that environment should include a variety of stimulating lifestyle amenities close at hand, including (reproduced from Volkerling):

- a thriving, street-level art, music and technology scene and outdoor recreational opportunities (Florida 2002:224, 232);

- thick labour markets offering plentiful job opportunities (224);

- opportunities for social interaction supported by plenty of venues like coffee shops,

- bookstores and cafes (225);

- a diverse population of different ethnic and racial groups, ages and sexual

- orientations (226);

- the existence of creative class peers $(229,230)$;

- tolerance to all types of people and ideas (232);

- unique offerings that are not accessible in other locations, such as in the architecture, music scene or cultural qualities of the place (228); and,

- an attractive natural and built environment (232). (Volkerling 2006, 297)

Prendergast rebranded Wellington as the "Creative Capital", a moniker which has proved durable and popular, and its reputation for lifestyle has emerged over the past decade. In 2011 Global travel guide Lonely Planet named Wellington "Cool-with-a-capital-C", and 4th in its "Top ten cities for 2011" (Lonely Planet 2010). Wellington prides itself on its urbanity; café culture is a major element of the inner city lifestyle, and small independent bars and coffeehouses are a feature throughout the city. The Wellington City Council proudly announced in 2012 that "95\% of residents and 77\% of New Zealanders think that Wellington has a culturally rich and diverse arts scene and $79 \%$ of residents and $61 \%$ of New Zealanders 
believe that Wellington is the arts capital of New Zealand." (Wellington City Council 2012, 35) A 2011 report by Creative NZ, the national arts funding body, found that residents of Wellington (along with those of Nelson) exhibited the highest level of engagement with culture of those of any New Zealand region, as well as spending the most on attending cultural activities. (Creative New Zealand 2011)

\section{Local urban identity}

Wellington's identity, like that of New Zealand more broadly, is influenced by its location and isolation. A fuller discussion of New Zealand identity will take place in Part 2, but of interest here is the extent to which both identities rely on an externalised perspective. Wellington's café scene is often compared to that of New York or London. The city continues to dine out (so to speak) on the favourable review (and catchy phrase) bestowed by Lonely Planet. (Lonely Planet 2010, 107) The format of the Wellington Jazz Festival has been influenced by a parochialism on the part of musicians (as we shall see in Chapter 5), and Wellingtonians, like other New Zealanders, are quick to claim vicarious success when a hometown hero makes good, whether in music (Fat Freddy's Drop, the Black Seeds, Brooke Fraser or the New Zealand Symphony Orchestra, for example), sport (All Blacks Tana Umaga, Ma'a Nonu and Conrad Smith), literature (Man Booker Prize winner Eleanor Catton), film (Oscar winners Peter Jackson and Weta Workshop), or other endeavours.

It is worth considering whether this speaks to a vaguely colonialist, defensive attitude, which reflects New Zealand's (and Wellington's) position in the world. It is easy to see how a small country located far from the action, in a global environment dominated by major powers, feels obliged to assert its identity (even if only to itself), and much could also be ascribed to the continuing phenomenon of "cultural cringe" in the context of New Zealand identity. ${ }^{40}$ But more significant in the context of this investigation is the extent to which New Zealanders give credence to (externally-based) hegemonic discourses of powerwhether geopolitical, cultural, or in terms of sport. Rather than setting its own agenda, New Zealand locates itself within a wider dialogue, in which it can only ever be a minor voice:

\footnotetext{
${ }^{40}$ It is interesting to consider whether articles such as Peter Calder's (2012), in attempting to move on from "cultural cringe", simply reinforce it.
} 
thereby consigning itself to a constant search for definition. In this way, New Zealand's location and posture feeds into its assertive identity (an interesting situation given New Zealand's self-image is one in which assertiveness is seen as undesirable).

The action of the Wellington jazz community is set within multiple frames, which constitute the "scene". Global geopolitical and social discourses inform New Zealand's national identity; that national identity in turn necessarily informs New Zealand jazz musicmaking (a fuller discussion of this process will form part of the basis of Part 2). But at the same time, the local Wellington artistic context inevitably has a significant effect on the community, and it is here that my investigation, in privileging local ("little j") perspectives, itself diverges from the hegemonic discourse. That artistic context is, of course, informed in turn by Wellington's geography, policy, and identity.

\section{Arts Events and Organisations}

As a result of the political drive towards the creation of a vibrant and creative community, Wellington now plays host to several national and international events. The strikingly original World of WearableArt (sic) competition and show, which combines theatre, fashion, sculpture, and dance, moved to Wellington from Nelson in $2005^{41}$; and the Wellington Rugby Sevens, a festival based on New Zealand's national sport, and which coincidentally involves costume on the part of the crowd, has been a feature of the local sporting and party calendar since $2000^{42}$. The New Zealand International Arts Festival is held every two years in Wellington, and involves acts ranging from Renaissance music to circus-style acrobatics, literature readings and contemporary theatre. According to the Wellington City Council's 2011-2012 Annual Report, in 2012 the festival

[...] utilised key waterfront and city venues with 300 performances and 900 artists from 31 countries. Over 110,000 tickets were issued and over 165,000 people

\footnotetext{
${ }^{41}$ The World of WearableArt began in Nelson in 1985, and features designers competing in various categories; designs are traditionally outlandish and could be described as much as sculpture as clothing. In recent years it has attracted international attention, presenting performances at the 2012 Hong Kong Arts Festival, and inspiring other similar events in Australia and the U.S.A.

${ }^{42}$ The event is one of the legs of the IRB Sevens World Series, a global seven-a-side rugby union competition which also incorporates tournaments in Las Vegas, Hong Kong, Dubai, Cape Town, and Glasgow. Uniquely among sevens tournaments, the Wellington Sevens has also evolved to include a significant element of fancy dress on the part of the crowd attending the event.
} 
attended free events. The Festival resulted in total expenditure in Wellington City of $\$ 56$ million... The Festival again reinforced Wellington's reputation as an arts and events capital. (Wellington City Council 2012, 27)

Other key events in the Wellington calendar also revolve around the performing arts: the ASB Gardens Magic is an annual concert series held in the city's Botanic Gardens; the Jim Beam Homegrown festival showcases local rock and pop bands on the waterfront; and the Wellington Jazz Festival, which forms one of the case studies later in this dissertation, celebrates local, national and international jazz acts in the Cuba Quarter of the city. Many smaller (but nevertheless popular) events take place throughout the year, including the Chinese New Year festival, the Diwali festival (the Hindu festival of lights), various indoor and outdoor Carols by Candlelight events, the Wellington Wine and Food Festival, Victoria University's Summer Shakespeare production, and various suburban events such as the Island Bay Festival, the Newtown Festival, the Eastbourne Carnival, the Petone Winter Carnival, and CubaDupa. ${ }^{43}$

Although Auckland has developed into the financial and economic centre of New Zealand, Wellington remains the site of the headquarters of many of the country's major national cultural organisations. Proximity to government means that along with the Ministry for Culture and Heritage, government-linked organisations including Creative New Zealand, the government arts funding body, and Te Māngai Pāho, a government agency dedicated to Māori language broadcasting, remain in the city. Radio New Zealand (which broadcasts nationally on two stations, Radio New Zealand Concert and Radio New Zealand National; RNZ Concert is dedicated almost entirely to classical Music, whereas RNZ National is similar in content to National Public Radio in the U.S.) has its head office and studios in Wellington, although Television New Zealand moved its headquarters to Auckland in 1989, and withdrew from its studios located in Avalon, north of Wellington, in 2011. Recorded Music NZ (known until June 2013 as the Recording Industry Association of New Zealand (RIANZ)) and the New Zealand Music Commission, however, are located in Auckland; the SOUNZ Centre for New Zealand Music is in Wellington.

\footnotetext{
${ }^{43}$ Shelley Brunt (2011) examines the Cuba Street Carnival (now rebranded CubaDupa) in relation to the performance of local identity/identities.
} 
The major performing arts organisations are split between Wellington and Auckland. The New Zealand Symphony Orchestra, the Royal New Zealand Ballet, the New Zealand Film Commission, Toi Whakaari: New Zealand Drama School, and the New Zealand School of Dance are located in Wellington; New Zealand Opera and the New Zealand Choral Federation have their head offices in Auckland. The New Zealand String Quartet and Chamber Music NZ are in Wellington; the NZ Trio (also a chamber music ensemble) is based in Auckland. The New Zealand School of Music (see Chapter 3), located in Wellington, is not, despite the name, a national institution, but a department of Victoria University ${ }^{44}$, on the same level as (although larger than) the music departments of other universities including the University of Auckland, Canterbury University in Christchurch, and The University of Otago in Dunedin. Of course, like any city, Wellington hosts its own institutions, which are too numerous to explore fully; among the larger and more influential are Orchestra Wellington, the Orpheus Choir, Circa and BATS Theatres, and the New Zealand International Arts Festival. Weta Workshop, which has produced special effects for films including the Lord of the Rings and Hobbit trilogies, Avatar, and King Kong, and which was celebrated by Richard Florida, is located in Miramar, in Wellington's eastern suburbs.

\section{Nightlife and Entertainment}

While arts and cultural activity is spread across the Wellington region, much of Wellington's nightlife is focused around two streets. Courtenay Place (which, along with the adjoining Blair, Allen, Tory, Dixon and Manners Streets is known as the Courtenay Quarter- see above), is lined with bars and restaurants, ranging from fluorescent-lit fast-food joints to sophisticated restaurants, and chic urban cocktail bars to dedicated dancehalls. Cinemas and larger performance venues such as the Opera House and the St James Theatre sit alongside smaller performance spaces including BATS and the Hannah Playhouse, but performance is not restricted to dedicated venues. Many of the establishments along the above streets host live music, or have hosted it in the past.

\footnotetext{
${ }^{44}$ And formerly a joint venture between Massey University and Victoria University; see Chapter 3.
} 
On Thursday, Friday and Saturday nights Courtenay Place is known as the vibrant heart of Wellington's nightlife (although this is not to everyone's taste (Stewart 2013)); but the more bohemian area of Cuba Street presents a contrast to the commercialised, "boozy culture ${ }^{\prime 45}$ of Courtenay Place. Businesses along Cuba Street (which is partially a pedestrian mall) and the adjoining Vivian and Ghuznee Streets (collectively the Cuba Quarter) consciously position themselves as alternative and hip, whether they are restaurants, bars, or retail outlets. ${ }^{46}$ Many of Wellington's live music venues are (or have been) located in the Cuba Quarter, including the Matterhorn, the San Francisco Bath House, Mighty Mighty, Havana, The Laundry, Thistle Hall, Valhalla (formerly the Vault, Bar Medusa, and Hole in the Wall), and the Hotel Bristol. Two of Wellington's concert halls, the Wellington Town Hall and the Michael Fowler Centre, are located at the end of Cuba Street; the other two large venues, the St James Theatre and the State Opera House, are on Courtenay Place.

\section{Music Scene}

Wellington's overall music scene is vibrant and eclectic. A very wide range of both Western and non-Western musicking takes place in the city, reflecting the diversity of its inhabitants. As well as jazz, particularly well represented are classical music ${ }^{47}$, indie $\operatorname{rock}^{48}$, soul / R\&B ${ }^{49}$, and dub/reggae: the "Welly dub sound" has become one of the more successful and widely known aspects of the Wellington music scene. Dub bands such as Fat Freddy's Drop, Rhombus, the Black Seeds and Trinity Roots have all achieved local, national, and international success in the last decade. Newer bands and artists including Louis Baker, Thomas Oliver, Estère, and Tunes of I are developing their reputations. Other musical communities include folk music (including country and bluegrass), hardcore / metal, barbershop, kapa haka, gamelan, and experimental / noise. Many of Wellington's iconic

\footnotetext{
45 (Cook, Stephanie, in Stewart, 2013))

${ }^{46}$ Shelley Brunt (2011) examines the importance of the Cuba Street Carnival (rebranded in 2015 as CubaDupa) in performing a "Wellington" identity.

${ }^{47}$ As well as the classical music organisations located in Wellington as detailed previously, Wellington hosts a broad range of classical music, ranging from early music to contemporary composition.

${ }^{48}$ For a more in-depth examination of the Wellington indie scene, see Stahl (2011). Notably successful Wellington indie bands include The Phoenix Foundation, Fur Patrol, and Fly My Pretties.

${ }^{49}$ Successful acts of recent years include Louis Baker, Iva Lamkum, and Bella Kalolo.
} 
music venues are located on, or close to, Courtenay Place or Cuba Street, including the Matterhorn, San Fran (formerly the San Francisco Bath House), Mighty Mighty ${ }^{50}$, Havana, and Meow. Larger venues include the Wellington Town Hall and Ilott Theatre (both closed from 2013-16 for earthquake strengthening), the Michael Fowler Centre, the TSB Bank Arena, St James Theatre, and the Opera House, as well as Old St Paul's (the name refers to its status as the former cathedral of Wellington), St Paul's Cathedral and St Mary of the Angels. Wellington musicians are consistently well served in terms of performing opportunities; a number of the city's bars and restaurants host (or have hosted) live music as part of their ambience, an attitude which particularly favours jazz musicians ${ }^{51}$.

Live music can be found every night of the week in Wellington. While the highest density of performances predictably occurs on the weekend, certain venues host live acts on Thursdays, Wednesdays and occasionally Mondays and Tuesdays. While venues and businesses come and go (over the course of this project several venues have closed, and several others have opened ${ }^{52}$ ), the demand from hospitality managers for live music remains consistent.

A feature of the Wellington music scene is the high degree to which musicians cross over stylistic boundaries, or straddle a variety of ensembles and contexts. Musical networks in Wellington tend to be closely interlinked; members of one band often appear in other bands at other times. While this is a hallmark of music scenes, it is a notable characteristic of the Wellington scene, in contrast to Melbourne, for example: a project I conducted there (Tipping 2014) revealed the extent to which jazz musicians were unaware of other jazz musicians, if they operated in separate networks. Wellington is an "overgrown village" (Cranson 2011) in which, broadly speaking, everybody knows everybody, and each new musical enterprise adds to the network of activity.

\footnotetext{
${ }^{50}$ Mighty Mighty closed down in May 2014.

${ }^{51}$ For a map of current and former Wellington jazz venues, see Figure 2 (p.59), or for an interactive version see http://bit.ly/1Bo9OmH.

52 Closed or stopped hosting music: Mighty Mighty (see footnote above), the Ruby Lounge, Bar Medusa, The Apartment, the Roxy Cinema
} 


\section{Wellington Jazz Networks}

The Wellington jazz community operates in the midst of this energetic scene. In the concentrated and varied Wellington environment, Wellington jazz musicians are faced with a wealth of opportunity. Even students of the jazz performance programme at the New Zealand School of Music are regular performers on the scene. Standards gigs operate alongside performances of original jazz compositions; free improvisation has a place, as does jazz rock fusion and classic jazz from the 1920s. The strength of the scene is a relatively recent phenomenon, however; in 1997 a group of musicians were driven to conceive and run the Wellington Jazz Festival, in part as a response to a lack of opportunities for local jazz

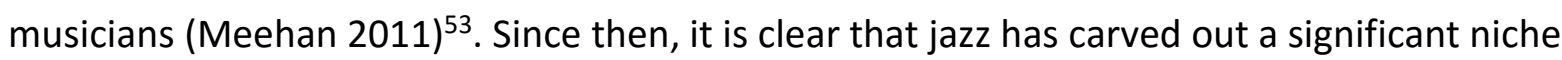
in the local music scene, with significant numbers of active musicians performing regularly.

In fact, the Wellington jazz community provides an interesting counterexample to those cited by Prouty and others, in that to a significant extent there is nothing "imagined" about it. One of the defining aspects of the Wellington scene, and that of other scenes around the country, in relation to larger scenes such as Melbourne, New York, or London, is its interconnectedness. A compact city, Wellington hosts a compact music scene. Most members of the jazz community are known to each other and there is little room for compartmentalisation. It is rare for a jazz musician to restrict themselves to one type of expression, one style, venue or ensemble. Versatility is valued, as it means greater opportunities for self-expression, exposure, and exploration.

In practice, this means musicians can often be found playing with a wide variety of other musicians, and in a range of musical contexts, with jazz one of multiple genres in a musician's portfolio. It would not be unusual for the same jazz player to perform with ensembles as varied as a reggae band, an indie / folk band, a contemporary jazz band, a Dixieland band, and a Balkan folk ensemble, for instance. To some extent this is a function of the economic environment in which Wellington musicians must operate. It is impossible to make a living just by playing in one ensemble (apart from the New Zealand Symphony Orchestra), and so in order to survive musicians must diversify. Teaching presents a certain

\footnotetext{
${ }^{53}$ An investigation of the relationship of the Wellington Jazz Festival to the Wellington jazz community forms part of Chapter 5.
} 
level of opportunity, but there are limited teaching positions and private students available. In order to avoid working in jobs unrelated to music, a musician must diversify and take advantage of a range of opportunities. To some extent this is a hallmark of musical scenes worldwide; where diminishing avenues of employment occasion the broadening of musical careers.

But in Wellington, as we shall see below and in Chapter 3, the valorisation of versatility both informs and is informed by the size of the scene, and both the breadth and limited number of opportunities available. Economic considerations are not the only factor in musical diversification; the breadth of the Wellington music scene presents opportunities to indulge a wide range of musical interests relatively easily. Musicians, therefore, may well perform in a variety of ensembles for interest's sake, despite low or non-existent financial benefit. $^{54}$

All of this means that Wellington jazz musicians, whether through membership of a range of ensembles, or through opportunism, tend to make and establish a broad range of contacts across the local jazz scene and beyond. The network of Wellington jazz musicians is exceedingly complex; it is likely ${ }^{55}$ that there is no more than one degree of separation between any two musicians in the city. Taking my own musical activity as an example, over the course of 2013, for example, counting only small group performances (not counting orchestral or big band performances, which formed a significant part of my own portfolio at that time) in the Wellington region, I played with 87 different musicians in 102 different gigs. Each of those musicians will have played with a number of others, thus expanding the network exponentially.

Effectively, the scene is democratised. There is such a low degree of separation, through the intertwined networks of the various players, that connections are easily made and virtually no-one is out of reach of anyone. Of course, reputation counts for a lot, but what hierarchy there is (established via teaching relationships, age or level of experience) is negated by dint of economics, geography and interpersonal relationships.

\footnotetext{
54 In fact, a number of Wellington jazz musicians have observed in conversation that if financial considerations were paramount, they would not be jazz musicians in the first place; there are few, if any, jazz musicians in New Zealand making a full-time living by playing jazz.

${ }^{55}$ Based on network mapping exercises undertaken as part of this study.
} 
As a result of the extensive connections between musicians, collaborations are usually just a phone call (or text or Facebook message) away. New combinations of musicians spring up almost weekly, sometimes for one performance and sometimes for a lengthier period. Bands may be formed for a particular project, or other purpose. Groups may be assembled for their own sake, in order to discover the effects of certain combinations: every musician in Wellington brings a different set of skills, proclivities and approaches, and new combinations always have the potential of engendering new creative outputs. At the same time, musicians tend to enjoy playing with certain other musicians, and so particular combinations often last: Paul Dyne (bass) and Roger Sellers (drums), or Myele Manzanza (drums) and Scott Maynard (bass), for example.

Occasionally, all-star groups may be assembled for particular performances. These often consist of unusual or irregular combinations of instruments: the four tenor saxophones of Daniel Yeabsley, Lucien Johnson, Blair Latham and Tim Hopkins, for example, or the ensemble shown in Figure 3 (p.61), which includes seven horns, keyboard, two guitars, two basses, two drummers and two percussionists (and several typos): the musicians are drawn from several high-profile Wellington bands, including Fat Freddy's Drop, the Phoenix Foundation, the Troubles, the Yoots (itself a band consisting of members of other high-profile bands), the Richter City Rebels, and the Black Seeds. In fact, it is difficult to find an ensemble with a reasonably high profile in Wellington which does not contain at least one member of another well-known ensemble, such is the extent of the cross-pollination and networking. Local star power plays a part, in that new and/or unusual combinations of musicians are more likely to attract interest if those musicians are wellknown. And musicians' reputations are, of course, enhanced by association with other, highly-regarded musicians.

\section{Networks and Versatility}

Jackson $(2012,72)$ describes the New York scene as a "network of networks"; in which "mini-networks" like the "Memphis pianists", the "New School crowd" or the "Smalls scene" interlink to form the wider network of musicians. To some extent the environment is similar in Wellington, although the mini-networks are difficult to define. For the sake of description, 
there are networks based around venues (the Meow guys, the Rogue and Vagabond crowd); around styles and groups (the Wellington Jazz Orchestra, the Latin players, the gypsy jazz guys or the free jazz people) ${ }^{56}$. However, membership of these networks is hard to define, and constantly changing; musicians are often a part of widely different networks concurrently. Paul Dyne, one of the most durable members of the Wellington scene, is both a well-recognised bop player (most notably with the Boptet), and an accomplished free jazz musician (with ensembles including Syzygy). Drummer Myele Manzanza has at different times been a member of reggae band Olmecha Supreme, funk band Electric Wire Hustle, his father Sam Manzanza's Afrobeat band, and his own eclectic modern ensemble, as well as developing a career as a DJ. Pianist Ben Wilcock, named in the footnote as part of the Meow crowd (with the vaguely "alternative" connotations that that association brings) also plays stride with his band the Jelly Rolls, modern soul with Bella Kalolo, and contemporary original jazz with the Reuben Bradley Trio. ${ }^{57}$ Lauren Ellis plays drums in swing ensembles at the Rogue and Vagabond, in the Wellington Jazz Orchestra, and in New Orleans-style marching band the Richter City Rebels. Matt Allison plays trombone in the New Zealand Symphony Orchestra, in the Richter City Rebels, and in the modern jazz octet The Jac. Daniel Yeabsley plays saxophone in The Troubles, and bass in the Jelly Rolls, and the Wellington International Ukulele Orchestra. Hikurangi Schaverien-Kaa plays drums with Latin group the Bandidos, modern jazz trio Trio Reflections, and in popular alt-folk groups French for Rabbits and City Oh Sigh.

Versatility is not restricted to individual musicians. The core members of popular reggae band Tunes of I, for example, are all trained jazz musicians, who also perform jazz/funk under the name Chocolate Thunder. An ensemble of which I have been a part presents another example in which a single group can transcend musical boundaries. The Reuben Bradley Trio, in which I play bass, Reuben plays drums and (until early 2015) Ben Wilcock played piano, Fender Rhodes and keyboard, performed in a wide range of contexts

\footnotetext{
${ }^{56}$ the "Meow guys" include musicians such as John Rae, who performs almost nightly at Meow, Dan Yeabsley, Ben Wilcock, and the Troubles; the Rogue and Vagabond crowd includes Chris Buckland, Adam Page, and Lauren Ellis; the Latin players include Alda Rezende, Rafael Ferrer Noel, and Mark Donlon; the gypsy jazz guys include Leigh Jackson, Nick Granville, and Nik Brown; and the free jazz people (a broad term in itself) includes musicians ranging from Jeff Henderson and Bridget Kelly to Nell Thomas and Daniel Beban.

${ }^{57}$ Wilcock moved to Rotorua in early 2015; it should be noted that other details are correct at the time of writing, but due to the constant change within the scene it is inevitable that such a list of activities will quickly become out-of-date.
} 
as a stable group. The most regular was as a jazz trio, playing music influenced by Jelly Roll Morton and later musicians, following the interests of Wilcock. The group also performed Bradley's original music, drawn from three albums: Resonator, which was awarded Jazz Album of the Year in New Zealand in 2011; MANTIS: The Music of Drew Menzies; and Cthulhu Rising, inspired by the horror writer H.P. Lovecraft. Additionally the trio performed as a backing band, in which guise we performed music ranging from jazz standards and originals to pop and rock covers. Yet covering the gamut from Jelly Roll Morton to Tina Turner is not necessarily unusual among Wellington jazz musicians.

Mini-networks, then, while only occasionally referred to within the scene itself, do act as Jackson describes, in "break(ing) a largely heterogeneous and shifting community into more manageable units"; (T. Jackson 2012, 72) but the effect is perhaps less marked than in a larger community like that of New York, London, or Melbourne (Tipping 2014), where, in contrast to Wellington, the members of one subcommunity may often be unknown to the members of another. In Wellington, where a working musician may play with a reasonably high proportion of the musicians on the scene at any one time, and will undoubtedly have personal relationships with many more, the demarcations of these mini-networks are much more subtle. Knowledge of these networks may allow for quick reference to particular groups for descriptive purposes, but practically speaking, the Wellington jazz community is so close-knit, and musicians are so catholic in their musical activities, that such classifications are of little use. The utility of networks or mini-networks as a means of description is eroded both by the breadth of their reach across the community, and by the versatility of the musicians themselves. A taxonomy which may make sense one week may be invalid the next (the same may be true from day to day); and whether a musician is a "jazz musician" may depend on the occasion.

Musical relationships, while more helpful in establishing a sense of the cohesion of the community, are equally fluid: musicians may tend to play with certain other musicians, or at certain venues, but such relationships are by no means permanent, and musical partnerships or residencies may come into being or cease at any time. Quite simply, the jazz community in Wellington is too small for any firm division into mini-networks to hold water: they do exist, but as a result of the varied opportunities on offer, musicians (and sometimes ensembles) regularly transcend network boundaries. 
Indeed, such is the multiplicity of approaches and activities, the most useful unit of classification in Wellington is the individual musician themselves. The Wellington jazz community can most usefully be seen as being composed of a constantly shifting set of individual musicians, many of whom defy easy categorisation, and who are connected by musical alliances which themselves are constantly in flux. Any attempt to map the community via performing relationships is almost immediately out of date.

\section{Big-J and Little-j in Wellington}

Thus the community in Wellington challenges and defies essentialisation; and it is evident, then, from just this overview of the type of activity which characterises just one localised jazz community, that a "little-j" jazz community may offer differing perspectives to "big-j" Jazz. Jazz in Wellington is played for artistic reasons, and musicians there place value on such endeavours. But commercial imperatives, social factors, and the element of enjoyment all significantly influence the makeup of the activity which characterises the community. At the same time, the local jazz community is subject to attitudes inferred from the veneration and study of "big-j" Jazz. Along with the local musical and cultural environment described above, these constitute a second set of frames, which contribute to the "scene". These frames inform the music (and associated actions) of Wellington jazz musicians to the same extent as local factors; in fact the influence may arguably be stronger, given the idealism inherent in the "big-j" discourse.

A brief glance at the community is enough to confirm that the majority of jazz played in Wellington is heavily influenced by "big-j" Jazz. Indeed, much of this dissertation is dedicated to parsing out that influence, and the various conflicts and synergies produced thereby. At this point, however, it is worth considering the extent to which such influence is inevitable, and the reasons it may be regarded as desirable.

To be a jazz musician is to participate in a wider community (recalling Prouty's community of practice model): a community whose reach extends in multiple dimensions. Jazz is both a tradition (see further discussion in Chapter 4) which extends longitudinally backwards in time, and a community which extends laterally across the globe. It is held 
together by commonalities of practice and purpose, which are both defined enough to allow the global community to cohere, and broad enough to admit significant variation. Although its boundaries are indistinct as a result, its central core ("big-j" Jazz) is invoked and idealised globally, in a temporal sense as a narrative, and in a communal sense as shared cultural knowledge. Thus to be a jazz musician in Wellington is to profess an affinity with (at least some of) the central tenets and tropes of jazz, which then both dictate the practice and define the identity of the musician. As we shall see, and as noted above, there is room for alternative perspectives in this model: most significantly in the invoking of the transformative quality of jazz to justify fresh and novel approaches to music and performance. However, such an invocation, in relying on a core element of the music, further proves my point.

In the context of the Wellington community, then, the influence of "big-j" Jazz provides a second frame against which the action is set. The examples I used to illustrate versatility among Wellington musicians above demonstrate the influence of the jazz canon on local activity; a list of genres performed locally reads like any jazz textbook: ragtime, Dixie, gypsy, swing, bebop, hard bop, cool, free jazz, big band, jazz funk, Latin, and extending into Balkan-influenced, gospel-influenced, R\&B- and soul-influenced jazz. A list of the canonical artists invoked directly or indirectly would fill a page, ranging from Jelly Roll Morton and Leadbelly to Robert Glasper, Stephane Grappelli to Wayne Shorter, and Papa Jo Jones to Eric Harland.

Yet this is not indicative of any especially derivative nature on the part of Wellington musicians. Knowledge of and dedication to the canonised artists and styles of the jazz tradition is considered by many in the (global) community to be required for entry. And acceptance of these values is not necessarily unaccompanied by critical reflection: one particularly interesting moment in my own process of consideration of these matters occurred in conversation with saxophonist and composer Lucien Johnson (2014), when we each argued (constructively, rather than defensively) that the other's practice lay more towards the periphery of jazz than our own. I had perceived his music as incorporating influences which were external to jazz, and the politicised framing of his practice as being out of step (though certainly not incompatible) with much of the local scene; he argued that 
my embrace of tradition and my (perceived) allegiance to a stereotyped model of jazz education ${ }^{58}$ were not consonant with the progressive nature of the music.

The valorisation of "big-j" Jazz, then, situates the Wellington jazz community within the frame of the global jazz community, by way of common cultural knowledge. But at the same time, as noted earlier, it also dampens the significance of localised practice. While the Wellington jazz community (and to some extent the wider New Zealand jazz community) is small enough that musicians are likely to be reasonably well-acquainted with each other, and each other's practice, there are significant ways in which that familiarity has not translated into an organic, local tradition. Wellington musicians do not play each other's tunes; local album sales are unsustainable (although this is in the context of low sales of jazz albums globally), and a New Zealand jazz sound or approach has not emerged. Instead, when local musicians are not playing their own music, they are playing either jazz standards or repertoire drawn from predominantly American (and European) artists. The styles of jazz (outlined above) performed in the Wellington scene also predominantly draw on styles developed (either as genres, or by individual musicians) in other contexts, or combinations of those styles.

Part 2 of this dissertation focuses on concepts of identity in jazz, and we pick up the threads of "big-j" and "little-j" at that point, by considering the concepts of authenticity and identity, which are generally predicated on "big-j" Jazz, but which are then invoked in relation to "little-j" practice. But it is worth further considering the extent to which the scene dictates the activity and values inherent in the community. To that end, the following chapters examine two major elements of the scene, and the way they reflect and impact on both the Wellington scene, and broader concepts of New Zealand jazz.

\footnotetext{
58 Of which more in Chapter 3; clearly, even three years on from having left employment at the New Zealand School of Music, I am still associated with it, despite my best efforts (as summarised in the Introduction).
} 


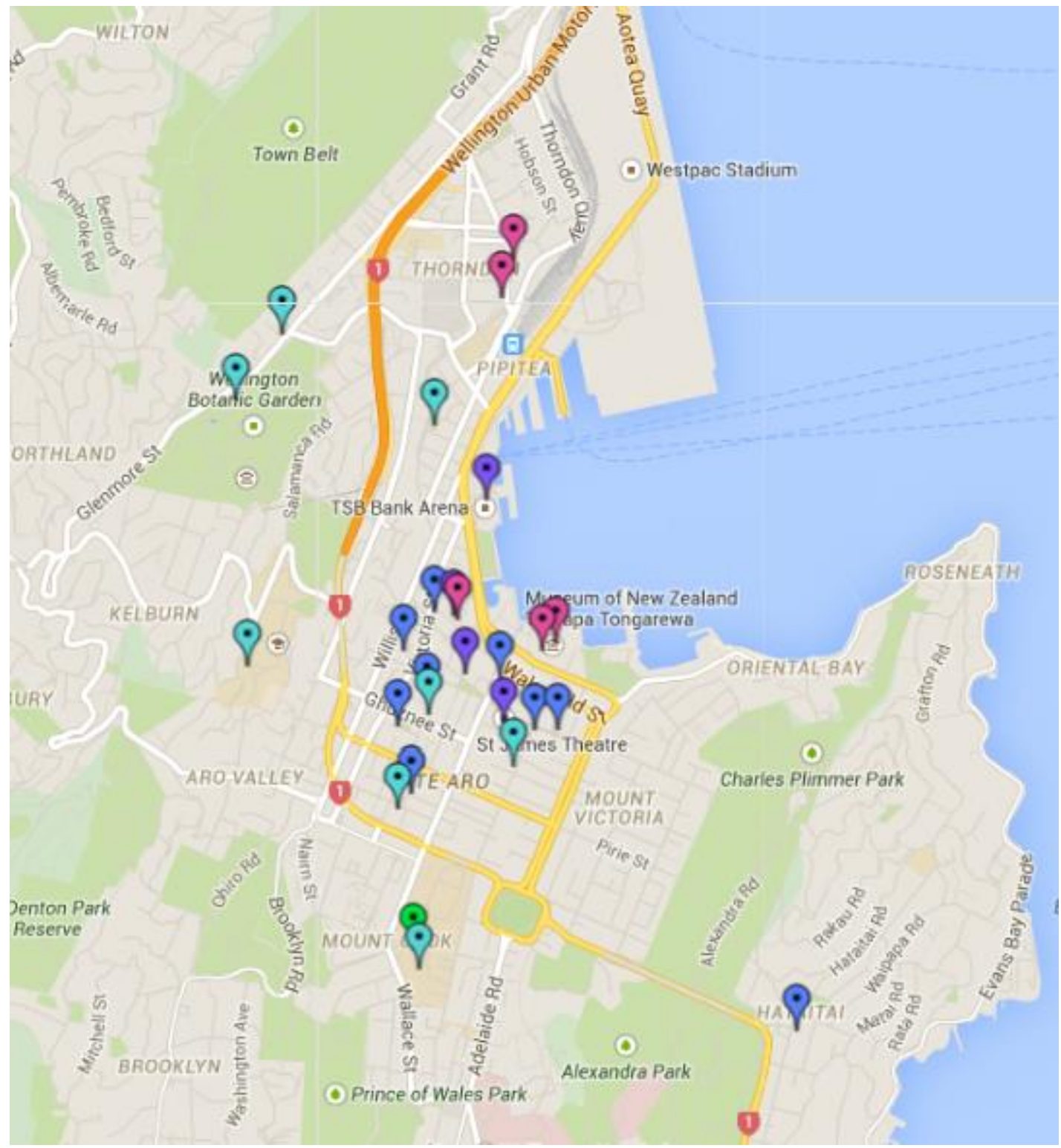

Fig. 2: Wellington Jazz Venues, as at April 2015

Dark blue: venues holding regular jazz performances Light blue: venues holding occasional jazz performances

Purple: concert hall venues

Green: NZ School of Music Mt Cook campus

Note: the area bounded on three sides with yellow (main) roads is approximately $850 \mathrm{~m}(1 / 2$ mile) square. 


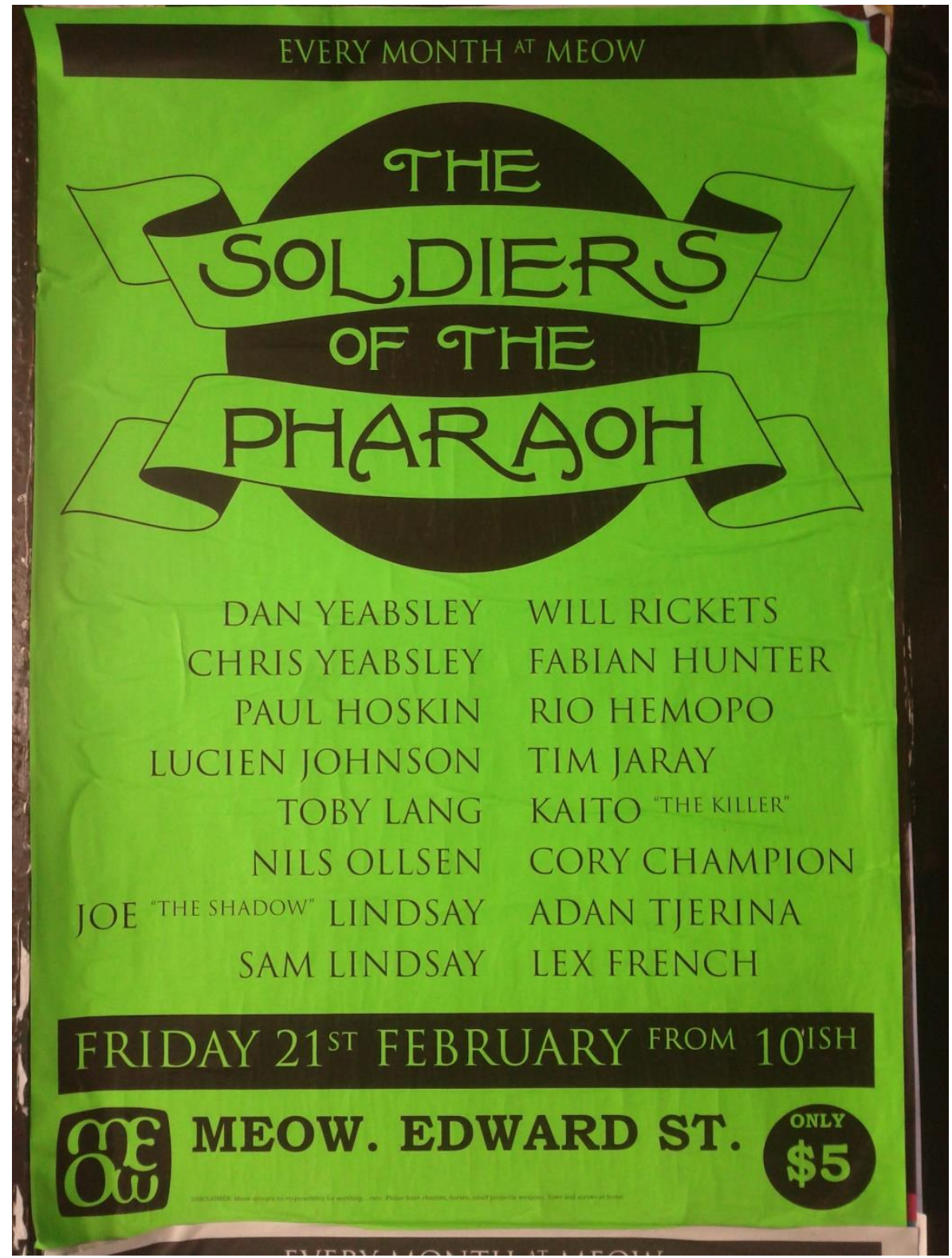

Fig. 3: Soldiers of the Pharaoh, February 2014 


\section{Chapter 2: Baby, it's cold outside: music funding and national identity}

To anyone who has spent any time in New Zealand, the phrase "New Zealand music" will be a familiar one. More than just a descriptor, "New Zealand Music" is an industry buzzword, adopted by organisations and entities such as the Vodafone New Zealand Music Awards, New Zealand Music Month, and the New Zealand Music Commission. As such it represents a trope which has been growing in currency in the past decade. Invoking nationalism through the lens of local culture, "New Zealand music" is a banner, deployed by musicians, politicians and policymakers in order to claim a unique place within the local and global cultural environment. The concept is not a new one: Douglas Lilburn called for New Zealand classical music composers to begin the search for a national identity as long ago as 1946. Recognising the potential within cultural nationalism, successive governments, since the late 1980s, as popular music and media studies researchers Roy Shuker (2008) and Jennifer Lawn (2006) note, have seen the creation and development of a New Zealand brand as a central strategy in the country's economic wellbeing; the promotion of New Zealand-ness as a point of difference in the arts (particularly in film and music) has been seen as a key aspect of this brand. Central government investment in New Zealand music is now at an all-time high in real terms.

Jazz in Wellington exists, of course, within the New Zealand music frame. In order to evaluate the place of jazz in New Zealand, therefore, it is useful to examine its relationship to the New Zealand music trope, which, while ideologically constructed, nevertheless exerts considerable influence over the local musical landscape. For music to be "New Zealand music", it presumably incorporates or connotes some element of "New Zealand-ness". New Zealand-ness is a value-added concept; within New Zealand, an artist or piece of music which connotes New Zealand-ness in some way (through subject matter, musical reference, or sound, for example) thereby sets up a resonance with New Zealand audiences. In doing so it appeals to and reinforces their sense of national identity in a positive way. As a result, marketing and political campaigns, for example, commonly appeal to New Zealand-ness. This is also the case in the local music industry, and, due to the value it is ascribed, it is a 
contested space. Of course, there are as many forms of New Zealand-ness as there are New Zealanders, and as such New Zealand is as much an imagined community as any other. Yet New Zealand-ness nevertheless carries sociocultural weight, and this effect is particularly visible in the case of New Zealand music. As we shall see, "New Zealand-ness" in music can be measured in different ways, using tradition, popularity, and sound as markers of authenticity. As such, it is a recurring theme in this dissertation.

The field of New Zealand central government music funding provides a lens through which one may assess the value of these various markers, and their relationship to New Zealand music. Decisions around such funding are overtly linked to a particular New Zealand identity, and so examining the structure and flows of capital involved provides a useful perspective on the values associated with that identity. While identity as conceived at a policy level may not fully represent all conceptions of New Zealand-ness, funding decisions nevertheless have a real impact on the music scene, as we shall see: funding is granted to some areas of music which would otherwise struggle to be viable, on the basis that they are integral to national identity; and conversely, practitioners of those areas of music which are underfunded must contend with the implication that they are not "New Zealand" enough. Of course, the prerogatives of funding bodies, and the messages implicit in funding decisions (which, as well as citing artistic merit, invoke factors such as commercial viability, and/or contribution to the local cultural environment), may well inform subsequent artistic projects as they are conceptualised; and thus those prerogatives have a significant downstream effect on the artistic output of New Zealand musicians.

This chapter represents a temporary broadening of my investigation, for a number of reasons. Through comparing and contrasting the treatment of various forms of music from a policy standpoint, I will develop a picture of the role of New Zealand-ness in music as a whole; from there I will consider the place of jazz within that broader landscape. Additionally, while individual funding agencies and policies have been the subject of scholarly and non-scholarly investigation (including Norris and Pauling (2012), Allan, Grimes \& Kerr (2013), Shuker (2007 \& 2008), and Scott (2008 \& 2012)), no broad survey of the nature of New Zealand central government music funding yet exists; in order to consider the place of jazz in the landscape, it is first necessary to lay out that landscape. Additionally, aside from concepts of New Zealand-ness, the politics of funding have been a bête noire of 
local jazz musicians for some time; bandleader Rodger Fox has been particularly vocal in pointing out the lack of jazz funding in New Zealand (Penman 2013).

Indeed, while "New Zealand music" is a pervasive concept, government funding of music in New Zealand focuses heavily on "high art" music, with a secondary focus on popular music. Such a dynamic will be familiar to musicians in many parts of the world; ${ }^{59}$ the campaign to label jazz as "America's classical music" sprang from such a dynamic.

In this chapter I begin by describing the four main agencies, and their stated aims, particularly as they relate to New Zealand identity. Examining the types of music funded by each agency, I draw conclusions about the kinds of musical activity that are perceived as valuable in relation to that identity. I consider the position of jazz within the identity politics which govern funding, and the place of aesthetics, national identity, prestige, and identity politics in the decision-making process. Lastly, I consider the place of jazz within the funding apparatus, and the reasons why jazz misses out so markedly on government support; and I draw conclusions about the relationship of jazz to "New Zealand music", which will inform discussion in later chapters.

\section{Funding Bodies}

In the 1980s, New Zealand popular music was struggling for support and airplay (Shuker 2007) As a result, the 1986 Report of the Royal Commission into Broadcasting and Related Telecommunications was followed by a popular petition in advocating for a legal quota of New Zealand music to be played on local radio (the Report suggested 10\%; the petition argued for 20\%; a voluntary code was established in 2001). The creation of government broadcast funding agency New Zealand On Air (NZOA) in 1991 led gradually to an increase in interest in locally-produced content of all kinds, and the newly-elected centre-left government in 1999 increased arts funding and policy support. The New Zealand music industry was identified as able to provide significant economic growth, (Shuker 2007) and as

\footnotetext{
59 The 2014 and 2015 budgets in Australia, for example, cut funding from the Australia Council (the national arts funding body) while protecting the interests of the 28 member companies of Australia's Major Performing Arts Group (AMPAG), a group whose musical membership is entirely made up of orchestras, chamber music and opera.
} 
a result the intervening years have seen further government initiatives established, such as the New Zealand Music Commission (NZMC, established 2001), and Creative New Zealand (CNZ, established 1996), the national government-sponsored arts funding agency. Along with NZOA, and Te Māngai Pāho (which supports Māori popular music; see below), each initiative targets a particular area of the arts sector, with specific goals.

\section{New Zealand On Air 60}

Funded initially by the national Broadcasting Fee, and since 2001 by direct government funding, NZOA covers all broadcast media, providing funding for radio and television programmes, as well as music and digital media. Initially, its stated aim was to ensure 'New Zealanders have a diverse range of broadcasting services that would not otherwise be available on a commercial basis...(which) reflect(ed) New Zealand identity and culture... including the broadcasting of New Zealand music.' (NZ On Air, 1996) However, as Shuker $(2008,275)$ notes, "NZOA's brief is not restricted to 'popular music', but in practice this is the case, with classical music having its own sources of funding and support." In practice, NZOA's music funding (around \$5.5 million each year over the last three years) has been targeted towards helping New Zealand pop artists achieve airplay for their songs on local radio, and for their music videos on local television. NZOA's Music Strategy 2011 makes explicit their direction:

In music, the song is paramount. "It starts with a song". Broadcasters- whether that is radio, music television or YouTube - play songs. That is the content currency we are dealing in. (NZ On Air 2011)

The terminology here reveals that the ambit of NZOA funding is largely confined to popular music. While the vast majority of the acts and projects they fund are from a broad range of popular music, NZ Broadcasting School researchers Paul Norris and Brian Pauling (2012) note the partnership between NZOA, SOUNZ (the centre for NZ Music) and Radio NZ Concert, which resulted in the remastering and broadcast of New Zealand chamber music

\footnotetext{
${ }^{60}$ Shuker (2008) provides a fuller account of the history of NZOA; the following summary is drawn largely from that article.
} 
works. However, and perhaps more pertinent to this investigation, the authors also note criticism of the agency's focus, which suggested "that NZ On Air had allowed NZ music to be defined as 'that which commercial radio will play' and in doing so have done a great disservice to the broad range of music that genuinely reflects the diversity of New Zealand culture." While NZ On Air is tasked with promoting "New Zealand music" in order to secure airplay on local radio and TV stations, in practice, given that commercial radio represents by far the best value for money, mainstream and alternative popular music is featured to the exclusion of almost every other genre in the agency's funding, promotion and strategic planning.

\section{New Zealand Music Commission (NZMC)}

The Commission (full name: New Zealand Music Industry Commission Te Reo Reka o Aotearoa) was created in 2000 , in order to build networks between government, industry players and musicians. Their mission statement is "To support the growth of the music industry in New Zealand, both culturally and economically, at home and abroad." The NZMC operates four major schemes: Outward Sound, which aims "to encourage the entry of New Zealand music and musicians into global markets" (New Zealand Music Commission Te Reo Reka o Aotearoa 2014); New Zealand Music Month, held each May, during which local artists and gigs are heavily promoted "to create a sharp peak in the audibility, visibility and sales of domestic sounds" (Scott and Craig 2012, 154); and two educational schemes: Mentoring in Schools, which places experienced musicians in secondary school music classrooms, and informal workshops designed to assist developing musicians in negotiating the various elements of the music industry at home and abroad. Additionally, the NZMC provides resources and advice to musicians and industry personnel outside of these major frameworks, and develops links between New Zealand artists and the "music industry". The NZMC does not fund projects; instead it focuses on upskilling, and enabling practitioners to develop and promote their music.

The NZMC is largely funded by the government, receiving $\$ 1.5$ million in funding in 2013 (New Zealand Music Commission Te Reo Reka o Aotearoa 2012). All indicators and analyses suggest the NZMC is performing well; its annual report (ibid.) outlines its success in 
meeting key indicators, and presents highlights from the year's activity in the New Zealand music scene. Closer analysis reveals that while its activities are pitched towards a broad cross-section of music and musicians ("(Outward Sound) is inclusive of music from all genres, styles and niches and applicants may target relevant markets around the world" (New Zealand Music Commission Te Reo Reka o Aotearoa 2014)), the focus is squarely on popular music. Although the NZMC caters for a wider range of popular styles than NZOA (and, in theory, does not discriminate, except on the basis of marketability), nevertheless like NZOA it measures its own performance in terms of the success of pop acts in New Zealand and overseas, and engagement with pop music by the New Zealand public.

\section{Te Māngai Pāho}

Te Māngai Pāho is a Crown Entity, set up under the auspices of Te Puni Kōkiri (the Ministry of Māori Development). As such it is "first and foremost a Māori language sector agency", part of a wider effort to implement the government's 25-year strategy for revitalisation of the Māori Language (Te Reo Māori). (Te Māngai Pāho 2011) It has clear and narrow objectives in the context of the broad music funding environment in New Zealand: to “...promote Māori language and Māori culture by allocating available funds for broadcasting and the production of programmes to be broadcast." (Te Māngai Pāho 2014)

Te Māngai Pāho awards funding towards the production of recordings, most often of full album length, but occasionally EPs or singles. The music funded tends heavily towards popular styles, which is clearly related to the agency's objective of providing material "that captures and sustains a youthful Māori audience", in an effort to safeguard the future of Te Reo. These recordings are funded largely with a view to their dissemination on television and radio, particularly through the 21 iwi radio stations ${ }^{61}$ and the Māori Television Service; both broadcasting arms are also funded (at least in part) by Te Māngai Pāho.

\footnotetext{
${ }^{61}$ Iwi (singular and plural) most closely translates as "tribe" or "tribes". For a list of iwi radio stations, see http://www.irirangi.net/iwi-stations.aspx.
} 


\section{Creative New Zealand (CNZ)}

Creative New Zealand is the national arts funding body, under the aegis of the Ministry of Culture and Heritage $(\mathrm{MCH})$. As such it is administers funding for all art forms, including performing arts, visual arts, theatre, Māori traditional arts (Ngā Toi Māori), music, and literature. CNZ's purpose is to ensure that: "New Zealanders participate in the arts"; "highquality New Zealand art is developed"; "New Zealanders experience high-quality arts"; and "New Zealand arts gain international success". (Creative New Zealand 2013)

CNZ awards funding in a number of categories. Most influential on the musical community at large are the grants (Quick Response and Arts grants), and the investment programmes; also available are residencies, scholarships and fellowships, funding for community arts activities (administered by local councils), assistance in developing international profiles and markets, and Māori arts development funding.

Funding decisions concerning Arts Grants (the larger of the contestable funding streams) are made by CNZ staff and external specialists; decisions regarding the smaller Quick Response grants are made by CNZ staff. The process and criteria used in making decisions are somewhat opaque, an issue which has led to frustration on the part of many unsuccessful applicants. However, a cursory survey of successful applicants in any one round demonstrates the breadth of activities funded: in terms of music, these include professional development, touring, commissions, marketing, and album production.

The wording of CNZ's strategic outcomes above is instructive. While anyone engaged in the creative arts may apply (including commercial acts), the key word is not "creative", as in the agency's title, but "arts"; and it is activities which fit with traditional ideas of artistic merit which receive the lion's share of available funding. ${ }^{62} \mathrm{~A}$ closer look at successful applicants reveals a clear slant towards activities which are normally considered "high art": as well as visual arts, sculpture, literature and dance, funding for music tends to favour art music (classical or contemporary), rather than genres not normally considered "artistic", such as heavy metal or rock. (I engage in a more detailed discussion of the various funding streams below.)

\footnotetext{
62 University of Otago researchers Drummond, Kearsley and Lawson made a similar comment in their "Culture Matters" report, commissioned by the Ministry of Research, Science and Technology: "Because Creative New Zealand uses the term 'the arts' in its work there must always be a temptation to understand the term in the limited sense of European art-forms and practices". (Drummond, Kearsley and Lawson 2008, 32)
} 


\section{National Identity and the Funding Environment}

New Zealand's centralised music funding is thus administered by a collection of agencies, each of which has a more or less specialised function within the sector. NZ On Air funds commercial popular music for broadcast; the New Zealand Music Commission provides assistance and training for musicians trying to succeed in the popular music industry. Te Māngai Pāho assists musicians to record music with Māori language lyrics, and Creative New Zealand covers most forms of music, with a focus on art music.

While Te Māngai Pāho is clear about its target audience and function, the other agencies each cite the aim of funding a broad base of musical activity, in order to allow a wide range of New Zealand music to reach a diverse audience. Yet in reality it is clear that New Zealand music funding is divided into two major streams, popular music and classical music; together they account for over $90 \%$ of all centralised music funding. Popular music receives $23.7 \%$ through a combination of all four agencies, and classical music $66.5 \%$, through both CNZ and a fifth funder, the Ministry for Culture and Heritage, which, as well as overseeing other funding bodies, directly funds the NZSO. ${ }^{63}$ According to the strategic guidelines of the funding organisations, most of that funding is guided by the principle that music funding should support and promote a distinctively New Zealand culture, and this is often tied to the phrase "New Zealand music". The institutional rhetoric is intentionally generic: the New Zealand Music Commission's mission is "Supporting the growth of the New Zealand music industry, both culturally and economically, at home and abroad"; the "Music Mission" of New Zealand On Air is "To connect great songs with diverse media audiences"; and the statutory purpose of Creative New Zealand is "...to encourage, promote, and support the arts in New Zealand for the benefit of all New Zealanders". However, in practice, what constitutes "New Zealand music" or "arts" is rather narrowly defined. In the case of Creative New Zealand, more than $70 \%$ of music funding is allocated to classical music organisations, and in the case of New Zealand On Air and the New Zealand Music Commission, it is difficult to find recipients of funding who are not popular music artists. The NZMC's New Zealand Music Month, "a 31 day celebration of homegrown talent across the length and breadth of the country, likewise heavily features popular music. The implication

\footnotetext{
${ }^{63}$ Based on figures from 2011-2013, sourced from data publicly available online via.
} 
is clear: from a policy standpoint, "New Zealand music" is either classical or pop music: and anything which does not fall under those two broad classifications is not "New Zealand music".

Government policy is by no means the main driver of New Zealand national identity. But given the close rhetorical link between funding decisions and that identity, and the impact of those decisions on the musical life of New Zealand, it is worth looking more closely at the ways identity is perceived (and created) through government intervention in the music industry. New Zealand's national identity is still evolving and is the object of much discussion in the media and scholarship. A discussion of the relationship of New Zealand identity to music will take place in Chapter 5, but in the context of funding, the most desirable factor seems to be uniqueness: that which makes New Zealand distinctive is to be identified and nurtured, and artistic activities which are worthy of support are those which celebrate that exceptionalism. A search across government websites for the phrase "New Zealand's unique..." (as in "New Zealand's unique culture") returns hits from across the spectrum of portfolios: among many others, the country's "biological heritage", "culture and heritage", "national identity", "way of life", "culture, creativity, innovation" and "legal, constitutional and Treaty of Waitangi arrangements" are each celebrated as singular. This perspective is central to the Vision Statement of the Ministry of Culture and Heritage, which oversees cultural activity in New Zealand: “New Zealand's distinctive culture enriches our lives" (Manatū Taonga - Ministry for Culture and Heritage 2013).

And yet, as historian Miles Fairburn (2008) suggests, it is difficult to point to anything particularly distinctive about New Zealand culture, way of life, or identity. Many of the concepts and tropes which inform New Zealand-ness, (which include, among others, the natural landscape; liberalism; a bicultural or multicultural heritage; a ruralist fascination with do-it-yourself (DIY), "number eight fencing wire" strategies; friendliness and hospitality; urban sophistication combined with nostalgia for simpler times; and a strong dose of nationalism, whether political, sporting, or social) are not in themselves unique to New Zealand. Fairburn (citing Gordon Mirams (1945)) traces such elements to the influence of British, American and Australian culture, and the patterns of migration which characterised the development of New Zealand as a nation after 1840. Advertising campaigns promote the notion of New Zealand as unique, and the idea that its attributes are worthy of celebration, with slogans like "100\% Pure New Zealand", "Buy NZ Made", and 
references to "Godzone". Yet as Victoria University cross-cultural researchers Liu, McCreanor, McIntosh and Teaiwa (2005) point out, identities are dynamic, multi-layered, and socially constructed, and are ideologically based; given such fluidity, it is little wonder that New Zealand-ness remains undefined. It is also significant that the tropes mentioned above all derive from Western European concepts of New Zealand, and Māori, Pasifika, or Asian concepts are far less frequently foregrounded.

Interestingly, however, while Fairburn mentions the adaptability of Māori and their receptiveness to Western culture, he stops there, concluding that "although Māori are the most distinctive element in the New Zealand contribution to the pastiche, it is an element that does not radically differ from the other - Pākehā - elements." $(40)^{64}$ While Māori have certainly integrated into New Zealand's Western European culture, Fairburn fails to consider the conscious reinvigoration of Māori culture, and the inclusion of Māori elements in mainstream New Zealand society, which has occurred in recent decades. All major institutions (including, for instance, the funding agencies above) now boast Māori as well as English names; Māori ritualised practices are now an integral part of national and local ceremony. Māori words (such as "ka pai", "kia ora" or "whānau") are now commonly found in New Zealand vernacular. Thus, in considering what is distinctive about New Zealand culture, it would be reasonable to conclude that the Māori element is the most (if not the only) distinctive quality.

The act of fostering New Zealand's distinctive culture, then, ought necessarily to focus particularly on activities which include a Māori element or perspective. Yet even a cursory survey of the activities funded reveals that this is clearly not the case, and a Western European / North American conception of cultural activities still prevails. The tendency is clearly connected to demographics: In the 2013 census, 70\% of the New Zealand population identified as "European" (compared with 14\% Māori, 7\% Pasifika, and 11\% Asian; the census allowed identification with more than one ethnic group) (Statistics New Zealand 2014), so it may well be assumed that Western European attitudes prevail in New Zealand culture by virtue of the numbers. Yet historian James Belich notes that "by 2000, an identity crisis had developed among Pākehā. While Māori were becoming increasingly assertive and other ethnicities were more prominent, too, some people are hard put to say what Pākehā culture

${ }^{64}$ 'Pākehā' is the commonly accepted term in New Zealand for New Zealanders of European ancestry. 
is, or even if there is any. [sic]" (Belich 2001, 425). Changing demographics in the second half of the $20^{\text {th }}$ Century resulted in a "multifaceted process of societal and cultural change", leading Ward and Lin $(2005,162)$ to conclude that "there is little to suggest that there is a clear understanding of what it means to be a New Zealander". It is perhaps little surprise, then, that New Zealand, having imported its cultural institutions from Western Europe since the 1840s (and earlier), should find it difficult to move away from them despite (and because of) demographic change.

But there is more than cultural conservatism at work. Comparative literature researcher Andreas Huyssen (1986) argues that the high/low art divide is actually a dialectic relationship, which since the mid-19 $19^{\text {th }}$ Century has remained a hallmark of Western European culture, each only existing in relationship to the other. The presence of this dialectic in a society is an indicator of maturity, or at least constructed maturity (given Small's comments on the pattern among (new) nations of establishing high-art institutions (and concert halls) as symbols of nationhood) (Small 1998, 37). Such institutions allow those nations (or at least their political and economic elite) to display wealth and sophistication in a Westernised manner. Of course, there is a flip side; such a display carries a subtext of marginalisation (from policy, at least) of non-elite, popular or indigenous forms of music and art.

\section{Classical Music Funding: status symbol}

In New Zealand, the dialectic is clear to see by way of the funding statistics detailed above, with $66 \%$ of all funding supporting Western art music. Support for music in general has become politicised in recent years: former left-wing Prime Minister Helen Clark's support for popular music contrasts with former Minister of Culture and Heritage Chris Finlayson's openly pro-NZSO stance ${ }^{65}$. Yet the dialectic has been present in New Zealand since the mid$19^{\text {th }}$ Century, when European settlers founded choral societies, orchestras and other

\footnotetext{
${ }^{65}$ Finlayson pre-empted his commissioned 2013 review of orchestral funding by stating "The NZSO is a jewel in the cultural crown. There is no question of its survival under this Government." (Chapman 2012) In the leadup to the 2014 general election, the ruling National Party's Arts, Heritage and Broadcasting Policy (New Zealand National Party 2014) made two promises specifically concerning music, both of which applied only to orchestras: to extend orchestral funding, and to develop further an existing educational scheme which teaches orchestral instruments to underprivileged children.
} 
institutions; a national orchestra was first proposed in 1925, although it was not firmly established until 1946. Writers such as New Zealand music historians Chris Bourke (2011) and Aleisha Ward (2012) have chronicled the (less easily traceable) early history of New Zealand popular music, noting that Western music was present in New Zealand from the very first days of European settlement (while Māori music-making was of course present for the preceding centuries).

One example which highlights the position of high art music in contemporary New Zealand culture is the funding of orchestras, which has taken place since 1946. The 2012-3 New Zealand Professional Orchestra Sector Review presented the opportunity for a national discussion on the place of orchestral music in modern New Zealand society and culture. The Review discussed the provision of significant funding for an orchestral sector in the face of a challenging economic environment, but the final report (Manatū Taonga - Ministry for Culture and Heritage 2013) did not discuss the relevance of orchestral music to New Zealand cultural life or identity, other than to state that "orchestras with a commitment to New Zealand music make an important contribution to the development of the art form, by providing New Zealand composers with opportunities to have their works rehearsed and performed", and "orchestral excellence also contributes to local and national pride and identity, and adds to the attractiveness of cities and towns as places in which people choose to live, work and visit." (19) In fact, the review report explicitly states that "This is not a baseline review. It assumes government funding for orchestras will continue", (10) thereby avoiding the more interesting question of whether (and perhaps more importantly, why) professional orchestras are a central element in contemporary New Zealand culture. ${ }^{66}$

On the basis, then, that orchestras allow composers to have their music performed and add value to cities, the status of orchestral classical music as by far New Zealand's most well-funded musical endeavour remained unchallenged, with an annual \$17 million

\footnotetext{
${ }^{66}$ For the record, I should state my opinion that orchestras are a valuable asset to New Zealand culture. As (originally) a classically trained musician with experience playing with several of New Zealand's professional orchestras, and as an audience member at concerts by almost all of them, I strongly feel that orchestral funding is justified. However, I contend that the overall funding should necessitate consideration of these deeper questions of relevance, just as they should for any art form; the orchestral review would have seemed the ideal forum for such reflection. I would also argue that rather than reducing funding for orchestras, government should increase funding for the many other art forms and institutions which make a similar contribution to New Zealand's contemporary culture.
} 
investment divided between the five orchestras (or an average of $\$ 45$ per audience member in 2013$)^{67}$, and the New Zealand Symphony Orchestra, which currently receives $\$ 13.4$ million of that amount, ${ }^{68}$ remains the country's only musical entity established and protected by a specific Act of Parliament ${ }^{69}$. Musicologist Christopher Small comments on the cultural value attached to classical music (and in particular orchestras and their concert hall venues), commenting that the presence of an orchestra in a society enhances that society's prestige; they are expensive to run, and connect the society with Western European postindustrial culture (New Zealand's colonial roots) and its core philosophies of "acceptance of the scientific worldview, of Western-style rationality, including the Cartesian split between body and mind, and the discipline of the clock". $(1998,37-8)$ An orchestra (or an opera or chamber music company) symbolises wealth (and "the desire and will to spend that wealth on this rather than on other things"), success and aesthetic taste. High art in general invokes these principles; and it is therefore understandable that New Zealand as a young nation has sought to claim, and maintain, status (both on an international stage and in its own eyes) through the support of high art institutions like classical music, dance and the visual arts. The Professional Orchestra Sector Review, working on the assumption that orchestras are indispensable to a modern multicultural society, reinforced New Zealand's commitment to Western European modes of creative practice, and models of artistic excellence.

The Creative New Zealand Music Review, also released in 2013, by necessity took a broader view, accepting submissions from across the sector, which are summarised in its report (Creative New Zealand 2013). Interestingly, and especially so in relation to the Orchestral Review above, it acknowledged that "there was criticism of the fact that the key infrastructure role for orchestras takes up over two thirds of the current budget for the (Arts Leadership Investment) programme". ${ }^{70}$

\footnotetext{
${ }^{67}$ Based on data from the sector report, and the NZSO Annual Report (New Zealand Symphony Orchestra 2013).

${ }^{68}$ The NZSO receives $43 \%$ of all central government music funding; the professional orchestras collectively receive around $54 \%$.

${ }^{69}$ The New Zealand Symphony Orchestra Act 2004, and previously the New Zealand Symphony Orchestra Act 1988

${ }^{70}$ Additionally, the report presented a clear signal that Creative New Zealand had noted criticism from jazz musicians in particular at the lack of funding for jazz performance, education and infrastructure: "Through the country's jazz schools and key jazz ensembles, New Zealand has some excellent jazz performers. It was recommended that Creative New Zealand should broaden its supported activities to include more jazz." (Creative New Zealand 2013, 24) It will be interesting to observe future developments in this regard.
} 


\section{Popular Music Funding: supporting 'our' music}

Where New Zealand art music funding appeals to heritage values, popular music funding is deeply affected by present-day cultural nationalism. The importance of popular music in government policy is demonstrated by the fact that pop is funded and supported jointly by all four major funding agencies, with each covering a different aspect of the industry:

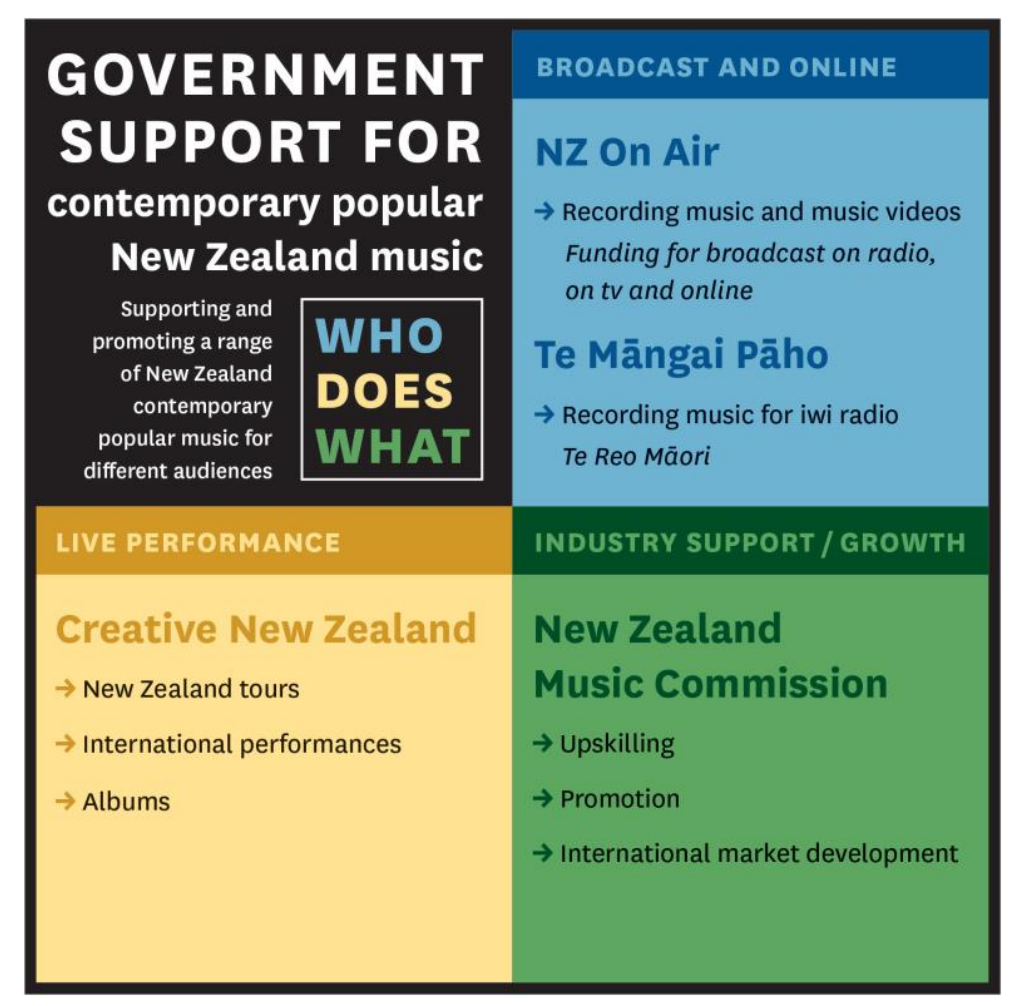

Fig 4: Popular music funding structure (New Zealand Music Commission Te Reo Reka o Aotearoa 2012)

This level of support has not always (and not long) been present, however. As outlined above, New Zealand popular music, although passionately pursued by its proponents, languished unsupported until the 1980s, when the left-wing Labour government "oversaw the state constitution of an 'institutional ecology' - an assemblage of subsidies, informal broadcast quotas, state-sponsored and co-ordinated social networks, formal and informal education programmes, and promotional activities that, in conjunction 
with shifting cultural norms around the value of domestic culture, founded the pop renaissance" (Scott 2013).

Zuberi (2007), Scott (2008), (2012), (2013), Scott and Craig (2012), Shuker (2007), (2008) and Shuker and Pickering (1994) all examine New Zealand's "pop renaissance" in light of government intervention in the music industry. The government-sponsored NZ On Air and New Zealand Music Commission feature heavily in scholarly discussion of the New Zealand popular music industry since the 1990s, and by most accounts have been the prime drivers of growth in the sector, alongside the voluntary 2002 New Zealand Music Code, through which the Radio Broadcasters Association (with governmental backing) encouraged (and achieved) a $20 \%$ quota of New Zealand music on commercial radio. How much the success of New Zealand popular music since 2000 owes to government intervention is, however, a contentious point. ${ }^{71}$

Popular music researcher Geoff Stahl alludes to "the institutionalisation of contestable funding and support apparatuses that are tied to a broader agenda of cultural nationalism". (Stahl 2011) Rhetoric around "New Zealand music"72 (as discussed above, the phrase is often appropriated to refer to New Zealand popular music) from government, industry, media and scholarship (Zuberi 2007) often employs nationalistic imagery or terminology, or sees local pop music used in evoking nationalistic feeling. Teenage singer Lorde, following her international success in 2013 and 2014, is referred to as "our Lorde" 73 , reflecting linguist Allan Bell's (1996) comment on the use of personal pronouns in establishing a "national community" (Bodkin-Allen 2011); and a series of pop and rock concerts by New Zealand musicians in conjunction with the 2011 Rugby World Cup was titled the "Real New Zealand Music Showcase [italics mine]". Composer and researcher Sally Bodkin-Allen (ibid.) examines the way New Zealand pop music is used to generate, maintain and intensify support for rugby, New Zealand's national game. The New Zealand Music Commission links the economic and cultural importance of music, asserting that "we can

\footnotetext{
${ }^{71}$ Geoff Stahl (2011) surveyed a number of Wellington "indie" musicians, none of whom had received government funding, and found that in their experience the funding environment (consisting of central and local government bodies, policy and initiatives) was hegemonic and prescriptive, existing mainly to support mainstream acts and to perpetuate Wellington's (then) image as the "Creative Capital"; their comments echoed criticism of NZ On Air's funding strategy from other sources.

72 Often also "Kiwi music", a term criticised by Tony Mitchell (2010) as a "jingoistic" and "exclusionary" appeal to national pride.

${ }^{73}$ Tom Cardy's pun (2014) is but one example of many in the print and online media; perhaps it proved irresistible.
} 
increasingly take pride in our music, appreciating it at home and as an international ambassador for our culture, enjoying its social and educational benefits, and growing a creative and innovative industry with global income potential" (New Zealand Music Commission Te Reo Reka o Aotearoa 2012).

The link between New Zealand popular music and national identity is clear: every overseas success story by a New Zealand artist (for instance Lorde, the Black Seeds or Hayley Westenra) is characterised as a national triumph; New Zealand Music Month is an annual festival of national pride in pop music; and the nostalgia value of artists like Gray Bartlett, Suzanne Prentice, Ray Columbus, or John Rowles, New Zealand singers whose success peaked around the 1960s, 70s, or 80s, endures into the present day. New Zealand popular music is often deployed to nationalist effect; the policymakers who support it (or, as described by Stahl, who have created and maintained the hegemonic funding system) gain kudos for having done so. It is worth noting the backlash experienced by New Zealand pop icon Neil Finn in 2007, when he criticised Prime Minister and Minister for Arts and Culture Helen Clark for making too much political mileage out of her Labour government's support for New Zealand music. Finn was in turn taken to task by other prominent figures in the music industry (Hunkin 2007) for, in effect, biting the hand that fed him. De-funding popular music (or classical music) would almost certainly be unpopular, so closely has "New Zealand Music" become linked with a national sense of identity.

\section{Is New Zealand music a 'thing'?}

And yet despite the long history of music in New Zealand, there is still no consensus about what constitutes a representative "New Zealand music". The term itself is deployed as a synecdoche for a variety of types of music (from the New Zealand Music Commission (popular music) to the SOUNZ Centre for NZ Music (largely contemporary art music)), but is seldom used in an all-encompassing sense. The comments of Belich, Ward and Lin in reference to national identity can be applied more specifically to music in New Zealand: despite the appeals to a distinctive culture contained in the mission statements of funding bodies and the relevant government ministry, there is little real sense of what "New Zealand music" means in terms of sound, practice, or genre. 
New Zealand pop music has been identified as a source of national pride, and is supported as such, whether or not the individual artists consciously attempt to sound "Kiwi" or to evoke some aspect of New Zealand-ness in their music. And yet, as Shuker and Pickering note, there is nothing inherently "New Zealand" about New Zealand popular music: "it is misleading to automatically assume that local musicians embody and support a local cultural nationalism in their work. Indeed, national music industries are characterised by considerable cultural diversity." $(1994,275)$ Artists such as Don McGlashan, Dave Dobbyn, Crowded House, and the Chills, or more recently Fat Freddy's Drop, Lorde and Bic Runga, are closely connected to many New Zealanders' sense of national identity; but it is doubtful whether overseas listeners would discern any particular New Zealand-ness in their music (NZ accent notwithstanding). Indeed, Shuker and Pickering observe that "local sounds are rarely distinctive from their foreign counterparts". (Shuker and Pickering 1994, 271)

In terms of classical music, there is as yet no consensus that New Zealand hosts a distinctive national style. Researcher Glenda Keam (2006a) examined seven New Zealand orchestral works written between 1976 and 1995, and one each from Australia, Canada, England, and the U.S.A. While Keam isolated certain characteristics which were commonly found in New Zealand orchestral music, the study was by no means comprehensive. All the New Zealand works she studied consciously tried to evoke New Zealand, mostly in terms of the natural environment; many included landscape or historical references in their titles, and so the question remains unanswered as to whether a New Zealand orchestral (or more broadly classical) style exists independently of programmatic efforts to represent the country. A deeper investigation into New Zealand national musical style in pop or classical music is beyond the scope of this project. However, it is worth noting Douglas Lilburn's comment that a national style may quite possibly emerge through the independent actions and output of a number of key figures.

In relation to jazz, composer and researcher Norman Meehan (2010) writes of the influence of the New Zealand landscape on the music of New Zealand-born jazz pianist Mike Nock, suggesting that this makes his a particularly "New Zealand voice"; but like Glenda Keam, notes in his article the suggestibility of audiences when it comes to such perceptions: "A seed is planted by the knowledge that Nock is from here, or by a title that evokes New Zealand, and that conditions their response... someone from the mid-west of the United States or coastal Australia could equally well hear their homeland evoked by the same 
tracks." (Meehan 2010, 109) Keam (2006) makes a similar observation with respect to New Zealand classical music, and many musicians I spoke to for this investigation expressed doubt that a New Zealand jazz sound existed (or that it ever will). The key point is that there is still a lack of consensus. Some composers or performers may evoke New Zealand (or some aspect of its identity) in their music, but it is still unclear whether a "distinctive" New Zealand movement exists in terms of style, aesthetic, or approach, whether across genres or within them.

"New Zealand music", therefore, is a category based on neither style, nor genre. Instead, it carries a variety of meanings dependent on context. To classical musicians and audiences, New Zealand music is music composed in New Zealand, as suggested by the name of the SOUNZ Centre for New Zealand Music, which collects and disseminates scores of locally composed classical music (and, recently, some jazz). To popular music fans and musicians, it has likewise come to signify the local origin of the music; the Homegrown Music Festival programmes exclusively New Zealand bands, playing original music, and the New Zealand Music Commission focuses on local popular music producers. So "New Zealand music" is connected to place, but it is a definition which owes more to nationalism than to evocations of local geography.

Tony Mitchell (2010) criticises the jingoism that accompanies the term "Kiwi music", and "New Zealand music" can likewise represent a strategically essentialised assertion of nationality. In this essentialisation, it has come to represent certain locally kinds of produced music more than others, particularly dub reggae, nostalgic and guitar pop, and works produced by New Zealand composers with significant public profiles, including John Psathas and Gareth Farr. The musics which fall into this category tend to be those which reflect back an idealised national identity (with which, again, Mitchell (ibid) takes issue): a DIY (do-it-yourself), low-fi, approachable, boy/girl-next door persona ${ }^{74}$, sometimes incorporating elements of Māori or Pasifika identity; examples include Fat Freddy's Drop, Crowded House, Dave Dobbyn, Six60, or bands under the 'Dunedin sound' umbrella like the Chills or the Verlaines. The identification by audiences with artists via this kind of reflection

\footnotetext{
74 Interestingly, such a persona is sometimes imposed on an artist regardless of whether it fits with their identity as a performer; an example of this is Lorde, who is consistently portrayed in the media as an ordinary Kiwi, when in fact her extraordinary global success might suggest otherwise.
} 
is described by Allan Moore as "second person authenticity": this occurs when "a performance succeeds in conveying the impression to a listener that that listener's experience of life is being validated, that the music is 'telling it like it is' for them."75

Interestingly for the purposes of this discussion, that strategic essentialism is linked both to marketing and funding. The perception that an artist reflects some form of (idealised) New Zealand identity is key in the selection criteria for the major central music funding agencies. New Zealand music, at its most basic level, is music made by New Zealanders; three of the agencies require applicants be New Zealand citizens or permanent residents. ${ }^{76}$ New Zealand On Air, which funds popular music, provides an interesting checklist to help applicants determine whether they are New Zealanders: they must answer "yes" to 3 of the 5 statements:

- $\quad$ You are predominantly based in New Zealand

- You recorded the work in question in New Zealand

- Your performance and/or recording career began, in some tangible form, while resident in New Zealand

- $\quad$ You have made some form of demonstrable contribution (financial, collaborative, promotional or otherwise) to the New Zealand music industry

- You describe yourself, and are described, in independent media coverage as a New Zealander (NZ On Air n.d.)

Thus, in the fifth criterion, weight is attached to the subjective description of the artist as a New Zealander, whether by the artist themselves, or others. This recalls both Anderson's "imagined community"; and the strategic essentialism of New Zealand identity as discussed above: the artist must fit widely accepted concepts of New Zealand-ness to such an extent that they are (despite, presumably, not fitting two of the other criteria) considered by a third, subjective party to be a New Zealander.

Taken overall, the way New Zealand music funding is channelled does not indicate that the concept of a New Zealand sound is a priority. Arguably, in art music at least the development of a "distinctive" music in New Zealand would be best served by supporting the composition and performance of new works; yet of the funds awarded to classical music, only a small fraction goes to supporting local composition, and the combined

\footnotetext{
${ }^{75}$ A discussion of authenticity, including Moore's typology, follows in Chapter 4.

${ }^{76}$ Although, to be sure, citizenship or residence does not in itself connote New Zealand-ness.
} 
repertoire of the major organisations includes a minority of locally composed music. New Zealand orchestras' direct contribution to the distinctive culture of New Zealand, then, consists mainly of representations of music composed elsewhere.

Yet on the other hand it would be inconceivable for pop music funding to support covers bands. In researching New Zealand music funding, I did not find any example of a popular musician receiving funding for consistently performing music composed by nonNew Zealand musicians. Popular music funding is very heavily weighted toward the composition and performance of original material, and a distinctive New Zealand musical culture may yet arise through the funding of local musicians to produce new music. But in many cases there are caveats placed on that funding, particularly regarding popular appeal. In the case of NZ On Air, music funding is allocated on the basis of commercial viability, rather than artistic merit or distinctiveness. The long-serving manager of NZ On Air, Brendan Smyth, put it plainly in an interview in 2004: "A lot of people still don't get that we're in the airplay business and not in the music business, and we've got a strategic priority to infiltrate commercial radio." (Smyth, quoted in Hobbs (2004)) Such a position has drawn the ire of fans, musicians and commentators; a more detailed exposition of the argument against the current NZ On Air direction can be found in Sweetman (2010) and Mayes (2010). In general, it follows that without some level of artistic integrity, or at least a strong degree of craft, music will not achieve commercial success; but the emphasis on the prospect of commercial airplay skews its focus away from artists who are either playing less popular styles of music, or who lack the resources to achieve success. Following a set of reports by former EMI executive Chris Caddick into NZ On Air's music funding scheme, the agency has adjusted its direction in order to include more support for emerging artists and alternative styles of music; however, it still aims for a 60:40 commercial pop / alternative pop split. (Norris and Pauling 2012, 139)

It is very difficult to extrapolate any unifying approach among the various directions in New Zealand music funding. On one hand, a key aim of all funders is the fostering of a distinctive local musical culture; but on the other it is difficult to discern whether the music that is made locally is distinctive. Likewise, funding for popular music is dependent on commercial imperatives; funding for classical music, which receives the majority of assistance, largely provides lifelines to organisations which would otherwise be commercially unsuccessful. Debate perennially occurs about the artistic merit of individual 
recipients, but it is impossible to draw any objective conclusion on that basis; hence the invocation of cultural nationalism in both popular and classical music. Once again the argument falters, given it is not possible to measure New Zealand-ness, except in the broadest terms.

Government funding, then, appears to have little to do with encouraging any extant New Zealand style, and is more targeted at than enabling and supporting a mix of the music and musicians deemed most worthy of investment against the hazy backdrop of "New Zealand's distinctive culture". Instead, there seems to be some other ideology at play in the allocation of New Zealand music funding. A summary of the inconsistencies in the application of criteria (across genres, rather than within them) reflects the lack of consensus both on what constitutes New Zealand-ness in music, and what should be supported if a distinctive musical culture is to be fostered. There is no requirement anywhere in the funding criteria that New Zealand music evoke New Zealand-ness; the local provenance of the material performed is important in some contexts but not in others; funding is awarded to some organisations which would not stay afloat without it, but other musicians must demonstrate the ability to survive independently in the market before applying.

Neither aesthetics, nor level of success, nor origin, are uniformly applied criteria. Instead, success in applying for funding depends not so much on what you do as a musician, but on what you represent. Those organisations and applicants which stand for key, politically weighted aspects of New Zealanders' aspirations for their identity (Kiwis being visibly successful, particularly on the world stage, sophisticated, and mature as a nation) stand the best chance of being funded. These identity politics arguably outweigh any explicitly cited priorities, and create a cycle through which some organisations are virtually guaranteed of funding (some, like the NZSO and other professional orchestras, have governmental support enshrined in either legislation or policy) while others must regularly attempt to convince decision-making panels that they are worthy of support. Funding classical music allows New Zealand to align itself with the dominant forces in global culture and politics, and funding commercially successful pop music, with its focus on original music, assists in the portrayal of New Zealand's "homegrown" values. The success of the likes of Lorde, Goldenhorse, Fat Freddy's Drop, and Flight of the Conchords allows New Zealanders a certain sense of parental pride (perhaps especially so given that the 
requirements for pop funding mean those artists necessarily earned success themselves before being given a "hand up" by funding bodies).

The musicians who receive funding, therefore, are the ones who are most likely to contribute to, and reinforce, desirable aspects of New Zealand-ness. The music itself does not have to be distinctive; what sets it apart in this context is the fact that it is known to be created by New Zealanders or New Zealand ensembles. In a sense, the process of definition is circular, and in actual fact that illustrates the issues around music funding in New Zealand, where New Zealand-ness is defined by cultural elements (and musicians and ensembles) which are defined by New Zealanders' aspirations for New Zealand-ness. And the funding follows the semantics.

\section{Jazz Funding in New Zealand}

All of the above describes a system which is institutionally predisposed towards two particular areas of music, which together receive $91 \%$ of available funding. Like many of the areas that must compete for the remaining 9\%, jazz does not meet the narrow criteria cited by the various agencies. Jazz does not hold the wide-ranging appeal required to gain a foothold on commercial radio stations; even smooth jazz (also known as "adult contemporary" in the U.S., where it was a popular radio format in the 1990s and 2000s) has failed to gain a deep foothold in New Zealand. As a result, it is ineligible to receive funding from NZ On Air, which concentrates on popular music for broadcast. Interestingly, while jazz musicians are eligible for assistance from the New Zealand Music Commission, none of the musicians I spoke to were aware of the fact; all had assumed, given the types of music it has funded, that jazz was not within its purview. In recent times, two jazz albums have been supported by Te Māngai Pāho: both contain versions of jazz standards recorded in Te Reo Māori (the Māori language), released in 2006 and 2007 by acclaimed soul singer Whirimako Black. However, jazz musicians who do not elect to take the same linguistic approach are ineligible for similar funding.

The sole avenue of central funding available in practical terms to jazz musicians is therefore Creative New Zealand. Despite the breadth of activities and genres of music funded by Creative NZ, an analysis of the agency's music funding reveals a remarkable 
imbalance. To take one example, across all funding streams over the three-year period 2011 to 2013 , jazz individuals, groups and organisations received $\$ 133,282 .{ }^{77}$ Over the same period, the major classical music organisations in New Zealand (excluding the New Zealand Symphony Orchestra) were collectively funded to the tune of $\$ 22.5$ million; or just under 71\% of all CNZ music funding. ${ }^{78}$ The NZSO, funded separately through the Ministry of Culture and Heritage, received an additional $\$ 40.3$ million over the same period. Centralised three-year funding for all jazz activity, therefore, as a percentage of that awarded to just the major NZ classical music organisations, ran at $0.2 \%$. No jazz organisation receives money through the CNZ investment schemes, and so jazz musicians rely on the smaller individual grants, such as those apportioned via the Quick Response or Arts Grant categories. Yet across 2012 and 2013, classical music also accounted for 63\% of those grants; popular music received $13 \%$, and "jazz and improvised/blues" received $6 \%$. The success rate for classical music applicants was $39 \%$, compared to $25 \%$ for jazz and $17 \%$ for popular music. ${ }^{79} 80$

Additionally, it is interesting to consider the nature of the successful jazz grants. Given the circumstances around music funding and identity, the perception exists among jazz musicians that classical and Māori music are better funded than jazz (as well as obtaining funding through the mainstream funding avenues, individuals, projects and organisations with Māori links or content may apply via CNZ's Toi Ake and Tohunga/Tukunga schemes, or through Te Māngai Pāho). It is unsurprising, therefore to see jazz applicants seeking to incorporate elements of those more successful art forms into their projects. Over the course of this project, several jazz musicians privately related their attempts to win favour from funding bodies by adjusting or conceiving of their projects in order to take advantage of CNZ's noted proclivities. Over the 2011-3 period, just over half of the funding

\footnotetext{
77 This figure was reached through a line-by-line survey of all funding recipients, as published on the CNZ website. This was necessary as there are no precise figures for CNZ investment in jazz; in the CNZ taxonomy, jazz, blues and "improvised" music are grouped together in one category.

${ }^{78}$ Based on figures provided by CNZ: http://www.creativenz.govt.nz/en/results-of-our-work/funding-statistics

${ }^{79}$ This data does not include special opportunity grants which are not tagged by genre; an analysis of the 2013 4 special opportunity grants (many of which were allocated to Christchurch-based projects to assist with postearthquake development) shows $61.5 \%$ went to classical music organisations, $20.5 \%$ to sonic artists and $18 \%$ to all other music.

${ }^{80}$ Disclosure: The Jac, a group of which I am a member, received a grant from Creative NZ in the July 2014 Quick Response round, which falls outside the scope of this investigation. It was the only jazz grant out of 18 awarded to musicians, representing just over $6 \%$ of the music grants. An additional grant was awarded to the Sound and Light Exploration Society, who support experimental and improvised music, which sometimes incorporates elements of jazz.
} 
awarded to jazz artists went in support of projects which overtly crossed over from jazz to classical or Māori music, including the commissioning of a jazz concerto for orchestra, a combination work for jazz and string quartets, an album combining jazz and taonga pūoro, and an album featuring jazz arrangements of works by well-known NZ contemporary composer John Psathas. Those New Zealand jazz projects which did not feature classical or Māori influences received $\$ 63,246$ across the three-year period, or $0.1 \%$ of the funding awarded to the classical musical institutions above. Clearly, jazz in its own right does not comfortably fit into the current Creative NZ rubric.

An article in the Telegraph in July 2014 (Hewett 2014) bemoaned proposed changes in jazz funding in the UK, suggesting that the image of jazz was to blame; cast as "not really art... a jolly, faintly nostalgic form of musical entertainment, often found in pubs on Sunday afternoon", jazz, in Hewett's opinion, lacks the cultural and artistic weight to secure funding commensurate with its fan base: not because of its nature, but because of its image. Given a lack of insight into jazz on the part of decision-makers, image is indeed one of the central issues in the lack of funding (or airplay, or other institutional support) given to jazz.

Decisions are made based on perception, and it would be difficult to draw any conclusion on the above basis other than that jazz is perceived to be less worthy of funding. Hewett draws the most obvious comparison, to classical music; but his focus on Arts Council England funding does not allow him to consider governmental support of popular music, and the place of jazz within the high/low art dialectic.

As we have seen, the same dialectic is firmly established and entrenched in New Zealand. It is clear from the analysis above that jazz does not fit into either the high or low art classification (at least as it is determined by policymakers). Anecdotal reports from fellow musicians suggest that jazz falls somewhere between high and low art; lacking the broad appeal of pop, it is considered an educated, complicated and artistic music, yet one which does not carry the prestige of classical music. Jazz applicants who align their projects with high art values by incorporating elements of classical music tend to be more likely to succeed in attracting Creative NZ funding. ${ }^{81}$ Likewise, jazz musicians have gained support from the NZ Music Commission or NZ On Air, just not when they are performing jazz.

\footnotetext{
${ }^{81}$ It is no coincidence, for example, that big band leader Rodger Fox has not only increased the number of locally-composed pieces in his band's repertoire, but also sought to tour with highly-regarded classical
} 
There are several issues at play here. Firstly, jazz is not regarded as "New Zealand music". The funding system is informed by New Zealanders' concept of and aspirations for their own national identity: the prestige and worldliness of classical music echoes New Zealanders' oft-cited desire for recognition on the world stage, and the homegrown "Kiwi"ness of New Zealand pop evokes the DIY, "number-8-wire" mentality, a central element of New Zealand's nostalgic, colonial, frontier idealism. But, as Prouty $(2012,167)$ and Davenport (2009) note, jazz has long been a tool of American cultural diplomacy; and depictions of jazz have often drawn from the concept of American exceptionalism. ${ }^{82}$ The latter half of the 20th Century saw U.S. jazz musicians attempting to assert the status of jazz as "America's classical music" in an effort to argue for a place at the academic table, funding, and the recognition of jazz as a quintessentially American art form. While they were successful, and jazz is also an accepted area of tertiary study in New Zealand, the successful branding of jazz as American still pervades the NZ context, and looms large over efforts by New Zealand musicians to establish their activity as legitimately homegrown.

Even by the musicians themselves, jazz is often branded as representative of another time or place. Regardless of its antipodean location, a New Zealand jazz gig might conjure up a back-room speakeasy, a New Orleans Mardi Gras parade, or a New York club; the roaring 20 's, the jazz age, West Coast cool or the swinging 60s. Although the personnel, compositions, and location might be grounded in New Zealand, characterisation of jazz as American is hard to escape. A recent review complimented the performance of the NZ National Youth Jazz Orchestra, playing in Wellington, as being "as American as culture gets" (Morris 2012); a recent spate of new bands in Wellington playing music drawn from early20th Century New Orleans, sometimes complete with costumes, is illustrative of the tendency of New Zealand jazz musicians to invoke some (often stylised) aspect of the U.S., whether through repertoire, name, costume, or affectation. The presentation of jazz in New Zealand is often tinged with exoticism, and that sense has become attached to the word itself ("jazz" has been used in New Zealand to give an exotic tint to everything from apples

musicians like the New Zealand Symphony Orchestra and pianist Michael Houston, at the same time as he is advocating for a nationally-funded big band.

82 Prouty even draws links between neoclassical attitudes towards jazz and modern American neoconservative politics, whereby jazz is aggressively marketed (worldwide) as American (a phenomenon which has a distinct bearing on Chapter 4). 
to cars, and even a prize-winning cow). The impact of this exoticism is examined in greater detail in Chapter 4.

In a climate in which New Zealand-ness is valued, then, jazz is unconnected to New Zealand identity. ${ }^{83}$ Recordings involving Te Reo, or traditional Māori instruments (taonga pūoro), surface occasionally, as noted above, but jazz and Māori music are not often associated with each other. Regardless of whether New Zealand or some aspect of it is truly evoked by some of the jazz produced here, however, what matters is image: jazz is not perceived as a New Zealand art form by the general public or by those in decision-making and policy roles. Jazz in New Zealand holds neither the cultural high ground of classical music, nor the populist mainstream position of pop music, and it is more associated with overseas culture than local. It does not seem to command enough of an audience share (although figures are hard to come by) to attract political interest.

The second issue which prevents jazz from accessing funding is that the music is almost invisible from a policy standpoint. New Zealand jazz is a vibrant and active subculture, but despite jazz gigs occurring with varying frequency in the major cities, ${ }^{84}$ there is no data detailing audience numbers, record or online music sales, or participation in jazz in New Zealand. The lack of information may well be because the taxonomy of New Zealand music, developed by Statistics New Zealand as part of a larger effort to track cultural activity, and used by researchers and organisations alike, lists just two types of musical performance: "Popular music performance" (which includes jazz along with everything from rock to brass and concert bands), and "Classical music performance" (which includes anyone "working in other than 'popular' styles"). It is perhaps little wonder that statistics on jazz are hard to come by. A recent application by the New Zealand Jazz Federation (see below) for funding from Creative NZ to investigate jazz audience numbers was unsuccessful. Funders and policymakers seem to operate without any real understanding of the nature of jazz ${ }^{85}$ : in

\footnotetext{
${ }^{83}$ As we shall see in Chapter 4, to be "authentic" (even within New Zealand), jazz must recall American cultural values and/or performative practices. Therefore any jazz which is identifiably New Zealand runs the risk of being labelled inauthentic; the catch-22 situation militates against the conception of a New Zealand approach to jazz.

$84 \mathrm{Jazz}$ in New Zealand is dominated by Wellington, Auckland, and Christchurch; but there are significant smaller scenes in Palmerston North, Tauranga, and Napier, among others.

${ }^{85}$ A source within the Ministry for Culture and Heritage made similar observations to me; at a recent big band concert at which I was present, Chris Finlayson, the then Minister for Culture and Heritage, wondered aloud where the violins were going to sit.
} 
Creative New Zealand's taxonomy jazz is coded under "Jazz and Improvised / Blues", although some jazz may fall under "World Music". The lack of familiarity with jazz on the part of those administering music funding means it is difficult to establish the merits of funding applications ${ }^{86}$.

\section{Summary: Jazz, the 'other'}

Despite common appeals to exceptionalism and New Zealand-ness, New Zealand government music funding is awarded to projects and institutions which most often do not represent a distinctive quality or attribute, other than being from, or domiciled within, New Zealand. Central government music funding in its present form, therefore, represents economic stimulus for the local industry, as suggested by Shuker (2007), rather than any push towards the construction or development of a uniquely New Zealand voice.

Yet, in a political context in which New Zealand-ness is (at least nominally) valued, the exoticism and countercultural capital of jazz militates against it in terms of funding. Local jazz musicians, despite being as "New Zealand" as any other musician, find it difficult to secure funding of any kind. There is little that is New Zealand about the season repertoires of the major local orchestras ${ }^{87}$, and much locally produced popular music draws on modes of expression developed overseas. Jazz is in the same position; yet it misses out, whether the music is composed in New Zealand or not. Jazz lacks knowledgeable advocates in music policy and infrastructure contexts. Its absence is, or course due in part to its minority status (although no statistics exist to prove or disprove this claim ${ }^{88}$ ); but its strong and durable characterisation as American (as opposed to the more acceptable Western European heritage of classical music) also prevents it establishing a connection with New Zealand identity. ${ }^{89}$

\footnotetext{
${ }^{86} \mathrm{An}$ issue that has been confirmed by a highly-placed figure in the area.

${ }^{87}$ Although each has a certain amount of New Zealand repertoire in their annual programmes, it tends to be played outside the most highly marketed events; this is doubtless due to commercial pressures.

88 In another catch-22 situation, a funding application which would have supported the gathering of such statistics was rejected, according to anecdotal evidence, because no statistics could be produced to support it. ${ }^{89}$ Such a position will be familiar to any New Zealand jazz musician who has entered a venue at which they are to play, to be greeted with bemused looks from their supposed audience; or who has resisted the descriptor "jazz" in order to avoid putting their audience off (Jellyman 2013). Despite its strong connections to all branches of the local music scene, jazz has still to persuade most New Zealanders of its relevance.
} 
As this chapter has shown, in the local discourse external to jazz, despite arguments to the contrary, jazz is still the "other". Such a position creates interesting tensions in the local Wellington context, as we shall see: the recontextualisation of jazz into a domestic New Zealand scene results in the creation of new meanings, which challenge both notions of New Zealand-ness in locally-made music, and assumptions about the globally accepted meanings of jazz. As we have seen in Chapter 1, the Wellington jazz community occupies a central place in the music scene; yet the music funding structure is set up in such a way as to exclude jazz from conversations about New Zealand-ness and the music industry.

Chapter 3, which examines the role of the New Zealand School of Music in the Wellington jazz community, continues to consider the concept of Americanness in jazz, in the context of the school's considerable influence on the Wellington community. Further, the implications of such a concept will be examined in more depth in Part 2, where the interrelated notions of authenticity, identity and tradition, and New Zealand-ness in jazz, are considered in relation to the place of jazz within the Wellington music scene. 


\section{Chapter 3: This is how you do it: the jazz school}

In a 31-day period over April and May 2013, 105 public jazz gigs took place in Wellington. For a city with the roughly the same population as Akron, Ohio, Shreveport, Louisiana or York, England, that is an astonishing statistic. There was no jazz festival or other special event in session; the number represents simply the regular, everyday jazz gigs which took place as a matter of course across that month. And that level of activity is not unusual; it continued along more or less the same lines across the period September 2014 to April 2015 , albeit with a hiatus over January (the traditional summer holiday period in New Zealand). The Wellington scene is remarkably hospitable towards jazz, and generally accommodates a broad cross-section of approaches: gigs in the initial 31-day period included ragtime, soul, swing, gypsy jazz, jazz with a DJ, standards, originals, Brazilian bossa and samba (separately), bebop, free jazz, jazz funk, jazz rock, and seven different big bands; bands led by vocalists, drummers, trumpeters, saxophonists, guitarists, bass players, and a trombonist. As such the jazz on display in that month covered most of the commonly accepted performance contexts and formats in mainstream jazz, as well as some more experimental practices.

Yet despite the eclecticism of the community, and the tremendous variety of offerings, there is a common thread: all but 3 of the 105 performances contained past or present students of the jazz programme at the New Zealand School of Music (NZSM), and two of the three others featured visiting artists hosted by the NZSM. ${ }^{90}$ Such is the depth of the connection between the school and the community that it could be described as symbiotic. Neither would function to the same degree without the other: the school populates the scene with trained musicians who are intent on performing (just over half the gigs in April/May 2013 contained one or more current student), and the scene provides the opportunities for NZSM students and graduates to perform- a level of opportunity which the school parlays into a marketing strategy. Furthermore, $43 \%$ of the gigs in the April/May period featured one or more current (permanent or adjunct) staff member.

\footnotetext{
${ }^{90}$ As mentioned previously, the school has operated under various names and institutional umbrellas since its inception; I will detail these in a subsequent paragraph.
} 
Any investigation into the nature of the jazz community and scene in Wellington, therefore, must consider the role of the NZSM. The school acts as both an element of the scene (in training the musicians who populate the community, and in employing many of the active members of that community) and, through those actions, as the engine room of the scene: the driver of many of the ideals and values of the community. Many of the issues at play in the community can be traced back to the pedagogical systems of the NZSM; and in some ways the NZSM can be seen as a microcosm of the local community, in which the discussions and ideologies evident in the community at large are placed in close (and, at times, contentious) proximity. However, at the same time, there are also conversations which take place in the wider Wellington jazz community which are (largely) absent from the NZSM. The nature of those conversations is instructive in terms of characterising (by omission) both the values held and taught by the NZSM jazz programme as a whole, and the somewhat contested relationship between school and community.

\section{Three Schools: a brief history of NZSM jazz}

The NZSM jazz programme traces its roots back to the mid-1970s, when trombonist and bandleader Rodger Fox (still a member of staff in 2015) began teaching jazz ensemble courses as electives within the classical music programme offered by the Wellington Polytechnic Conservatorium of Music. By the mid-1980s the Conservatorium established a full diploma course in jazz performance (which, along with the classical performance course, was accredited as a Bachelor's degree in 1998). As it was a polytechnic department, the Conservatorium's focus was on practical skills; the qualification offered was a diploma (and subsequently an advanced diploma) in executant music. Courses such as music history, theory, business skills and physics of music were conceived as supporting the central focus of the programme, which was musical performance. Over its first twenty years the jazz and classical programmes produced a number of successful and high-profile musicians: bass baritone Paul Whelan (winner of the Lieder Prize at the Cardiff Singer of the World competition in 1993); harpist Anna Christensen, NZSO oboist Robert Orr, jazz trombonist Nick van Dijk, drummer Lance Philip, and jazz pianists Anita Schwabe and Jann Rutherford. 
Interestingly, the Conservatorium existed as a small ${ }^{91}$ but distinct entity within the polytechnic, in that courses largely remained off-limits to students who were not enrolled as music majors, and the demands of the music degree programme meant that music students had little scope within their study to include courses from other areas. Additionally, from 1989 to 1997 the Conservatorium was geographically isolated, located separately from the rest of the Polytechnic in a converted hospital in the Town Belt area, on the top of $\mathrm{Mt}$ Victoria: a strenuous (on the way up, at least) half hour walk from the main campus.

In 1998, the Conservatorium moved back onto the Polytechnic campus, into a converted panel-beating school; and in 1999, the Polytechnic was wholly absorbed into the Palmerston North-based Massey University, thus allowing Massey to establish a campus in Wellington. The Conservatorium became the Massey University Conservatorium of Music, but, as it had under the Polytechnic administration, remained a discrete entity within the university. The jazz and classical programmes, likewise, remained focused on performance, with other courses acting as contextual support. Student numbers had been increasing, and the jazz programme now enrolled around 25 per year-group.

Interestingly, the Conservatorium was not the only university music school in Wellington. Victoria University had established its School of Music in 1946, which focused on composition, sonic arts, musicology, and ethnomusicology as well as classical performance. Additionally, Whitireia Community Polytechnic began offering qualifications in commercial music in 1994, from its campus in Porirua, $20 \mathrm{~km}$ north of Wellington city. Following protracted negotiations, in 2006 the Massey Conservatorium and the Victoria University School of Music amalgamated under the banner of the New Zealand School of Music (NZSM), jointly owned by Victoria and Massey Universities. All programmes previously offered by each school were maintained, and degree structures were broadened so that students might more easily incorporate elements of other approaches into their degrees. Yet the NZSM remained split across two Wellington campuses, another strenuous 25-minute walk apart: the former Massey classical performance programme left the Massey site to amalgamate with the Victoria University-offered classical programme. The jazz programme remained on the Massey campus along with the music therapy programme; and

\footnotetext{
${ }^{91}$ The initial student cohort numbered 17 across all three years combined.
} 
the Victoria campus housed classical performance, musicology, ethnomusicology, composition and sonic arts, as it had before the amalgamation.

The NZSM remained a joint venture until 2014, when full ownership was transferred to Victoria University, ${ }^{92}$ and Massey University announced its intention to establish a new music school, focusing on commercial music practice, music technology and music industry issues, albeit with a more artistic focus than the Whitireia Polytechnic courses. The jazz and music therapy programmes moved to new premises on the main Victoria University campus in 2016.

Thus the "jazz school" 93 has operated in, and fed, the Wellington jazz scene for four decades. It has attracted (and continues to attract) young musicians from across New Zealand, and has thus contributed to the liveliness of the local community by concentrating much of New Zealand's young jazz talent in one place. While other jazz programmes have developed around New Zealand (at the Christchurch Polytechnic Institute of Technology (CPIT) since 1991, and at the University of Auckland since 2000), the NZSM programme remains the most significant in terms of both longevity and student numbers; and its position within New Zealand's most energetic jazz scene means that it exercises considerable influence.

\section{Influence}

Until recently, jazz education was all but non-existent in New Zealand secondary schools; even now it is limited in scope, existing in the classroom in terms of the analysis of a handful of classic recordings, and in performance largely via concert bands and big bands. The NZSM, therefore, often provides students with their first in-depth experience of jazz; and students' formative years as jazz musicians are therefore heavily influenced by the philosophy and pedagogy of the NZSM. ${ }^{94}$ That philosophy, therefore, carries significant

\footnotetext{
${ }^{92}$ I began work on this PhD under the Victoria / Massey NZSM, enrolled via Victoria University systems but assisted by a Massey University doctoral scholarship.

${ }^{93} \mathrm{As}$ it is enduringly termed; it is also still metonymically referred to within the community as "Massey" or "the Con". The existence of such monikers, singly and in combination, indicate the complexity of the machinations surrounding its changes in ownership and management.

${ }^{94}$ An examination of the NZSM curriculum follows.
} 
weight within the community: but it is clear from the variety of perspectives extant in Wellington jazz that that influence manifests itself in a variety of ways. Musicians in the Wellington community take a variety of approaches to jazz performance, and to a certain extent this is a reaction to the focused pedagogical approach of the NZSM: graduates (and current students) find outside the school a wealth of opportunities to expand and extend their musical activities in a way that is not possible within the curriculum as it stands (and has stood for a long time). Yet at the same time, elements of the philosophy conveyed by that same curriculum pervade the Wellington scene, shaping it in particular ways.

While the philosophy (or philosophies) evident within the NZSM affect the community, the inverse is also true. Until recently, the permanent and adjunct faculty of the jazz school have all tended to be active members of the local jazz community; ${ }^{95}$ their teaching philosophies are undoubtedly (and overtly) informed by their experiences as performers. The visibility of the staff within the local community confers authority; and it is an authority based on performance, rather than other aspects of jazz study such as critical reflection or compositional prowess.

The diversity of approaches within the community is, to a lesser degree, represented in the perspectives of NZSM staff. Permanent and adjunct staff represent a plurality of approaches to jazz and beyond; instrumental and ensemble teachers have in recent years been performers in genres including free jazz, roots reggae, and psychedelic rock, as well as mainstream jazz, and as we shall see, versatility is considered a desirable attribute in Wellington.

It is important to note that education provides significant employment opportunities for local jazz musicians. As in scenes and communities worldwide, in Wellington musical performance (for the most part) does not pay the bills; despite the wealth of performance opportunities on offer, the low rate of pay does not allow musicians to survive solely on the strength of their performance career. As a result, musicians must diversify, and the teaching of music provides a convenient method of enhancing one's income. The NZSM is by no means the only institution providing such opportunities: local jazz musicians find a

\footnotetext{
${ }^{95}$ However, as of 2015/16 very few jazz and jazz-related permanent staff of the NZSM are regular jazz performers in the Wellington or New Zealand scenes.
} 
significant amount of work as itinerant teachers at local secondary schools, ${ }^{96}$ and in recent years jazz musicians have undertaken postgraduate teaching qualifications in small but increasing numbers, resulting in their employment as classroom music teachers.

Nevertheless, the NZSM, given its connection to the jazz community, remains the highest-profile employer of jazz musicians in Wellington, and to a certain extent it trades on the performance reputations of its teaching staff. The cachet of musicians like Paul Dyne, Roger Sellers, Colin Hemmingsen, Reuben Bradley, Lex French, Anita Schwabe, Tom Warrington, Lance Philip and Rodger Fox ${ }^{97}$ adds weight to the marketing strategies of the school. Again, the relationship is symbiotic: musicians depend on the NZSM for employment ${ }^{98}$; and without the legitimacy conferred by the employment of musicians who are significant to the scene, the NZSM would lack the local connections and authority vital to its ongoing success in a competitive educational environment.

Thus the effect of the NZSM on the Wellington scene is significant. The school plays an important role in shaping the local context, through providing a financial foundation on which those performers employed through the jazz programme may rely: in turn that allows those performers to survive as performers by removing (at least partially) the financial uncertainty that attends a career in jazz performance. Likewise, the values and knowledge conveyed via the NZSM curriculum are carried into the scene by the interacting of NZSM students and alumni with the wider Wellington jazz community. A closer examination of the materials and approaches promoted through the curriculum reveals the extent to which the conservative methods of the school affect jazz activity in the Wellington context.

\footnotetext{
${ }^{96} \mathrm{An}$ itinerant teacher teaches a small number of hours (during class time) at a local primary or secondary school, usually in a one-on-one instrumental setting, but sometimes also coaching instrumental or vocal ensembles. Due to fluctuating demand, such employment is often tenuous, and is usually fixed-term; and due to the limited number of hours involved, musicians often teach at a number of schools concurrently. ${ }^{97}$ The above are a mixture of permanent and adjunct staff; due to the temporary nature of adjunct staff employment (see footnote below), not all may be currently employed by the NZSM.

${ }^{98}$ Although such employment is frequently on unstable terms: adjunct staff contracts are usually temporary, and of fixed duration, with no guarantee of ongoing employment.
} 


\section{NZSM Curriculum}

In recent times, an increasing amount of scholarly discourse has come to portray conventional jazz pedagogy (as exemplified by Jamey Aebersold, David Baker and Jerry Coker, among others ${ }^{99}$ ) as outdated, conservative and restrictive ${ }^{100}$. The codified approach to improvisation and chord/scale relationships, useful in that it provides an easily quantified syllabus and method of assessment, arguably proved vital in the admission of jazz into academic institutions in the first place ${ }^{101}$; yet these very features are the focus of much criticism, for removing jazz from its cultural roots and thus divesting it of its meaning. Ken Prouty $(2005,88)$ and Stuart Nicholson $(2005,99-127)$ deconstruct the commonly accepted tenets of jazz education in the United States, portraying it as a pedagogical production line which, while providing a set of common skills and approaches reinforced by a commonly accepted historical narrative, reduces innovation and privileges instrumental prowess over the pursuit of artistic expression. While a graduate may be able to play with any other jazz graduate from anywhere else in the world, Nicholson argues, they will also sound like any other jazz graduate. Moreover, their understanding of the original prerogative of jazz, as a means of expression which challenged a dominant, hegemonic culture, is supplanted by commercial imperatives: the drive to get a gig through the adoption of the norms of musical performance practice has replaced the drive to challenge cultural norms by way of selfexpression. Speaking more generally, Garrett et al challenge the "U.S. higher education music system" for having become "too comfortable with the reproduction of formulas that aspire to ensure its own replication. When a system occupies itself with reproducing a given

\footnotetext{
99 Jamey Aebersold is particularly well-known for his series of "play-a-long" (sic) jazz recordings, which introduce students to the concept of chord-scale relationships. David Baker's Jazz Pedagogy (1979) has been for many years the seminal text in jazz education, providing lesson plans and repertoire lists, and promoting the "memorization of songs and jazz-related harmonic theory." (Prouty 2008) Jerry Coker's textbook Improvising Jazz codifies some of the major concepts of jazz including the major styles, jazz harmony, and the swing rhythm.

100 Numerous authors have contributed to the debate over jazz education: see Prouty (2005), (2008), Ake (2002), (2012); Nicholson (2005, 99-128); Kennedy (2002), and Collier (1993), for example.

101 Prouty (2008) argues that in order for jazz to gain acceptance within an academic tradition which was built on the tenets of Western music, a certain amount of such codification was necessary so that jazz might be seen as a serious art form, comparable with classical music. Jazz educators began to treat recordings as artefacts, to relate jazz structures to classical forms, and to emphasise "elements of the improvisational process that appealed to formal and structural sensibilities seemingly reflected in the western canon. This response was as much about legitimizing jazz as a cultural form as it was about musical practice."
} 
set of aesthetic values (absolute music, organicism, harmonic complexity, the idea of musical genius, teleology, etc.) and their embodiment in a given musical repertoire... it becomes more a matter of propaganda than a project in critical thinking." (Garrett, et al. $2011,701)$

Interestingly, Nicholson notes (while acknowledging the generalisation) that European jazz education has developed in a more pluralistic manner, ${ }^{102}$ in which lower student numbers allow for a more individually tailored approach to each student, and in which the vast heritage of European classical music provides a broader backdrop against which students may develop individual approaches. Thus the contextual difference has resulted in a parallel approach to the U.S. model, informed by the cultural context in which it has developed, and that provides an alternative to the dominant discourse of jazz education. Yet alternative approaches (such as Nicholson describes) have not been widely influential; the ongoing dominance of American models perhaps speaks to assumptions about the authenticity of jazz and jazz philosophy which arises from the U.S. ${ }^{103}$

The NZSM jazz curriculum closely follows the traditional American approach, described by Nicholson as "bebop technicist". (Nicholson 2005, 118) The curriculum focuses on the learning of standard licks and repertoire, as well as ensemble skills. Students are required to demonstrate proficiency in the application of patterns to standard progressions, and combo classes focus on the learning of standards and the ability to perform on demand the canonical styles of jazz history (at least up until the early 1960s). As such it draws on, and connects itself to, the weight of tradition; as we shall see in Part 2, in a local context in which jazz lacks a strong identity, such a connection is useful in conferring legitimacy and authenticity.

For the three years of the Bachelor's degree, ${ }^{104}$ then, NZSM jazz performance students follow a tightly structured curriculum. Instrumental and ensemble skills are central

\footnotetext{
102 The most commonly-cited contrasting approach to "American" method is the "European" method, which takes a more catholic, multinational approach in terms of canon and perspective. Tony Whyton $(2010,75-6)$ is careful to describe the dichotomy as one of "approach", given the multitude of differing perspectives within both the U.S. and Europe.

${ }^{103}$ See Chapter 4 for a discussion of authenticity in jazz.

104 In New Zealand, undergraduate degrees (with some exceptions) are 3 years in duration, and focus on the major subject; this is different to the American model, in which a 4-year undergraduate degree includes a significant liberal arts component in addition to the major.
} 
in all three years, as are improvisation classes. Students are required to attend one-on-one instrumental lessons each week for the duration of the programme, and to pass skills- and transcription-based assessments throughout. Likewise, all performance students must attend two combo classes each week, which focus on the acquisition of ensemble skills and mainstream stylistic techniques (how to play ragtime, swing, bop, and so on), each through the playing of standards. Additionally, all students must attend three big band rehearsals each week, which ostensibly teach sight-reading and large ensemble skills.

As a result, for the three years of their undergraduate degree, students are almost entirely engaged in the standard, mainstream American ${ }^{105}$ jazz tradition. Indeed, that would seem to be the obvious way to begin a student's education, especially in a context where many students arrive on the first day of class with little concept or background knowledge of jazz. Treating the jazz tradition, with its great men, standard repertoire, and stylistic conventions, as the fundamental knowledge base for jazz education provides the NZSM with a convenient and practical method, which is well-suited to a standardised pedagogy. ${ }^{106}$ Students emerge with a reasonable level of instrumental proficiency, and a set of musicianship skills that allow them to construct a gig, perform in a band, and sound like the conventionally accepted archetype of a jazz musician.

Despite the NZSM jazz school having transitioned in nature from a polytechnic to a university, its jazz programme still follows the model it has since the 1980s, in which classes in subjects other than performance are accorded ancillary status. Theory classes are mandatory for the first two years, and composition and arranging is core in the second year. Two musicology courses are required, both in the first year: "Jazz History", and "Music Now", which examines the $20^{\text {th }}$ and $21^{\text {st }}$ Centuries through a pan-musicological lens: all NZSM students are required to take this course, regardless of major; and so it is less an ancillary course than a concession to membership of the NZSM. For jazz performance students, other musicological and composition / arranging classes are available as options, but it is possible (as many students manage to do) to complete a degree with no

\footnotetext{
${ }^{105}$ The amount of European, Australian or even New Zealand jazz (repertoire, history, or other aspect) incorporated into the NZSM curriculum is minimal.

106 And one which, as noted above, "had advantage for those who sought to legitimize jazz (in the academy) as a serious art form with its own set of objective standards and definable history" (Whyton, in Nicholson 2005, 117).
} 
musicological / critical element beyond the first year, or with only one 12-week composition and arranging course.

Interestingly, a second option is open to jazz students at second- and third-year level; instead of majoring in performance, students may instead opt for one-on-one composition lessons. In practice, this has historically provided students without the necessary skills to succeed in jazz performance with a second option; few students have enrolled in the degree programme specifically to major in jazz composition. Indeed, given the corequisites of many second- and third-year jazz ensemble courses require enrolling students to be jazz performance majors, jazz composition students are often unable to participate in the central activities of the school; as a result of both factors, jazz composition is seen by students as a second-class option. It is worth noting that in the New Zealand tertiary music education system, classical composition is accorded very high status, on a par with classical and jazz performance: in a typical year, 120 classical composition majors are enrolled across all levels at the NZSM.

The NZSM jazz programme is conscious of its focus on the emulation and assimilation of the styles of canonical American jazz masters: as Rodger Fox put it, “Everything we do is mirrored off what we've heard - you don't come to school and learn New Zealand jazz... you are listening to the masters who are American primarily." As such, it follows the pedagogical model which was criticised by Nicholson, but which was thereafter staunchly defended by David Ake:

In jazz, as in every other discipline offered in higher education, good teachers provide students with a foundation in what has come before, offer suggestions to shore up perceived weaknesses, and foster a challenging, creative, and supportive environment in which students can focus on their work. (Ake 2010, 254)

In his defence of American jazz education, Ake (dismissing Nicholson's “Europhilia” (242)) cites a long list of successful jazz musicians who studied at U.S. colleges. Indeed, Ake's apologetics have merit: the strength of the Wellington scene, considered alongside the deep influence of the NZSM, also could be understood to constitute a robust defence of the pedagogical system. I am a product of that system; most Wellington jazz musicians are. The fact that the scene consistently plays host to students who perform professionally while still 
enrolled as undergraduates speaks to the standards achieved by the student cohort year after year.

Yet the NZSM jazz programme remains focused on quite particular outcomes, to the exclusion of others; and it is instructional to note the connections between those outcomes and the nature of the Wellington scene and community. The NZSM, via a curriculum which takes an uncritical, decontextualised perspective on the mainstream American jazz tradition, characterises jazz as a set of quantifiable, acquirable skills and techniques, based largely on the bop and post-bop styles, and borrowing from modal and Latin approaches. Students are judged (in the first instance) on the appropriate and correct deployment of those skills in standard situations; while improvisation is foregrounded, the focus is on product rather than process. Indeed, as Prouty (2008) and Nicholson both suggest, such a systematic approach resulted from the demands of academia, and the need for measurable, definable outcomes.

\section{The individual voice}

Interestingly, the notion of the individual voice, while central to emerging definitions of jazz creativity (Meehan 2014), is not central to this model. Students must demonstrate that they have assimilated prescribed elements of jazz improvisation, to the extent that imitation and emulation become ends in themselves: all students are tested on their ability to memorise and perform transcriptions, and students who stray too far from the set syllabus of expressive materials when improvising are penalised. As a result, over the past few years, several successful musicians, whose artistic voice did not fit within the province of the NZSM curriculum, have abandoned their studies only to succeed in the broader Wellington scene. The individual voice is acknowledged within the curriculum; but, as one permanent staff member implied, without study and assimilation of mainstream, codified jazz expression, such individual expression is considered invalid:

'Finding your own voice,' in place of learning jazz language is code for 'I don't want to do the work necessary to be a jazz musician.' Of course the ultimate goal is to be a unique player and we talk about that early and incessantly, but the lava lamp, bong hit, I'm a more creative jazz player simply because I say so approach, doesn't actually produce players of substance... If four years ago, Umar [Zakaria, a former NZSM 
student who currently studies in Boston] takes that approach, doesn't learn to phrase well, doesn't learn to swing and doesn't play actual language, he doesn't go to Boston and get comments like, 'What a novel approach. Where is he from?' he gets 'The cat can't play.' ((name withheld) 2015)

Indeed, it is a common trope both inside and outside institutionalised jazz education that one must learn the history of one's art form in order to make a valid (informed) contribution to it; such is the nature of tradition (a deeper discussion of which is incorporated into Chapter 4). Of course, for a musician's practice to be given any particular label it must conform to a certain degree to the commonly accepted attributes implied by that label. Crucially, however, under the pedagogical model adopted by the NZSM (alongside, according to Nicholson and Prouty, many other (North American) institutions), that conformity, at least in the first instance, is the goal. The programme aims to produce jazz musicians; and, moreover, jazz musicians who are recognisably jazz musicians, identifiable via conventions of style, language, and performance practice. As Stuart Nicholson allows, "before meaningful glocalization can take place, local jazz musicians need to have absorbed and become fluent in American hegemonic jazz styles - in other words, have a thorough understanding of "the rules of the game" - before selectively borrowing from the local to produce a viable hybridized, or localized, product." (Nicholson 2014, 99) Thus the conservative pedagogical approach of the NZSM may be validated through its portrayal of codified jazz performative strategies as a lingua franca, or "the rules of the game": rules which must be learnt before they are broken.

\section{Context}

Such an approach is notably surface-focused; it provides young musicians with the tools needed to create jazz, but the meaning of that practice, so heavily discussed in scholarly contexts, is largely left to the students to discern. Given the nature of the curriculum, any core formalised instruction in the context in which jazz was and is created is confined to one 12-week course in the first year (although elective courses in jazz studies are available, which sometimes take a critical perspective, and which compete for uptake with other, ensemble-focused electives). Consideration of jazz as a product of its context is therefore 
limited in comparison to consideration of the performative strategies involved in its production. The meaning of jazz, in either its original context or its Wellington and New Zealand context, must therefore be inferred by students through their interactions with each other, with their teachers and the curriculum, and with the scene; and the implication is that such meaning, and the critical reflection required in its pursuit, is a minor consideration at best. Notably, Ake, in his defence of jazz education, likewise focuses only on the ability of institutions to provide high-quality skills-based learning. Of course, a "jazz performance" curriculum is just that; but it is interesting to note that the NZSM programme has changed little in this regard over the $\mathbf{3 0}$ or more years of its existence, despite transitioning from a polytechnic programme to a university one, and then to a combined school in which musicology is a major strength.

Indeed, the specific Graduate Attributes of the NZSM jazz programme indicate that graduates of its 3-year degree will "perform, improvise, compose and arrange music with skill and artistry as a jazz musician in solo and/or group settings." (New Zealand School of Music 2014) Such a profile is in keeping with the nature of the curriculum, as I have discussed. Moreover, its practical focus also closely matches the values evident within the Wellington jazz community. As we shall see in Chapter 4, in the Wellington context, knowledge of the original cultural context and meaning of jazz is difficult to attain, and not considered an integral part of a valid jazz identity; and critical reflection, while inevitably occurring on a certain level (as it does with most practice), is not actively pursued to a deep level by most local jazz musicians.

\section{Pragmatism}

The commonalities in the value systems of both the NZSM jazz programme and the Wellington jazz community extend further. In fact, they can be broadly characterised as privileging pragmatism: the curriculum focuses on the skills required to survive as a working musician in the local (and broader) scene, while the scene is to a large extent informed by the values taught by the school, including versatility and vocationality.

The versatility mentioned in Chapter 1 as a hallmark of the Wellington community is championed at the NZSM both by staff and by virtue of the curriculum. "Repertoire Combo" 
class in students' first and second years is designed to teach and assess students' working knowledge of the most common mainstream jazz styles. Three big band rehearsals per week for the duration of the degree programme are assessed not via performance, but in terms of sight-reading, on the grounds that it is a vital vocational skill. The combo, improvisation and theory curricula are designed around the common "jazz language", based on bebop / hard bop (the bebop-technicist approach derived from Aebersold, Baker and Coker, and cited by Nicholson), on the basis that not only does it provide a helpfully quantifiable (and assessable) introduction to jazz improvisation (as Aebersold announces on the cover of one of his DVD learning aids, "Anyone can improvise" (REF Aebersold 2007)), it is also the "lingua franca of jazz". (Herzig 2011, 83), (Prouty 2012, 54) Knowledge of bebop language is characterised as one's ticket to the global scene, without which one could not hope to gain meaningful opportunities to work or study further. Furthermore, other classes also couch the development of skills in terms of work opportunities: for example, the Jazz Fusion ensemble focuses on classic soul and $R \& B$ repertoire on the basis that familiarity with that repertoire is of more use to a working musician than genre-specific knowledge of jazz rock fusion. ${ }^{107}$

In the community, such values are visible in the breadth that characterises the portfolios of many jazz musicians, both inside and outside the bounds of jazz performance. The musicians listed in Chapter 1 as examples of players who work across genres are not unique, but rather indicative of the fact that adaptability and the possession of a broad spectrum of working knowledge are valued within the Wellington context. What is key in this environment is not the development and possession of an individual voice, but more a chameleon-like ability to fit seamlessly in to a variety of musical situations. In fact, it could be argued that in this context the concept of one's 'voice' has been replaced by one's 'footprint': the unique blend of performative modes and contexts through which a musician interfaces with the wider music community, and by which each musician is known. Such a functional conception of a musician's identity is clearly related to the value system which underpins the NZSM curriculum.

\footnotetext{
107 See Nicholson (2014, 1-38) for a discussion of the relative merits of advancing the art form of jazz or catering to the audience, and the importance of the middle ground.
} 
Yet functionality and versatility are not the only drivers in Wellington. The scene contains a number of musicians whose approach extends the concept of the "footprint" in such a way that they have developed an identifiable voice, which, crucially, manifests as the sum of their unique combination of influences. Such musicians include drummers Shaun Anderson, whose work spans jazz and metal, and Rick Cranson, who blends hard bop, free jazz and rock; and pianist Norman Meehan, whose work contains a strong gospel tinge. Musicians whose voices are similarly unique, but who draw on a complex array of influences, include saxophonist Jeff Henderson, drummer John Rae, bass player Tom Callwood, and saxophonist /composers Jasmine Lovell-Smith (now resident in Boston), James Wylie (working in Thessaloniki) and Lucien Johnson. All but the Scottish-born Rae are former students of the jazz school in Wellington (under various institutional banners), and it is interesting to note the diversity of approaches among alumni of a course that cleaves so closely to a bop-centric tradition.

\section{Power Dynamics}

The pragmatic approach, as I emphasised earlier, valorises performance skills at the expense of critical training. Such a value judgement, while often implicit, is symptomatic of a tendency among jazz musicians to distinguish "between academic and non-academic practices" (Prouty 2005, 79). Indeed, as a performer who also specialises in scholarly work, I have found myself overwhelmingly in the minority in the Wellington (and national) context. As we have seen, in the local environment the tendency towards uncritical performance can be attributed to the long-established structure of the NZSM's curriculum, in which critical and musicological approaches are included only insofar as they are understood to have a direct impact on performance. Interestingly, such a distinction has become somewhat entrenched since the establishment of the NZSM, and in recent years, as a result of the overall NZSM structure, it has been characterised in terms of power relationships.

In 2011, I examined reactions among local musicians to the notion of my larger project, and in doing so I explored local attitudes towards academia in jazz. The overarching response I encountered from both NZSM employees and freelance musicians was cynicism towards academia in general; and this has been reinforced through many informal 
conversations with others in the scene. University academics (at least in relation to jazz)

were perceived as untrustworthy, ill-informed, presumptuous and the beneficiaries of an unequal power dynamic:

If you've never done it, you don't really deserve a right to talk about it. You can talk about what you've done, and if you've done a whole lot of study in something, then you have every right to talk about what you've studied. You don't have any right to talk about playing, if you haven't played. ... It's the same with me, I wouldn't pretend to go and advise those academics on anything academic... I'd be laughed out of the room! They would be looking at me going 'who is this guy?' But yet academics seem to think it's ok to go and tell players about playing. Why is that? (Granville 2011)

I think we're sceptical (in relation to academia). I think people are, and we're very cynical now too. (Brown 2011)

People always thought music is something they just- you gotta do cos you're a creative person. Now people think 'what research output can I attain out of this?' or 'how can I get this- how will this help with my music career?'108... the unfortunate thing is the academics do far better in this environment... because they're the better ones at writing proposals... to get the research funding, because it's all become about qualifications. (Granville 2011)

In this environment, academic investigation into jazz is perceived as a side-activity; one which is of little benefit except to the person doing the investigating, ${ }^{109}$ and which presents more of a hindrance than a help to creative practice. ${ }^{110}$ Its relationship to practice is

\footnotetext{
${ }^{108}$ Since 2006, the same year that the NZSM was established, government funding of tertiary education has in part been contingent on the research outputs of university staff. $30 \%$ of funding was essentially cut, with the requirement that it be earned back via a process (known as PBRF - or Performance-Based Research Funding) in which individual staff were rated on the basis of the level of their research. Built on a peer-review / publishing model, the system of assessment did not easily account for artistic disciplines including music (with the arguable exception of musicology). Musicians were forced to argue, in academic language, the merits of their practice by characterising it as peer-reviewed research on the basis of reviews, CD publications (on recognised labels), performance invitations, and commissions. For NZSM jazz staff, most of whose "outputs" (by the nature of their work) are on a local level, are not reviewed, and are not released on big-name labels, and who seldom have the opportunity to interact with international musicians, this constituted a further alienation from the tertiary education system.

${ }^{109}$ I have been required to defend the merits of this investigation in those terms on several occasions in conversation with members of the scene.

${ }^{110} \mathrm{It}$ is interesting to note the parallel between the academic / performance dichotomy, and the criticisms raised about jazz pedagogy. In both cases, debate centres on legitimacy in relation to jazz performance: whether codified jazz instruction is a true road to authentic jazz expression, and whether academic and critical investigation of jazz is truly relevant to jazz.
} 
considered tenuous at best; almost none of the musicians active in Wellington have qualifications in musicological / critical disciplines, and given that most musicians in the community are alumni of a programme in which such work is given a low priority, critical reflection and investigation is of little relevance to a performing career. The performance / academic debate is a familiar one in jazz education worldwide; Tony Whyton (Whyton 2010, 72-3) summarises the argument against academic involvement in jazz education, which "goes against the grain of the music's fundamental tenets of intuition and impulse."

Adding currency to this perspective is the dynamic within the NZSM itself. The amalgamation of the Massey and Victoria University music schools meant that the largely performance-based Massey programmes were now part of a school in which many members of the senior academic and leadership team were perceived as having little experience of, or sympathy towards jazz. In this environment changes which were made to the jazz programme, especially in terms of staffing, were perceived as originating from an illinformed perspective, which privileged the interests of classical music. While it is not at all clear that this was the case, the resulting perceptions of the power dynamic, combined with scepticism regarding the benefits of critical study in jazz, fed the reluctance on the part of jazz staff to increase the scholarly or critical component of the curriculum.

Yet power dynamics are inherent in the pedagogical system of the NZSM. Drawing on Foucault (1980), Wink (1997), and Giroux (1989), Ken Prouty (2008) notes that the organization of knowledge in service of a curriculum or pedagogical system is in itself an exercise in power. The NZSM wields significant influence over young musicians in the first stages of their jazz career, enabling its definitions (of what is "jazz", what is useful knowledge for a jazz musician, which approaches are most valid, which artists a young musician should listen to - and which they should not - for example) to gain significant traction. Given the social structure inherent in a conservatory (as detailed by Kingsbury (1988)), the implications are clear: in order to succeed, students must adhere to notions of aesthetic, approach, and execution which are defined by staff. Given that musical performance, and its assessment, is a deeply subjective area, determinations of success or failure are made based purely on staff members' opinions, within the context of the relatively conservative pedagogical approach of the school as a whole. 
Interestingly, while many Wellington musicians expressed to me concerns about the direction of the school, few were willing to go on record for this investigation in calling into question its aesthetic or methods. This reluctance illustrates the way that the power dynamic inherent in the NZSM's relationship to the Wellington jazz community is not restricted to the influence it may exert over students, but in fact pervades the community in subtle, yet potent ways. Musicians are cognisant of the role the NZSM plays as employer; and in a small, tightly knit scene like Wellington it pays not to bite the hand that may one day feed you. In the Introduction I outlined some of the ways my own role(s) at the NZSM have affected my investigation; it is quite possible that in some ways I remain an "insider" in terms of the school, through my historical connection with it and the fact that my doctorate project has been conducted under its auspices. In a sense it is near impossible to divest myself completely of my connection to the school; and so I acknowledge, as in the Introduction, that some of the responses I have received when discussing the NZSM have been coloured by that connection.

Yet that proves the point, by illustrating the ongoing dynamic in Wellington, in which the NZSM is a dominant force by virtue of the various roles it plays. Operating within a compact local scene, the NZSM jazz programme thus exerts power via both its pedagogical approaches, and through its role as employer (or potential employer). This in turn illustrates the many ways the school impacts the lives of the musicians in the Wellington community: in determining one's validity as a jazz musician, through the assessment of a student's performance against pedagogical ideals; in establishing an aesthetic which defines acceptable jazz practice; in defending that aesthetic through the invocation of commercial considerations; in championing various approaches to jazz, most of which valorise the American tradition; in promoting the importance of versatility, which arguably characterises the Wellington community (and scene) as much as any other single factor; and in playing down the importance of critical reflection in ongoing practice.

\section{Summary}

Key to the local context, then, is that the NZSM is arguably the foundational element of the Wellington jazz scene. It has provided a consistent output of new graduates since the 1970s, 
and many of those graduates remain in Wellington, participating actively in the local community. The success and energy inherent in the Wellington community may, at least partially, be ascribed to the hothouse environment of the jazz school, in which talented musicians interact with active members of the local community, and receive instruction by which the values of the scene are passed on. While the NZSM does focus narrowly on traditional jazz practices and a canonical approach to history and tradition, it also privileges the tools required to operate successfully as a professional performer. Young musicians acquire these tools, and at the same time are exposed to a local jazz community in which versatility, and consequently eclecticism, are highly valued. Importantly, those young musicians receive little contextual or historical information about the music they are studying. As a result, to musicians learning jazz in Wellington, the only context in which jazz may be observed is, by default, that of Wellington itself. This has interesting implications in terms of appropriation and emulation; in a sense, by learning jazz in Wellington, from other Wellingtonians, and contextualising their own performance in Wellington, young jazz musicians are free from considerations of appropriation, ownership and cultural practice (the implications of which will be discussed in Chapter 5).

Such freedom has major implications in terms of Wellington musicians' interactions with notions of identity, authenticity and tradition. The reduction of jazz to a set of practices that can be assimilated through formalised learning and instruction is, as I outlined earlier, commonly critiqued, for creating a system through which musicians are reduced to playing the music of the past, and new creative practices are de-emphasised. Yet it is by virtue of this decontextualisation that jazz in Wellington may generate new meanings: meanings which, while stemming fundamentally from concepts of Americanness, are also unique to the local Wellington and New Zealand context. In Part 2 of this thesis, I examine the generation of these new meanings; as we shall see, while many of the normative practices of Wellington jazz may be traced directly back to the U.S., their existence in this new context may challenge preconceptions of authenticity in a jazz sense, and assumptions about New Zealand identity. The conservatism evident in the NZSM curriculum has not necessarily hindered the Wellington jazz community in its creative practice; new music is created regularly in Wellington. In a sense then, in the greenhouse environment of Wellington, a small isolated scene with few other major influences (at least in the formative period of 
young jazz musicians' careers), the system may be seen to work; in this way, Wellington presents a challenge to critics of the jazz education model the NZSM employs. And yet the fact that Wellington is a thriving scene challenges the presumptions inherent in the pedagogical model itself. Valorising great American musicians, styles, scenes, and repertoire over local developments ignores the fact that Wellington plays host to a varied and energetic scene. The fact that (until now) it has not been thought worthy of investigation by its own scholars illustrates the dynamic. While postgraduate and faculty projects at the NZSM (and other tertiary jazz programmes around New Zealand) focus on hagiographic examinations and emulations of canonical artists from the U.S., the staff and students who undertake those projects participate in the Wellington jazz community, contributing to a scene which stimulates and inspires them; and in which they may participate in activities which, while artistically rewarding, would not receive official sanction from an NZSM curriculum which focuses exclusively on the canon. 


\section{Interlude: Faubus at the Southern Cross}

In part 1 of this thesis I have described the Wellington scene: the circumstances in which jazz is made in New Zealand's capital city, and the deep connections between the local jazz community and the wider music scene. Through two extended case studies, I have shown the practical and rhetorical environment in which the values inherent in the Wellington scene are established and reinforced, and which has a profound effect on the way that jazz is perceived both by performers and non-performers. Chapter 2 demonstrates the very real effect of this exoticism. Jazz lacks funding, despite being demonstrably as "New Zealand" as any of the better-funded forms of music, because it is still perceived as being an exotic, imported other. The result of that discursive disconnect is a lack of traction for local jazz in policy, media, and government funding. Closely linked to that disconnect are the values inherent in the jazz programme at the New Zealand School of Music, which pervade the community as a result of the school's broad and enduring sphere of influence. The majority of the jazz musicians in Wellington developed in a system which framed jazz as an American art form, and which imported its American values wholesale; consideration of (or even exposure to) New Zealand jazz has played little (if any) role in the NZSM's pedagogical process.

Jazz in Wellington, therefore, is both local and exotic. While none of these factors seem to have prevented jazz musicians in Wellington from establishing a creative and vibrant community, the community is dominated by discourse which itself privileges (sometimes subtly) a hegemonic, U.S. (rather than New Zealand)-based value system. In the introduction to this thesis I articulated some questions, borne of my participation in the community, and the consideration of which led me to this project in the first place. Those questions had to do with identity and context, and were driven by my own experiences as a performer and teacher. Throughout the duration of my investigation I have continued in both roles; and the questions have continued to be relevant. As I have continued to teach classes at the New Zealand School of Music and the University of Auckland, I have encouraged students to consider their own practice in relation to the various contexts in which they operate, and the discourse surrounding jazz in a local and global context. And as 
I have continued to perform with jazz combos, big bands, orchestras, and pop bands, the various issues I have wrestled with throughout my investigation have inevitably led me to question my own practice, and to consider my own identity and legitimacy as a jazz musician.

One performance, which took place at the very end of my project, encapsulated some of the major negotiations I have made over the course of the last few years. In late May 2015 I was invited to play a gig with the Wellington Mingus Ensemble, a big band which has, since 2012, developed a relatively popular following in Wellington. As the name suggests, the Mingus Ensemble plays exclusively Charles Mingus tunes, in a big band format; its founder, bass player Adrian Laird, had until recently, directed the band. ${ }^{111}$ However, as Laird had recently left Wellington to study at the University of North Texas, I was asked to join the band for a gig at the Southern Cross. A quick rehearsal took place a few days beforehand at which we ran through each of the charts in turn, and then we reconvened on the night of Friday the $22^{\text {nd }}$ of May for the gig. The Wellington Mingus Ensemble is almost entirely made up of current NZSM students or recent alumni; as a result, because of my involvement with the NZSM as Programme Leader from 2007-11, many of the members of the band are my own former students, whether directly or as members of the programme I oversaw. If anything, this added to my enjoyment of the occasion, in that I could remember most of the band members arriving as first-years (freshmen), and I had followed their progress and development with interest. With one exception, the band members are in their early-to-mid-twenties; and I was delighted to see an ensemble as large and complicated as a big band created and run by young musicians.

The gig itself was a revelation. The music was drawn from Mingus' more energetic and canonical repertoire: "Haitian Fight Song", "Boogie Stop Shuffle", "E's Flat, Ah's Flat Too", and "Nostalgia in Times Square"; as might be expected, it was relentless and highenergy. Yet it was the audience's reaction, and interaction with the band, that took me by surprise. The atmosphere was electric: the crowd cheered (and occasionally screamed) for each song, and most of the soloists, from the first tune of the night until the last note we played. In turn, the band responded with shouts, energy, and improvisations which mixed

\footnotetext{
${ }^{111}$ Laird originally formed the Mingus Ensemble as a postgraduate project; its success led him to take it on the road.
} 
skill and soul with occasional humour and caricature. The area at the Southern Cross in which the band played was packed with late teens and twentysomethings, who formed an enthusiastic wall a few feet in front of the saxophone section. Audience members danced from the beginning (even starting during the held chord at the very beginning of the gig) until the band put down their instruments at the end of the two-hour set. The repertoire, by and large, was energetic, and the music grooved in the typically heavy way common to Mingus' style. But this was also Charles Mingus' music; dark and grotesque, brooding and soulful: not the type of music with which one might normally expect a crowd of Wellington twenty-somethings to identify.

The second revelation occurred for me in the last song of the night. Introducing the encore, without naming the tune, baritone player Oscar Lavën simply announced "This is an anti-establishment song." With that, baritone sax and trombones launched into the familiar theme from "Fables of Faubus": one of the most overtly political of Mingus' compositions $^{112}$. As it had until that moment, the crowd roared its approval and then continued to dance; and the band applied its considerable musicality and sense of humour to the chart, capping off an exciting night. Yet it was at this point that a number of things crystallised for me, even as I played the bass part along with the band. In playing "Fables of Faubus" at a late-night party-style gig at the Southern Cross in Wellington, the Wellington Mingus Ensemble set up a tension which speaks to the heart of my thesis.

"Fables of Faubus" is one of the most politically charged pieces of music Charles Mingus wrote (although by no means the only one). While many of his tunes carry somewhat oblique titles, Mingus goes so far as to include the Governor's name in the title of this tune; and given that the intent behind its creation is explicit, therefore, it might follow that any performance should bear witness in some way to the context in which it was created (in the same way that the loaded meaning of "Strange Fruit" is widely acknowledged, for example). ${ }^{113}$ While scholars and performers in the field of historical

\footnotetext{
112 "Fables of Faubus" was written to protest the actions of Arkansas Governor Orville E. Faubus, who deployed the National Guard to prevent the integration of a high school in Little Rock, Arkansas, in 1957.

113 "Fables of Faubus" was by no means the only tune the band played that night which Mingus had written with political intent; the set opened with "Haitian Fight Song", about which Mingus said "I can't play it right unless I'm thinking about prejudice and hate and persecution, and how unfair it is... and it usually ends with my feeling: 'I told them! I hope somebody heard me." (Hersch 1998, 110)
} 
performance practice, for example, might devote considerable energy to the determination of the intent behind a particular work, the same is not true of jazz; at least on a piece-bypiece basis, unless a tune carries very specific connotations, the individual creative voice of the performer is at the centre, rather than consideration of the intention of the composer. ${ }^{114}$

As I began to play "Fables of Faubus" in this contemporary New Zealand context, then, I was at the same time wrestling with issues of identity and legitimacy, and reflecting on the way that the Wellington context, its location, and its pedagogy, have created an environment in which one meaning may be so readily exchanged for another: the first relevant to the creation of the tune, and the second relevant to the context in which it is being performed. Chapter 5 examines this phenomenon in more detail, through considering the contextualisation of jazz in Wellington; and through that discussion I attempt to answer the questions of relevance which I raised in Chapters 2 and 3. Can a recreation, in Wellington, of the jazz of another context, be relevant to Wellington? What are the tensions which are created and how are they resolved? Does the recreation, of which I am a part, contain some element which is distinctively of Wellington? Given the band is made up of New Zealanders, their solos are improvised here, and the music obviously touches its local audience, is this New Zealand jazz? Or does this illustrate the reason why jazz is most often considered "other" - that it is clearly and obviously derived from elsewhere ${ }^{115}$ Is the influence of the New Zealand School of Music (all but one member of the band are alumni) visible here, in terms of both instrumental proficiency, and decontextualisation?

Before I tackle those questions, however, it is necessary to take a step back, and construct an additional frame through which to view Wellington jazz. The example drawn from the Wellington Mingus Ensemble performance, in which I was an enthusiastic participant, performs two functions. Firstly, as I have outlined above, it demonstrates the tensions inherent in a local Wellington band reframing music which is clearly connected to a different cultural context. And secondly, in demonstrating such issues, it highlights questions of legitimacy. Is it legitimate for Wellingtonians to play this music? Given the

\footnotetext{
${ }^{114} \mathrm{~A}$ prime example of the difference between composer's and performer's intent is the development of John Coltrane's "Giant Steps" from a study in chord-scale relationships to a vehicle for displays of virtuosity; David Ake $(2002,112-145)$ provides a detailed assessment. ${ }^{115}$ The provenance of the repertoire of most New Zealand orchestras notwithstanding.
} 
original context in which the music was created, and Mingus' reasons for doing so, should local musicians refrain from playing it? This path leads quickly to difficult, and fundamental, questions: as Travis Jackson suggests, "what is arguably at stake is legitimation: who can rightfully lay claim to jazz and on what grounds?" (T. Jackson 2012, 24)

While the "Fables of Faubus" example is particularly striking, it illustrates the fundamental issue confronting Wellington jazz musicians, and which I have alluded to throughout this thesis. Jazz in Wellington (and New Zealand) takes place in the face of a range of discourses which essentially suggest that it is invalid or "other". Jazz discourse globally focuses on "big-J" jazz, the vast majority of which is based in the U.S. The term "jazz" itself is modified only when jazz outside the U.S. is discussed (compare Ken Burns' Jazz (2000), and Ted Gioia's The History of Jazz (2011), both of which deal exclusively with jazz inside the U.S., ${ }^{116}$ and the various books and articles describing "European jazz", "Japanese jazz", and, of course, "New Zealand jazz"). The standard repertoire of jazz is almost entirely American, as are its major figures. Even the language of jazz ("cool”, "soul”, "blues", "woodshed", "swing", for example) is imported from the U.S. And while scholarly and literary attention is being paid to jazz in locations other than North America, there has been next to no work on jazz in New Zealand. As we have seen in Chapter 3, the curriculum of the New Zealand School of Music jazz programme reinforces this perspective, through the privileging of American voices and narratives. ${ }^{117}$ The result is that, in discursive terms, New Zealand jazz does not exist; and if discourse represents that which is worthy of discussion, then New Zealand jazz should not exist. On the other hand, the discourse around both music in New Zealand and "New Zealand music", as I describe in Chapter 2, privileges an aesthetic of New Zealand-ness; jazz, via its portrayal as "other", fails to connect with that aesthetic, and is therefore, again, unworthy of inclusion on those terms. As a result, a band of New Zealanders playing "Fables of Faubus", or any other Mingus tune, would ordinarily find itself included neither in the discourse on jazz, nor in the discourse on New Zealand music. New

\footnotetext{
${ }^{116}$ Gioia does mention jazz in Europe, but (save for two pages on Django Reinhardt) only through the lens of (visiting) American musicians.

${ }^{117}$ I should be clear that while I embrace the "big-J" jazz created in the U.S. as inspirational and aspirational, the issue to which I am pointing is not a lack of equality of representation between New Zealand and U.S. jazz, but the absence of any representation of New Zealand jazz in the discourse.
} 
Zealand jazz musicians are therefore faced with a loss of identity and legitimacy, in relation to both discourses.

The solution to this conundrum, to musicians in Wellington, is authenticity. Where legitimacy is brought into question by the discourse, the concept of authenticity, through its relationship to tradition, provides the credentials by which musicians may establish their right to play. As we shall see in Chapters 4 and 5, in a situation in which jazz has become decontextualised, an authentic performance in Wellington (which may be defined in a number of ways) may both reconnect jazz to its original context, and connect it to its new, contemporary Wellington environment. This dual recontextualisation takes place through the invocation of tradition and the assertion of identity, and we shall see through a number of case studies the way that the process results in a valid form of self-expression, which transcends contextual differences. 


\section{Part 2: New Contexts, New Meaning}

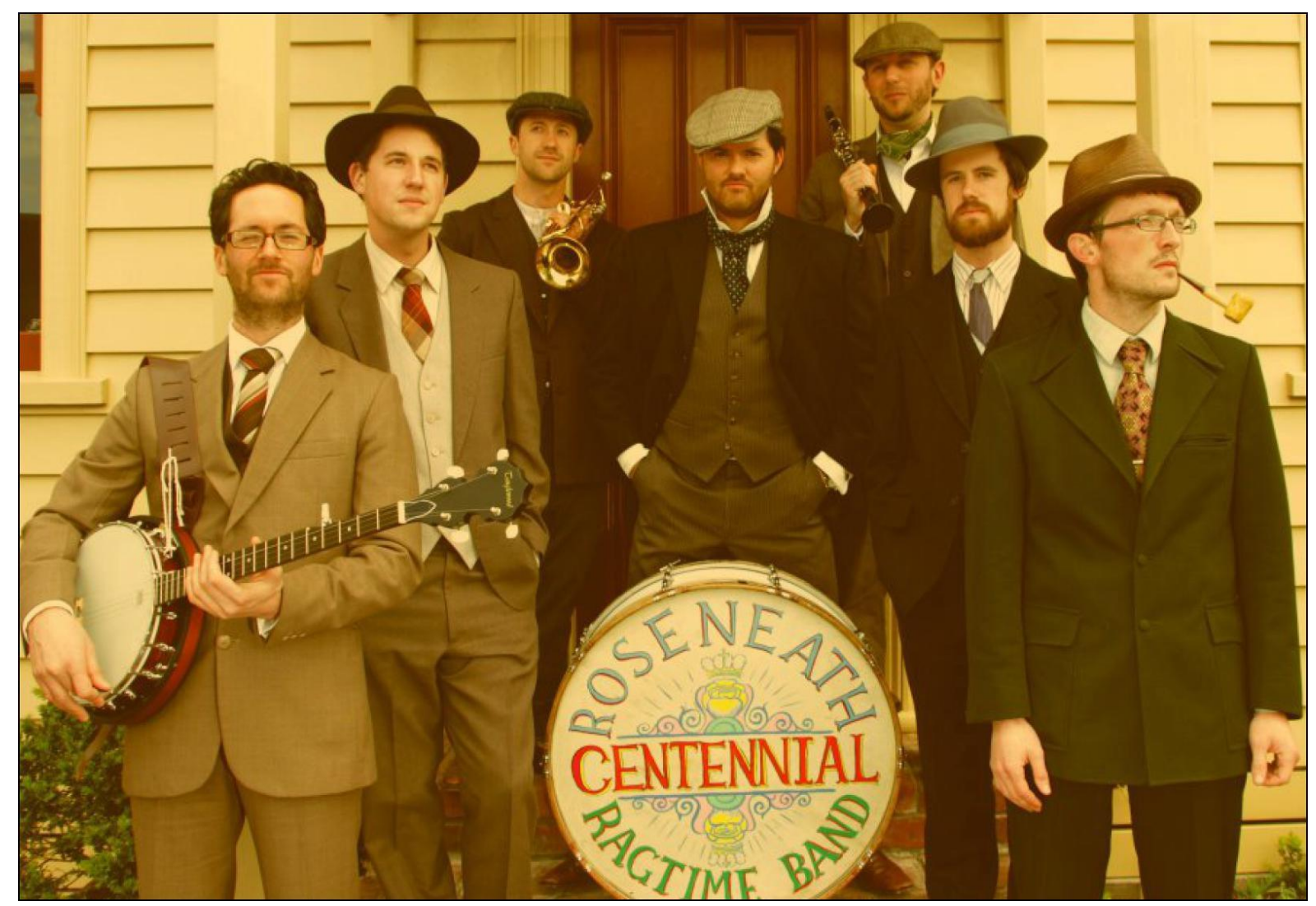

Fig. 5: The Roseneath Centennial Ragtime Band of Wellington, pictured in c.2014. 


\section{Chapter 4: You got to know to understand: the problem of authentic jazz performance ${ }^{118}$}

As we have seen through representations of jazz in Wellington in the contexts of education and performance, there is a disconnect between New Zealand (musical) identity and jazz. In a marginalised jazz community like that in Wellington, therefore, establishing a connection to wider jazz culture is of utmost importance in the forging of that community's sense of identity. Faced with rhetoric which implies that their practice is somehow of less consequence than that which takes place in the centres of jazz (wherever they are), one's natural reaction is to defend oneself and one's practice; and to establish oneself as worthy of inclusion. In Wellington, that defensive posture, while not overt, leads to the invocation of authenticity as a legitimating strategy.

The concept of authenticity has generated much discussion (Taruskin 1988), yet it remains central to the values of the global (and local) jazz community. While it is a truism that jazz, as an improvisatory art-form, allows its practitioners the opportunity for selfexpression, that self-expression is governed and categorised by reference to various frameworks. The more obvious and heavily discussed frameworks within the jazz community tend to be practical in nature: issues of style and repertoire, for example. But more abstruse, and yet arguably as integral to the art form, authenticity (and the related notions of identity and tradition) is still present as a frame within jazz discourse, relating to jazz practice in a number of ways. As Jackson points out $(2012,24)$, at stake is legitimacy, and the right to claim authority in jazz: the concept of authenticity adds value to the practice of those who are authentic, by casting their practice as ideal.

The tropes of authenticity, identity and tradition are used both as lenses through which to evaluate jazz, and as concepts to which to aspire. Although they might at first seem fixed, the concepts are highly mutable: they are heavily dependent on one another, and on the context in which their relationship to jazz practice is assessed. In the eyes (and ears) of Wellington musicians, authentic performance may be, on one hand, a demonstration of the performer's knowledge of the jazz tradition, which thereby establishes the connection of that performer to the tradition. On the other hand, authentic representations of New 
Zealand-ness through performance may connect the musician to the discourse of New Zealand music. Through performing jazz "authentically", (in one or more of the ways described below) a musician may counter the marginalising effects of discourse. As we shall see, these two authenticities may appear to be in competition; yet they are not mutually exclusive.

In this chapter, I address the impact of these tropes on jazz practice writ large, and on the Wellington scene in particular. I examine various concepts of authenticity and tradition, and the way that the discourse presents a culturally exclusive version of jazz practice; but I also suggest ways in which the same concepts, interpreted in a different way, may in fact allow Wellington jazz musicians to claim a place within the jazz tradition.

Authenticity and tradition are myths; they are each constructions which, as we shall see, often serve ideological purposes. Yet despite their constructedness (or perhaps because of it) they are central to Wellington jazz musicians' notions of identity. In this chapter I consider them as such; and I draw on both my own experience and the many conversations, formal and informal, which I have had with local musicians, in which the gravitational force(s) of authenticity and tradition have been clearly evident. In the context of this discussion, then, I portray these concepts from both insider and outsider perspectives. In practice, this means that I simultaneously accept and question notions of authenticity and identity, examining their ideological foundations from the outside, while discussing their importance to the community from the inside.

The argument I trace through Chapters 4 and 5, then, is both critical and uncritical. Firstly, by deconstructing the authenticity concept, I in turn illustrate and examine its construction in a broad jazz context; and secondly, by accepting, and to some extent reifying (for the purposes of discussion) the myth of authenticity, I illuminate and illustrate local responses to it. Broad statements (especially relating to authenticity, tradition, and AfricanAmericanness and Americanness in jazz), which appear to essentialise (and/or mythologise) issues pertaining to the argument, are drawn from my ethnographic work, in that they represent the perspectives of a majority of the local musicians with whom I have communicated; they are used deliberately in order to illustrate and illuminate attitudes within the community, and the implications of those attitudes in terms of the values of Wellington jazz musicians. 


\section{Authenticity}

To many authors, commentators and musicians, authenticity is the ultimate measure of value in jazz practice. Yet, as Atkins points out, the concept of authenticity itself also takes many forms, and can be judged in a variety of different ways: "it is so malleable a trope that each author can and does construct a plausible definition appropriate to virtually any historical or artistic subject." $(2001,23)$ Indeed, the authenticity concept appears across the social sciences, as well as in discussions outside the academy, where it informs ideas including group identity and self-expression. Authenticity appears in multiple guises, and may be characterised as sincerity, realism, faithfulness, or correctness: a mode of action or manner of being which is not "morally tainted" (Lindholm, The rise of expressive authenticity 2013). Philosophers including Heidegger, Nietzsche, Sartre and Camus cast authenticity as the exercising of free will in the service of self-realisation; "a dynamic process of endless becoming in a changing society and world" (Yacobi 2015). Yet such a quest is necessarily complicated by the need of the individual to interact with that world, whether (or both) in contrast to it, or as a functioning part of it. To Rousseau, such a contrast reflected well on the authentic individual, who rose above restrictive society to find true selfhood; but for Goethe's character Werther, self-realisation had tragic results, illustrating the taxing dichotomy between authenticity, or internal reality, and external reality.

Authenticity in these contexts has thus historically been one side of a dialectic, in which self-integrity is placed in opposition to externality. But as Lindholm (2013) also notes, there is a collective, externalised notion of authenticity. Jolly (1992) and Lindholm (2002), among others, note that the colonialist perspective, in contrast, characterises authentic primitive societies as pristine and unsullied, and authentic practice as unexamined and unselfconscious. Authenticity, in this context, is the romanticised manifestation of some cultural essence, which, when polluted by contact with an external culture (usually Western), loses that authenticity by virtue of its adoption of extra-cultural elements. While such notions have been deconstructed more recently in postcolonial anthropological scholarship, they are nevertheless still prevalent in non-scholarly discourse. The contrast is interesting: on one hand, Western philosophical ideals of authenticity revolve around 
personal freedom and self-actualisation; yet at the same time, they valorise unselfconsciousness, and/or resistance to change.

The moral and value-laden authenticity concept is still very much an issue in contexts as different as heritage studies, journalism, and art, and it has deep implications for Western music. The Western artist is pulled in a number of directions by the concept of authenticity, which necessitates faithfulness to the intent of the composer, to historically correct performance, and to one's own artistic self. For a performer, these clearly come into conflict: music is expression, but expression of what, or perhaps more importantly, whom? Is it possible to express oneself with integrity, while remaining faithful to the intent of the composer, or to a system or mode of performance which was current decades or centuries ago?

Richard Taruskin famously dismisses "the false belief that authenticity can derive only from historical correctness" $(1992,311)$, revealing (as Scott DeVeaux (1991) did in a jazz context) the constructedness of tradition and history, and their resulting unreliability as sources of historical (read authentic) truth. His complaint against the notion of authenticity in historical performance practice relates to the sacrificing of personal artistic agency at the altar of a perceived, yet inevitably inaccurate, tradition, or the elusive (and, if the composer is no longer living, constructed) notion of composer's (rather than performer's) intent. Yet in promoting artistic agency among performers, Taruskin is arguing for the notion of authenticity as it applies to philosophical notions of self-realisation; the fact that the term is so often used in relation to historicity belies this more personal sense, in which the artist's intent is paramount.

“Do we really want to talk about authenticity any more?" Taruskin sighed in 1995, lamenting the persistence of the term in historical performance practice contexts. However, while Taruskin may complain about the use of the term, as any regular consumer of classical music will recognise, authenticity as a concept is still very much a factor in classical music performance. Authentic performance remains linked to hierarchical notions of the composer (or, in their absence, the urtext) as the ultimate authority, from whom all creative 
decisions emanate, ${ }^{118}$ albeit with a certain amount of leeway for artists to 'interpret' works through the application of their own personal artistic signature. The authority of the composer devolves to the authentic performer; and in a circular fashion, one who has achieved authenticity of performance or interpretation in turn earns the right to judge authenticity in others. In this way authenticity is a politics of power, in which value and legitimacy are ascribed to an authentic performance, work or performer, based on criteria which are in turn set by those who are deemed 'authentic'. The authenticity of the performer, then, is judged by external standards, based on the (perceived) will, and/or the context, of the composer.

In discussing the concept of authenticity in the context of the historical performance practice of classical music, Peter Kivy $(1995,7)$ approaches it from both directions. He proposes four authenticities, relating respectively to the composer's intention, the performance practice extant during the composer's lifetime, the sound as it would have been heard and produced during the composer's lifetime, and the performer's own identity (in other words, eschewing derivativism); he classes the first three as "historical authenticity", and the last as "personal authenticity".

Authenticity in the context of jazz performance is similarly nuanced. In his examination of the "authenticity complex" in Japanese jazz, Taylor Atkins (2001, 24-5) analyses authenticity in jazz as carrying significance on two levels. To be authentic as a jazz improviser, one must be true to oneself; one must authentically represent one's identity as a performer (or, as Small $(1998,134)$ might suggest, an idealized version thereof). On the other hand, authenticity in a jazz performance context is often contingent on the inclusion of a set of normative performative elements, or of faithfulness to the sound, style, or approach of a particular artist or stylistic school. That a normative perspective exists as a powerful determinant of value in jazz owes much to the historicisation of jazz as described in Chapter 3, through which jazz gained (and has maintained) its position in the academy (and, tellingly, as "America's classical music").

\footnotetext{
${ }^{118}$ As per Christopher Small's deconstruction of an orchestral concert, in which he describes the quasireligious, ritualistic adherence to performative norms, through which the dead composer as creative genius (and to a lesser extent the live conductor as interpretive genius) is celebrated.
} 
The tension between the two authenticities, as a result of which an artist is both expected to uphold tradition and express their individuality, echoes Ralph Ellison's assessment of identity in jazz:

...each solo flight, or improvisation, represents... a definition of his identity; as individual, as member of the collectivity and as a link in the chain of tradition. Thus because jazz finds its very life in improvisation upon traditional materials, the jazz man must lose his identity even as he finds it. (Ellison 1953, 234)

In a discussion on the jazz tradition, Travis Jackson $(2004,360)$ outlines the middle ground, in which successful personal expression in a jazz context is dependent on assimilating and building on the tradition. Such a dualistic perspective is common in both jazz scholarship and jazz education, and, interestingly, illustrates and elides the two Western concepts of authenticity above: on one hand, personal agency and self-realisation is foregrounded, yet on the other the purity of the tradition must be maintained. The result is a kind of circular logic: for a performance to be of value, it must display its relevance to the tradition, which is a determinant of value by dint of its durability and pervasiveness, which itself is a result of its status as arbiter of relevance.

Yet for jazz musicians such as those from Wellington, who bring alternative perspectives or frames of reference, ascribing importance to concepts of authenticity may be problematic. The pursuit of authenticity of self-expression within the context of an expressive form, the authenticity of which is dependent on normative elements which much first be assimilated and therefore superimposed on that self-expression, presents a conundrum: as Ellison's analysis implies, the negotiation between jazz and New Zealand identities is not a straightforward one.

Further complexity, which is yet helpful in parsing out this conundrum, is added by Allan Moore's article (2002), in which he distinguishes between first, second, and third person authenticity. First person authenticity, in Moore's definition, is characterised by terms such as "honesty" and "unmediated expression" (212); as Atkins suggested, performing first person authenticity involves being true to oneself. Yet, like all forms of authenticity, this can easily be constructed; a performer can affect certain mannerisms or performance or recording techniques which convey emotion or other paramusical 
information, which may be interpreted by the listener as real, and therefore "authentic". Moore cites raw-voiced singing and low-fi punk performance as examples of first-person authenticity, which is often tied to the notion of primality (213); this has a clear equivalent in jazz, ${ }^{119}$ where primality is often celebrated by reference to concepts such as creative flow, funk, and the blues.

Moore's second person authenticity exists in the binary distinctions between mainstream and alternative, in combination with the insider / outsider dialectic. The 'second person' refers to the listener, in contrast to the performer. A performance that is authentic in second person terms "convey(s) the impression to a listener that that listener's experience of life is being validated, that the music is 'telling it like it is' for them." (220) The listener identifies with the performance, because the elements within it reflect back on them. Thus the meaning of the performance is appropriated: the authenticity of the performer is transferred to the listener, in the process reinforcing the projected identity of the performer. (219) Moore cites 1980s guitar rock as providing a contrast to mainstream synth-based pop, and, via the perception of the guitar as an instrument accessible to the majority of listeners, as a "metaphorical escape to a pre-modern communitarian ideal" (ibid).

Moore's third person authenticity (214) refers to the type of authenticity invoked by musicians who adopt the style of others (the 'third person', neither the performer nor the audience) and subsequently present it as "authentic". They thereby present dual authenticities: the authenticity of self (first person authenticity), and the authenticity of the original artist. The music transcends identities; as Taylor (cited by Moore) points out, it "must be both timeless and new" $(1997,28)$. For this to work, the music must exist separately from both; yet this is at odds with first person authenticity, which, presumably, must exist for third person authenticity to inhere. The two therefore exist concurrently: the authenticity of each performer (original and subsequent) both competes with and validates the other.

\footnotetext{
${ }^{119}$ Alan Moore (2002) and Hilary Moore $(2007,53)$ cite Tim Taylor's (1997) typonomy in discussions of primality as authenticity.
} 
Moore's typonomy, and those of Kivy and Atkins, share various commonalities. Most importantly, authenticity is a construction, and is therefore wholly subjective; it is perceived by performer and audience, but is not inherent in any particular performance or action. Yet despite this, and despite Taruskin's entreaties above, it carries a great deal of weight in artistic communities. Hence I consider it in my analysis; as a concept of value in the Wellington community, and in the jazz community more broadly, the quest for authenticity, in a number of forms, sits behind many of the artistic choices of Wellington jazz musicians. Secondly, authenticity is closely connected to identity, whether that is the identity of the performer, the listener, or the original performer, as perceived by both performer and listener. When a performance invokes, evokes, or otherwise connects to one or more of these identities, that performance is in some way authentic.

Crucially for the discussion which follows, in the analyses of Kivy, Atkins, and Moore, authenticity is perceived / constructed both internally and externally in relation to the performer. Authenticity is always in the eye of the beholder; but it may present as adherence to normalised performance practices, or as faithfulness to one's own inner vision (to borrow from Stevie Wonder). In order to explore the notion of authenticity in jazz performance, as it relates to the Wellington community, I adapt and elide concepts of authenticity from Kivy, Atkins, and Moore, in light of my own experience as a jazz musician in Wellington, New Zealand. I broadly theorize 'inward' and 'outward' authenticity. 'Inward' authenticity is derived from Kivy's 'personal authenticity', and Moore's first person authenticity; it may best be summarised in the term 'self-expression'. 'Outward' authenticity is derived from Kivy's second and third authenticities (and, in this context, loosely from the first) and Moore's second and third person authenticities. It is the concept of authenticity found in historical performance practice and covers bands; in this context it relates to an adherence to the 'tradition', or accepted norms of jazz performance. 'Inward' and 'outward' authenticity are linked, but do not necessarily correlate, and they carry quite separate connotations; as we shall see, it is possible to have one without the other. 


\section{Outward Authenticity}

The concept of 'outward authenticity' in jazz refers to those outwardly visible or audible elements which connect a jazz performance to standardised, or 'traditional' notions of jazz practice. They might range from what Sherrie Tucker refers to as "eager definitions... (jazz is improvisation; it must swing; it is noncommercial; it is played on these instruments and not these, and so on) all of which have been debunked at one time or another in both old and new jazz studies" $(2012,169)^{120}$ to more tightly circumscribed representations of the style of particular musicians, but what is common is that they are externalised; and that they derive from commonly (though not universally) accepted, sometimes dogmatic representations of what jazz 'is', or more importantly, 'should be'. The fact that they derive from jazz history confers on them the same moral weight and value judgements as one finds invoked in the discourse of historical performance practice, and in each case judgements are made against the backdrop of a constructed tradition. Indeed, the historicisation of jazz practice reflects a similar preoccupation with notions of re-creation as authenticity. As we have seen in Chapter 3, in the context of jazz education, historical jazz performance practice has become highly codified ('repertoire combo' classes at the New Zealand School of Music, for example, convey notions of authentic performance via a modularised approach focusing on the practical application of stylistically appropriate techniques: essentially, how to play Dixie, swing, bop, etc).

Interestingly, such codifications, alongside developments in jazz since the 1980s, which involved a retrospective approach to style and instrumentation, have pervaded jazz culture to such an extent that the question "what is jazz" might well be answered in reference to conservative, historical norms. Indeed, the concept of outward authenticity depends on a conservative approach: the act of defining something, even by implication, sets up boundaries, which in turn exclude some practices as 'not jazz'. In this conservatism, outward authenticity in jazz is again homologous to historical performance practice, which, by definition, looks backwards. The "battlefield" to which Taruskin refers (1988), on which debates over authenticity in historical performance practice have been fought, has its

120 Tucker's chapter, of course, is published within Jazz/Not Jazz: the Music and Its Boundaries (Ake, David; Garrett, Charles Hiroshi; Goldmark, Daniel (eds.) 2012), which is entirely devoted to discussion of the changing definition of jazz. 
equivalent in the debate over the nature and provenance of jazz (Evans 2000, 1-10). While scholars have learnt to avoid essentialised descriptions, ${ }^{121}$ that reluctance to nail one's colours to the mast has left a vacuum, which is filled, ironically, by essentialised, inherently conservative descriptions which focus on broadly accepted traits borne of tradition.

In a Wellington context, then, the notion of authenticity as defined outwardly is closely tied to notions of traditional practice. Jazz musicians may aim for authenticity of appearance (as in the Richter City Rebels, who wear New Orleans fancy dress in Wellington, or bands who evoke 50's cool through the adoption of suits or even tuxedos); they may strive for authenticity in terms of sound, whether through the use of "period" instruments, strings, mouthpieces, amplifiers, or microphones, or through strict adherence to conventions of instrumentation (double bass instead of electric bass, acoustic grand piano as opposed to upright or electric piano). Authenticity may be counted in terms of repertoire or arrangement: the commonly reproduced head arrangement of the 1958 Miles Davis version of "Autumn Leaves", for example, or the introduction to Wes Montgomery's 1962 "Full House", both of which are reproduced on a regular basis by aspiring and accomplished jazz musicians alike. More subtly, outward authenticity may take the form of "channelling": a singer emulating Billie Holiday or Louis Armstrong, perhaps, or a guitarist adopting the style of John Scofield, Pat Metheny, or Kurt Rosenwinkel.

Outward authenticity overtly links a performer to the jazz tradition, thereby lending their performance greater legitimacy (if Charlie Parker did it, it must be right), and demonstrating their dedication, both to the musician or style in question, but also to their own craft. It is the sort of authenticity often connected to jazz education; the kind of "interpret(ation), translat(ion), codif(ication), and communicat(ion)" referred to by Atkins (himself referring to Bourdieu (Atkins, Blue Nippon: Authenticating Jazz in Japan 2001, 245)). In a similar manner to historical performance practice, it imbues externalised gesture with meaning; in these terms, a performance is judged on how much it sounds (or even looks) like accepted, canonical notions of jazz. But outward authenticity presents a double-

\footnotetext{
${ }^{121}$ Indeed, scholars' definitions of jazz may be somewhat oblique: Travis Jackson, in Blowing the Blues Away, (2012) defines jazz for his purposes as the jazz "mainstream"; the kind of music played by certain radio stations in New York City, and not by certain other radio stations, which excludes styles such as smooth jazz, free jazz, and jazz rock fusion. Others simply imply a definition: neither DeVeaux and Giddins in Jazz (2009), nor Heble and Wallace in People Get Ready: the future of jazz is now! (2013) define jazz, for instance, but their field of reference may be inferred via an overview of their subject matter.
} 
edged sword. On one hand, many definitions of jazz do rely on external measures as descriptors, by which to assess how "jazz" an artist, tune, or genre is. On the other, musicians who are seen to privilege outward authenticity over inward authenticity may be subject to charges of derivatism; adopting in a wholesale manner the outward elements of jazz of a particular type suggests that a musician has sacrificed their own identity. ${ }^{122}$

\section{Inward Authenticity}

In contrast with outward authenticity, inward (personal) authenticity is what would determine whether a musician who, on the surface, appeared to fulfil all the requisite criteria of a jazz performer, was in fact performing authentically. Atkins (ibid., 25) highlights the centrality of personal authenticity to "superlative jazz performance", while acknowledging the strength of concepts like "national authenticity" and "ethnic authenticity" in determining authenticity more broadly, given that they are easier to judge. I am sure that neither Jackson, nor other commentators like Marsalis, Stanley Crouch or Amiri Baraka, would assume that such a musician was authentic based only on the outward facets of their authenticity; the hidden, inward factor, then, is crucially important. ${ }^{123} 124$

And yet inward authenticity is tremendously difficult to quantify, or to judge. Discerning whether a musician is playing with integrity is next to impossible, given that the issue depends on what lies below the surface. To a point, any musician who is improvising is allowing their inner self to determine the direction of the music; yet improvisation does not automatically indicate authenticity. It is a slippery concept, yet one which is of crucial importance to the musical (and moral) weight of a performance. A jazz musician must, through performing, reveal something of their identity; given that inward authenticity

\footnotetext{
${ }^{122}$ Atkins $(2001,38)$ discusses the discomfort felt by Japanese musicians when, as a result of stylistic similarities, they are billed as the "Japanese version" of great American artists.

${ }^{123}$ I will discuss issues of ethnicity and nationality in relation to jazz in a later section.

${ }^{124}$ It is interesting to consider this notion in relation to classical music, and the primacy of the composer over the agency of the performer. As I noted earlier, while classical performers are permitted leeway in their interpretation of a work (and, indeed, given the notes are most often not in question, that interpretation is restricted to elements such as tempo, dynamic, and phrasing; a wholehearted display of personal / inward authenticity, or autonomy, on the part of the performer would result in an inauthentic performance by the standards of the work.
} 
constitutes the representation of the self, by that criterion a player who recreates an improvisation, or who plays in the style of another musician, lacks integrity ${ }^{125}$. It is not enough to simply produce a unique improvisation; each performance, to be authentic, must demonstrate that the musician is applying something of themselves, of their experience and identity, to the music. Technique, execution, skill, and method are secondary. Practical considerations are but a means to an end; what matters is that the performer is communicating at a deep level.

Yet how is one to determine whether a jazz performer is in fact, being inwardly authentic, or true to themselves? All listeners have to go on are externalised facets of performance: the notes, the expression, the visible signs that the musician is engaging on a deep level with those around them, while bringing something of themselves to the music. The "greats" of jazz are all acknowledged to have had this ability; it is what made them "great". Writers describe deep engagement in varied terms; Jackson $(2012,151-2)$ describes it as reaching the "next level", in which "every element of a performance seems to fit"; Monson $(1996,139)$ takes a close analysis approach, referring to "taking it to another level", or "intensification"; Hytönen-Ng (2013) borrows the term "flow" from Mihaly Csíkszentmihályi; see also Meehan (2014). Yet it is not clear how much reaching the "next level" depends on inward authenticity, and how much on a confluence of factors including interaction between musicians, and the energy of the audience.

Confusingly, I know from experience as a musician myself that I have given some performances in which I felt creative "flow", yet this was not apparent to the audience (or sometimes even to other musicians); and others in which I felt I was playing nothing of myself, yet with which my bandmates and/or audience connected. From my own experience, therefore, I surmise that inward authenticity can not necessarily be discerned from the outside (or perhaps not even reliably from the inside) in such abstract terms; there

\footnotetext{
${ }^{125}$ Although this is certainly not the case in either classical music or pop music: the whole concept of covers and tribute bands is based on the notion that recreating the music (and costume) of famous artists (thus completely subjugating the inward authenticity of the performer) is a valid and worthy pursuit, and much of the repertoire of major orchestras and choirs consists of re-presentations of well-known works. In opera, originality tends to be the province of the artistic, not musical, director. The contrast was highlighted by the debate surrounding the note-for-note cover of Miles Davis' Kind of Blue, released as Blue in 2014 by New York band Mostly Other People Do The Killing; a quasi-subversive act which raised questions of authenticity and even accusations of plagiarism. (Graham 2014)
} 
must therefore be some reliable signifiers that a performer is performing authentically. While jazz expression is a process, rather than a product, those signifiers do exist; and by and large they are represented in terms, and modes of expression, which are particular to African-American culture. As we shall see, this is problematic for artists who are unfamiliar with that culture.

\section{Authenticity and African-Americanness}

An artist who demonstrates inward authenticity represents something of their own identity through musical expression. Yet in jazz discourse, this representation must be made via modes of expression which are derived from African-American culture, and remain relatively tightly circumscribed (discussions such as those in Ake, Garrett and Goldmark (2012), which consider the boundaries of jazz, notwithstanding). The most highly regarded musicians are those who, while also displaying technical mastery and outward authenticity, demonstrate qualities such as 'the blues', 'the truth', and 'signifyin"; qualities which are as elusive as 'sincerity' or 'freedom', or even 'swing' (especially for non-African-American artists), yet which are considered vital to jazz expression. Norman Mapp (and Betty Carter, and Esperanza Spalding, among others) sang "jazz ain't nothing but soul"; but that leaves us no closer to knowing what soul (or the blues, for that matter) is, or how it may be discerned. How does it feel? Who has it, and how does one get it? Can it be taught? Is it innate?

The connection between jazz and African-American culture remains fundamental to the music's history. Indeed, although jazz has developed and spread across the globe (B. Johnson 2002), the fact that authenticity in jazz is determined by criteria derived from African-American culture remains central to the discourse. Atkins acknowledges the same: "Simply put, it is no mystery that many regard African-American ethnicity as a basic precondition of authentic jazz expression." (Atkins 2001, 25) Commentators such as Murray, Crouch, and Jackson, who link authenticity in jazz to the black experience or a black (blues) aesthetic, imply that musicians or artists who have not lived that experience lack the insight necessary to play the blues, tell the truth, or signify. While this approach has its roots in the Black Arts Movement and Black Aesthetic of the 1960s, it still affects contemporary jazz discourse (as Jackson's advocacy of the blues aesthetic demonstrates). Judgements of 
inward authenticity in jazz are, perversely, rooted in outwardly authentic African-American frames of reference, modes of expression, and methods of processing lived experience. ${ }^{126}$

In Blowin' the Blues Away, Travis Jackson argues that "arguments that, through selective historical interpretation, reduce jazz to technical parameters and render it as a neutral and expansive American tradition are perhaps arguments that paint over AfricanAmericanness to assuage European American anxiety." $(2012,48)$ Taylor Atkins argues that “jazz and other folk or 'black expressive' forms value precisely those human qualities that constitute lived experience: earthiness, funk (bodily odour), pain, anger, carnality, and joy"; a set of qualities established by a "historically despised underclass - whose aesthetic values are then interpreted, translated, codified, and communicated by bourgeois bohemians (jazz critics) who explicitly reject the value system in which they were brought up." $(2001,24-5)$ As a result, it is difficult to establish whether such values in fact remain the province of that underclass, or whether they have achieved (a measure of) universality; if a musician in Germany or Argentina, for instance, adopts African-American values in jazz performance, then, are they being derivative or authentic?

Jackson's 2012 book, Blowin' the Blues Away, focuses on the "Blues Aesthetic" and its centrality to both jazz performance and the understanding of that performance, and wrestles with this very notion of the racial essentialism that seems to underlie any acknowledgement of the impact and influence of African-American culture on jazz style. While Jackson argues that access to the blues aesthetic is not contingent on race but on culture, he maintains that successful jazz musicians (those who are successful in artistic, rather than commercial terms) will either be African-American, or will have been heavily influenced by African-Americans and their culture, quoting figures as diverse as Archie Shepp, Leadbelly, Ralph Gleason, and Rickey "Uhuru Maggot" Vincent, who espouse similar views. This argument depends to a certain degree on the provenance of jazz, and it is certainly not my intention to enter into that debate; while the arguments for jazz as either broadly American or African-American music have been well-rehearsed, more pertinent to

\footnotetext{
${ }^{126}$ The essentialism inherent in such a statement is acknowledged; I couch the argument in these terms as a reflection of the arguments present in the discourse, in which authors including Jackson, Murray (1976), and Baraka (1998) describe jazz in reference to "Black music" or "Negro music".
} 
this discussion is the fact that, in either case, jazz performance and creation still foregrounds African-American cultural practices and modes of expression.

Both Atkins and Jackson imply that authenticity in jazz is achieved, rather than inherited; and therefore that it may be learned by anyone from another culture. Yet both suggest it is easier for some than for others: those with an African-American ethnic background, for example, are more likely to have been exposed to the kinds of cultural practices which underpin jazz expression. Jackson's line of reasoning is self-fulfilling; if a jazz artist is not African-American, he argues, they must necessarily have been influenced directly by African-Americans. Given his field (mainstream jazz in New York City in the 1990s) and sample (a handful of selected jazz musicians) it is likely that there are few artists within the scope of Jackson's study whose influences are not thus. Indeed, the connection between American-ness and African-American-ness goes some way towards explaining the preoccupation with U.S. jazz among the jazz scholars mentioned above. If authenticity (and thus authority) in jazz is reliant on the outworking of a direct African-American influence, then it is no wonder that the scholarship still tends to focus on jazz made in the U.S., in the context of a culture in which a rich variety of African-American influences can be traced.

However, predicating assessments of authenticity in jazz on cultural practices, and the assimilating of those practices via direct cultural contact, as Jackson suggests, fails to take into account those countless practitioners of ("little-j") jazz who have not had the direct contact necessary for such transmission. The implications for jazz musicians in other cultures (Japan, in the case of Atkins, or New Zealand, for example), then, are serious, as we shall see below. To much of the world, jazz practices are foreign, or at least exotic. In order to achieve authenticity in these terms, New Zealand jazz musicians, like the Japanese musicians described by Atkins, are in a quandary of identity; in order to express themselves "authentically", they must adopt practices from another culture, thereby undermining the integrity of their self-expression as New Zealanders. Deviation from those modes of expression, in an effort to somehow more truly represent New Zealand-ness, for example, carries with it the risk that musicians may be labelled "inauthentic" in a jazz context. Tucker (2001/2002) asserts that "while the influences, practitioners, and audiences of jazz have been diverse in all kinds of ways, I would argue that none of them have been free from the profound historical legacy of jazz as an African-American cultural formation developed 
largely under Jim Crow conditions". But to what extent must jazz created anywhere else in the world bear witness to its origin in the U.S.?

\section{Jazz: American or African-American?}

Atkins contextualises jazz in terms of its derivation, noting that it is "regarded as an authentic folk expression of quintessentially American values (although since many regard American values to be universally acceptable, that fact does not necessarily disqualify jazz as a 'universal language'". Yet at a juncture when studies (such as this one) are emerging that examine jazz in a variety of contexts and thus embodying a variety of sets of values, such a definition needs updating. To persist in claiming jazz as either exclusively American or exclusively African-American is to eliminate from the discussion the possibility that as it has evolved within the U.S., so it has done so elsewhere.

The discussion is not new. The notion to which Jackson takes exception, that jazz is an American art form rather than African-American, is a most convenient consensus; although it is, as Horn writes, "an uneasy agreement at best", the concept of jazz as "America's classical music", which "articulated uniquely American feelings and thoughts, which eventually came to transcend ethnic boundaries" (B. Taylor 1986, 21), has nevertheless proved attractive. How else is one to explain the continual presence and influence of European Americans, Native Americans, Asian Americans, Hispanic Americans, and others in jazz, if not by alluding to a universally (and exceptionally) American perspective which informs and is informed by the development and vitality of the music? ${ }^{127}$ Writers such as Ho (1995) and Asai (2005), for example, draw similarities and links between the Asian American and African-American experiences, using jazz as a common method of empowerment in the face of oppression by the dominant European American majority. Clearly, such claims are open to the charge of essentialism; but by the same token, claims that any African-American is privy to a more privileged understanding of jazz given their closer connection to the cultural practices which have underpinned the music from its inception a century ago must be met with scepticism. The adaptability of jazz, which has

\footnotetext{
127 Jerome Harris (2003) problematizes non-African-American involvement in jazz.
} 
driven its evolution from the very start, has clearly allowed for the incorporation of alternative perspectives, to which no one group can hold the key.

And yet the sense that jazz is somehow the province of an exclusive group endures. As authenticity grants those who attain it the authority to judge it in others (Atkins 2001, 24); it gives access to an exclusive community, built on a seemingly innate and occasionally mysterious (to outsiders) claim to knowledge and/or truth. As the apocryphal quote (attributed to Louis Armstrong) declares: "If you have to ask (what jazz is), you'll never know"; students of jazz will be very familiar with the sinking feeling that true jazz expression is somehow ineffable, and that authenticity is forever out of reach.

The quality shared by African-Americans, European American, Hispanic Americans, and the other groups listed above is that they are American. Discussions of ownership, access, and understanding, like the literature more generally, tend to reinforce that regardless of a more specific provenance, jazz remains the province of Americans and American musicians. Whether the site of authenticity in jazz is considered to be the AfricanAmerican body, cultural practices, or understandings, or more broadly American culture, what is clear from the discussions above is that personal, inward authenticity is somehow dependent on outward factors; per the construction of authenticity, certain attributes enable a musician to understand and interact with jazz, thereby conferring the right to play it. Given that much of this discussion takes place within the U.S., musicians from outside that country may be forgiven for two responses: that the discussion renders their efforts irrelevant, and/or that the discussion is irrelevant to their efforts.

\section{American / non-American jazz}

Musicians outside the U.S. must still contend with the persistent perception that notions of authenticity in jazz, as embodied through "big-j Jazz", remains rooted in the United States. Ken Prouty $(2012,164)$ notes that “American-dominated jazz narratives represent a hegemonic force in global discourses", and Eric Porter $(2012,20)$ comments that "recent work on jazz scenes outside of the United States have demonstrated how the Americanness embedded in the practice of jazz has become a touchstone for its authenticity." Evidence 
suggests that Europe, for example, is providing a significant number of both new and interesting directions in jazz, and of performance opportunities for European and nonEuropean artists (Nicholson 2005, 223-42); and data provider Nielsen reports that jazz now lags behind all other genres of music in terms of sales within the U.S. (La Rosa 2015). Yet Ake, Garrett and Goldmark $(2012,6)$, while acknowledging that "geography is (a) significant factor that has helped to define "real" jazz from what some aficionados see as inauthentic practices" (the inverted commas around "real" seemingly acknowledging the arbitrariness of the sentiment), go on to describe the United States' "continued position as arbiter of global jazz tastes", thereby dismissing the authority, the authenticity, and therefore the basic relevance and value, of jazz practice outside the U.S. Whether or not that "position as arbiter" is contingent on the presence and influence of African-Americans in particular is unclear, but the message is not. While introducing a book which deals directly with the boundaries of jazz, the editors consciously eschew the particular boundary of geography, which might present some of the deepest challenges to traditional views of jazz (the authors do, interestingly, acknowledge that the U.S. represents "a perceived establishment against which musicians from other lands might push", yet do nothing to challenge that perception). Two of the most definitive recent works of jazz scholarship, Paul Berliner's Thinking in Jazz (1994) and Ingrid Monson's Saying Something (1996), both operate under the tacit assumption of universality, but neither contains a single interview with a musician from outside the U.S. Scott DeVeaux and Gary Giddins' authoritatively-titled textbook Jazz (2009) likewise all but ignores jazz from any other part of the world, despite DeVeaux's previous work in calling into question the preconceptions inherent in most jazz historiography (1991). The perception that the U.S. is a hegemonic "establishment" in jazz culture, therefore, has merit.

In much of the discourse, then, authenticity remains contingent on geography, or, at least, on the practices of a geographically located community, despite Eric Porter's contention that scholarship has moved on from studies which "assumed too homologous a relationship between jazz (and) American or African-American identities and politics..." (Porter 2012,13) Yet this assumption erroneously conflates the notions of inward and outward authenticity. Jazz in contexts from Tokyo to Copenhagen, for example, may well share aspects of outward expression which are common to jazz, and which act (as noted in 
Chapter 3) as a lingua franca; yet, inwardly, the identities of musicians in those places are surely very different. To insist that those musicians also necessarily share some common understanding of (African) American lived experience, which (according to the discourse cited above) alone confers inward authenticity in a jazz context, is unrealistic. The other alternative is equally unlikely: for musicians, by this logic, to express inward authenticity, they would paradoxically have to discard their own identity.

\section{Identity}

Inward authenticity, despite the discussions above, remains a comment on, and a projection of, the performer's identity. Stuart Nicholson (2005), in examining developments in jazz outside the U.S., takes his cue from Billy Taylor (1986), and dismisses the notion that jazz must retain some form of ethnically or geographically determined content or approach in order to survive intact. Quoting Tony Mitchell, who wrote that "such essentialist notions of authenticity and musical stability 'amount to fixed traditional orthodoxies which fail to account for often radical processes of evolution which musical forms undergo" (Mitchell (1996) in Nicholson $(2005,37))$, Nicholson goes on to warn that "this robs (jazz) of its potential for growth, because when music - or any art form - becomes a refuge from the present, from facing up to the world today, then its force is diminished; it becomes an embalmed corpse, beautiful to behold but ultimately inert." (38) Jazz identities today are necessarily different from those of twenty, fifty, or a hundred years ago: the music has always developed through its major (and minor) figures playing their way. In fact, as we look back from the vantage point of the present day, it becomes apparent that the conditions and factors by which outward authenticity is determined have been created by musicians asserting their identities through inward authenticity. That is to say, while on one hand we judge authenticity in jazz today by holding musicians up to the standard set by the musicians of the past, on the other we idolise those past musicians for the way they changed the music, by asserting their identities in opposition to the commonly accepted norms of jazz practice. Greg Tate, introducing Howard Mandel's Miles, Ornette, Cecil: Jazz Beyond Jazz (2007), perhaps put it most clearly: “(Miles', Ornette's and Cecil's) unteachable, gutsy and rigorous desire to take irrational and absurd risks in the name of stamping jazz with a 
personal sonic signature is the only thing... that the current generation of jazz musicians owes to jazz history and the jazz tradition." (Tate, in Mandel 2007, xii)

Therefore, the tradition of jazz is one of change via the assertion of identity. Discourse and attitudes (however subtle) which restrict "jazz" to that created by one particular group, or in the manner of one particular group, deny its practitioners the opportunity to stamp the music with their own signature. Self-expression that is seen to borrow too heavily from outside sources is dismissed as derivative, or inauthentic: among the worst insults a jazz musician can attract. Clearly, borrowing modes of expression or techniques can easily have this result: a musician playing "in the style of" another runs the risk of such charges. The key is that jazz is both product and process. (Harris 2003) It is the process which must follow the patterns of creativity laid down by generations of musicians: and which must employ a method of transformative creativity using uniquely AfricanAmerican approaches to material, through intertextuality (Monson 1994), signifyin' (Tomlinson 1991) and other methods common to African-American music and literature.

In employing that process in performance, according to Small, musicians "are in effect saying... 'This is who we are.' ...in the context of the performance, who an individual is, is to a large extent who he or she chooses to be or imagines him or herself to be. Who we are is how we relate, and the relationships articulated by a musical performance are not so much those that actually exist as they are the relationships that those taking part desire to exist." (Small 1998, 134) Yet this poses a problem for jazz musicians of cultures based outside the U.S. According to the argument above, New Zealand musicians, it follows, must be articulating a borrowed set of idealised relationships and values, given that the system of authenticity set up in jazz (involving methods of relating to each other, of transformative creativity, intertextuality, and so on) derives from a foreign culture. And the values in question are heavily mediated: many New Zealand jazz musicians have spent little if any time in the U.S., and so they will be articulating values received via a third party (or chain of parties), or through audio recordings, YouTube, DVDs, and so on (see below).

The other possibility is that when playing jazz, New Zealand musicians are, in fact, successfully articulating their own identity, albeit while using a mode of expression derived from an external culture. Certainly, the vitality of the jazz activity in Wellington suggests that there must be some sense of community, of shared values, which underpin the 
extraordinary interconnectedness and cohesiveness of the scene. Playing jazz is, to each of the musicians I interviewed, a central aspect of their identity (although at the same time, as we have seen in Chapter 1, a negotiable one). Yet on whose terms is this the case? To Jackson, Wellington jazz musicians may or may not exhibit the requisite aspects of the blues aesthetic in performance, and presumably may not qualify as jazz musicians on that basis. But Small asserts that "each musical performance articulates the values of a specific social group, large or small, powerful or powerless, rich or poor, at a specific point in its history, and no kind of performance is any more universal or absolute than any other. All are to be judged, if judged at all, on their efficacy in articulating those values." (Small 1998, 133) By this token, any musician in performance is inwardly authentic, in that they are inevitably articulating something of their identity; if that musician is employing aspects of outward jazz authenticity (playing in the tradition, using accepted harmony, employing appropriate modes of creativity), then the requirements of outward and inward authenticity are fulfilled. Distinctions based on the type of identity (inward authenticity) that must be articulated are divisive; what is surely important is the depth of that articulation.

In fact, this interaction of identities is akin to DuBois' concept of doubleness: a notion of composite identity, in which Africanness and Americanness "whirl around each other separate yet one." (Du Bois 1985, 49). A New Zealand jazz musician must negotiate two identities, which (in view of much of the scholarship above) seem mutually exclusive, but which yet coexist. Interestingly, where jazz, across much of the $20^{\text {th }}$ Century represented the self-expression of a minority group in an oppositional relationship to a dominant culture, for New Zealand jazz musicians the negotiation is reversed: in the face of a musical culture in which (African) Americanness is privileged, it is New Zealanders who must now maintain a composite identity, in which being a New Zealander, to some extent, challenges the dominant "jazz" identity.

\section{Creating New Authenticities}

Additionally, the notion of transformative creativity, so central to African-American expression, provides a potential solution to the problem of the non-American jazz musician. 
Jackson's "blues aesthetic" provides an example of a frame in which this mode of creativity is employed:

A blues aesthetic... is the sum of the reflective and normative assertions that musicians have made regarding processes of performance, interaction, and evaluation. In the simplest terms, it is constituted by (learned) practices derived from and continually fed by the interaction between African-American musics and culture and others... Participants in musical events, using a blues aesthetic as a performative and evaluative framework, place a premium on individual expression within established frames for performance and on equally patterned interaction with other performers and participants. Such events are oriented toward each performer "saying something" about how to take the materials at hand... Novelty is not among the primary concerns of the participant motivated by a blues aesthetic; creativity, distinctiveness, and interactivity are. These concerns manifest themselves in the ways in which performers sometimes reinforce and sometimes push against the frames that surround jazz performance. Even more, a blues aesthetic is a statement of an egalitarian, enabling myth of jazz performance, a myth that says that any musician who understands and actualizes the normative criteria can be a good performer. (T. Jackson 2012, 126-7)

If the blues aesthetic is truly egalitarian and enabling, then by employing the concept of creativity described by Jackson (above) and Monson (1994), in which materials and concepts are transformed, and through which performers "push against the frames that surround jazz performers", jazz musicians are given licence to redraw the boundaries set up around jazz (which include, for instance, the blues aesthetic itself). If it is appropriate and traditional to challenge both musical and paramusical preconceptions through the deployment of such creative processes, then surely the projection of new New Zealand identities (and authenticities) through performance is valid. Yet for the authors cited above (and others), the flexibility inherent in jazz from its very conception ${ }^{128}$ does not apply to the necessary centrality of African-American modes of expression in the music itself; that requirement, by this logic, is perhaps the only immutable law in jazz performance.

Turning the creativity inherent in jazz back on itself in this manner is not without precedent. Robert Glasper, for example, overtly challenges the borders of jazz by incorporating R\&B, electronica, and pop harmony; while at times he projects ambivalence

\footnotetext{
128 Jelly Roll Morton remembered "we had so many different styles that whenever you came to New Orleans, it wouldn't make any difference that you just came from Paris or any part of England, Europe or any place whatever your tunes were, we played them in New Orleans" (Walser 1999, 308), and referred to the "Spanish tinge" in his own music.
} 
about the borders themselves, on other occasions he has been vocal in advocating change: "You gotta accept it, that was some bad shit back then. Love it... Now, let's do this. Know what I mean? And move on. And accept... John Coltrane's a human being. I'm a human being. He's not God... You gotta move on... and be great, just like Trane was" (Benevento, et al. 2010). Glasper is himself African-American; given the context of this discussion, a more compelling example (cited by Nicholson $(2005,195-222)$ and Meehan $(2014,211-233)$ ) is the Norwegian saxophonist Jan Garbarek, whose work is heavily influenced by Scandinavian folk melodies, does not swing (in any conventional sense) and, aurally at least, bears little resemblance to African-American music. Garbarek, too, qualifies as a jazz musician under Jackson's definition: he served apprenticeships with the African-Americans George Russell and Don Cherry, thereby receiving jazz wisdom directly. His music is far removed from its jazz origins: yet in Meehan's analysis, Garbarek's music employs the creative strategies inherent in all jazz performance: transformative creativity, the privileging of the individual voice, and improvised interactivity.

So perhaps Garbarek, more than Glasper, represents a jazz musician applying that transformative creativity inherent in the art form to the art form itself (and one who, by Jackson's logic, has the right to do so): Garbarek takes jazz as his raw material, subjects it to a creative meta-process in which he privileges his own inward authenticity over the outward authenticity which might locate it within the jazz tradition, and thus transforms it as a mode of expression. As such, he is one of a variety of European jazz musicians who, since the liberation of the free jazz era, have come to embody a new, "rapidly growing pool of individual, specifically European approaches (which are) now informed by a consciousness of domestic musical traditions"; and in which American "influences" represent only one, disposable, part of the picture. (Hellhund 2012, 437)

Yet the question remains: is it jazz? To what extent may inward authenticity outweigh outward authenticity? Is it more important to remain true to adopted, but normative, modes of practice, or to one's own inner identity? The question is difficult to answer in practice: objectivity is elusive in discussions of identity. Jackson's assertions remain compelling, if only through a lack of contradictory evidence.

But the potential for conflict between inward and outward authenticity, between identity and tradition, remains significant; and especially so for communities far removed 
from jazz's traditional centres. Such communities (located, for instance, in Japan (Atkins 2001), Australia (Johnson (1987), (2000); Shand (2009), or New Zealand (A. Ward (2012), Tipping (2014)), must, through the deployment of strategies including creativity, strategic anti-essentialism (Lipsitz 1994) and identity politics, negotiate preconceptions surrounding identity and authenticity arising from within both the broad jazz scene, and their own local community. I am deeply mindful of such preconceptions as they relate to my own position; the comments I make and the conclusions I reach, in discussions of authenticity and identity and more broadly, are inevitably affected by my own identity. My own development as a jazz musician has much in common with that of other Wellington musicians; thus a detailed examination of the ambivalences in my own history and context may illustrate the dilemma which these larger cultural assumptions force on a jazz musician from a country like New Zealand.

\section{Bringing it Home: my jazz identity}

Discussions of ethnicity, culture, identity and jazz are, as we have seen, rehearsed regularly. They are keenly felt, as they impact on our notions of self. In a sense, while such notions define who we are, they also define who we are not; or perhaps who is not us. They are exclusionary by nature: every identity or socio-cultural community that exists does so in opposition to others. Jazz, by virtue of the hybridity and fusion which has characterised it from its inception, remains an incredibly diverse and catholic art form, yet one whose boundaries are still policed in terms of cultural knowledge and indispensable practices. As my background lies outside those boundaries, and as I remain geographically on the margins, the negotiation of these boundaries remains significant in terms of both my own practice, and my ability (and right) to comment on the issues at all.

I am a New Zealander of European ancestry, who enjoyed a relatively privileged middle-class upbringing in Wellington. As the child and grandchild of classically-trained performing musicians, my own upbringing involved participation in choirs and orchestras, and study of the classical canon: a tradition I found (and still find) rich and fulfilling, and for which I hold a deep love. Forays into barbershop and Christian pop music represented the only serious steps I took into 'outside' music; I studied musicology at Victoria University, and 
it was not until I subsequently returned to university in 1998 to undertake study in jazz performance that I was exposed to jazz in any real or meaningful way. My first jazz performances were under the auspices of the local jazz programme at Wellington Polytechnic and Massey University; my first exposure to jazz history and the greats of the canon was through the jazz history class (taught by Norman Meehan, whose work I have cited above $)^{129}$. In a sense I was the quintessential jazz student, as per the pedagogical model cited in Chapter 3: my education, while life-changing, involved the application of standard, somewhat theoretical jazz approaches to standard jazz progressions, in order to equip me for a broad range of performance situations; an ethos which still characterises much of my performance even now.

Two years of study in the U.S. exposed me to a wider world, but not necessarily to a broader range of approaches. The University of Nevada, Las Vegas, combined a canonical pedagogical approach with connections to the somewhat laid-back Los Angeles jazz community. Concepts of African-Americanness, the centrality of the blues, and the sociopolitical context of jazz were, as in Wellington, not emphasised.

On my return to Wellington, and over the 12 years since, I have found immense fulfilment in jazz performance. My career has developed and broadened, to the extent that from 2007 to 2011 I managed the jazz programme at the New Zealand School of Music (a later incarnation of the Wellington Polytechnic programme I had attended). In that capacity I held overall responsibility for the education of successive generations of Wellington jazz musicians. At the same time I have remained active in the scene, in contexts ranging from duo and trio to big band; to some extent my performing career reflects my education, as I regularly play both original music and "standards gigs", which involve the same standard approaches to standard repertoire that I was taught in the late 1990s. I have also been heavily involved in larger ensembles, which demand a high standard of reading "the notes"; a skill which reflects my upbringing as a classical musician.

So, as a performer, I came late to jazz (my first experience of jazz performance occurred in an academic institution at the age of 21). While I play in a number of ensembles

\footnotetext{
${ }^{129}$ Although the $20^{\text {th }}$ Century music course within my musicology degree did devote one hour to the entirety of jazz history.
} 
which perform original music, I tend towards standard performing situations (vis-à-vis repertoire and context). While I celebrate and advocate for original music, my playing is strongly informed by the classics. Yet if I do employ African-American performative strategies, I do so having learnt them theoretically, and through performing with other nonAfrican-Americans. My preferred listening in jazz is somewhat skewed towards the bopbased artists and styles of the middle of the $20^{\text {th }}$ Century, and to African-American artists; yet by dint of my upbringing, education and location, I can have no first-hand knowledge or understanding of the sociocultural origins of the music. My positionality in this regard is no doubt duplicated by many.

Yet I call myself a jazz musician. My identity is deeply bound up with jazz performance, my relationships to other performers, my love of the music, and my commitment to it. My PhD thesis found its genesis in my desire to investigate this very contradiction. When I perform with my colleagues in Wellington, I have no doubt that we are demonstrating inward authenticity. According to Christopher Small, we are boldly stating "this is who we are" (Small 1998, 134); our performance is an articulation of our values. (133) Yet the "soul" inherent in our performance, the blues aesthetic which must be present in order for it to be truly jazz, must necessarily have reached us via a chain of multiple links. Many Wellington jazz musicians have never visited the U.S.; while I have, I consider my own exposure to such values to have been relatively minimal. Our reception of such information is heavily mediated, and usually purely sonic in nature.

Who am I, then, to discuss the blues aesthetic, notions of ethnicity, authenticity, and jazz identity, in the first place? With little access to first-hand African-American cultural memory and knowledge, my authority to comment on the issues of authenticity above may be called into question. Yet this is exactly the problem; as Atkins notes, authority is conferred by authenticity, which depends on identity. I am aware that challenging notions such as these is therefore a dangerous proposition, and I leave myself open to criticism. Am I (and are my colleagues in Wellington) authentic? Are we, with only mediated access to jazz outside New Zealand, "true" jazz musicians? Or, since most of us learnt how to play jazz at university, and then emerged into the scene to play with others from the same background, are we simply appropriating cultural expression (albeit with the best of intentions)? It is in 
the concept of tradition that the solution to the isolation (geographical and cultural) in which Wellington (and New Zealand) jazz musicians find themselves may be found.

\section{Tradition and Myth}

One of the central organising elements of jazz, tradition provides the diverse developments across its history with a backbone; a framework around which a narrative history, a set of canons (of artists, repertoire, locations, etc.), and a system of authority can be constructed. Indeed, since 1991, construction has been the operative concept, at least among scholars; Scott DeVeaux's landmark essay (DeVeaux 1991) deconstructed the notion of a progressive jazz tradition, instead illustrating the selective process by which a neatly cohesive, linear (if not teleological) narrative has been arranged. Tucker (2012) notes the concomitant rise of jazz academia, suggesting that the construction of a jazz tradition conveniently provided academics with a starting point. Jackson (2012) summarises the development of the jazz tradition concept over the latter part of the $20^{\text {th }}$ Century, illustrating the effect of different perspectives on the construction and propagation of differing versions of the tradition. Indeed, as noted above, Taruskin (1992) argues that traditions must always be constructed: we are only ever privy to a selective or incomplete account of history, which, through transmission, is contaminated (317), and even our own self-histories are constructed, based as they are on selective memory.

However, as any jazz musician, scholar or fan can attest, traditions are powerful constructions; and, constructed or not, they have a significant part to play in the issues above, in that they provide a host environment for mythology. Myths provide a community with a vehicle for communicating exemplary accounts of idealised practice (Humphreys, Ucbasaran and Lockett 2012, 46), (Small 1998, 99). As such, the acting out of a myth (or of the ideals exemplified therein) takes on a ritualised form and function: such rituals are performed to reassure (Small 1998, 119, 215-6), and to reinforce accepted relationships and processes. Historically accurate or not, once a myth is generally accepted, it is often adopted as the gospel truth; as such, myths form a central aspect of tradition. 
Jazz musicians the world over share myths as part of the "jazz tradition". Myths generally contain a moralising element: intended to illustrate some aspect of idealised jazz practice, they are told and retold with quasi-pedagogical intent. Examples such as Coltrane's incessant practising, and the institutionalised approach to his "Giant Steps" progression (Ake 2002, 112-145), Jo Jones throwing a cymbal at the feet of a 16-year-old Charlie Parker, the mysterious Buddy Bolden, and the tortured, volatile genius of Mingus, Buddy Rich and Billie Holiday, all have something to tell us about the way jazz has been, and therefore the way it should be. Often the concept of genius is itself mythologised; the "next level" or "flow" state to which jazz musicians aspire is granted a "proto-heroic" quality (Humphreys, Ucbasaran and Lockett 2012), as in recordings such as Coltrane's A Love Supreme, Paul Gonsalves' solo on "Diminuendo in Blue and Crescendo in Blue", from Ellington at Newport, or Miles Davis' Kind of Blue.

More germane to this discussion is the potential that myths, the practices to which they relate, and the tradition to which they contribute, possess to act as shared cultural knowledge. In this way they provide a means by which jazz musicians from diverse contexts may find common ground; and by which they may feel connected to a greater whole. The significance of this to an isolated jazz community is obvious: with shared cultural knowledge comes a communal identity ${ }^{130}$. Thus, through this shared identity, a jazz community located in Wellington may relate itself to the broader narrative of jazz history, and musicians in Japan may consider themselves participants in the ongoing development of jazz. The "we" in Small's "this is who we are" takes on heightened meaning: given the commonalities, "we" now refers to the performers who share cultural knowledge, in the context of the community, which itself is contextualised within broader and broader frames, until links may be drawn between any two jazz musicians in any locations or time periods on the basis of that shared knowledge. Where aesthetic and authenticity are exclusive contexts, tradition includes. Any jazz musician, by identifying with the tradition, may avail themselves of its cultural and moral weight.

But tradition offers more than moral support; it also has significant potential for driving change. Both Taruskin (1988) and Jackson (2004) describe the value that tradition

\footnotetext{
${ }^{130}$ Tony Whyton $(2010,106-126)$ illustrates the role of anecdote in both mythology and the reinforcement of community.
} 
has as a foundation for development; rather than being fixed, therefore, a tradition is constantly reinvented, not reified. The tradition is a tool by which musicians (and commentators) may add value to (or subtract it from) a performance or performer. And, as in Jackson (2004), the tradition may then act as a springboard for further experimentation; a grounding in the tradition may confer the authority to extend it. In fact, the notion that the nature of the tradition demands that its adherents extend it is commonly cited by progressive writers and performers; like Glasper (Benevento, et al. 2010), and Jackson, Taruskin argues (quoting Grout):

If, Donald Grout wrote some forty years ago, a composer of old music 'could by some miracle be brought to life in the twentieth century to be quizzed about the methods of performance in his own times, his first reaction would certainly be one of astonishment at our interest in such matters. Have we no living tradition of music, that we must be seeking to revive a dead one?' (Taruskin 1988, 141)

Organist Joey DeFrancesco, who I interviewed for this project, sees himself as both heir to a particular tradition, and the principal agent of its extension:

When I play (I) echo a lot of masters, because I studied them all hard... But I play in a way that was never really done on the instrument. As I should, because I have the opportunities to be able to do that. Somebody like Jimmy Smith or some of those guys can't go back, didn't have a body of work of all these cats before them they can go borrowing stuff from, twisting it around, playing it backwards if you want. We're lucky nowadays, there's no excuse... it has no depth if it doesn't have tradition in it. (DeFrancesco 2013)

Thus, crucially for this discussion, the tradition is (to musicians and commentators) a gatekeeper of authenticity, both outward (in terms of traditional performance practice) and inward (in terms of traditional processes of expression). The cultural memory it represents, constructed or not, presents a standard by which the appropriateness (pace Taruskin (1988)) of a jazz performance may be judged. Thus, it provides the criteria against which outward authenticity is measured: if a musician can be seen (or heard) to have internalised the tradition (to the extent that that is possible), then they have earned the right to play the music, by virtue of their demonstrated commitment to it. Hollerbach, using the straw man of "L.C.", an unnamed musician in an unnamed local U.S. scene, reports that "he has assimilated prior musical voices of the jazz past, internalised them, and recast them 
according to a jazz aesthetic that promotes individual expression within a framework of collective musical dialogue and interaction." (Hollerbach 2004, 163) In this way inward authenticity and outward authenticity are both achieved: the musician is achieving true selfexpression, while remaining overtly connected to the ethos and aesthetic of jazz.

To non-American musicians, this provides an alternative to the exclusive notions of the blues aesthetic, or the persistent Americo-centrism of jazz discourse, as a way in to authentic jazz practice. Familiarity with tradition is more easily achieved than the kind of experiential cultural knowledge mandated by concepts and terms such as "the blues" and "soul". Identifying (or aligning one's identity) with the jazz tradition allows musicians in these other cultural contexts to claim authenticity independent of such concepts. They do so via the retelling of myths, the participation in (and understanding of) rituals; demonstration of tradition-based cultural knowledge and practices; and, where possible, invocation of one's direct connections with the "tradition". Familiarity with codified practices such as jazz language, performance structure, and repertoire (while criticised by some commentators), alongside knowledge of central myths and elements of the tradition, provides musicians from widely divergent backgrounds with the opportunity to engage with each other: a lingua franca of jazz practice, which allows the global jazz community to coalesce. ${ }^{131}$

\section{Summary: Authenticity, Identity and Tradition in Wellington Jazz}

For a Wellington jazz musician, partaking in the traditional practices, myths and rituals of jazz culture is the primary method of identifying as a member of the jazz community. Such identification is of strategic importance, on a number of levels: it forms a connection with the global scene, it legitimises the musician's practice, in the context of the local jazz community, and it provides a method of identifying oneself in contrast (opposition) to nonjazz musicians (which has significance in terms of both inclusion in the community, and

\footnotetext{
${ }^{131}$ I can testify to the power of such shared knowledge, having enjoyed impromptu performing experiences with musicians from countries such as Italy, Austria, the U.S., South Korea, Australia, Canada, Cuba, Germany, Croatia, France and Mexico; in many cases, although we did not share a verbal language, we were able to communicate via our shared, learned cultural knowledge of jazz (and its practices).
} 
marketability in a crowded freelance environment). But the variety of approaches in the Wellington community mean a variety of attitudes towards authenticity, and of course, as in the global community, there is not always agreement among musicians as to what constitutes authenticity in a jazz context.

As I have noted above, constant reminders that jazz is an American (if not AfricanAmerican) art form abound in the Wellington scene. In a review of Jazz Jazz Jazz, the main concert of the 2012 New Zealand School of Music Jazz Festival, Colin Morris waxed lyrical about the future of jazz. Referring to a performance of Duke Ellington's “Jeep's Blues", featuring young Wellington tenor player Tyaan Singh in performance with the New Zealand National Youth Jazz Orchestra, Morris proclaimed that "this is as American as culture gets" (Morris 2012); an interesting choice of phrase, given that he was describing a teenage New Zealander, playing with New Zealanders in Wellington to a New Zealand audience. It is more so when one considers Morris was correcting his own assertions that jazz has become more European than American: the implication being that jazz may be an expression of American or European culture, but not of New Zealand-ness.

And the perception is fed by musicians themselves. In the past few years, the Wellington community has generated a number of bands which play music directly evocative of past eras of jazz, employing aspects of historical performance practice: a collection of big bands at the jazz club Meow playing the music of Ellington, Mingus and Basie, sometimes note for note (including the solos); two distinct gypsy jazz bands ${ }^{132}$; a band dedicated to playing the complex music of the San Francisco Jazz Collective ${ }^{133}$; and a Friday evening gig in a hotel bar, playing only the music of Wes Montgomery and Charles Mingus ${ }^{134}$.

The influence of the HBO series Tremé (Simon 2010-13) has, in recent years, led directly or indirectly to a further collection of ensembles which explore, recreate and develop the music of New Orleans, whether contemporary or drawn from the ragtime era. The Richter City Rebels, the Bayou Bros., the Roseneath Centennial Ragtime Band (pictured

\footnotetext{
132 Hot Café and Black Spider Stomp

133 The Jac, of which I am a member; the band has transitioned to playing exclusively original music, but which is still inspired by the San Francisco Jazz Collective.

134 The Nick Granville Trio
} 
in figure 5, p.116), the Uprights, the Wellington City Shake 'Em On Downers, Gold Nugget Pawn Shop, and the Jelly Rolls all use (to differing extents) period instruments and dress, historically accurate methods of structuring performance, and "traditional" musical style to evoke a broadly "New Orleans" sensibility. Much of their appeal (musically, and from a commercial perspective) relies upon the conscious invoking of exoticism; New Orleans, and the ragtime era, are a long way from Wellington geographically, temporally (ragtime), and culturally.

Of course such (re)tellings, which privilege outward authenticity by engagement with the tradition, do not represent the totality of the jazz being played in Wellington; nor do they indicate any absence of inward authenticity. While the strong original jazz community presents a variety of approaches which belie its small size, much of the original jazz being played in Wellington (by musicians such as Reuben Bradley, Lex French, Jake Baxendale, and Lucien Johnson, for example) makes use of conventional jazz practices, in terms of orchestration, structure, harmony, and so on. Yet, like the more tradition-based bands above, and as we shall see in Chapter 5 , they necessarily represent something of the identities of the performers (as I have argued with reference to Christopher Small). ${ }^{135}$

The deployment and invocation of jazz ritual and mythology thus provides Wellington musicians with a connection to the jazz tradition. Thirteen hours by plane from the nearest mainland U.S. city, decades removed and culturally remote from the canonical figures and sites of the jazz tradition, Wellingtonians may nevertheless connect with, and draw meaning from, a powerful external heritage. In this way they construct an identity which is rooted in both the tradition and the present day; in both contemporary Wellington, and the U.S. (and to a lesser extent Europe) of the past century. As a result, jazz in Wellington may itself be considered a hybrid; and the interaction of identity, tradition and context generates new meanings: and it is those meanings which will be discussed in Chapter 5.

\footnotetext{
135 The smaller subcommunity of experimental jazz, which is freer in nature and therefore less tied to convention, presents perhaps the most arguably 'New Zealand' approach, by virtue of its overt rejection of convention; yet, interestingly, they often eschew the term 'jazz' as overly restrictive.
} 


\section{Chapter 5: The song is you: the unique meaning of Wellington jazz}

We don't have that culture here. We don't have anything like that. So-it's like, we need to figure out how to play this stuff properly- know the history I guess. (Ellis 2013)

It can be hard to be a jazz musician and be honest to yourself. The stuff that matters is that you're a New Zealander. (Isaacs 2013)

As Taylor Atkins noted in his introduction to Jazz Planet, "Practically all jazz discourse rests on the premise of American exceptionalism". (2003, xiii) Jazz histories including Ken Burns' Jazz (2000), Ted Gioia's The History of Jazz (2011), and Scott DeVeaux and Gary Giddins' Jazz (2009), and anthologies including The Jazz Cadence of American Culture (O'Meally, The Jazz Cadence of American Culture 1998) portray jazz as the product of a uniquely American context, and its practices, mythology and tradition as remaining deeply connected with African-American experience. That jazz arose in the U.S. is not in dispute (the rapid, parallel development of the European jazz scene notwithstanding); but the phenomenon of the “jazz diaspora" (B. Johnson 2002) or "transnationalism" (Nicholson 2014) has resulted in jazz existing in contexts far removed from those in which it arose. Inevitably, the process of recontextualisation and relocation results in jazz developing new significances in new contexts: Johnson (2000), Atkins (2001), Moore (2007), Ballantine (2012) and Feld (2012) are but some of the scholars who have examined this issue, in locations such as Australia, Japan, the UK, South Africa, and Ghana. Jazz, in coming to exist in a new social context, interacts with that context in different ways, to generate new significance. In this chapter I examine a number of case studies; each demonstrates the recontextualisation of jazz in Wellington, and examines it through the lenses of authenticity and identity which I constructed in Chapter 4. 


\section{New Contexts}

In Wellington (and New Zealand), access to jazz from anywhere else is highly mediated. Much of the music which reaches New Zealand, whether through recordings, video, or live performance, arrives more or less stripped of its social context. It is very difficult to gain an appreciation of the socio-cultural circumstances in which music was made, if the primary source is a recorded performance; the music, in effect, is decontextualized. Swedish musicologist Krister Malm describes this process as "transplantation" (1993, 347-8): a "movement of musical sound in time and space". Reporting the experience of samba and steel bands in Stockholm, Malm reports that "very few of the performers in the carnival bands have actually visited a carnival in Port of Spain or Rio. Their information comes from the media." (349) And the experience of Wellington jazz musicians is similar to those in Britain and Europe between the 1920s and 1950s (as recounted by Nicholson $(2014,53-7)$ ), who largely experienced jazz through the medium of recordings. Musicians in such circumstances must glean what contextual information they can from sources which, by their nature, are extremely selective. The music arrives as disembodied sound, the concepts of which must be extracted and, essentially, re-embodied by local musicians. Ultimately, such musicians must fill the gaps in their contextual knowledge by guesswork and supposition, and / or replace the original meanings of jazz with new, locally derived meanings.

In Wellington, while direct contact with jazz musicians from other parts of the world does occur, it is usually in the form of attendance at a workshop, or concert. Sustained interaction between Wellington jazz musicians and those from further afield rarely takes place, apart from the rare occasions on which international artists work or tour with local musicians (given the prohibitive financial cost involved in bringing artists from other countries to New Zealand, most such artists are engaged by institutions: examples include several major artists touring with Rodger Fox and the Wellington Jazz Orchestra, and others who have given performances and workshops at the New Zealand School of Music; notable extended visits (in other words, visits which have lasted more than one day) to the school have been made by Bennie Maupin (2012) and Rakalam Bob Moses (2013). In many cases, arrangements rely on pre-existing personal connections between New Zealand musicians 
and visitors, which result in repeat visits ${ }^{136}$. On most of those occasions the bulk of interaction focuses on practical musical considerations; it is rarer still for Wellington musicians to have the opportunity to interact on a deeper level, especially when contact is limited by time. Of course, much musical and extra-musical information may be exchanged through the rehearsal and performance process; yet that information is limited by the length of the tour or workshop.

Some Wellington jazz musicians I interviewed (including Norman Meehan (2011), Rick Cranson (2011), and Lucien Johnson (2014)) consider critical thinking and mindfulness of issues (including the context in which jazz was created) to be essential to creative practice. For others, however, paying undue consideration to meanings that developed in, and apply to, different contexts potentially holds back self-expression. Several musicians I spoke to for this investigation privately questioned the relevance of the jazz's original sociocultural context to contemporary New Zealand jazz, but few would go on record with their concerns; a decision which speaks volumes about the power relationships and identity politics inherent in jazz in a global sense, and which have been apparent in the discussions in Chapters 3 and 4 . While Wellington musicians are aware that the roots of jazz are embedded in the turbulent history of the African-American experience, the decontextualisation of the music in its transplantation to the New Zealand cultural context has lessened the impact of that history in this new context. In a conversation on the issue, Wellington bandleader Robert Henderson told me "It's important to remember (the issues), but more important to put (them) in the past....the music should continue as far as we are concerned." (Henderson 2013) Nevertheless, in discussing the question of recontextualisation, some musicians clearly felt that to express such thoughts would be unwise, if not politically incorrect; an interesting dynamic, suggesting that Wellington musicians are aware of the contextual background of jazz, and that they consider it culturally significant, but that the significance pertains to another, different culture, which still maintains a proprietary hold over the meaning of jazz.

\footnotetext{
${ }^{136}$ Bandleader Rodger Fox has brought San Francisco-based blues guitarist Chris Cain to Wellington in 2007, 2013, 2014, 2015, and 2016, Los Angeles tenor saxophonist Bob Sheppard in 2010, 2011, 2013 and 2015, and Los Angeles trumpeter Jon Papenbrook in 2003, 2007, 2012, 2013, and 2015, for example.
} 
Yet the fact that the majority of musicians I spoke for this study to had rarely considered such questions indicates the extent to which decontextualisation has informed the ethos of Wellington jazz. Unlike the Japanese musicians in Atkins' study (Atkins 2001), whose tortured attitudes towards authenticity are indicative of a constant struggle with issues of ethnicity and identity, jazz musicians in Wellington are (tacitly) comfortable with the cultural remove, and by and large operate untroubled by the kind of angst which characterises Atkins' subjects. This freedom allows them licence to borrow freely from, imitate, or immerse themselves in jazz from other cultural contexts, and to construct new performing identities which place jazz alongside other forms of music, whether in a single performance or across the span of a career. Malm describes the result of this process as "media music hybrid styles": "the blending of international styles with local styles". (349). Pianist, composer and researcher Norman Meehan refers to this phenomenon in the music of New Zealand-born pianist Mike Nock, commenting on Nock's reflection of New Zealand's DIY (do it yourself) culture. To Meehan, Nock embodies this approach due to his "willingness to use whatever materials (are) on hand to make his music. Nock uses techniques from many styles to forge his music, and his catalogue is consequently very diverse." (Meehan $2010,104)$ Despite having lived out of the country since the age of 18 , Nock is one of New Zealand jazz's favourite sons; ${ }^{137}$ and his approach is markedly similar to that of the Wellington scene overall. "Nock's borrowing from so many sources is guileless - it's done to serve the emotional values of his music - and is not a comment on the provenance of his materials." (107)

Meehan quotes art critic Hamish Keith: "New Zealand from its very beginning has had a rich history of adoption and adaptation of the things the original travellers carried here with them and the things subsequent travellers brought. If we deserve a reputation for ingenuity and inventiveness, the reason lies there and not in some miracle of number-eight fencing wire." (Keith 2008, 132) Such tropes as "ingenuity and inventiveness" and a freedom and independence born of a pioneering spirit are central to New Zealand identity. Along with others including the natural landscape, and a brand of New Zealand exceptionalism (Fairburn 2008), as in the country's "distinctive culture" (Manatū Taonga - Ministry for

\footnotetext{
${ }^{137}$ Although, having lived in Australia since 1986, he is often featured as an iconic Australian musician: he is featured in John Shand's Jazz: the Australian Accent (2009), for example.
} 
Culture and Heritage 2013), they recall both New Zealand's history as a frontier nation, and its ongoing isolation, geographically and culturally, from the rest of the world. Making the most of the resources at hand, early settlers (both Māori and Pākehā) and contemporary musicians alike forge(d) new paths; ${ }^{138}$ and in the same vein, popular music researcher Tony Mitchell (1996) has described NZ musicians' tendency to "poach, consume and reconstruct selected fragments from imported musical practices, often assembling them in new idiosyncratic combinations." Like Mike Nock, local jazz musicians use what they hear, and they place importance on sonic considerations above issues of cultural origin or meaning ${ }^{139}$. It is the contextual difference (via decontextualisation and recontextualisation) which is of critical importance here. "Number-eight fencing wire" (mentioned by Keith above) is a commonly-cited trope in discourses of New Zealand identity, alluding to New Zealanders' ability to bend the (largely imported) materials at hand to their will, using them in new ways and thereby problem-solving in an adverse environment. Likewise, as we shall see, jazz musicians in Wellington make free use of decontextualized musical sounds; largely untroubled by their original meaning, they re-present them in a new context, generating their own meanings as they do so.

Of course, Wellingtonians do not operate in a vacuum. Some meanings make the jump, although they tend to be intellectualised as opposed to viscerally understood, as a result of the cultural distance involved; yet, cultural information which may be of obvious significance in some contexts is not necessarily so in others: Nicholson points out that "this is not to say an American jazz recording played inside the United States somehow sounds "different" when played outside America, but to non-American ears it might produce a different set of connotations and referential meanings from those experienced by American listeners." (Nicholson 2014, 41) It is not the place of an investigation such as this to prescribe what meaning(s) should transfer regardless of context, ${ }^{140}$ but the question does have much to do with authenticity; if the U.S. is (as Ake, Garrett and Goldmark (2012)

\footnotetext{
${ }^{138}$ See Keam (2006a) for a further examination of New Zealand identity, in the context of locally-composed classical orchestral music.

${ }^{139}$ My own love of jazz was, and still is, informed largely by the way it sounds. It represented a sonic freedom from (and extension of) the classical and popular music in which I had been participating. The freedom of interaction inherent in the music quickly drew me in further, but that was not what attracted me to the music. ${ }^{140}$ Although it is worth noting the parallels between such a question, and the prescriptive values of historical performance practice.
} 
suggest) the arbiter of global jazz tastes, and/or if specific cultural knowledge is necessary for authentic jazz performance, then the authenticity (and, implicitly, value) of much of the jazz played in Wellington, and other scenes outside the U.S. is called into question. While Nicholson, addressing the issue of authenticity in a global jazz context, points out that "glocal, or localized jazz styles do not emerge in isolation from American jazz, but from the interface between the two, with the notion of "authenticity" increasingly being expressed in terms of local, rather than global or American significance", (Nicholson, Jazz and Culture in a Global Age 2014, 100) it is, however, not clear that this has yet happened in Wellington. Perhaps mindful of perspectives such as Ake et al, which privilege American jazz as somehow more authentic (as we have seen in Chapters 2, 3 and 4), Wellington musicians still derive their concept of authenticity from American practices, and even American identities.

However, as we shall see, the tensions between the Duboisian doubleness inherent in a Wellingtonian playing jazz are negotiated in a variety of subtly different ways. As I argued in Chapter 4, with reference to Christopher Small, Wellingtonians are necessarily articulating something of their identities when they improvise; by the standard of inward authenticity, then, those performances are authentic. The execution of that self-expression and its content reflect different influences; New Zealand visual artist Toss Woollaston, discussing the same issue for local visual artists, highlighted the outward/inward authenticity dialectic, advising that "international influences may give our work manner environment should give it character" (Woollaston, quoted in Lilburn $(2011,64)$ ).

National (or even local) identities are, of course, constructed. Wellingtonians and New Zealanders do not necessarily bear in mind the landscape, or a pioneering mentality, as they create art; such elements of identity are mapped onto the art retrospectively. New Zealand composer Douglas Lilburn, calling in 1946 for New Zealand composers to consider their own national identity, noted that this was already possible in the field of New Zealand literature:

...it hasn't happened as a result of groups of people self-consciously setting out to produce a national literature. These people have been working independently of each other, getting to grips imaginatively with things about them, and when 
Sargeson or Curnow collects the best of this work together we find that a literature with some distinctive trends has already emerged. (Lilburn 2011, 28) (141 $^{2}$

New Zealanders are fond of characterising themselves as a nation; as New Zealand writer C.K. Stead wryly commented, "What's currently shaping our identities as New Zealanders, I suppose, is the attempt to shape our identities as New Zealanders." (Keam 2006a, 11) Column space is frequently given to reports (positive and negative) of the country received from abroad, and comparisons between New Zealand and other nations by a variety of measures; ${ }^{142}$ an old joke describes a visitor to the country, on arrival at Auckland airport, being immediately asked what they think of New Zealand. Yet as Anderson (1983) points out, nations are artificial constructions themselves. New Zealand may, perhaps, be less of an artificial construction, given its geographical isolation: anyone who lives in the country was either born there or (presumably) travelled there intentionally. But like the citizens of any nation, New Zealanders are a diverse group in all aspects. Musicologist Glenda Keam (2006a) examines the concept of New Zealand identity in relation to locally-composed orchestral music, noting a restive resistance to what some commentators characterise as a monolithic, all-encompassing identity, driven by insecurity; she quotes poet Bill Manhire and scholar Claudia Bell as lamenting the dependence of national identity on a nostalgic adherence to outdated imagery, drawn from Pākehā conceptions of themselves (which, presumably, include the tropes mentioned above). Mitchell (2010) notes the same issue in reference to New Zealand popular music.

Meehan's and Keith's invoking of eclecticism as a national characteristic (in art) is, of course, a generalisation; however it is a useful one inasmuch as it is broad enough to cover a plurality of approaches. It is that guileless repurposing of decontextualized materials that characterises much of the creativity inherent in the Wellington jazz community. ${ }^{143}$ In a

\footnotetext{
${ }^{141}$ Although Fairburn (2008) argues that many of the traits often considered distinctive to New Zealand are in fact found elsewhere.

${ }^{142}$ Recent articles proudly report that New Zealand ranks \#1 globally in social progress (Collins 2014) and $9^{\text {th }}$ for happiness (stuff.co.nz 2015), and its passport is the $8^{\text {th }}$ most desirable (ONE News 2015).

${ }^{143}$ David Edwards' chapter on the experimental music community centred on alternative venue The Space reflects this freedom of influence. Interviews with Jeff Henderson, Chris O'Connor, Kieran Monaghan, Chris Palmer and others illustrate the flexibility and breadth of the music created by a relatively small group of musicians: drummer Anthony Donaldson reported "I've got a bunch of different bands... some are jazz, some are groove-based, some are folk, some more heavy metal, some psychedelic, some use electronics." (Edwards 2009)
} 
context in which jazz is a style (or a collection of styles) of performance, and there is little connection to the kind of deeply significant racial and cultural meanings which derive from its origins in the U.S., there is in turn little to prevent Wellington jazz musicians from adopting any jazz identity they choose. It is the freedom which comes from the uncoupling of jazz from its cultural origins which allows Wellington jazz musicians to pick and choose from the entirety of jazz history.

\section{New meanings}

In his chapter "The Globalization of Jazz" (2014, 89-153), Stuart Nicholson, drawing on the work of sociologist Jan Nederveen Pieterse (2006), describes popular culture (including jazz) as exhibiting both "cultural convergence", in which aspects of global culture gravitate towards Westernised (Americanised) models, and "hybridization", in which local and global cultures are integrated, creating new cultural forms. Such traits are evident in different ways and combinations in jazz which is created in different locations, as a result of the different cultural contexts in those locations. In those local, non-American contexts, jazz typically exhibits cultural convergence via the adoption by local musicians of American modes of performance, sounds, and even language; and hybridization via the incorporation of local cultural elements in "glocalised" jazz approaches. (Nicholson, Jazz and Culture in a Global Age 2014, 93-99).

Wellington jazz musicians, receiving jazz from elsewhere as a sonic, but not cultural, phenomenon, create new and unique meanings by the act of performing jazz in Wellington. These meanings, as well as drawing on the self-expression inherent in jazz, are generated by the negotiation between the music and the local Wellington sociocultural environment; and they are unique both in relation to the various cultural meanings that jazz holds for communities in different locations, and in relation to the place that music (in general) holds in New Zealand society. Despite the constant activity in the scene, jazz in Wellington is still a minority pursuit; the vast majority of Wellington jazz, while publicly performed, maintains a low profile (see Chapter 1 ). As a result, the relationship of jazz to its Wellington context is complicated. While jazz musicians do take part in a variety of other musical endeavours, and in doing so influence the broader local music scene, jazz in its own right lacks a connection 
to local (and national) notions of identity (as we have seen in Chapter 2). When jazz does appear, therefore, it is unusual; it exists in contrast to much of the more visible musicmaking in the Wellington scene. In a city in which the most visible (and most widely supported) musical forms remain the two professional orchestras, the opera company and the local indie pop scene, jazz presents an exciting (and sometimes challenging) other. It is this otherness, in relation to more "conventional" types of music, which, in a variety of forms, most often distinguishes jazz from other types of music in Wellington.

In the Wellington scene, the most visible jazz activity reinforces this perception: jazz is often (implicitly or explicitly) characterised as the music of elsewhere, of another time and place, and its meaning is therefore bound up with a kind of subtle exoticism. Even in the form of original compositions, jazz in Wellington is often evocative of canonical, American styles or approaches; hence reviewer Colin Morris' compliment quoted in Chapter 4 ("This is as American as culture gets"). The only two New Zealand jazz musicians with any real profile outside the jazz community, Nathan Haines ${ }^{144}$ and Rodger Fox, both draw on conservative attitudes towards jazz. Haines' recent album The Poet's Embrace was recorded using techniques and equipment dating back to the 1950s; his liner notes describe it as Haines' "first 'real' jazz record, in light of his commitment to reviving the almost extinct art of analogue recording". ${ }^{145}$ Fox has directed big bands in Wellington and Auckland for 40 years, choosing repertoire largely drawn either from the Buddy Rich / Woody Herman / Maynard Ferguson era, or from classic swing arrangements (complete with the original recorded solos).

Given the commercial imperatives involved in the music, it is perhaps not surprising that much (though not all) Wellington jazz recalls earlier styles; after all, in order to work, musicians must meet the demands of the marketplace. The scene is crowded; while this illustrates its strength, it also means that musicians must find a point of difference if they are to compete successfully for work. As a result, some Wellington musicians consciously engage with the preconceptions and exoticism surrounding the music, looking for ways that self-expression and commercial success can be combined, at the expense of neither. Roseneath Centennial Ragtime Band founder Dayle Jellyman, describing the mindset which

\footnotetext{
${ }^{144}$ Haines also maintains a successful career in electronica and dance music, in London and New Zealand 145 (Recorded Music NZ 2013)
} 
informed his founding of the band, recounted that "I felt that at the time in Wellington, jazz was viewed as something that you play quietly in a corner while the audience talks over the music and claps politely at the right moments. I wanted to make an attempt at confronting that mindset" (Jellyman 2013); and leader of the Wellington City Shake 'Em On Downers Robert Henderson also "felt that a lot of people's perception of what jazz was, is and can be was limited to nerdy high school kids during a school assembly... We wanted people to dance to jazz again and have some good times." (Henderson 2013) Both bands play danceable, ragtime-influenced music, and in recent years they have been among the more visibly exotic Wellington jazz acts.

Yet it is not simply exoticism that lends jazz in Wellington unique meaning relative to global jazz. When they perform jazz, Wellington jazz musicians are performing two simultaneous identities. On one hand, they are representing themselves, in their own context; and yet at the same time they are performing the "other"; embodying a culture that (for the most part, at least) is not their own. As a result, the meaning of jazz in Wellington is also connected to the notion of performing multiple identities. An examination of one of the more visible Wellington jazz bands of recent years, the Richter City Rebels, demonstrates one way in which the meaning of Wellingtonians' jazz performance is generated at the junction of these identities, in a variety of negotiations: the otherness of the process of jazz creation in relation to the various musical practices taking place in Wellington; the temporal dynamic between contemporary Wellington and the pastness connoted by much Wellington jazz performance (whether intentionally or not); in the liveness of live performance within the urban space of Wellington; and in the interaction between Wellington musicians, in their own culture.

\section{Doubleness: the Richter City Rebels}

The Richter City Rebels present an interesting example of a Wellington band seeking to channel the music of a different time or place, while holding more than a passing regard for the different cultural contexts involved, and exhibiting a conscious awareness of the differences. The Rebels purposefully play on those contrasts, maximising the impact of the various meanings generated by the contradictions inherent in their practice. The Rebels are 
a New Orleans-style marching band, which formed after a group of Wellington musicians found inspiration in the HBO TV series Tremé. Initially performing repertoire derived from recordings and video of contemporary New Orleans marching bands such as the Rebirth Brass Band, the Rebels have since incorporated an increasing proportion of original material into their set: material which stays true to the various melodic, rhythmic and structural practices the members of the band gleaned from the recordings. The Rebels draw their members not just from the jazz community, but from the New Zealand Symphony Orchestra and the Central Band of the New Zealand Air Force as well. Thus, they set up a kind of panWellington musical identity, which, while it creates synergy, also generates contrasts in a number of directions, both within and outside the jazz community.

Notably, the Rebels sometimes wear what could loosely be described as New Orleans fancy dress: beads, "Native American" headdresses, basketball jerseys, and an eclectic combination of other seemingly random pieces including a roman centurion's helmet, cowboy regalia, and baseball caps. Dressed to thrill, they perform at the various jazz-friendly bars and clubs in Wellington, particularly Havana and the Rogue and Vagabond.

In the Wellington jazz scene, the Richter City Rebels are perhaps one of the more vivid examples of recontextualisation. Directly inspired by a specific set of musical practices, they re-embody those practices while remaining clearly of Wellington. As is the case with other bands described in Chapter 1, the members of the Rebels are individually well-known and visible in the community, outside their membership of this band, and the band itself has become relatively well known in relation to local jazz bands. Their name is also a clear evocation of Wellington ${ }^{146}$, and so they strongly identify with the city. As such, the fact that they play music so specifically associated with another city means that they represent the confluence of two identities. Thus, they challenge notions of authenticity, and illustrate the way in which transplantation (Malm 1993) can divorce music from its cultural context, while enabling it to find new meaning in a second context.

Interestingly, and unusually among Wellington jazz musicians, the Rebels are aware of the implications of transplantation. To many Wellington musicians the re-presenting of

\footnotetext{
${ }^{146}$ Although it is Christchurch which has recent (and devastating) experience of earthquakes, Wellington has long been associated with seismic activity (the "big one" has long been expected to cause significant damage).
} 
music from another context is, as well as an assertion of the right to play that music, a sign of respect for that music and the musicians who create it. Perhaps because of the effect of the television series, which portrays the marching bands as occupying a central position in a living culture, the Rebels take that notion of respect very seriously ${ }^{147}$. In putting together the Rebels, its founding members were deeply mindful of the cultural significance of the New Orleans marching bands they were trying to emulate. Drummer Lauren Ellis told me:

We don't have that culture here. We don't have anything like that. So- it's like, we need to figure out how to play this stuff properly- know the history I guess. (Ellis 2013)

Instead of simply copying the music, which might leave the band open to charges of appropriation, the founding members of the band tried to find out about the cultural background behind it before they even convened for the first time. The Richter City Rebels understand New Orleans marching band music as conveying meaning- and significantly, meaning which may not be inherently clear to them. They understand that musical meaning is not only conveyed sonically; that not only do they have to play right, they have to be right as well. Trumpeter Lex French told me:

...we're trying to do it, trying to pay homage to it as best we can, trying to be as deep with it as best we can, you know? (French 2013)

And the sentiment was echoed by Lauren Ellis:

I wanted to do it properly. Cos when you play a Latin tune, or an Afro-Cuban tune for a Cuban person it's like... am I being offensive? Or am I making, like hybrid beats? I don't know- is it right? Is it traditional? (Ellis 2013)

To the Rebels, a casual re-presenting of the New Orleans second line sound is not enough. Identifying the need to understand not only the music but also its cultural origins reflects a certain critical reflection on the part of the musicians; a recognition of their own externality in relation to the sociocultural contexts in which second line music developed. Seeking to engage with a set of practices from a different cultural context, the Rebels found it

\footnotetext{
${ }^{147}$ The notion of cultural sensitivity is not a foreign one in New Zealand, as a result of the promotion of Māori culture, and a bi- and multi-cultural New Zealand identity.
} 
necessary to consider their own positionality: their questioning of meaning, recontextualisation and authenticity has resulted in a mode of performance which selfconsciously incorporates cultural elements:

And like, wearing feathers on gigs and stuff? We were like, we don't want to be offending people by... you know? But then Lex looked into it and found out why they wear the feathers, and it was a sign of respect for the Indians... and it was sort of like, well we're playing the music out of respect as well, so, we wear that stuff.' (ibid.)

One might describe the result as 'informed performance', which observes cultural sensitivities while acknowledging the difference in context between New Orleans and Wellington. ${ }^{148}$ Yet it also illustrates the deculturation process, in that the Rebels had to make the conscious choice to seek out cultural information in order to understand more fully the implications of their choice to re-present New Orleans marching band performance.

The Rebels are at perhaps their most visible and arresting when parading through the city. The festive sight and sound of a New Orleans-style marching band, dressed in colourful attire, and playing at full volume in the streets of a contemporary New Zealand city (whether by day or by night) is striking in its incongruity. A promotional video filmed on one such occasion (Richter City Rebels 2013) features the varied reactions of Wellingtonians as the Rebels pass by: from dancing (that awkward dance of someone faced unexpectedly with the need to acknowledge and participate) and full-fledged applause, to startled stares, or the studied disinterest of the late teen.

The sight of a marching band is itself highly unusual in Wellington. Like the New Orleans marching bands in Matt Sakakeeny's 2010 study (Sakakeeny 2010), the Rebels challenge notions of public space and music making in Wellington, by treating the urban public spaces around Cuba Street as a performance space. That they do so while performing identities derived from another culture is significant, as it heightens the contrast, and gives

\footnotetext{
${ }^{148}$ I adapt the term from the field of historically informed performance practice. The Rebels do not attempt to recreate the music of New Orleans marching bands wholly faithfully; but they do consciously consider the original context and cultural significance of the music and gestures they are performing.
} 
them licence to challenge preconceived boundaries; passers-by find it hard to ignore the band, given the volume of their performance and their arresting outfits. Cuba Street is commonly the site of buskers, but busking performances are usually less confrontational (musically or culturally) than those of the Rebels. ${ }^{149}$ Sakakeeny describes the way public performance assists in the reclaiming of a contested public space by the Tremé community; the context in Wellington is different, and the public spaces around Cuba Street are less contested; the Rebels are claiming the space rather than reclaiming it.

In staking a claim on the city streets, by adopting a name with recognisably Wellington connotations, by not moderating their New Zealand accents when they sing ${ }^{150}$, and by appearing (despite their costume) to be Wellingtonians (like the majority of Wellington residents, the members of Rebels are of European extraction, in contrast with the usual makeup of a New Orleans marching band), the Rebels further cement their Wellington-based identity. The Richter City Rebels thus have a complex relationship with authenticity, but it is a relationship of which they are aware. Lauren Ellis expressed concern that the band should learn as much as possible about the music they were playing, in order to avoid causing offence if "people saw things on YouTube" (Ellis 2013); and felt strongly about the respect they had shown the music, and the culture from which it came:

Some people, like- we were in Mighty Mighty, it was the only place where someone goes "you know that's a culture not a costume", and it was like "well we're not wearing it as a fucking costume, thank you." (ibid.)

Awareness of the issues, knowledge of, and attention to detail in the execution of the music, and respect for the 'tradition', allow the Rebels to feel comfortable importing the concept of a New Orleans marching band into the Wellington scene. Performing one identity while also highlighting a second is a juggling act; and it is one that Wellington jazz musicians must perform regularly. Yet the Rebels, and many other bands in Wellington which re-present recognisably American styles of jazz, are largely not troubled by the kind of existential crisis reported by Atkins (2001) in his study of jazz in Japan. That jazz is inherently American is not

\footnotetext{
${ }^{149}$ Bruce Johnson $(2000,53-7)$ presents an engaging analysis of a busking experience with a jazz band in Wangaratta, Australia.

150 See Gibson (2010) for an investigation into the common differences between the New Zealand accent when spoken or sung.
} 
only uncontested, but often celebrated; but in embracing the music Wellingtonians assert their right to create and recreate it.

Such a dual representation is common in Wellington. Bands as diverse as the Wellington City Shake-'Em-On-Downers (ragtime), Twinset (cool jazz), the Troubles (postmodern jazz, incorporating classical, Arabic, and gypsy elements, among others), and Hot Café (Reinhardt / Grappelli- style gypsy jazz) perform their identities in two ways simultaneously. On one hand, through faithfulness to the dominant (hegemonic) culture of jazz, participants acknowledge tradition, by the act of aligning their identities with it and adopting (overtly) its values through performance (whether those values entail adherence to convention, or, in the case of the Troubles, self-conscious defiance of it). On the other, they embody New Zealand-ness, by way of personal identity, spatial location, and the implicit evocation of New Zealand identity through a (mostly) unselfconscious appropriation of cultural signifiers. The tension created by the Rebels through the juxtaposing of strongly New Orleans and Wellington elements is replicated through many other performances around Wellington. This simultaneous assertion of identity and "othering" recalls cultural theorist Stuart Hall's "negotiated code"; a mode of interpretation which "accords the privileged position to the dominant... while reserving the right to make a more negotiated approach to 'local conditions'“ (Hall (1999), quoted in Nicholson $(2014,52)$ ). In fact, the Rebels' approach, more theatrical than most Wellington jazz performances, is so strongly evocative of another culture as to be mildly subversive (an unusual quality among Wellington jazz musicians), highlighting the irony inherent in a group of European New Zealanders embodying and emplacing New Orleans culture in an urban Wellington setting.

\section{Local sounds: the Wellington Jazz Festival}

A second approach, in which local identity is foregrounded while still being expressed through the evocation of adopted modes of performance, can be seen in the history of the Wellington Jazz Festival (WJF). The development of the WJF over the last two decades illustrates Hall's "negotiated code" at work in a different context, in which, perhaps unexpectedly, Wellington-ness is asserted both over and through the dominant global jazz culture. As we shall see, a sense of identity as Wellington musicians, fuelled by the level of 
synergy present in the Wellington jazz community, contributes to the sense of community felt by Wellington musicians. Interestingly, the Wellington jazz scene, like the New Zealand jazz scene, is not often conceptualised as an entity in itself (this investigation notwithstanding), although in the broader New Zealand cultural context, such essentialisation, as we have seen, is often of strategic importance (in terms of funding applications or advertising, for example) (Lipsitz 1994). The development of the WJF, however, has highlighted the emergence of a local communal identity.

In 1997, a group of Wellington jazz musicians put together what was to become an annual event. The WJF initially had a number of aims, which could be broadly categorised as providing opportunities for local Wellington-based musicians to perform. There were opportunities to collaborate with each other in new ways, and in combination with international guests, and it was hoped that the success of the festival would translate to more gigs in Wellington on an ongoing basis. While there had been some performance opportunities in Wellington up until that point, it was thought that the existence of a dedicated festival would allow musicians the room to develop creative projects which wouldn't otherwise see the light of day. The festival would also bring in a small number of overseas artists, thereby creating opportunities for local players to collaborate with, and learn from, experienced artists of international standing. The international guests were often, as former board member Norman Meehan put it, "peripheral to the world of jazz" (Meehan 2012): artists included Caribbean pianist Mario Canonge and German / New Zealand quartet Root 70. The festival's budget was small, and it frequently operated at a loss. Festival director Simon Bowden recalled that

...it was so incredibly hard to fund it. So we got a grant from city council in (the festival's) first official year of $\$ 25,000$, and it stayed the same the entire time I was there, so if you add the impact of inflation- this tiny amount of money to run a bloody jazz festival. It was really an underground music, and on our best nights there was 300 , 400 people... on ticket sales it was never sustainable. (Bowden 2012)

However, profitmaking had never been the intention; the festival was a way for Wellington jazz musicians both to assert their identity, to explore, and simply to perform. The festival 
was aimed at promoting jazz as a participatory art form in a Wellington context, with a focus on collaboration, development, and empowerment.

After the festival in 2007, the New Zealand International Arts Festival, based in Wellington, approached the organising committee of the WJF, with a proposal to take over its name and management, and to run a biennial jazz festival, alternating with the International Arts Festival, which already took place every two years. The board of the WJF decided that they had succeeded in their aim to create performance opportunities for jazz musicians, and as a result of both that and the stress of running a jazz festival in their spare time, they agreed to hand the festival on. The Arts Festival management would now run the WJF every second year beginning in 2009.

In 2009 the WJF was held for the first time since the handover. Under its new management, the focus of the festival changed. More high-profile ("big-j") international acts were included, such as Otis Taylor, Brad Mehldau, Tomasz Stanko, and the Mingus Big Band. The New Zealand acts included more national figures, many with somewhat tenuous jazz connections, such as dub band Fat Freddy's Drop, ${ }^{151}$ and pop singer LA Mitchell. A handful of Wellington musicians were given the opportunity to participate in three free outdoor events in Civic Square, and the "impromptu" jam sessions held after midnight in the Wellington Town Hall. The festival's brand was aligned with the slick, professional and recognisable branding of the International Arts Festival, and it was billed in its promotional literature as "a jazz festival, the likes of which New Zealand has never seen before" (Twomey 2009). The budget grew to around a million dollars (Paterson 2012): a 40-fold increase.

In 2010 no festival was held, as the new management had moved to a biennial delivery model. In 2011, however, the WJF management announced that that the festival planned for that year would be cancelled due to insufficient funding: a development which had a significant impact on jazz musicians' perceptions of the festival organisation. Questions were raised at the time by many in the jazz community, concerning the rationale for the cancellation, and pointing out that a significant amount of funding (which far outstripped the budgets of the successful 1997-2007 festivals) had, in fact, been secured. In

\footnotetext{
${ }^{151}$ Fat Freddy's Drop is based in Wellington, and has counted a number of trained jazz musicians among its members, including Toby Laing and Warren Maxwell.
} 
an effort to make amends, Festival management announced that Sonny Rollins would visit for a concert in June, and members of his rhythm section gave a masterclass at the New Zealand School of Music. However, there was still scepticism as to whether the WJF had "sold out"; whether in attempting to align the festival with an international model, which relied on the presence of high-profile and expensive "big-j" international jazz acts, the new management had abandoned the ethos of the original festival.

In 2013, the WJF was held for the first time since 2009. The format was significantly different; international artists still comprised the central focus of the festival and its marketing, but in response to criticism from the jazz community, the 2013 festival featured extensive local engagement. Local venues and jazz musicians worked together to organise gigs, which were then advertised through the festival's publicity materials. The result was an energetic weekend, in which more than 20 gigs per day, all involving Wellington musicians, took place in the compact Wellington city centre. Annual funding was secured, and the 2014 and 2015 festivals have continued the concept; both festivals were met with an enthusiastic response from the local community, who now had extensive opportunities to participate in their city's celebration of jazz.

It is interesting to examine the progression of the festival in relation to the notion of a Wellington jazz identity. When the WJF began in 1997, generating and maintaining that sense of identity among jazz musicians in Wellington was one of the driving factors. The festival was initiated by a group of musicians, in order to create an environment in which the local community of jazz musicians could coalesce, be energised, and develop the kind of momentum which would endure beyond the period of the festival. At the same time, and as a result, it provided a chance to bring creative projects to a larger audience than might otherwise hear them. Norman Meehan told me that "it was sort of a way to energise the Wellington scene (and) to provide meaningful opportunities for international improvising musicians to collaborate in interesting ventures with local musicians." (Meehan 2012). Former festival director Simon Bowden commented that "it was run by musicians as a vehicle for presenting jazz as a living art form... and also as a vehicle for a peak kind of performance environment for Wellington musicians." (Bowden 2012)

It is clear to see the shift in terms of emphasis when the festival was handed over to the International Arts Festival. Having been organised from within the community at a grass- 
roots level, the WJF was now aligned with the International Arts Festival's brand. The International Arts Festival has an impressive track record: it runs for three or four weeks every two years, hosting dozens of international acts, and covering the gamut of the performing arts. In 2012, it "delivered 300 performances with 900 artists from 31 countries. Over 110,000 tickets were issued and over 165,000 people attended free events. A Business and Economic Research Limited survey found that the festival contributed 56 million dollars to the Wellington economy." (New Zealand International Arts Festival 2012)

Clearly, the capabilities of the International Arts Festival allowed their management to adopt a larger, higher profile model for the 2009 WJF, and to feature a roster of overseas artists. In fact, the model adopted in 2009 is similar to that of most major jazz festivals around the world, in that they tend to feature top-level artists from the international scene, rather than musicians from the local community. ${ }^{152}$ However, it is important to note that there was in fact a significant New Zealand presence in terms of headline acts in the 2009 festival. Mike Nock, Roger Manins, Jan Preston, and Whirimako Black were all promoted alongside the higher-profile, overseas artists. But given that the only Wellington-based act among the headliners was dub band Fat Freddy's Drop, it was still perceived that the connection to local jazz musicians had been greatly eroded.

It was felt among Wellington jazz musicians at the time that the festival that had been started to celebrate their own identity had been abandoned in favour of one that celebrated a broader, less specific "big-j" jazz identity. A number of the jazz musicians I interviewed commented privately that while attending gigs and concerts featuring top jazz musicians is an important factor in terms of the development and inspiration of musicians, the kind of opportunity presented by the first version of the WJF, in which local musicians were able to play and collaborate with the visitors, were felt to be of much greater value to them as musicians. Pressures in terms of funding from the Wellington City Council and corporate sponsors, and the high ticket prices necessary to pay for top-level international musicians, had resulted in a 2009 festival that was no longer owned by Wellington musicians.

\footnotetext{
152 Recent major jazz festivals around the world have displayed a worrying trend in engaging headline acts with little or no relation to jazz, presumably for commercial reasons. The 2015 New Orleans Jazz and Heritage Festival featured Elton John, Jimmy Buffett and Ed Sheeran, for example. A similar trend has emerged among New Zealand jazz festivals.
} 
This feeling was compounded in 2011, when the festival management announced that that year's festival would not go ahead, as the money they had managed to raise, while far in excess of the budget of any of the festivals from 1997 to 2007, wasn't enough to put on a good enough festival. The Wellington scene went from hosting a festival every year to hosting just one in four years. The announcement of Sonny Rollins's concert as a way of making up for the loss of the festival was greeted both warmly (who wouldn't want to get to hear Sonny live?) and sceptically, as a single concert by an overseas superstar was not perceived as compensating for the loss of the festival. (Prendergast and Tipping 2011)

Yet the most telling factor in Wellington musicians' reaction to the developments between 2009 and 2013 remains the concept of identity. The WJF, in its original form, was focused on Wellington musicians: celebrating them as a community, while allowing them to develop new directions, and in a more publicly visible forum than would usually be the case. When the festival began to operate under a new model in 2009 (a model similar to that of the International Arts Festival), the focus changed; and consequently Wellington artists, while appreciative of the calibre of the international (and national) artists featured in the festival, felt the Wellington identity that had been central to the festival until that point had been discarded. The festival had, although taking up only a week or so in an otherwise busy calendar for many in the community, provided higher-profile performance opportunities than those allowed by the regular gigging scene, a nexus around which the community could coalesce once a year, and perhaps most significantly, the means to reinforce a Wellington jazz identity in a local and national context, while locating it in the global scene. The revised format in 2013, 2014, and 2015 allowed Wellington musicians to take the initiative in planning their own gigs, which would then be supported by the festival's marketing strategy. The resulting panoply of jazz performances, at a wide range of venues, speaks to the energy of the community.

Yet in the context of a celebration of local jazz identity, it is interesting to note the nature of the performances, with regard to the notion of identity: a very significant number (although by no means all) of the self-organised gigs at both festivals created and promoted a connection between Wellington musicians and the canonical jazz 'tradition'. Concert 
series consisting of Wellington musicians playing rearrangements of classic jazz albums ${ }^{153}$ took place at the Rogue and Vagabond in 2014 and 2015; other performances featured "Monk meets the Mars Volta", the Wellington Mingus Ensemble, and performances dedicated to the music of Sun Ra, Tom Jobim, and well-worn jazz standards. At the same time, many original projects performed, some of which had been mounted specifically for the festival: these included drummer and composer Reuben Bradley's Cthulhu Three, inspired by the writing of H.P. Lovecraft; the ARA Taonga Pūoro ensemble; drummer Darren Matthiassen's 'Global Warming Will Change Everything'; and octet the Jac.

The nature of these performances is instructive. Bearing in mind the strongly held feeling by Wellington musicians that the WJF must represent their identity, the fact that many of the resulting performances contained representations of canonical jazz identities (whether through original or borrowed repertoire) suggests that the notion of authenticity in a Wellington jazz context is multifaceted, combining elements of the various ideas discussed earlier. On one hand, to be authentic, jazz performed in Wellington must be of Wellington; it must contain some essential Wellington element, thereby achieving inward authenticity. Yet that element may be as fundamental as the simple matter of personnel, in that jazz played by members of the Wellington jazz community is authentically Wellingtonian; this is more complex than it may seem at first, given that the improvisatory and interactive elements of jazz dictate that it is, to some extent at least a reflection of the identities of those who play it (hence Christopher Small's comment that "those taking part in a musical performance are in effect saying... This is who we are." (Small 1998, 134)). This view is perhaps informed by the pedagogical approach of the New Zealand School of Music, as I outline in Chapter 3, which focuses on canonical and mainstream approaches. On the other hand, perhaps for jazz to be truly of Wellington, it must be wholly created in Wellington (in other words, the structures around which the improvisation and interaction occurs must be created in Wellington). This is an extension of the previous argument; if improvisation reflects context, surely composition does too. Yet by that logic, all of the jazz performed by local artists is Wellington jazz, whether it consists of original compositions or of improvisations over standard progressions.

\footnotetext{
153 Including Brubeck's Time Out, Davis' Birth of the Cool, Kind of Blue and Bitches Brew, Coleman's The Shape of Jazz to Come, Hancock's Headhunters and Joni Mitchell's Shadows and Light.
} 
Yet, for jazz to be outwardly authentic, it must follow some kind of tradition, or be in keeping with a particular mode (or modes) of expression which are essentially jazz. This is complex as well; such authenticity could be represented by the execution of canonical performance practices, meaning that a Wellington artist playing bebop is performing authentically. Or it might be that emulation of a canonical artist confers authenticity: such emulation lends the performer(s) a moral weight; the invocation of tradition adds value to the performance. However, emulation is not the only way to place oneself within a tradition; as Jackson (2004) and Glasper (Benevento, et al. 2010) (among others) argue, extension of that tradition counts as valid, traditional expression in itself. Artists, who push boundaries, therefore, perform with a traditional ethos; and so Wellington musicians as diverse as Lucien Johnson, Jeff Henderson, and Tom Callwood, who often perform at the junction of jazz and experimental music, or Reece McNaughten, who combines jazz with electronica, are in fact invoking traditional notions of jazz while performing new, innovative identities.

The key, however, is that Wellington jazz musicians' performances in the Wellington Jazz Festival allow them the opportunity to foreground their identity as both Wellingtonians and jazz musicians, in a more public (or at least more publicised) forum than might usually be the case. Thus it is an annual affirmation of the fact that the Wellington community exists: a celebration of its connection to a broad and celebrated tradition, and an assertion of its Wellington-ness (and by extension New Zealand-ness) in a crowded Wellington scene in which, to a significant extent, jazz struggles to establish itself as being of "Wellington". By overtly linking the Wellington jazz community to the broader Wellington scene, the festival has become a de facto advocate for the community. ${ }^{154}$

Additionally, by bringing international artists to Wellington, the festival continues the ethos by which the first festivals were organised: to "energis(e) the scene", in Meehan's words (Meehan 2012), by providing opportunities for musicians to witness high-profile and inspiring artists from elsewhere. The opportunities to directly engage are fewer (although

\footnotetext{
${ }^{154}$ I have directly contributed to this position over the last year; due in part to the deep knowledge of the scene which I have developed through both performance and investigation, I have worked for the festival as social media co-ordinator since July 2014. Part of the brief is to maintain both the public visibility of the festival across the year, and the festival's connection to the Wellington jazz community. In this capacity I instigated a weekly listing of Wellington jazz gigs on the festival's Facebook page: this filled a gap in the scene, but also reinforced the position of the festival as an advocate for local jazz.
} 
they do occur), but of crucial importance is the creation of a tangible connection between the Wellington community and the international scene. This allows Wellingtonians to claim membership of, and to locate themselves in, a global community, in a similar (though arguably deeper) manner to that by which (in musicologist and jazz researcher Ken Prouty's concept of community) listeners to jazz are connected: "Thus a listener who puts on a recording of Armstrong's Hot Fives, for example, is engaging in an act of community with Louis Armstrong that is not simply imagined; the connection between artist and listener is not simply on a cognitive level." (Prouty 2012, 43) The audience at Cassandra Wilson's 2013 concert at the WJF, or at that given by the Joshua Redman Quartet in 2014 , share a connection with the artist; but they also share an act of community with anyone who has ever heard those artists live, anywhere in the world.

Wellington jazz musicians, then, are afforded by the WJF both a highly visible opportunity to assert their identity, and to locate it within the concentric and overlapping frames of Wellington music, Wellington city, New Zealand jazz, and the global jazz scene; and the opportunity to experience the breaking down of the usual barriers of geography by having international artists visit them in Wellington. The dissatisfaction surrounding the change of festival model implemented in 2009 is perhaps understandable, given the significance that the development of the festival has been infused with Wellington jazz musicians' identity, their notions of authenticity and their interaction with the jazz tradition. The enthusiasm with which the jazz community embraced the subsequent model in 2013, 2014 and 2015 attests to its ongoing significance.

The festival allows Wellington jazz musicians to project their identity in both global and local terms. In the process, that identity is developed and reinforced in opposition to other identities. The WJF contributes to the Wellington jazz identity in a number of ways: as a nexus around which the community can coalesce once a year, which is important in terms of visibility and sense of community; and by representing Wellington (and the Wellington scene) in a crowded national calendar of jazz festivals ${ }^{155}$.

\footnotetext{
155 Other notable jazz festivals in New Zealand include the National Jazz Festival in Tauranga, the New Zealand Jazz \& Blues Festival in Christchurch, Queenstown JazzFest, the Manawatu International Jazz \& Blues Festival, the Auckland Jazz Festival, the Waiheke Jazz Festival, the Nelson JazzFest, the Christchurch Big Band Festival, the NZSM Jazz Festival, and the Bay of Islands Jazz and Blues Festival; additionally, other festivals include jazz
} 


\section{A Distinctive Approach? New Directions in Melbourne}

The preceding two case studies offer two examples of the ways in which the Wellington jazz community is developing its own identity, driven by co-location and collaboration. While it may be loosely characterised, in that it is close-knit, and valorises versatility across genres in combination with a conservative approach to the performance of jazz itself, it is not yet clear that this has translated into a distinctive "Wellington sound", or a localised version of jazz. The hothouse effect of the compact local scene has not automatically resulted in an organic move away from the dominant discourses and attitudes of the jazz tradition; and in fact, as can be seen in Chapter 3 as well as the examples above, those attitudes are still an essential part of the makeup of the local jazz community.

An investigation I undertook in Melbourne (Tipping 2014), however, presents an interesting comparison, and illustrates contrasting approaches to context, identity and legitimacy. Musicians in that city operate in a quite different context: Melbourne is ten times the size of Wellington, and plays host to several dedicated jazz clubs, while Wellington has none. Consequently, Melbourne musicians are presented with more extensive opportunities to play original and experimental music than those in Wellington. Perhaps as a result, while there are plenty of gigs in both cities dedicated to standard repertoire, representations of historical and contemporary approaches, and original music, and while some Wellington jazz musicians consistently push boundaries and challenge performative norms, I detected a distinct momentum in Melbourne towards playing jazz which tests the boundaries of expression or style. The diversity of approaches and experiences in a city of four million (and a country of 23 million) militates against an essentialised jazz identity. Yet among Melbourne's jazz musicians, identity and inward authenticity are potent concepts. Pianist and composer Andrea Keller told me that despite a lack of grounding in the "tradition", her expressive identity was still valid:

I was thinking I didn't feel legitimate playing this music, but then when I thought about it from a different angle, and thought about actually why Allan [Browne, drummer and bandleader] kept calling me to do the gig, I realized it wasn't because of my legitimate knowledge of the jazz tradition, it was about something else. It was about the spirit in the music and all these other things that made me me, and made

to a greater or lesser extent. The Wellington Jazz Festival is notable for the fact that it includes only jazz in its lineup, and it is also worth noting that all major jazz festivals in New Zealand feature Wellington jazz artists. 
me different to other people, and that's actually what he wanted, and then I realized that that's actually legitimacy. If I play it the way I hear it then I'm being legitimate. (Keller 2014)

To Keller, inward authenticity is consonant with the jazz tradition, in that it draws on the creativity inherent in jazz. Yet in doing so, it necessarily involves actively discarding elements which are not consonant with a musician's own experience, and treating jazz purely as a creative process. Keller, citing Australian pianist Paul Grabowsky's description of jazz as an adverb (2007), told me:

It's a way of doing things, it's a process. Some people think it's a noun, it's a pre1950s style of music, but actually, if you approach it as a way of doing things and a process, then it is all about something else. (Keller 2014)

Thus, deemphasising the centrality of a somewhat ossified canon in favour of a processbased approach, which involves prioritising the search for authenticity in one's own context above adherence to normalised performative strategies, provides those Melburnian artists who do so with the opportunity to acknowledge the jazz tradition without compromising their own identity.

That such an approach has taken hold in Melbourne in part reflects the influence of the two local jazz education institutions, the Victorian College of the Arts and Monash University. Neither programme focuses exclusively on jazz, but each allows students to explore a variety of methods of expression in addition, thereby placing emphasis on the development of the individual voice. Pianist and composer Tony Gould, who has held positions of responsibility at both institutions, advocates strongly for the importance of contemporary context above historical tradition, and the primacy of inward authenticity in the context of personal expression:

(Students would) sing Ella Fitzgerald... I'd say to the singers, "Why are you doing that? She's dead. You're not black. Write your own music. Learn from it by all means, but don't do it in front of me please. Unless you're totally brilliant and you're an impersonator, you're going to sound third rate." (Gould 2014)

I think you have to respect the past. I always think study the past, but don't live in it. I'm of the fairly strong view that we're living in a post-jazz period, especially in this 
country where I think there's now more Australian improvisers writing their own music, and less playing the standards... you go to Bennett's Lane (jazz club) most nights you won't hear a whole bunch of standards... everyone in this city's writing their own music. (ibid.)

Although such an approach privileges individual expression over group identity, it might yet be expected that, given commonalities of context, a particular localised approach might develop; yet it is not clear that this has happened on either a local or a national level in Australia. In our interview, Gould referred his perception of a "gothic mode" in Australian jazz, in which a rough-and-ready approach and DIY values are central, in combination with a jazz-based freedom of expression; such an assessment recalls that of artist Toss Woollaston (above), and Japanese critic Ono Masaichirō, in his description of Japanese jazz: "Japanese jazz is the Japanese artist's expression of the Japanese heart through the Esperanto of jazz." (Atkins 2001, 245) As authors such as Shand (2009) and Rechniewski (2008) point out, the major scenes around Australia are varied in terms of size, influences, and dynamics, and so it would be difficult (and outside the scope of this study) to settle on one essentialised identity in terms of either Australian jazz, or even jazz in Melbourne. And certainly, Melbourne jazz, like Wellington jazz, encompasses music both in the tradition (like guitarist James Sherlock, or singer Michelle Nicolle), and which crosses genre boundaries (composer / instrumentalists Keller, Tim Willis, or Gould). However, in the context of my limited project, the distinct implication among musicians I interviewed was that inward, rather than outward, identity is paramount; expression is valid regardless of form, as long as the choice of expressive form is made consciously. Were a collective identity to exist, it would result (as it would in Wellington) from an accumulation of individual identities, or tendencies, among local musicians.

\section{A New Zealand approach?}

In Wellington and New Zealand society, as illustrated above, any particular local identity must necessarily be loosely defined. Indeed, the concept of "New Zealand jazz" as a distinctly local tradition, approach, or sound, remains relatively uninterrogated by scholars or musicians. While Lilburn suggested a local or national style could be detected 
retrospectively via a survey approach, such an investigation has not been attempted in New Zealand jazz. In fact, various musicians have expressed doubt that such a style existed in either Wellington or New Zealand, and suggested that if commonalities do exist, they may be found in terms of an undefined New Zealand-ness:

"I don't think we have (a unique sound) yet, but I think it is coming... So long as musicians and composers stay within the tradition, then the music we make here will always sound like traditional jazz, it will always sound like an imported culture. It will only become something unique to New Zealand when we find our own voice within that tradition." (Steve Garden, in Burns (2010))

"It can be hard to be a jazz musician and be honest to yourself. The stuff that matters (in terms of self-expression) is that you're a New Zealander." (Mike Isaacs 2013)

"I'm just trying to do my music. That's it. I'm not really thinking that it's New Zealand music. I mean it is, because I'm a New Zealander and I wrote it in New Zealand... But it's in a jazz style because that's the music I like... It's hard. If you want to... put out music in NZ that is uniquely and obviously New Zealand then there's not many things you could do. You're going to have to sing in Māori or... use taonga pūoro... that's all legit but it's not exactly what I want to do right now." (Reuben Bradley 2013)

Composer Douglas Lilburn $(2011,65)$ suggested that an identifiably New Zealand approach to composition had not yet crystallised; he was speaking in 1969 , but the earlier discussion about New Zealand identity suggest that the same may still be the case today. Arguments against a monolithic shared identity, as noted above, imply that a single identifiable approach is unlikely to develop. Keam (2006a) investigated the existence of a national style in her thesis "New Zealand Orchestral music in the Late Twentieth Century", although her sample is restricted to orchestral works which specifically seek to evoke New Zealand, particularly through landscape or other natural phenomena, and therefore does not answer the question of whether tendencies exist more broadly. Indeed, the landscape (and more broadly, place) is a popular trope in investigations of New Zealand music and musical style (Keam (2006a and b), Meehan (2010) and (2011), Mitchell (2009), Bollinger (2002)). Certainly its popularity as a trope in analyses of New Zealand music reflects (or is reflected in) the popularity of place in New Zealand composition itself, and jazz is no exception. Conscious representations of the New Zealand landscape via sonic psychogeography 
(Mitchell 2009) are not uncommon in New Zealand jazz either: pieces such as Phil Broadhurst's “Matai Bay”, Drew Menzies' “Mansfield (Street)”, and Brian Smith's "Taupo", are recent examples; Guitarist Nick Granville's album Home is wholly dedicated to evocations of place. Expatriate New Zealand jazz pianists Mike Nock ("Ondas", 156 and "Land of the Long White Cloud") and Alan Broadbent ("The Long White Cloud") ${ }^{157}$, and bassists Matt Penman ("Haast Pass") and Thomas Botting ("Balclutha") likewise consciously evoke the sound of their native country. While it is inevitable that New Zealand musicians are influenced by their context, and the New Zealand landscape is famous as a source of inspiration, it would obviously be unwise to assume a connection where one is not explicitly indicated. Norman Meehan $(2010,109)$ warns that suggestibility plays a role in the identification by listeners of music as representing a place: "A seed is planted by the knowledge that (Mike) Nock is from here, or by a title that evokes New Zealand, and that conditions their response... someone from the mid-west of the United States or coastal Australia could equally well hear their homeland evoked by the same tracks." (Meehan $2010,109)$ Holly Kruse makes a similar point, in a discussion about local indie sounds: "the assertion that a local sound exists leads one to listen for the similarities between [and among] bands within a locality: those who seek to find a local sound therefore tend to find it." (Kruse 2003, 133) The examples above, therefore, represent personal responses to particular places, but as music is a symbolic (as opposed to referential) language, such interpretations are unlikely to be universal. Attempts to draw connections between a New Zealand jazz sound or approach and the landscape (in compositions whose titles are not directly evocative of distinct locations) are thus on shaky ground (pun intended).

However, a more overt approach to "New Zealand-ness" in jazz has developed in recent years; as Bradley's comment above suggests, attempts have been made to represent the cultural heritage of New Zealand through the incorporation of taonga pūoro, or Māori traditional instruments, into a jazz context. Musicians including Chris Mason-Battley, The Efficient Five, Dave Lisik, Tim Hopkins, and Paul Dyne have incorporated various Māori instruments into a variety of recordings; helpfully, New Zealand's most accomplished exponent of taonga pūoro, Richard Nunns, who has recorded with each of the above

\footnotetext{
156 See Meehan (2010)

157 The Māori name for New Zealand, Aotearoa, loosely translates as "land of the long white cloud".
} 
musicians, has a background in jazz. For many New Zealanders, the sounds of taonga pūoro are deeply evocative of the country; their timbre and limited pitch range are instantly recognisable, and are often used to create an otherworldly atmosphere in television and film. Yet it is unlikely (though not impossible) that taonga pūoro form a part of the musical context in which most of the above musicians regularly operate (with the exception of the Efficient Five, some of the members of which have undertaken study in taonga pūoro); they are used comparatively rarely in public performance. Their use in a jazz context, therefore, is perhaps more of a conscious appeal to New Zealand-ness than an inevitable result of living in New Zealand ${ }^{158}$.

Two albums by singer Whirimako Black, Soul Sessions (2006) and Whirimako Black Sings (2007) present an interesting case: both albums consist of jazz standards translated into Te Reo Māori (the Māori language). Black is Māori, and is fluent in the language; while there is nothing ground-breaking about the repertoire or arrangements, the act of translation is nevertheless a tangible comment on authenticity. In translating the lyrics into Te Reo, Black adjusts the manner of her expression as well as the content (in the words of Woollaston above). It is therefore arguable that Black achieves an authentic performance, which projects her own identity while blending two distinct traditions.

However, Black's approach is unusual, in that as Keam notes "nature - not culture is how most New Zealanders most identify themselves with where and who they are". Certainly, there seems to be little that is self-referential in Wellington jazz. While the community is small and cohesive, inspiration is most often drawn from elsewhere. Patterns develop (such as the cluster of bands playing ragtime and Dixie music), but in other respects, if musicians in Wellington follow a tradition, it is not a Wellington (or New Zealand) tradition. It is interesting to note that no Wellington (or even New Zealand) repertoire has developed; musicians either play their own tunes, or those written by musicians external to Wellington (and New Zealand) ${ }^{159}$; very often this is in the form of standards, but compositions by contemporary heroes are also imported. The "Kiwi Real

\footnotetext{
${ }^{158}$ For a discussion on how this relates to New Zealand music funding, see Chapter 2.

${ }^{159}$ In a case of the exception proving the rule, two concerts inspired by New Zealand Music Month featured local jazz musicians covering the music of other New Zealand musicians: on May 1, 2015 a group of local Wellington bands covered exclusively the music of other Wellington bands in a concert titled "Under the Covers"; and a concert by Myele Manzanza, Scott Maynard and Daniel Hayles, on May 24, presented jazz interpretations of New Zealand music.
} 
Book", (Broadhurst and Key (eds). (1996) (2000)) which contains in two volumes compositions by a broad array of musicians, has not achieved any kind of currency. The history of jazz in Wellington and New Zealand is little-known, and musicians tend not to trace their lineage (in terms of teaching or mentoring) back any further than one generation.

\section{Identity in the Wellington Scene}

And so the notion of identity in Wellington jazz exists as an interesting combination of attitudes. On one hand, there is no distinctive Wellington-centric approach or sonic aspect to jazz; such a quality might be the most obvious manifestation of a jazz identity, but, as in New Zealand jazz more generally, it has yet to develop. On the other, in Wellington a focus on tradition in jazz and a strong sense of community combines and contrasts with the valorising of versatility, and the high level of activity in the scene, to generate a community which continues to create and play jazz at a high level of intensity for a city of its size. Such intensity is perhaps surprising, given the low profile jazz still maintains in the media, or in public life more generally: apart from during the Wellington Jazz Festival, jazz struggles for relevance beyond acting as a form of entertainment, and in the New Zealand media the term is as commonly applied to a model of car or a brand of apple as to the music itself. ${ }^{160}$ As a result, jazz musicians in Wellington rely on the moral force of the jazz tradition as a foundation on which to build their identity. Yet at the same time, through the process of decontextualisation which occurs when jazz is imported to New Zealand (largely through digital media), much of its original meanings (which derive from the variety of cultural contexts in which it was created) are removed. As a result, the socio-political meaning of the music is largely lost (although not to everyone; musicians including John Rae, Rick Cranson (2011) and Lucien Johnson (2014) still consciously engage in political commentary through their music); and Wellington jazz musicians are free to create and recreate without the kind

\footnotetext{
${ }^{160}$ My informal ongoing survey of mentions of the word "jazz" in New Zealand media throws up this discomfiting phenomenon. The car referred to is the Honda Jazz, described in stereotyped Kiwi vernacular in its branding as "jazz as" (i.e. 'very jazz'); and the "jazz apple" is a cross between the popular Braeburn and Royal Gala varieties.
} 
of existential angst which attends the process of jazz creation in Japan, for example. (Atkins 2001)

The identity of Wellington jazz, then, is a composite one, borne of contrasts.

Wellington jazz musicians are both innovators and traditionalists (often on the same gig). They are creative musicians who are well aware of their status and function as entertainers. And, crucially, they are proud Wellingtonians and New Zealanders, who yet perform American identities as part of their "New Zealand music" personae, and whose activity poses challenges to commonly accepted definitions of both jazz and New Zealand music. 


\section{Chapter 6: Conclusion: A happening scene}

The last weekend of September 2014 holds no major events in Wellington; the jazz festival has been and gone three months previously, and staff and students at the New Zealand School of Music are beginning to think about the upcoming exam period. The weather is, as usual for the early spring in Wellington, unsettled; clear skies on Friday give way to rain on the Saturday and Sunday, with the usual Cook Strait wind providing a constant throwback to winter.

The jazz community enjoys a typically busy few days: nine gigs on the Friday, six on the Saturday and three on the Sunday. Yet the spread of venues, styles, and personnel exemplifies the intensity which characterises the Wellington scene, and which inspired this project in the first place: as many as four gigs happening simultaneously, all of them free to enter, and fourteen of them in the city centre, within a ten-minute walk of each other. ${ }^{161}$

Friday's fare begins with a lunchtime set of Jimmy Giuffre tunes, played to a moderate crowd at the jazz school by staff and a former student of the New Zealand School of Music, in the regular NZSM end-of-the-week concert slot. Halfway through the afternoon, the Tin Foil Hats hit their groove down at the Amora Hotel at the bottom of Cuba Street: they play an afternoon swing show, in combination with members of the local swing dancing club.

The after-work drinks begin with two solo piano gigs: Daniel Hayles and Dayle Jellyman, at opposite ends of town, accompany Friday debriefs and the drowning of sorrows with a couple of sets each; Hayles reaches in to his eclectic grab-bag of swing, contemporary, blues, and hard bop at the Wellesley Hotel near the railway station, and Jellyman, in his first gig of the night down at the Rogue \& Vagabond pub just off Cuba Street, focuses on the stomp blues style for which he has become renowned.

Over dinner, Ben Wilcock and his trio evoke Jelly Roll Morton, Earl Hines and other great early pianists at the Crafty Tavern, at the far end of Courtenay Place. Half an hour later, and 250 metres up the road at the old Grand Hotel, it's the turn of the Wellington Jazz

${ }^{161}$ For a map of the weekend's activity see Fig. 6 (p.182). 
Orchestra, who are touring with San Francisco-based blues guitarist Chris Cain and regular guest vocalist Erna Ferry. The band warms up with a couple of numbers from their regular set, then it's into the zany but heartfelt blues vibe of Cain.

As the Jazz Orchestra gig finishes at 10pm, over at Meow, which is tucked down a dead-end laneway with three other bars, a double bill is kicking off: self-described "Afroelectro futurefunk" outfit Zllynz shares the stage with Wellington Afrobeat superband Soldiers of the Pharaoh. ${ }^{162}$ Half an hour later and Dayle Jellyman is back, this time leading the Three Rays over at the Laundry Cuba Street in a mix of blues and boogie-woogie. At the same time, and a five minute walk away, Wellington-based Brazilian singer Alda Rezende kicks off with the Samba Society at the iconic Wellington restaurant and venue, the Matterhorn. The party goes until the small hours.

Saturday's gigs start at 4, when durable sax and organ trio Twinset hit the Southern Cross Garden Bar Restaurant at the top of Cuba Street with their laid-back hard bop vibe. But later in the evening the scene starts getting hectic. First up it's the turn of singer Mary Watson and her band Noir, who mix jazz standards with pop classics down at long-running venue The Lido Café from 8:30. Half an hour later two gigs kick off at the same time: the Rogue and Vagabond hosts Niko Ne Zna, a group of jazz musicians who play Balkan gypsy music (Dayle Jellyman is there again, this time on percussion), while across town at MOON 1 in Newtown, Twinset backs up their earlier show, sharing the bill with Fuyuko's Fables, an alternative / indie folk band made up entirely of trained jazz musicians.

An hour later, at subterranean craft beer bar Hashigo Zake, just off Courtenay Place, alto player Jake Baxendale leads his sax / organ trio, the JB3, in standards and originals, mixing swing, funk, and Latin. Half an hour later, the Matterhorn hosts its second gig of the weekend: Wellington-based Mexican singer Carlos Navae caps off the night with a pan-Latin show, played by a band of jazz musicians, and including mariachi, Afro-Cuban jazz, and calypso.

Sunday, unusually, represents a lighter day for the community. Three gigs share the afternoon and early evening: acclaimed Australian guitarist James Sherlock fronts a trio (including the author) playing post-bop-inflected standards at the Rogue and Vagabond,

${ }^{162} \mathrm{~A}$ band I mentioned in Chapter 1, consisting of members of other, high-profile jazz and dub bands. 
while at the same time Ben Wilcock is back, this time at the Roxy Cinema restaurant out in the suburbs on the east side of town: he plays duo with Daniel Yeabsley, the saxophone player from Twinset; Dan swaps his saxophone for a double bass, as they reprise the early piano jazz Ben played on Friday night. The eighteenth and final gig of the weekend is, somehow appropriately, the longest-running in Wellington (and possibly New Zealand): the members of the Boptet, who have played at the Lido Café every Sunday for 26 years, cap off the weekend with bop-flavoured jazz standards, as they have done for decades.

Eighteen jazz gigs in three days is a typical weekend for the Wellington jazz community; and yet, judging from the popular and scholarly discourses around both jazz and New Zealand music, Wellington jazz is almost entirely without significance. Against the backdrop of that singular conundrum, this thesis raises, and attempts to answer, questions surrounding the implications of playing jazz in Wellington, New Zealand. It does so in a relatively theoretical sense, while connecting many of the weightier issues to actual jazz practice in the Wellington scene. Yet underneath all the discussion, the observation, and the analysis, one simple (and obvious) fact is crucial: Wellington jazz happens. The above survey of the jazz activity in Wellington over one single, average weekend, illustrates the intense way that it does so. All but four of the eighteen gigs took place within an area of half a square kilometre, at most a five- or ten-minute walk apart (figure 6, p.183). Gigs ranged from bop and stride-based standards to Afro-Cuban and samba, Afrobeat, and blues. There was a big band show, and a number of solo, duo and trio gigs. Collectives of jazz musicians played Balkan gypsy music, Latin pop and alt-folk. The gigs contained original music and standards, pop tunes and old-school blues. Many musicians performed double- or even triple-duty. And the activity surveyed above still did not include many of the biggest and busiest names of Wellington jazz; neither Myele Manzanza, nor Rick Cranson, Tom Callwood, Anita Schwabe, Jonathan Crayford, Lex French, Oscar Lavën ${ }^{163}$, the Wellington City Shake-'Em-On-Downers,

\footnotetext{
${ }^{163}$ Following the 2014 and 2015 Wellington Jazz Festivals, Lavën and French won informal awards for being Wellington's busiest jazz musicians, having played in twelve and nine gigs respectively during the two events. The fact that they were absent from the weekend's activities is notable.
} 


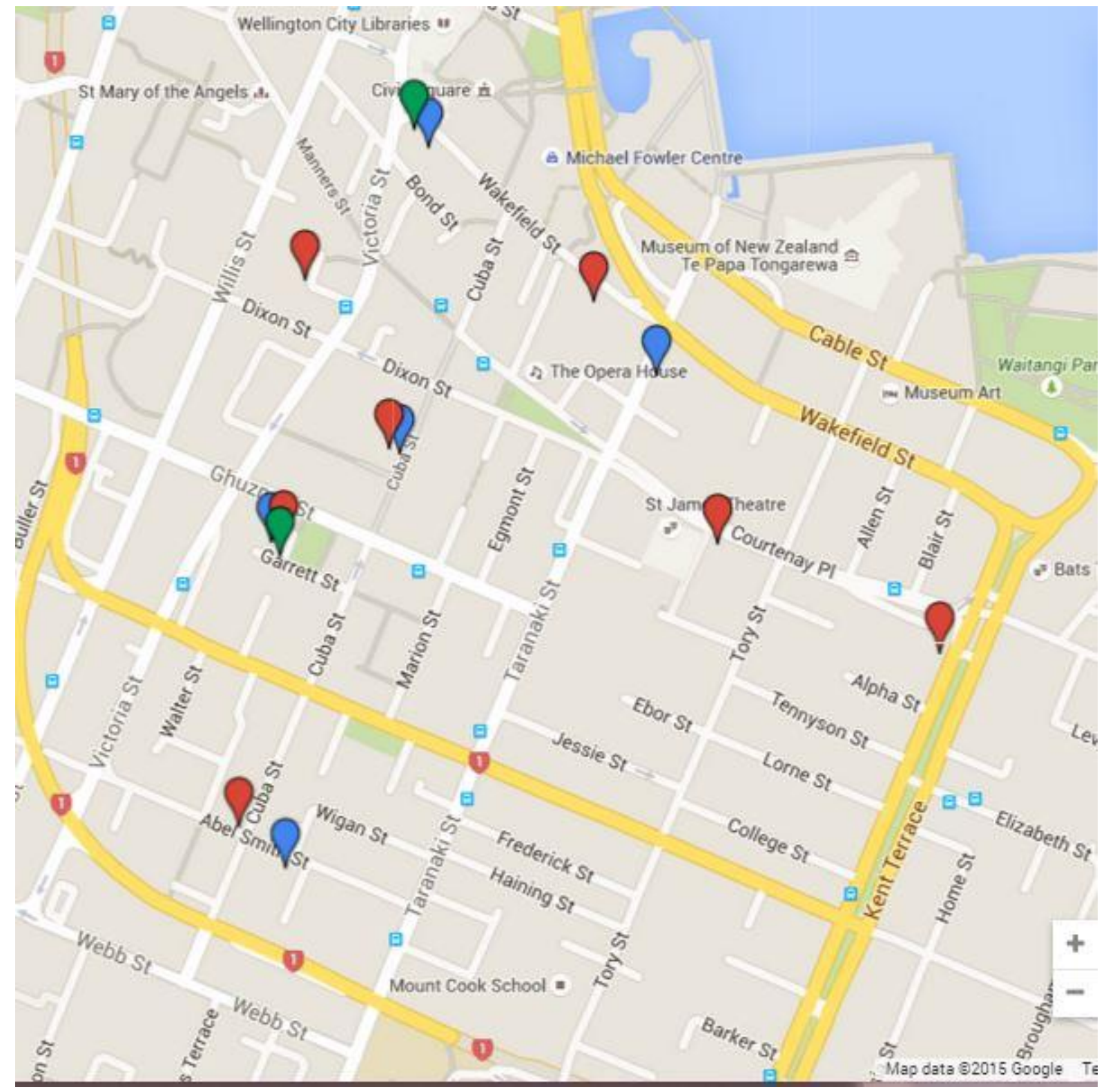

Fig.6: Wellington jazz gigs in the last week of September 2014.

Red: Friday

Blue: Saturday

Green: Sunday

Map is $1200 \mathrm{~m}$ (3/4 mile) square. 
As in Figure 2 , note that the area within the yellow main roads is approximately $850 \mathrm{~m}(1 / 2$ mile) square. This map excludes four venues located outside the city centre.

the Richter City Rebels, nor the Troubles, happened to play that weekend, and yet the scene was busy. Wellington jazz happens; and it is 'happening'.

And it happens / is happening despite the significant cultural issues which I have outlined in the preceding chapters. Indeed, by virtue of the fact that it happens, Wellington jazz presents conundrums, and it is those conundrums that give rise to the discussions which form the heart of this thesis. That jazz takes place in a small city, thousands of kilometres away by sea from the culturally distant scenes which inspire it, presents fundamental challenges to accepted jazz discourse. That it takes place in the Wellington context, where it is played and created by Wellingtonians, presents similarly fundamental challenges to discourses of New Zealand music, and New Zealand-ness in music. Indeed, the existence of a strong Wellington jazz community poses questions of value: is Wellington jazz absent from the discourse because the discourse privileges jazz in reference to American (or European) standards? Should it be judged in those terms at all? Or should the value of local jazz be determined in relation to musical and cultural values that are rooted in a New Zealand (or even Wellington) context? Perhaps most significantly, if a discourse continues to marginalise scenes outside of a canonical few, do its values require updating?

Wellington jazz musicians know they are a long way from the rest of the world. Despite the ease with which music can be experienced and viewed online, direct contact with musicians from another country is expensive and time-consuming. At the same time, Wellingtonians must deal with notions of authenticity (propagated through both academic and informal discourse) which imply that their practice is to a certain extent peripheral to the jazz tradition. While this is never explicitly articulated, the fact that local musicians consistently look overseas for inspiration (in terms of the style, substance and purpose of the music - the above survey illustrates the clear impact and presence of overseas styles and approaches) speaks to the weight that jazz from the U.S. (and, to a much lesser extent, Europe) continues to carry in the discourse, both inside and outside the academy. A coherent, reified tradition has yet to develop among New Zealand jazz musicians. At the same time, however, the discrete nature of the Wellington jazz community informs a local identity that is characterised in relation to other, dominant identities: the global jazz scene, 
through the Wellington jazz festival, for example; and the broader local music scene, through the invocation of otherness as a point of difference.

Wellington jazz is, by virtue of the difference in context between Wellington and any other city, unique. The inward authenticity and expression of selfhood of the members of the Wellington jazz community is necessarily connected to their environment; so, in playing jazz at all in their local context, they are creating new meanings which must, if recognised, contribute to the understanding of global jazz (as well as the global understanding of jazz). As we have seen, this assertion of identity and contextual positioning applies whether the musician is playing original music or standards. In a Wellington context, jazz musicians perform inward authenticities which are different to, but not necessarily mutually exclusive of, the inward authenticity privileged by much scholarship, as connoted by terms like "soul" and "blues aesthetic".

It is the existence of alternative inward authenticities, and those new meanings, which have broadened and enlivened jazz discourse in recent years. In previous chapters I have cited the work of respected scholars which ignores (explicitly or implicitly) the implications of jazz outside the borders of the U.S.; ${ }^{164}$ but jazz in locations like New Zealand, Australia (Johnson 2000), Ghana (Feld 2012), or Japan (Atkins 2001) can, by engaging with the very circumstances by which it is marginalised, challenge and extend accepted notions of authenticity, identity and tradition. African-American poet Langston Hughes ${ }^{165}$ described $^{-1}$ the "racial mountain" that faced proponents of black popular culture in their efforts to be taken seriously. Heble and Wallace $(2013,7-8)$ argue that this hurdle was created by both European Americans, via racist sentiment, and upwardly mobile African-Americans, who feared the stigma of the "low culture of black urban centres". Hughes decried this cultural cringe, arguing that pride lay in celebrating African-American cultural difference, in the face

\footnotetext{
${ }^{164}$ I have already noted Ake, Garrett and Goldmark's assessment of the U.S. as the "global arbiter of jazz tastes" (Ake, David; Garrett, Charles Hiroshi; Goldmark, Daniel (eds.) 2012, 6), and the implication therein that other parts of the world lack agency in assessments of jazz within their own borders. Travis Jackson observes (from within the United States) that "studies of jazz outside the United States... act as supplements that mildly challenge the standard narratives without necessarily expanding the role of geography. Those nations and regions are simply other places whose roles in jazz's development merit consideration. The master narrative itself, however, remains intact - at least in the United States - and isn't subject to modification or elaboration." (T. Jackson 2012, 53)

165 Although Hughes' essay "The Black Artist and the Racial Mountain" was written in 1926, it has been republished many times; Heble and Wallace cite its inclusion in Walser (1999).
} 
of hegemonic European American culture. This study describes a similar phenomenon, but one which occurs within the frame of local Wellington jazz. Wellington jazz musicians create music in their own context, with other Wellingtonians, many of whom have never visited the U.S.; and yet their musicking is infused with and surrounded by hegemonic attitudes, in which American jazz is privileged and emulated, and which preconceptions about authenticity present Wellington jazz with a similar hurdle. The hegemony continues largely unexamined; this dissertation is the highest-level exposition thus far of its cause and effect in the New Zealand context, although others (such as Atkins) have raised similar questions in other environments.

The geographical and cultural distance between jazz in New Zealand and jazz in the U.S. (or elsewhere) has a profound effect on the shape of the jazz community in Wellington. Rather than proving a barrier, it is manifested in the mediation which occurs when jazz is imported to this country; the sound survives, but the cultural context is removed. As a result, Wellington jazz musicians feel little compunction in terms of appropriation, appropriateness, or cultural barriers. The original meaning of the music in its sociocultural context disappears, and a new meaning is created via the reframing of jazz in a new context. At the same time, that cultural distance (between present-day New Zealand and the (stereotypically) traditional sites of jazz culture) requires Wellington jazz musicians to assert their authenticity and identity through the invocation of an essentialised jazz identity, manifested through the "jazz tradition". In effect, musicians are freed from cultural convention on one hand, but bound by practical convention on the other.

Counterintuitively, then, much of the jazz played in the Wellington community, while it is exciting, creative and vital, yet remains fundamentally stylistically conservative as a result of its isolation from the jazz which inspires it. As we have seen, Wellington jazz, although often creative and exciting, still (even subtly) privileges canonical, American-based styles and approaches, through repertoire, style, technique, or even dress or language: mastery of such concepts, as Nicholson observes, "represents something intrinsically American, whereby issues of "authenticity" are raised if the music is performed outside the "mother tongue" context of American styles." (Nicholson 2014, 95) Indeed, the New Zealand School of Music's focus on canonical styles and approaches reinforces such a connection. And in fact, despite the broadening of approaches which occurs as alumni 
enter the wider world of the community, most musicians in Wellington see such adherence to tradition as unproblematic: the majority of musicians I interviewed highlighted the value of the tradition in informing their own practice, and conceptualised "New Zealand jazz" not as some local hybrid, or new offshoot, but simply as the jazz that happens to be played in New Zealand.

In Chapter 5, I presented the Richter City Rebels and the Wellington Jazz Festival as cases in which Wellington jazz musicians paradoxically assert confident, local identities via the foregrounding of close links to the "jazz tradition". In the case of the Rebels, the presence of a form of jazz with clearly exotic connotations creates new meanings in the Wellington scene, by virtue of its stylised nature, and the multiple layers of incongruity it sets up. But this is not only the case with the most obviously exotic forms of jazz; all the gigs described above act in more or less subtle ways to create new meanings, which are new by virtue of the difference in cultural frame between contemporary Wellington and 1950s New York, 1920s Chicago or 1970s Rio de Janeiro, for example. Thus jazz occupies an interesting, liminal space in Wellington, in which it is partially "other" and partially "same". Wellington jazz sounds like jazz from somewhere else, but it is played in Wellington by Wellingtonians, who derive legitimacy both from their identification with their home environment, and from their adoption of the performative norms of jazz. Interestingly, and as we have seen, Wellington musicians who convey that legitimacy as jazz musicians on one night may very often perform the next evening in a covers band, a Balkan folk ensemble, a classical orchestra, or in genres from soul to electronica to heavy metal, with no less claim to legitimacy in each, and without eroding their legitimacy as jazz musicians. Such is the nature of the Wellington music scene; in constructing such eclectic performing careers, local jazz musicians connect the jazz community with the broader scene in fundamental ways.

Conversely, Wellington jazz musicians, qua jazz musicians, must contend with a sense of marginalisation in their own local context: as local musicians, they are legitimate, yet the music they play when they are being jazz musicians is somehow still "other". While the Wellington community is rich and active, it operates largely off the radar, and without attracting the attention of policymakers, funders, or the media (although not for a lack of 
activity, as we have seen, ${ }^{166}$ or a lack of trying (Rodger Fox Big Band 2012)). The discourse of "New Zealand music", like that around jazz, presents implicit messages which are inclusive of some forms of music, but exclusive of others. While this is at least in part due to entrenched attitudes around high art, the "New Zealand" element within the "New Zealand Music" concept also militates against the inclusion of jazz under that umbrella. Thus the conservatism inherent in much of the jazz played in Wellington, while legitimising it in one sense, also undermines its legitimacy in another. In the funding environment, for example, it is difficult to argue that jazz is "New Zealand music" while it remains so strongly characterised in terms of its Americanness. And yet the parochial exclusion that results is hard to justify, given that the repertoires of the major New Zealand orchestras, opera companies and chamber music ensembles, which receive the bulk of the funding earmarked for the promotion of a "distinctive New Zealand culture", are dominated by European composers. In fact, it is New Zealand pop musicians, who, like jazz musicians, play original music in styles overtly derived from the U.S. (or the U.K.), who are most closely associated with the term "New Zealand music". Thus, as we have seen, "New Zealand music" means music played by New Zealanders, but only inasmuch as it fits with entrenched cultural attitudes about New Zealand-ness.

And yet, while I wrestle with issues of hegemony and cultural cringe, of conservatism and American-ness, by and large Wellington jazz musicians are not concerned with such matters on a day-to-day basis. While funding itself is a sore point, discussions of identity and authenticity do not tend to feature in musicians' discourse; while elements of the tradition are frequently discussed, New Zealand's place in it (or outside of it) is not often considered by the musicians on whom it might reflect. Indeed, the scene in Wellington is rich enough that the isolation is not keenly felt: clearly, there is enough going on in Wellington that Wellington musicians do not often consider themselves bereft of a connection to the "action" (although when I raised the issue of distance in interviews, that isolation was usually acknowledged). Yet as I have shown through this thesis, beneath the surface the

\footnotetext{
166 Over the last year, there have been an average of 18-20 jazz gigs per week, every week in Wellington; over a year that represents between 900 and 1100 gigs. It is hard to imagine a similar number of classical concerts taking place in Wellington over the same time, for example.
} 
issues matter; local musicians' activities implicitly reflect their perspective on all of the concepts discussed above. In all performance, to re-invoke Small's analysis, the musicians "are in effect saying... This is who we are. ...in the context of the performance, who an individual is, is to a large extent who he or she chooses to be or imagines him or herself to be. Who we are is how we relate, and the relationships articulated by a musical performance are not so much those that actually exist as they are the relationships that those taking part desire to exist." (Small 1998, 134) At the same time, the fact that Wellington musicians do not tend to engage in such critical reflection has allowed the development of a scene in which musicians may freely choose from a variety of modes of expression, without the encumbrance of issues of ownership or appropriation.

Ultimately, then, neither geographical nor temporal distance, nor cultural difference, precludes Wellingtonians from playing jazz; and it is in that simple fact that Wellington jazz presents its clearest challenge to the discourses of jazz and New Zealand music. Wellington jazz does not just happen; it is happening. It is vibrant, creative, eclectic, and driven. It is sometimes original, and sometimes borrows heavily from established models. It is colourful and drab, artistic and workaday. It is both organic, and inspired from outside. Jazz in Wellington happens regardless of the preceding discussions; and it will go on happening regardless of this investigation. In a sense that fact alone speaks for itself; Wellington jazz may be excluded from the discourses which pertain to it, but the fact that it exists, and does so with vitality and creativity, reveals the shortcomings of those discourses.

This dissertation, then, acts on several levels. It represents the first scholarly acknowledgement that contemporary jazz occurs in Wellington (and New Zealand). Using Wellington jazz as an example, it represents an attempt to break open traditional models of authenticity in jazz, by turning them back on themselves. And it challenges the assumptions surrounding "New Zealand music", pointing out that authenticity in Wellington jazz conflicts with commonly accepted definitions. Finally, it poses a further set of questions. Given the inadequacy of the discourse in which New Zealand jazz is framed, how can we more constructively frame jazz in New Zealand? And might we articulate a set of values which better suit New Zealand jazz in its own context, rather than judging it on values imported from elsewhere? How might such an articulation impact New Zealand jazz education? Might it occasion a revisiting of the discourses of local classical or popular music, for example? And 
if a new set of values are required for local New Zealand jazz, then how does that affect the global values which yet dominate jazz discourse? 


\section{Afterword}

During this project I have frequently been asked my opinion as to whether there is a "Wellington sound". The fact that such a quality is considered by Wellington musicians to be of value speaks to the underlying sense of pride and parochialism which characterises New Zealanders' search for national identity. The "paradigm shift" to which Nicholson refers, in which authenticity in jazz becomes detached from American-ness and assessed in terms of local significance (Nicholson 2014, 100) has not yet occurred in Wellington. Yet there are signs that it is happening: in the generation of new meanings by creative musicians in Wellington (through both the Wellingtonian dynamic of versatility, and as a result of de- and re-contextualisation); in the search for New Zealand-ness through the connection of jazz to Māori music; and in scholarship, where studies like this one, and that by Aleisha Ward (2012), a small number of courses run through the NZ School of Music, and isolated publications such as Jazz Aotearoa (Hardie, Richard; Thomas, Allan (eds.) 2009) have begun to examine critical issues in local New Zealand jazz. The effects of such examination and reflection can be seen in the Melbourne scene, in which musicians combine jazz with a variety of other musics in an effort to evoke and construct new identities in jazz. The circumstances are ripe for a similar movement in Wellington.

Likewise, this thesis lays the groundwork for further study of local New Zealand jazz. In that context, there are major issues yet unexamined: the connection (or lack of it) between jazz and Māori / Pasifika music and musicians; the gender imbalance in the New Zealand jazz community; New Zealand jazz and its interactions with classical music, popular music, visual art, business (Burns (2010) notwithstanding), national identity, tourism, and other economic considerations. The scholarly literature on New Zealand jazz education, besides this thesis, consists of a single Master's dissertation (Roberts (2009)). As I began by citing Richard Hardie and Allan Thomas (2009), so at this stage I again echo their call for further scholarly investigation into this rich seam of New Zealand musical culture.

At the same time, this thesis presents a challenge to scholars engaged in the description and analysis of jazz in the $21^{\text {st }}$ Century (and before). As I have shown, the most common and persistent assumptions about authenticity and value in jazz have failed to keep 
pace with its development and spread; this study sits alongside that of Atkins (2001), for example, in highlighting the disconnect between the experiences of countless jazz musicians worldwide, and the American experience or cultural knowledge which is held to be central to jazz practice: a disconnect which is still maintained not only by modern histories of jazz, but also anthologies which, in other ways, take a proudly revisionist perspective.

Yet this thesis does not represent a call for Wellington musicians to abandon hegemonic, traditional values and to begin the search for identity. In fact, my own playing, which in part provided the impetus behind this study, remains, at its conclusion, strongly centred in classic, non-experimental jazz styles; and I still derive as much enjoyment from a swinging 60's hard bop groove as from any other form of expression and participation. ${ }^{167}$ Galvanising a New Zealand-based jazz movement is not the point; as composer Douglas Lilburn suggested in both 1946 and 1969 (Lilburn 2011) such a process must take place organically. In any case, like many Wellington jazz musicians, I enjoy playing classic styles and listening to classic recordings of classic musicians, and I feel no pressing urge to deny the music which has inspired me. In contrast to studies which concentrate on the most progressive elements in jazz, in this investigation I have broadened my focus to include "little-j" jazz musicians; those who play for a variety of motivations, of which creative innovation is but one. In discussing the relationship of these musicians to concepts of tradition, authenticity and identity, I have sought to describe the various motivations and values which underpin jazz in Wellington, and in that quest lies perhaps my own initial motivation: to examine my own practice in its home context. Having considered such motivations deeply, I hope to prick the consciences of other local musicians just enough to generate a reflexive conversation: to encourage discussion and consideration of the 'whys' of Wellington jazz. Through that conversation, regardless of outcome, may be generated the kind of self-consciousness that prompted Lilburn, in 1969, to conclude:

I accept and trust and work to maintain my particular heritage, this unique experience of life conferred on me at this time, in this place. It is through awareness of this timeless tradition, I think, that I may best hope to identify myself, that self which... I cannot possibly define but still might wish to celebrate in music or, more soberly, simply attempt to express. (Lilburn 2011)

\footnotetext{
${ }^{167}$ In fact, over the course of this investigation, I have felt more (rather than less) comfortable about expressing myself in this way, given the conclusions I have reached in terms of authenticity and identity.
} 


\section{Sources}

Ake, David. 2002. Jazz Cultures. Berkeley: University of California Press.

-. 2010. Jazz Matters: Sound, Place, and Time since Bebop. Berkeley: University of California Press.

-. 2012. "Crossing the Street: Rethinking Jazz Education." In Jazz/Not Jazz: The Music and its Boundaries, edited by David Ake, Charles Hiroshi Garrett and Daniel Goldmark, 237-263. Berkeley and Los Angeles: University of California Press.

Ake, David; Garrett, Charles Hiroshi; Goldmark, Daniel, eds. 2012. Jazz / Not Jazz: the Music and its Boundaries. Berkeley: University of California Press.

Allan, Corey, Arthur Grimes, and Suzi Kerr. 2013. Value and culture: An economic framework. Wellington: Manatū Taonga - Ministry for Culture and Heritage.

Alvarez, Wilfredo. 2013. "Finding "Home" in/through Latinidad Ethnography: Experiencing Community in the Field with "My People"." Liminalities: A Journal of Performance Studies 49-58.

Anderson, Benedict. 1983. Imagined Communities. London and New York: Verso.

Asai, Susan M. 2005. "Cultural Politics: The African-American Connection in Asian-American Jazz-Based Music." Asian Music 36 (1): 87-108.

Atkins, E. Taylor. 2001. Blue Nippon: Authenticating Jazz in Japan. Durham: Duke University Press.

—, ed. 2003. Jazz Planet. Jackson: University Press of Mississippi.

Baker, David. 1979. Jazz Pedagogy: A Comprehensive Method for Teacher and Student. Chicago: db Music Workshop/Maher Publications.

Bakriges, Chris. 2003. "Musical Transculturation: From African American Avant-Garde Jazz to European Creative Improvisation." In Jazz Planet, edited by E. Taylor Atkins. Jackson: University Press of Mississippi.

Ballantine, Christopher. 2012. Marabi Nights: Jazz, 'race' and society in early apartheid South Africa. Scottsville: University of KwaZulu-Natal Press.

Bannister, Matthew. 2005. "Kiwi Blokes: Recontextualising White New Zealand Masculinities in a Global Setting." Genders OnLine Journal. Accessed November 11, 2012. http://www.genders.org/g42/g42_bannister.txt.

Baraka, Amiri. 1998. "Jazz and the White Critic." In The Jazz Cadence of American Culture, edited by Robert G. O'Meally, 137-142. New York: Columbia University Press.

Becker, Howard. 1982. Art Worlds. Berkeley: University of California Press.

Béhague, Gerard, ed. 1984. Performance Practice: Ethnomusicological Perspectives. Westport, CT: Greenwood Press. 
Belich, James. 2001. Paradise Reforged: a history of the New Zealanders from the 1880s to 2000. Auckland: Allan Lane.

Bell, Claudia. 1996. Inventing New Zealand: everyday myths of Pākehā identity. Auckland: Penguin.

Benson, Dale. 1998. "New Zealand's Existentialist Men Alone: A Survey of Their Development from the 1890s until the 1970s." Deep South. Spring. Accessed May 18, 2015. http://www.otago.ac.nz/deepsouth/1198/MenAlone.html.

Berliner, Paul. 1994. Thinking in Jazz: the Infinite Art of Improvisation. Chicago: University of Chicago Press.

Black, Whirimako. 2006. Soul Sessions. Auckland: Mai Music.

-. 2007. Whirimako Black Sings. Auckland: Mai Music.

Boden, Margaret. 2009. "Creativity: How does it work?" In The Idea of Creativity, edited by Michael Krausz, Dennis Dutton and Karen Bardsley, 237-250. Boston: Brill.

Bodkin-Allen, Sally. 2011. "'Welcome Home": Music, rugby, and place." In Home, Land and Sea: Situating music in Aotearoa New Zealand, edited by Glenda Keam and Tony Mitchell, 62-72. Auckland: Pearson.

Bollinger, Nick. 2002. "Sounds like home." NZ Listener, June 22: 56.

Bourke, Chris. 2011. Blue Smoke: The Lost Dawn of New Zealand Popular Music 1918-1964. Auckland: Auckland University Press.

Bowden, Simon, interview by Nick Tipping. 2012. (October 11).

Broadhurst, Phil, and John Key, eds. 1996. The Kiwi Real Book. Wellington: Crayfish Productions.

-. 2000. The Kiwi Real Book 2. Auckland: publisher unknown.

Brown, Bruce, interview by Nick Tipping. 2011. (September 14).

Brunt, Shelley. 2011. "Performing identity and place in Wellington's Cuba St Carnival." In Home, Land and Sea: Situating Music in Aotearoa New Zealand, edited by Glenda Keam and Tony Mitchell, 161-174. North Shore, NZ: Pearson.

Burns, Ken (dir.). 2000. Jazz. Produced by PBS.

Burns, Lori. 2010. Challenges to the Wellington Jazz Community from a Business Perspective. MBA Thesis, Wellington: Victoria University.

Calder, Peter. 2012. "Hear our voices: 'Cultural cringe' an obsolete bias." The New Zealand Herald. September 10. Accessed August 11, 2014.

http://www.nzherald.co.nz/lifestyle/news/article.cfm?c_id=6\&objectid=10832337.

Cardy, Tom. 2014. The year of our Lorde. April 30. Accessed May 14, 2014.

http://www.stuff.co.nz/entertainment/music/9992416/The-year-of-our-Lorde. 
Cattermole, Jennifer. 2011. "'Oh, Reggae But Different': The Localisation of Roots Reggae in Aotearoa." In Home, Land and Sea : Situating Music in Aotearoa New Zealand, edited by Glenda Keam and Tony Mitchell, 47-61. Rosedale (N.Z.): Pearson.

Chapman, Katie. 2012. Minister rules out axing NZSO. July 24. Accessed November 12, 2014. http://www.stuff.co.nz/entertainment/arts/7334706/Minister-rules-out-axingNZSO.

Collier, James Lincoln. 1993. Jazz: The American Theme Song. New York: Oxford University Press.

Collins, Simon. 2014. "NZ ranked \#1 for social progress." New Zealand Herald. Accessed May 29, 2015.

http://www.nzherald.co.nz/nz/news/article.cfm?c_id=1\&objectid=11231593.

Comerford, J.W. (dir.). 2010. Icons among us: Jazz in the present tense. Produced by Indiepix Films. Performed by M. Benevento, T. Blanchard, B. Frisell, H. Hancock, W. Marsalis, M. Rivoira, L. Larson, et al.

Cranson, Rick, interview by Nick Tipping. 2011. (September 8).

Creative New Zealand. 2011. Audience Atlas New Zealand Report 2011. Wellington: Arts Council of New Zealand Toi Aotearoa.

-. 2013. 2013 Annual Report. Wellington: Arts Council of New Zealand Toi Aotearoa.

-. 2013. Music Review: final report. Wellington: Arts Council of New Zealand Toi Aotearoa.

Crouch, Stanley. 2002. "The Negro Aesthetic of Jazz." Jazz Times. Accessed October 14, 2014. http://jazztimes.com/articles/19772-the-negro-aesthetic-of-jazz.

Davenport, Lisa E. 2009. Jazz Diplomacy: Promoting America in the Cold War. Jackson: University Press of Mississippi.

DeFrancesco, Joey, interview by Nick Tipping. 2013. (September 7).

DeVeaux, Scott. 1991. "Constructing the Jazz Tradition: Jazz Historiography." Black American Literature Forum 25 (3): 525-560.

-. 1996. "What Did We Do to Be So Black and Blue?" Musical Quarterly 80 (3): 392-430.

DeVeaux, Scott, and Gary Giddins. 2009. Jazz. New York: W.W. Norton \& Co.

Drummond, John, Geoff Kearsley, and Rob Lawson. 2008. Culture Matters: a report for the Ministry of Research, Science and Technology. Wellington: Ministry of Research, Science and Technology.

Du Bois, W. E. B. 1985. "Beyond the Veil in a Virginia Town." In Against Racism: Unpublished Essays, Papers, Addresses, 1887-1961, edited by Herbert Aptheker, 49-50. Amherst: University of Massachusetts Press.

Dyne, Paul, interview by Nick Tipping. 2011. (September 9).

Ellis, Lauren, interview by Nick Tipping. 2013. (October 11). 
Ellison, Ralph. 1953. "The Charlie Christian Story." In Shadow and Act, by Ralph Ellison, 233240. New York: Random House.

Evans, Nicholas M. 2000. Writing Jazz: Race, Nationalism, and Modern Culture in the 1920s. New York: Garland.

Fairburn, Miles. 2008. "Is there a good case for New Zealand exceptionalism?" Thesis Eleven (Sage Publications) (92): 29-49.

Feld, Steven. 2012. Jazz Cosmopolitanism in Accra: Five Musical Years in Ghana. Durham: Duke University Press.

Florida, Richard. 2002. The Rise of the Creative Class, and how it's transforming work, leisure, community and everyday life. New York: Basic Books.

-. 2004. "Creative Class War: how the GOP's anti-elitism could ruin America's economy." Washington Monthly. January / February. Accessed February 12, 2015. http://www.washingtonmonthly.com/features/2004/0401.florida.html.

Foucault, Michel. 1980. Power/Knowledge: Selected Interviews and Other Writings. Edited by Colin Gordon. New York: Pantheon.

Fox, Aaron A. 2004. Real Country: Music and Language in Working-Class Culture. Durham, NC: Duke University Press.

French, Lex, interview by Nick Tipping. 2013. (May 6).

Gabbard, Krin, ed. 1995a. Jazz Among the Discourses. Durham, NC: Duke University Press.

—, ed. 1995b. Representing Jazz. Durham, NC: Duke University Press.

Garrett, Charles Hiroshi, Carol J. Oja, George E. Lewis, Gayle Sherwood Magee, Alejandro L. Madrid, Sherrie Tucker, and Robert Fink. 2011. "Studying U.S. Music in the TwentyFirst Century." Journal of the American Musicological Society 64 (3): 689-719.

Gibson, Andy. 2010. "New Zealand identity in popular music: Vowel differences between singing and speaking." In Many Voices: Music and National Identity in Aotearoa/New Zealand, edited by Henry Johnson, 111-121. Newcastle upon Tyne: Cambridge Scholars.

Gioia, Ted. 2011. The History of Jazz. New York: Oxford University Press.

Giroux, Henry, and Roger Simon. 1989. "Popular Culture and Critical Pedagogy: Everyday Life as a Basis for Curriculum Knowledge." In Critical Pedagogy, the State and Cultural Struggle, edited by Henry Giroux and Peter McLaren, 236-252. Albany: SUNY Press.

Gould, Tony, interview by Nick Tipping. 2014. (June 24).

Grabowsky, Paul. 2007. "Introducing...Paul Grabowsky." State Library of Queensland. June 13. Accessed October 8, 2014.

http://www.slq.qld.gov.au/_data/assets/pdf_file/0004/65587/SLQ-

Paul_Grabowsky_transcript-9_Jun_07.pdf.

Graham, David A. 2014. "Why Did This Band Recreate Jazz's Most Famous Record Note-forNote?" The Atlantic. October 28. Accessed June 22, 2015. 
http://www.theatlantic.com/entertainment/archive/2014/10/when-is-a-miles-davisrecord-not-jazz/381983/.

Granville, Nick, interview by Nick Tipping. 2011. (October 6).

Grow Wellington. 2010. WellingtonNZ Live - Home. Accessed January 14, 2014. http://live.wellingtonnz.com/page/home.aspx.

Hall, Stuart. 1999. "Encoding/Decoding." In The Cultural Studies Reader, edited by Simon During, 513. New York: Routledge.

Hanson, Allan. 1989. "The Making of the Maori: Culture Invention and Its Logic." American Anthropologist, New Series 91 (4): 890-902.

Hardie, Richard; Thomas, Allan, eds. 2009. Jazz Aotearoa: Notes Towards a New Zealand History. Wellington: Steele Roberts.

Heble, Ajay, and Rob Wallace. 2013. "People Get Ready: The Future of Jazz is Now." In People Get Ready: The Future of Jazz is Now!, edited by Ajay Heble and Rob Wallace, 1-28. Durham, N.C.: Duke University Press.

Heffley, Mike. 2005. Northern Sun, Southern Moon: Europe's Reinvention of Jazz. New Haven: Yale University Press.

Hellhund, Herbert. 2012. "Roots and Collage: Contemporary European Jazz in Postmodern Times." In Eurojazzland: Jazz and European Sources, Dynamics, and Contexts, edited by Luca Cerchiari, Laurent Cugny and Franz Kerschbaumer, 431-446. Boston: Northeastern University Press.

Henderson, Robert. 2013. pers. comm. October 16.

Hersch, Charles. 1998. Democratic Artworks: Politics and the Arts from Trilling to Dylan. Albany: State University of New York Press.

Herzig, Monika. 2011. David Baker: A Legacy in Music. Bloomington: Indiana University Press.

Hewett, Ivan. 2014. "Jazz: the Cinderella of arts funding." The Telegraph. July 17. Accessed November 13, 2014. http://www.telegraph.co.uk/culture/music/worldfolkandjazz/10971234/Jazz-theCinderella-of-arts-funding.html.

Ho, Fred Wei-Han. 1995. "What Makes Jazz the Revolutionary Music of the 20th Century, and Will It Be Revolutionary for the 21st Century?" African-American Review 29 (2): 283-290.

Hobbs, Richard. 2004. "Show Me the Money - NZ On Air." NZ Musician 11 (4). Accessed May 18, 2014. http://www.nzmusician.co.nz/index.php/ps_pagename/article/pi_articleid/255.

Hollerbach, Peter. 2004. "(Re)voicing tradition: Improvising aesthetics and identity on local jazz scenes." Popular Music 26 (2): 155-171. 
Humphreys, Michael, Deniz Ucbasaran, and Andy Lockett. 2012. "Sensemaking and sensegiving: stories of jazz leadership." Human Relations 65 (1): 41-62.

Huyssen, Andreas. 1986. After the Great Divide: Modernism, Mass Culture, Postmodern-ism. Bloomington, IN: Indiana University Press.

Hytönen-Ng, Elina. 2013. Experiencing 'Flow' in Jazz Performance. Farnham, Surrey ; Burlington, VT: Ashgate.

Isaacs, Mike, interview by Nick Tipping. 2013. (May 22).

Jackson, Roland. 1997. "Authenticity or Authenticities?--Performance Practice and the Mainstream." Performance Practice Review 10 (1). Accessed October 29, 2014. http://scholarship.claremont.edu/cgi/viewcontent.cgi?article=1187\&context=ppr.

Jackson, Travis. 2004. "'Always New and Centuries Old': Jazz, Poetry, and Tradition as Creative Adaptation." In Uptown Conversation: The New Jazz Studies, by R. O'Meally, B. H. Edwards and F. J Griffin, 357-373. New York: Columbia.

-. 2012. Blowin' the Blues Away: Performance and Meaning on the New York Jazz Scene. Berkeley: University of California Press.

Jellyman, Dayle. 2013. pers. comm. 18 October.

Johnson, Bruce. 1987. The Oxford Companion to Australian Jazz. Melbourne: Oxford University Press.

-. 2002. "The jazz diaspora." In The Cambridge Companion to Jazz, edited by Mervyn Cooke and David Horn, 33-54. Cambridge: Cambridge University Press.

-. 2000. The Inaudible Music: Jazz, Gender and Australian Modernity. Sydney: Currency Press.

—. 2014. "Editorial: Jazz in Australasia." Jazz Research Journal 8 (1-2): 5-22.

Johnson, Lucien, interview by Nick Tipping. 2014. (August 21).

Jolly, Margaret. 1992. "Specters of Inauthenticity." The Contemporary Pacific, 4 (1): 49-72.

Kaufman, James. 2009. Creativity 101. New York: Springer.

Keam, Glenda. 2006a. "Exploring Notions of National Style: New Zealand Orchestral music in the Late Twentieth Century." Ph.D. Dissertation, University of Auckland.

—. 2006b. "New Zealand and the Land's Imprint." Sounds Australian 68: 18-24.

Keith, Hamish. 2008. Native Wit. Auckland: Random House.

Keller, Andrea, interview by Nick Tipping. 2014. (June 24).

Kennedy, Gary. 2002. "Jazz Education." In New Grove Dictionary of Jazz, edited by Barry Kernfeld. New York: Macmillan. Accessed May 15, 2012. http://www.oxfordmusiconline.com.helicon.vuw.ac.nz/subscriber/article/grove/mus ic/J602300?q=jazz+education\&search=quick\&pos=1\&_start=1\#firsthit. 
Kingsbury, Henry. 1988. Music, Talent and Performance: A Conservatory Cultural System. Philadelphia: Temple University Press.

Kisliuk, Michelle. 1998. Seize the Dance! BaAka musical life and the ethnography of performance. New York: Oxford University Press.

Kivy, Peter. 1995. Authenticities: Philosophical Reflections on Musical Performance. New York: Cornell University Press.

Kruse, Holly. 2003. Site and Sound: Understanding Independent Music Scenes. New York: Peter Lang.

La Rosa, David. 2015. "Jazz Has Become The Least-Popular Genre In The U.S." The Jazz Line. March 9. Accessed March 13, 2015. http://thejazzline.com/news/2015/03/jazz-leastpopular-music-genre/.

Lawn, Jennifer. 2006. "Creativity Inc.: Globalizing the Cultural Imaginary in New Zealand." In Global Fissures, Postcolonial Fusions, edited by Clara A. B. Joseph and Janet Wilson, 225-45. Amsterdam: Rodopi.

Lewis, George. 2004. "Gittin' to Know Y'all: Improvised Music, Interculturalism, and the Racial Imagination." Critical Studies in Improvisation 1 (1): 1-33.

Lilburn, Douglas. 2011. A Search for Tradition \& A Search for a Language. Wellington: Lilburn Residence Trust in association with Victoria University Press.

Lindholm, Charles. 2002. "Authenticity, Anthropology, and the Sacred." Anthropological Quarterly 75 (2): 331-338.

-. 2013. "The rise of expressive authenticity." Anthropological Quarterly 86 (2). Accessed March 17, 2015.

http://go.galegroup.com.helicon.vuw.ac.nz/ps/i.do?id=GALE\%7CA330678658.

Lipsitz, George. 1994. Dangerous Crossroads: Popular Music, Postmodernism and the Politics of Place. London and New York: Verso.

Liu, James H., Tim McCreanor, Tracey McIntosh, and Teresia Teaiwa. 2005. "Introduction: Constructing New Zealand Identities." In New Zealand Identities: Departures and Destinations, by James H. Liu, Tim McCreanor, Tracey McIntosh and Teresia Teaiwa, 11-20. Wellington: Victoria University Press.

Lonely Planet. 2010. Lonely Planet's Best in Travel 2011. London: Lonely Planet.

-. 2010. Lonely Planet's top 10 cities for 2011. Oct 31. Accessed March 24, 2015. http://www.lonelyplanet.com/travel-tips-and-articles/76165.

Mahika, Kelly. 2013. Editorial: Cautious note on big band funding. January 14. Accessed February 24, 2014. http://www.nzherald.co.nz/bay-of-plentytimes/opinion/news/article.cfm?c_id=1503346\&objectid=11087358.

Malm, Krister. 1993. "Music on the Move: Traditions and Mass Media." Ethnomusicology 37(3): 339-352 
Manatū Taonga - Ministry for Culture and Heritage. 2013. New Zealand Professional Orchestra Sector Review: final report. Wellington: Manatū Taonga - Ministry for Culture and Heritage.

-. 2013. Vision. October 17. Accessed May 16, 2014. http://www.mch.govt.nz/aboutministry/overview/vision.

Mandel, Howard. 2007. Miles, Ornette, Cecil: Jazz Beyond Jazz . New York: Routledge.

Martin, Peter. 2005. "The Jazz Community as an Art World: A Sociological Perspective." The Source, 5-13.

Mayes, Rob. 2010. "Sounds Like Us - A NZ On Air Analysis." mediafire.com. November. http://download1588.mediafire.com/v7kw2d5ye5ig/uqg11bmvvvem426/SoundsLike Us-An_NZonAir_Analysis\%28Final+03+12+10\%29.pdf.

McKay, George. 2005. Circular Breathing : the Cultural Politics of Jazz in Britain. Durham: Duke University Press.

McLean, Chris. 2013. "Wellington region: Economic fall and rise: 1976-2006." Te Ara: The Encyclopaedia of New Zealand. October 25. Accessed February 12, 2015. http://www.teara.govt.nz/en/wellington-region/page-11.

Meehan, Norman. 2010. "Mike Nock: A NZ Voice in Jazz." In Many Voices: music and national identity in Aotearoa/New Zealand, edited by Henry Johnson, 103-110. Newcastle: Cambridge Scholars.

-. 2011. Serious Fun: The Life and Music of Mike Nock. Wellington: Victoria University Press.

-, interview by Nick Tipping. 2011. (October 4).Meehan, Norman. 2014. "Creativity in Jazz." PhD dissertation. New Zealand School of Music.

-. 2011. "'Sounds Like Home": TrinityRoots and Jazz-Dub-Reggae in Wellington." In Home, land and sea : situating music in Aotearoa New Zealand, edited by Glenda Keam and Tony Mitchell, 134-144. Rosedale (N.Z.): Pearson.

-, interview by Nick Tipping. 2012. (September 24).

Merriam, Alan. 1964. The Anthropology of Music. Evanston, IL: Northwestern University Press.

Mirams, Gordon. 1945. Speaking Candidly: Films and People in New Zealand. Hamilton: Blackwood and Janet Paul.

Mitchell, Tony. 1994. "Flying in the Face of Fashion: Independent Music in New Zealand." In North Meets South : Popular Music in Aotearoa/New Zealand, by Philip Hayward, Tony Mitchell and Roy Shuker, edited by Philip Hayward, Tony Mitchell and Roy Shuker, 28-72. Sydney: Perfect Beat.

-. 1996. Popular Music and Local Identity: Rock, Pop, and Rap in Europe and Oceania. New York: Leicester University Press. 
-. 2009. "Sonic Psychogeography: A Poetics of Place in Popular Music in Aotearoa/New Zealand." Perfect Beat: The Pacific Journal of Research Into Contemporary Music and Popular Culture 10 (2): 145-175.

-. 2010. ""Kiwi" music and New Zealand national identity." In Many Voices: Music and national identity in Aotearoa New Zealand, edited by Henry Johnson, 20-29. Newcastle: Cambridge.

Mitchell, Tony, and Tama Waipara. 2011. "Kaupapa and Whakapapa in Contemporary Māori Music." In Home, land and sea : situating music in Aotearoa New Zealand, edited by Glenda Keam and Tony Mitchell, 2-20. Rosedale (N.Z.): Pearson.

Monson, Ingrid. 1994. "Doubleness and Jazz Improvisation: Irony, Parody, and Ethnomusicology." Critical Inquiry 20 (2): 283-313.

-. 1996. Saying Something: Jazz Improvisation and Interaction. Chicago: University of Chicago Press.

Moore, Alan. "Authenticity as Authentication." Popular Music 21(2): 209-223.

Moore, Hilary. 2007. Inside British Jazz: Crossing Borders of Race, Nation and Class. Aldershot: Ashgate.

Morris, Colin. 2012. "Three Hours of Pure Jazz Delight." Accessed August 24, 2012. http://nzyjo.shutterfly.com/reviewed.

Murray, Albert. 1976. Stomping the Blues. New York: McGraw-Hill.

New Zealand International Arts Festival. 2012. New Zealand International Arts Festival contributes \$56 million to Wellington economy. June 14. Accessed November 20, 2012. http://www.nzfestival.nzpost.co.nz/media/news/new-zealand-internationalarts-festival-contributes-56-million-to-wellington-economy/.

New Zealand Music Commission Te Reo Reka o Aotearoa. 2012. "NZ Music Commission Business Plan 2012-13." New Zealand Music Commission Te Reo Reka o Aotearoa. Accessed April 16, 2014. http://nzmusic.org.nz/resources/nz-music-commission/nzmusic-commission-business-plan-2012/.

-. 2012. "NZ Music Commission Strategic Plan 2013-16." New Zealand Music Commission Te Reo Reka o Aotearoa. Accessed April 16, 2014.

http://nzmusic.org.nz/resources/nz-music-commission/.

-. 2014. International. Accessed April 16, 2014. http://nzmusic.org.nz/international/.

New Zealand National Party. 2014. "Arts, Heritage and Broadcasting Policy." NZ National Party. Accessed November 12, 2014. https://www.national.org.nz/docs/defaultsource/PDF/2014/policy/arts-heritage-and-broadcasting-policy.pdf.

New Zealand Symphony Orchestra. 2013. Annual Report 2013. Wellington: New Zealand Symphony Orchestra.

Nicholson, Stuart. 2005. Is Jazz Dead? (Or Has It Moved to a New Address). New York: Routledge. 
-. 2014. Jazz and Culture in a Global Age. Boston: Northeastern University Press.

Norris, Paul, and Brian Pauling. 2012. "NZ On Air: an evaluative study 1989-2011." NZ On Air. March. Accessed April 18, 2014. http://www.nzonair.govt.nz/research/allresearch/evaluative-study-of-nz-on-air-may-2012/.

NZ On Air. n.d. "NZ Music Definition." NZ On Air. Accessed March 30, 2015. http://www.nzonair.govt.nz/document-library/nz-music-definition/.

-. 2011. "NZ Music Strategy." NZ On Air. Accessed April 15, 2014. http://www.nzonair.govt.nz/document-library/music-strategy-2011/.

O'Meally, Robert G., ed. 1998. The Jazz Cadence of American Culture. New York: Columbia University Press.

O'Meally, Robert G., Brent Hayes Edwards, and Farah Jasmine Griffin, eds. 2004. Uptown Conversation: the New Jazz Studies. New York: Columbia University Press.

ONE News. 2015. "New Zealand passport ranked the world's eighth most desirable - but why?" tvnz.co.nz. April 17. Accessed May 29, 2015. http://tvnz.co.nz/worldnews/new-zealand-passport-ranked-s-eighth-most-desirable-but-why-6291646.

Paterson, Sue, interview by Nick Tipping. 2012. (September 24).

Penman, Carla. 2013. Call to support budding musicians. January 24. Accessed February 24, 2014. http://www.stuff.co.nz/entertainment/music/8218686/Call-to-supportbudding-musicians.

Pieterse, Jan Nederveen. 2006. "Globalization and Culture: Three Paradigms." In McDonaldization, edited by G. Ritzer, 278-83. London: Pine Forge Sage.

Pietraszewski, Igor, 2014. Jazz in Poland: improvised freedom. Frankfurt am Main: Peter Lang

Porter, Eric. 2012. "Incorporation and Distinction in Jazz Historiography." In Jazz / Not Jazz, edited by David Ake, Charles H. Garrett and Daniel Goldmark, 13-30. Berkeley: University of California.

Prendergast, Kerry, and Nick Tipping, interview by Eva Radich. 2011. Upbeat (February 3).

Prouty, Ken. 2005. "The History of Jazz Education: A Critical Reassessment." Journal of Historical Research in Music Education 26 (2): 79-100.

-. 2008. "The "Finite" Art of Improvisation: Pedagogy and Power in Jazz Education." Critical Studies in Improvisation 4 (1). Accessed June 2, 2012. http://www.criticalimprov.com/article/view/346.

-. 2012. Knowing Jazz: Community, Pedagogy and Canon in the Information Age. Jackson, MS: University Press of Mississippi.

Radano, Ronald, and Philip V. Bohlman. 2000. "Introduction: Music and Race, Their Past, Their Presence." In Music and the Racial Imagination, edited by Ronald Radano and Philip V. Bohlman, 1-53. Chicago: University of Chicago Press. 
Rechniewski, Peter. 2008. "The Permanent Underground: Australian Contemporary Jazz in the New Millennium." Platform Papers 16: 1-59.

Recorded Music NZ. 2013. Best Jazz Album 2013. April 3. Accessed March 1, 2015. http://www.nzmusicawards.co.nz/award-category/best-jazz-album-2013/.

Russell, Mark, dir. 2013. Richter City Rebels! Performed by Richter City Rebels.

Roberts, Karen. 2009. "The Jazz Canon Within New Zealand's Tertiary Education System: Perceptions and Experiences (MMus Thesis)." Auckland: University of Auckland.

Rodger Fox Big Band. 2012. "The Legendary Band That Hasn't Been Paid For 40 Years." Scoop News. November 13. Accessed November 13, 2012. http://www.scoop.co.nz/stories/CU1211/S00261/the-legendary-band-that-hasntbeen-paid-for-40-years.htm.

Sakakeeny, Matt. 2010. "“Under the Bridge": An Orientation to Soundscapes in New Orleans." Ethnomusicology 54 (1): 1-27.

Scoop Media. 2012. "The Legendary Band That Hasn't Been Paid For 40 Years." Scoop News. November 13. Accessed November 13, 2012. http://www.scoop.co.nz/stories/CU1211/S00261/the-legendary-band-that-hasntbeen-paid-for-40-years.htm.

Scott, Michael. 2008. "The Networked State: New Zealand on Air and New Zealand's Pop Renaissance." Popular Music 27 (2): 299-306.

-. 2012. "Popular Music as Social Policy: Hybrid-hierarchies and social inclusion through New Zealand's pop renaissance." Journal of Sociology 48 (3): 304-322.

-. 2013. Making New Zealand's Pop Renaissance: State, Markets, Musicians. Farnham, UK: Ashgate.

Scott, Michael, and David Craig. 2012. "The promotional state 'after neo-liberalism': ideologies of governance and New Zealand's pop renaissance." Popular Music 31 (1): 143-163.

Shand, John. 2009. Jazz: The Australian Accent. Sydney: University of NSW.

Shelemay, Kay Kaufman. 2011. "Musical communities: rethinking the collective in music." Journal of the American Musicological Society 64 (2): 349-390.

Shuker, Roy. 2007. "That was then, this is now: the New Zealand music industry, 19882006." Perfect Beat 8 (3): 19-30.

-. 2008. "New Zealand popular music, government policy, and cultural identity." Popular Music 27 (2): 271-287.

Shuker, Roy, and Michael Pickering. 1994. "Kiwi Rock: Popular Music and Cultural Identity in New Zealand." Popular Music 13 (3).

Small, Christopher. 1998. Musicking: The Meanings of Performing and Listening. Middletown, CT: Wesleyan University Press. 
Stahl, Geoff. 2011. "'DIY or DIT'! Tales of Making Music in a Creative Capital." In Home, Land and Sea : Situating Music in Aotearoa New Zealand, edited by Glenda Keam and Tony Mitchell, 145-160. Rosedale, NZ: Pearson.

Stanford, Charles Villiers. 2013. Interludes, Records and Reflections. London: Forgotten Books. Accessed May 19, 2015.

http://www.forgottenbooks.com/readbook_text/Interludes_Records_and_Reflectio ns_1000105787/113.

Statistics New Zealand. 2013. 2013 Census Usually Resident Population Counts. Accessed October 4, 2013.

http://www.stats.govt.nz/browse_for_stats/population/census_counts/2013Census UsuallyResidentPopulationCounts_HOTP2013Census.aspx.

-. 2013. "New Zealand Income Survey: June 2013 Quarter." Statistics New Zealand.

October 4. Accessed January 14, 2014.

http://www.stats.govt.nz/browse_for_stats/income-and-

work/Income/NZIncomeSurvey_HOTPJun13qtr.aspx.

-. 2014. Ethnic group (total responses) by age group and sex, for the census usually resident population count, 2001, 2006, and 2013 Censuses (RC, TA). November 11. Accessed November 20, 2014.

http://nzdotstat.stats.govt.nz/wbos/Index.aspx?DataSetCode=TABLECODE8021\#.

Stewart, Matt. 2013. Boozy youngsters give bar strip bad name. June 4. Accessed January 21, 2014. http://www.stuff.co.nz/dominion-post/news/8750618/Boozy-youngstersgive-bar-strip-bad-name.

stuff.co.nz. 2015. "New Zealand ranked 9th in world for happiness." www.stuff.co.nz. April 25. Accessed May 29, 2015.

http://www.stuff.co.nz/travel/destinations/nz/68022386/new-zealand-ranked-9thin-world-for-happiness.

Sweetman, Simon. 2010. "The joke that is NZ On Air funding." stuff.co.nz. August 31.

Accessed May 18, 2014. http://www.stuff.co.nz/entertainment/blogs/blog-on-thetracks/4077202/The-joke-that-is-NZ-On-Air-funding.

Taruskin, Richard. 1988. "The Pastness of the Present and the Presence of the Past." In Authenticity and Early Music, edited by Nicholas Kenyon, 137-210. Oxford: Oxford University Press.

-. 1992. "Tradition and Authority." Early Music 20 (2): 311-314; 317-320; 323-325.

Taylor, Billy. 1986. "Jazz: America's Classical Music." The Black Perspective in Music 14 (1): 21-25.

Te Māngai Pāho. 2011. Briefing to Incoming Minister of Māori Affairs 2011. Wellington: Te Māngai Pāho. Accessed May 27, 2014.

http://www.tmp.govt.nz/uploads/nimbl_file/file/21/TMP_BIM_2011.pdf.

-. 2014. Why We Are Here. Accessed May 27, 2014. http://www.tmp.govt.nz/why-we-arehere. 
Tipping, Nick. 2014. "Cuba Street Parade: identity, authenticity and self-expression in contemporary Australasian jazz scenes." Jazz Research Journal 8 (1-2): 115-130.

Tomlinson, Gary. 1991. "Cultural Dialogics and Jazz: A White Historian Signifies." Black Music Research Journal 11: 71-105.

Tsioulakis, Ioannis. 2013. "The Quality of Mutuality: Jazz Musicians in the Athenian Popular Music Industry." In Musical Performance and the Changing City: Post-industrial Contexts in Europe and the United States, edited by Fabian Holt and Carsten Wergin, 200-224. New York: Routledge.

Tucker, Sherrie. 2001/2002. "Big Ears: listening for gender in jazz studies." Current Musicology (71-73): 375-408.

-. 2012. "Deconstructing the Jazz Tradition: The "Subjectless Subject" of New Jazz Studies." In Jazz/Not Jazz: The Music and Its Boundaries, edited by David Ake, Charles Hiroshi Garrett and Daniel Goldmark, 264-284. Berkeley: University of California Press.

Turino, Thomas. 2008. Music as Social Life: The Politics of Participation. Chicago: University of Chicago Press.

Twomey, Lissa. 2009. "Welcome to the Wellington Jazz Festival." Wellington Jazz Festival Programme. Wellington Jazz Festival.

Volkerling, Michael. 2006. "Wellington as a 'Creative City': After Florida - and before." Asia Pacific Journal of Arts and Cultural Management 4 (2): 296-306.

Walser, Robert, ed. 1999. Keeping Time: Readings in Jazz History. Oxford: Oxford University Press.

Ward, Aleisha. 2012. "Any Rags, Any Jazz, Any Boppers Today?: Jazz in New Zealand 19201955." Ph.D. Dissertation, University of Auckland.

-. 2014. "Got a little rhythm? The Australian influence on swing in New Zealand during the 1930s and 1940s." Jazz Research Journal 8 (1-2): 71-90.

Ward, Colleen, and En-Yi Lin. 2005. "Immigration, Acculturation and National Identity in New Zealand." In New Zealand Identities: Departures and Destinations, edited by James H. Liu, Tim McCreanor, Tracey McIntosh and Teresia Teaiwa, 155-174. Wellington: Victoria University Press.

Wellington City Council. 2012. "Annual Report 2011/12." Wellington City Council. Accessed April 10, 2013. http://wellington.govt.nz/ /media/your-council/plans-policies-andbylaws/plans-and-policies/annualreport/2011-12/files/2011-2012annualreport.pdf.

Whyton, Tony. 2010. Jazz Icons: Heroes, Myths and the Jazz Tradition. New York: Cambridge University Press.

Wink, Joan. 1997. Critical Pedagogy: Notes from the Real World. New York: Longman.

Yacobi, Ben G. 2015. "The Limits of Authenticity." Philosophy Now. Accessed March 17, 2015. https://philosophynow.org/issues/92/The_Limits_of_Authenticity. 
Zemke-White, Kirsten. 2007. "'This Is My Life": Biography, Identity and Narrative in New Zealand Rap Songs." Perfect Beat: The Pacific Journal of Research Into Contemporary Music and Popular Culture 8 (3): 31-52.

Zuberi, Nabeel. 2007. "Sounds like us: Popular music and cultural nationalism in Aotearoa New Zealand." Perfect Beat 8 (3): 3-18. 